V1rus 



\section{1 r u S}

Beiträge zur Sozialgeschichte der Medizin.

\section{0}

Herausgegeben von Elisabeth Dietrich-Daum, Werner Matt, Wolfgang Weber und Carlos Watzka

für den Verein für Sozialgeschichte der Medizin

Wien 2011

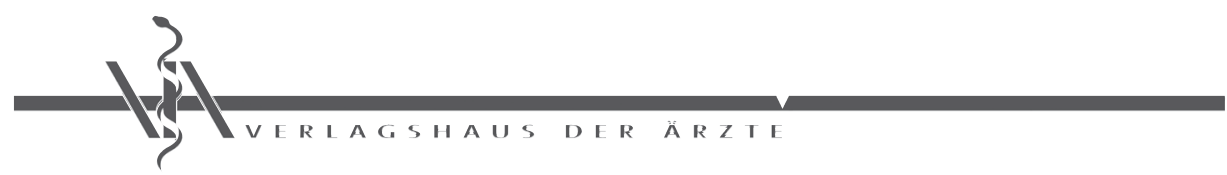




\section{Virus - Beiträge zur Sozialgeschichte der Medizin}

Die vom Verein für Sozialgeschichte der Medizin herausgegebene Zeitschrift versteht sich als Forum für wissenschaftliche Publikationen mit empirischem Gehalt auf dem Gebiet der Sozial- und Kulturgeschichte der Medizin, der Geschichte von Gesundheit und Krankheit sowie angrenzender Gebiete, vornehmlich solcher mit räumlichem Bezug zur Republik Österreich, ihren Nachbarregionen sowie den Ländern der ehemaligen Habsburgermonarchie. Zudem informiert sie über die Vereinstätigkeit. Der Virus wurde 1999 begründet und erscheint mittlerweile jährlich im Verlagshaus der Ärzte in Wien.

Der Virus ist eine peer-reviewte Zeitschrift und steht Wissenschafter/innen aus allen Disziplinen für Beitragsvorschläge offen. Einreichungen für Beiträge im engeren Sinn müssen bis 31.10., solche für alle anderen Rubriken (Projektvorstellungen, Veranstaltungs- und Ausstellungsberichte, Rezensionen) bis 31.12. eines Jahres als elektronische Dateien in der Redaktion einlangen, um für die Begutachtung und gegebenenfalls Publikation im Folgejahr berücksichtigt werden zu können. Nähere Informationen zur Abfassung von Beiträgen finden sich auf: www.sozialgeschichte-medizin.org. Diesbezügliche Anfragen richten Sie bitte an: Carlos Watzka: carlos.watzka@uni-graz.at

Neuere Vereinspublikationen sind über das Verlagshaus der Ärzte lieferbar. Altere sind teils noch direkt beim Verein verfügbar. Hierfür, sowie für Anfragen betreffend Vereinsmitgliedschaft bzw. Abonnement des Virus wenden Sie sich bitte an: Andreas Golob: an.golob@uni-graz.at. Die Mitgliedschaft kann auch online beantragt werden: www.sozialgeschichte-medizin.org.

\section{Impressum}

Herausgeber: Verein für Sozialgeschichte der Medizin, A-1210 Wien, Georgistraße 37. Redaktion: Carlos Watzka (carlos.watzka @uni-graz.at), Elisabeth Dietrich-Daum (Elisabeth.Dietrich@uibk.ac.at).

Das Werk ist urheberrechtlich geschützt. Die dadurch begründeten Rechte, insbesondere das der Übersetzung, des Nachdrucks, der Entnahme von Abbildungen, der Funksendung, der Wiedergabe auf fotomechanischem oder ähnlichem Wege und der Speicherung in Datenverarbeitungsan- lagen, bleiben, auch bei nur auszugsweiser Verwendung, vorbehalten. Autoren und Verlag haben alle Buchinhalte sorgfältig erwogen und geprüft, dennoch kann keine Garantie übernommen werden. Eine Haftung der Autoren bzw. des Verlags wird daher nicht übernommen. Namentlich gekennzeichnete Beiträge geben die persönliche Meinung des Verfassers/der Verfasserin wieder und stellen nicht unbedingt die Auffassung der Redaktion dar.

(C) 2011 Verlagshaus der Ärzte GmbH, Nibelungengasse 13, A-1010 Wien - www.aerzteverlagshaus.at

Gedruckt ohne Förderung des Bundesministeriums für Wissenschaft und Forschung in Wien.

Umschlag: Lisa Hahsler, Deutsch-Wagram

Umschlagfoto: Celia Di Pauli, Innsbruck

Layout-Entwurf: Mag. Herbert Moser, CCM, Salzburg

Layout und Satz: Thomas Brunner \& Carlos Watzka, Graz

Projektbetreuung: Mag. Hagen Schaub, Wien

Druck \& Bindung: Ferdinand Berger \& Söhne GmbH, Horn

Printed in Austria ISSN 1605-7066

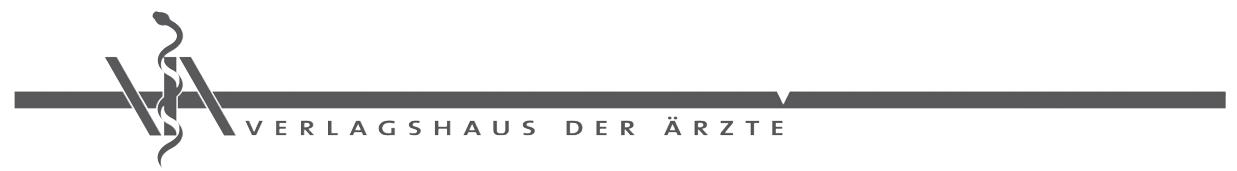




\section{Editorial}

Liebe Leser/innen des Virus,

das Herausgeberteam freut sich, Ihnen mit dieser Ausgabe die erste ,Jubiläumsnummer' des Virus, die Nummer 10, vorlegen zu können. Dies umso mehr, als unsere Zeitschrift weiterhin auf steigendes Interesse in der ,scientific community' stößt, was sich in zunehmenden Mitglieder- und Abonnentenzahlen manifestiert.

Der vorliegende Band spiegelt in seinen Bestandteilen einmal mehr auch das ReferentInnen- und Themenspektrum der vorangegangenen Jahrestagung „Geschichte(n) von Gesundheit und Krankheit" des Vereins für Sozialgeschichte der Medizin in Österreich, welche im Juni 2010 in Dornbirn stattgefunden hat und dem Generalthema „Medizin und Psychiatrie im 20. Jahrhundert in Deutschland, Österreich und Italien" gewidmet war. Auch an dieser Stelle sei dem Organisationsteam dieser Veranstaltung und den Kooperationspartnern vor Ort im Namen des Vereins nochmals herzlich gedankt.

Neben insgesamt acht Beiträgen, die sich diesmal - mit einer auf Deutschland verweisenden Ausnahme - der österreichischen Medizingeschichte zwischen dem Erstem Weltkrieg und der Nachkriegszeit der 1950er/60er Jahre widmen, enthält der vorliegende Band auf zusammen rund 180 Seiten vier Projektvorstellungen, einen Tagungsbericht und eine Rezension.

Es sei die Gelegenheit genutzt, an dieser Stelle alle Leserinnen und Leser daran zu erinnern, dass eine Einreichung von Beitragsvorschlägen für alle Rubriken jederzeit möglich ist - und dies nicht nur für Vereinsmitglieder, sondern jede/ $\mathrm{n}$ medizinhistorisch Forschenden. Insbesondere sind qualifizierte Beiträge zur österreichischen Medizingeschichte, wie auch die Beisteuerung von einschlägigen Projektvorstellungen, Tagungsberichten und Rezensionen sehr erwünscht. Nähere Informationen zur Gestaltung von Beiträgen sind im Virus Nr. 9 abgedruckt und können auch auf der Vereinshomepage abgerufen werden. Für weitere Mitteilungen zum ,Vereinsleben' sei hier auf die Vereinsnachrichten am Ende dieses Bandes verwiesen.

Wie hoffen, Ihnen auch in diesem Jahr wieder interessante und ertragreiche Lektüre bieten zu können.

Für den Verein für Sozialgeschichte der Medizin in Österreich

Die Herausgeber 



\section{Inhaltsverzeichnis}

\section{Beiträge}

\section{Andreas Golob}

Das Engagement der Grazer Medizinischen Fakultät in der Universitätsausdehnungsbewegung. Grundfragen eines vernachlässigten Forschungsfeldes

\section{Angela Grießenböck}

„Absender: Dr. Johann W., auf ein Jahr für ein Narr erklärt“.

Die Konfliktfelder Politik, religiöse Bewegung und Psychiatrie

im Tirol der 1930er Jahre im Beispiel des Franziskanerpaters W.

\section{Maria Hermes}

Zwischen Front und Heimat: Deutungen des Ersten Weltkrieges in Krankenakten am Beispiel des Bremer St.Jürgen-Asyls

\section{Barbara Hoffmann}

Blinde Menschen unter dem NS-Regime in der „Ostmark“ -

Eine Problematisierung

\section{Florian G. Mildenberger}

Im Zerrspiegel von Eugenik, Emanzipation und Sexualwissenschaft:

Helene Stourzh-Anderle (1890 - 1966)

\section{Markus Rachbauer}

Die Ermordung und das „Sterben-Lassen“ von psychisch und physisch kranken ausländischen ZivilarbeiterInnen im „Gau Oberdonau“.

\section{Melanie Ruff}

Der Erste Weltkrieg ,,in“ den Patientenakten von Kieferschussverletzten der Österreichisch-Ungarischen Landstreitkräfte

\section{Wolfgang Weber}

Eine typische österreichische Ärztebiographie?

Annotationen zu Medizinalrat Dozent Dr. Edwin Albrich 


\section{Projektvorstellungen}

\section{Elisabeth Dietrich-Daum / Maria Heidegger}

Psychiatrische Landschaften. Die Psychiatrie und ihre Patientinnen und Patienten im historischen Raum Tirol-Südtirol von 1830 bis zur Gegenwart /

L'assistenza psichiatrica istituzionale e territoriale nell'area del Tirolo storico

(secoli XIX-XXI). Ein Interreg IV Projekt Italien-Österreich (2008-2011)

\section{Thomas Feurstein}

Die Lorenz-Böhler-Ausstellung der Vorarlberger Landesbibliothek (VLB)

\section{Barbara Peintinger}

Giovanni Alessandro Brambillas Appendice eine Quelle zum Gesundheitswesen im Josephinismus

\section{Felicita Ratti}

Die Grippeepidemie 1918 hinter der italienisch-österreichischen Front. Das Land Salzburg und die Provinz Modena zwischen Waffenstillstand und ärztlicher Not..... 156

\section{Tagungsberichte}

\section{Andreas Golob}

Medizinhistoriographische Themen am 13. Internationalen Kongress zur Erforschung des 18. Jahrhunderts

(Karl-Franzens-Universität Graz, 25. - 29. Juli 2011) 163

\section{Rezensionen}

Christian Baudelot, Roger Establet, Suicide. The Hidden Side of Modernity. Cambridge-Malden (Polity Press) 2008, rezensiert von Carlos Watzka

\section{Vereinsnachrichten}

Rückschau 2011 


\section{Beiträge}





\title{
Das Engagement der Grazer Medizinischen Fakultät in der Universitätsausdehnungs- bewegung. Grundfragen eines vernachlässigten Forschungsfeldes
}

\section{English Title}

Efforts of Graz Medical Faculty in the university-extension movement. General questions on a neglected field of research

\begin{abstract}
Summary
Members of the Medical Faculty of Graz University showed conspicuous efforts in the local university extension. Right from the start, there were not only regular presentations. Administrative activities were also clearly visible. Both ways of commitment could also partly be traced in predecessors, competitors and supplementary initiatives around the university extension. All in all, full professors shaped the movement. Topics were drawn from a rich repertoire of numerous branches of scientific and applied medicine. Overlapping subjects, especially as far as natural science is concerned, need further consideration. Illnesses and academically accredited methods to cure them demanded broader space than general preventive measures. In dealing with infections, provisions for public health are evident. Summarily, motives of the philanthropic popularisation of knowledge on health care are represented and competed with professional ambitions of scientists and physicians. As competition grew in the interwar period, the competitors included those strata of society that had not been convincingly integrated in the university extension; namely workers and farmers can be named in this context. Moreover, "bourgeois" concurrence showed more practical approaches. This character might also be stated regarding social services and their informal ways to popularise knowledge. Political traits surfaced right at the beginning of the educational movement. German-nationalist and liberal positions prevailed. Trends of radicalisation can be particularly observed in the field of racial hygiene. Starting at the end of World War One, these tendencies intensified in the 1930ies. Moderate efforts in the local university-extension movement during the war must be assessed against the background of war-related teaching and the increased commitment in (field) hospitals. The case of Oskar Zoth finally demonstrates how the Medical Faculty even joined political agitation. Furthermore it hints at means which were used to popularise knowledge.
\end{abstract}

\section{Keywords}

University Extension, Graz, Habsburg Monarchy, World War One, Fin de Siècle, Interwar Period, Popularisation of Knowledge, Public Health 


\section{Einleitung und Forschungsstand}

Das Epizentrum der University Extension lag 1871 in Cambridge. Von dort breitete sich die Universitätsausdehnung über das Commonwealth und in die Vereinigten Staaten aus. Belgien bildete 1892 den Brückenkopf am europäischen Kontinent. 1895 wurde Wien zu einem maßgeblichen Zentrum der Volkstümlichen Universitätsvorträge. Innerhalb der Habsburgermonarchie engagierten sich in weiterer Folge Hochschulen in Graz, Innsbruck, Brno (Brünn), Prag, Czernowitz und Budapest. Aus diesem mitteleuropäischen Kreis ist das Wiener Engagement umfassend untersucht worden. ${ }^{1}$ Desiderate sind jedoch nach wie vor vorhanden. Wilhelm Filla regte etwa die Befassung mit den „tatsächlichen Inhalte[n]“ an; ${ }^{2}$ die bloßen Titelangaben können diese sozusagen subcutane Ebene nicht ersetzen. Allgemeiner betrachtet betreffen die vorgebrachten Entwicklungslinien wissenschaftlicher Durchdringung Personennetzwerke, die mediale Unterstützung, Details der Institutionalisierung, Wandlungsprozesse in den Trägerorganisationen sowie die Einbettung in den gesellschaftlichen, wirtschaftlichen und kulturellen Kontext. ${ }^{3}$ Die Betonung der Universitätsgründungsphase in Großbritannien ${ }^{4}$ lässt sich in der Tat kaum auf die Habsburgermonarchie übertragen. Allerdings verdient der Ausbau der Sekundarstufe und des Fortbildungsschulsektors $^{5}$ wohl im Umfeld mehr Beachtung. Insbesondere in Anbetracht des Einbezugs der Lehrerschaft als Auditorium scheint diese Verknüpfung in der Forschung bis dato unterschätzt worden $\mathrm{zu}$ sein. Einzelne Informationssplitter könnten schließlich schlaglichtartig Ansichten des Auditoriums ausleuchten. ${ }^{6}$

Am Universitätsarchiv Graz (UAG) finden sich die Akten der Volkstümlichen Vorträge, etwa im Umfang eines Laufmeters, ${ }^{7}$ die Sitzungsprotokolle des einschlägigen Ausschusses, ${ }^{8}$ Verzeichnisse der beteiligten Vortragenden inklusive Vortragsthemen und Auflistungen zur Verrechnung. ${ }^{9}$ Letztere enthalten zum Teil auch mehr oder

1 Für den Überblick: Wilhelm FILLA, Volkstümliche Universitätskurse - Ein historisches wie aktuelles Modell der Wissenschaftsverbreitung. In: Peter FAULSTICH (Hg.), Öffentliche Wissenschaft. Neue Perspektiven der Vermittlung in der wissenschaftlichen Weiterbildung (= Theorie Bilden 4, Bielefeld 2006) 51-72, hier 54-57. Vorwiegend zu Wien: Hans ALTENHUBER, Universitäre Volksbildung in Österreich 1895-1937 (= Publikationen zur Erwachsenenbildung. Zur Geschichte der Erwachsenenbildung 1, Wien 1995). Für wertvolle Details zu Innsbruck während des Ersten Weltkrieges: Werner AUER, Kriegskinder. Schule und Bildung in Tirol im Ersten Weltkrieg (= Tirol im Ersten Weltkrieg. Politik, Wirtschaft und Gesellschaft 7, Innsbruck 2008) 311-313.

2 FILLA, Universitätskurse 60.

3 Ebd. 55.

4 Ebd. $54 f$.

5 Vgl. Helmut ENGELBRECHT, Geschichte des österreichischen Bildungswesens. Erziehung und Unterricht auf dem Boden Österreichs. IV: Von 1848 bis zum Ende der Monarchie (Wien 1986) $147-$ 220, auch 329-360 (über die Erwachsenenbildung). Für die Fortbildungsschulen als Faktor in der Volksbildung sporadisch: Kurt KOJALEK, Volksbildung in der Steiermark 1819-1979. Joanneische Wege in bewegten Zeiten. Eine Dokumentation (Graz 1999) 36.

6 Im Rektoratsarchiv der Universität Graz findet sich beispielsweise ein herbes Protestschreiben eines Zuhörers gegen die allgemeine Organisation und die speziellen Unzulänglichkeiten eines Vortrages, Universitätsarchiv Graz (UAG) Rekt[orat] Zl. 1353 ex 1906/07.

7 Zitiert als UAG, V[olkstümliche] V[orträge], Ausschussakten.

8 UAG, Sitzungs-Protokoll des Ausschusses für volkstümliche Univ. Vorträge [zitiert als Sitzungsprotokoll inklusive Datum].

9 Vor allem: Verzeichnis der Vortragenden in den auswärtigen Orten. Verzeichnis der volksthümlichen Vorträge in Graz begonnen 1898/1899. Verzeichnis der auswärtigen Orte in welchen Vorträge gehalten wurden. Protokoll über die eingelaufenen Geldbeträge für die volkstümlichen Vorträge und 
weniger vage Aufschlüsse über die Stärke des Auditoriums. Diese Materialien ergänzen die vor dem Ersten Weltkrieg veröffentlichten offiziellen Berichte. ${ }^{10}$ Der Nachlass des Physiologen Alexander Rollett birgt zudem zwei Vortragsmanuskripte. ${ }^{11}$ Im Kryptonachlass seines Nachfolgers Oskar Zoth ${ }^{12}$ sind sogar alle zehn volkstümlichen Vorträge vertreten. Die Quellenlage für die inhaltliche Erschließung populärmedizinischer Vorträge ist also durchaus erfreulich. Bevor abschließend eine dieser Raritäten referiert wird, muss das Umfeld bereitet werden. Die Einleitung bildet ein allgemeiner Überblick zu den Grazer Bestrebungen. Darauf folgt eine Auseinandersetzung mit dem speziellen Engagement der medizinischen Fachvertreter. Der Erste Weltkrieg wird zunächst vor allem als Zäsur interpretiert werden. Abschließend steht die einschlägige Tätigkeit der Medizinischen Fakultät während des Krieges im Mittelpunkt.

\section{Die Volkstümlichen Vorträge an der Universität Graz}

Die Universitätsausdehnung hielt im Studienjahr 1898/99 Einzug an der Universität Graz. ${ }^{13}$ Das Statut von $1897^{14}$ sah eine „Ausdehnung“ in dreifacher Hinsicht vor ( $(1)$. Einerseits widmete sich die Einrichtung ,allen Jenen, welchen der regelmäßige Besuch der Universität unmöglich ist ${ }^{*}$. Dabei muss vor allem an eine soziale Erweiterung gedacht werden, zudem muss an die begrenzten Bildungsmöglichkeiten für Frauen ${ }^{15}$ erinnert werden. Andererseits handelte es sich um eine regionale Ausweitung, denn dezidiert wurde die Steiermark einbezogen; ,vorbehaltlich der Genebmigung des k. K. Ministeriums für Cultus und Unterricht" gedachten die Initiatoren auch der Länder Kärnten und Krain.

Statistik. Im Text werden daher die Namen der Vortragenden als Referenz ausreichen. Die Statistiken über die 375 Vorträge vor dem Ersten Weltkrieg und die 195 Vorträge der Zwischenkriegszeit beruhen ebenfalls größtenteils auf dieser Grundlage. Für die 1930er Jahre wurden ergänzend die Ausschussakten und die Sitzungsprotokolle herangezogen. Venien und akademische Stellung der Vortragenden wurden den Personalständen und Vorlesungsverzeichnissen entnommen.

10 N.N. [Ausschuß für volkstümliche Vorträge der k. k. Karl Franzens-Universität in Graz], Bericht über die volksthümlichen Universitätsvorträge in den Studienjahren 1898/99, 1899/900, 1900/01 (Graz 1901). N.N. [DERS.], Bericht über die volkstümlichen Vorträge der k. k. Universität Graz 1898-1907 und über den Universitäts-Ferialkurs für Lehrer vom 5. bis 24. August 1907 in Graz (Graz 1907). N.N. [DERS.], Bericht über die volkstümlichen Vorträge der k. k. Universität Graz 1907-1910 (Graz 1910). N.N. [DERS.], Bericht über die volkstümlichen Vorträge der k. k. Universität Graz 1911-1913 (Graz 1913). [Zitiert als Bericht inklusive Jahr des Erscheinens.] Die ausführliche Berichtlegung in dieser Form riss nach dem Ersten Weltkrieg ab und folgte somit allgemeinen Mustern. (Vgl. Carlos Watzkas Vortrag bei der Jahrestagung 2010 in Dornbirn.)

11 UAG, Nachlass Alexander Rollett 4 (Über das Hirn als Sitz. der Intelligenz; Vorgänge bei der Athmung und ibre Bedeutung für das Leben) und 6 (Über das Hirn als Sitz der Intelligenz und Oberflächen-Karten des Hirn[s] einst und jet:t).

12 Die eigentlich mit „O. Zoth Vorlesungen“ betitelte Schachtel ist Teil des Nachlasses Rudolf Rigler.

13 Siehe bis dato vor allem peripher bei: Walter HÖFLECHNER, Die Baumeister des künftigen Glücks. Fragment einer Geschichte des Hochschulwesens in Österreich vom Ausgang des 19. Jahrhunderts bis in das Jahr 1938 (= Publikationen aus dem Archiv der Universität Graz 23, Graz 1988) 74, 82f., 103, $149,195,521$.

14 N.N. [Commission für die Einrichtung volksthümlicher Curse], Statut der volksthümlichen Vorträge der Universität in Graz (Graz 1897). Eingeheftet in: UAG, Sitzungs-Protokoll.

15 Zum Frauenstudium in Graz: Alois KERNBAUER, Karin SCHMIDLECHNER-LIENHART, Frauenstudium und Frauenkarrieren an der Universität Graz (= Publikationen aus dem Archiv der Universität Graz 33, Graz 1996). Im Bereich der Medizin waren etwa Vorträge des Privatdozenten für Geburtshilfe und Gynäkologie Max Stolz über Das Geschlechtsleben des Weibes (1908/09) nur für Frauen zugänglich. In diesem Jahr zeigte die offizielle Statistik der Hörerinnen und Hörer tatsächlich einen weiblichen Überschuss. Vgl. Graphik 2. (Alle Graphiken und Tabellen finden sich am Ende des Beitrags.) 
Eine gleichzeitige wesentliche Begrenzung wurde jedoch symptomatisch nicht thematisiert. Die Vorträge wurden nämlich ausschließlich in deutscher Sprache gehalten. Die slawischsprachige Bevölkerung im Umfeld der deutschsprachig dominierten Städte insbesondere Steiermarks und Krains wurde ignoriert. Selbst die Veranstaltungen in Triest(e) wurden in deutscher Sprache abgehalten. Insgesamt fügte sich dieser Aspekt in die dezidiert deutschnationale Ausrichtung der Grazer Universität. Zur inhaltlichen Disposition standen schließlich „[a] lle Wissensgebiete“, Abstand nahmen die Verantwortlichen ursprünglich jedoch von Materien, ,die sich auf politische, religiöse und sociale Kämpfe der Jetztzeit" (S 2) bezogen. Die Bestreitung der Kosten (\$S 8f.) speiste sich idealiter aus ministeriellen Subventionen, privaten Spenden, Beiträgen von Vereinen sowie aus dem Kartenverkauf (\$ 11). Die Stadt Graz und der Landtag beteiligten sich regelmäßig an der Finanzierung und wurden bis zum Ausbruch des Ersten Weltkrieges ${ }^{16}$ neben den Zuwendungen des Ministeriums zu einem Rückgrat der universitären Volksbildung. Spenden kamen beispielsweise auch aus der Finanzbranche. ${ }^{17}$ Vorträge außerhalb des Universitätsstandortes mussten von den lokalen Veranstaltern mitfinanziert werden ( $(\mathbb{1 4})$. Personell ruhte die Durchführung grundsätzlich auf Professoren, Privatdocenten, Adjuncten und Assistenten ( $(13)$. Nach dem Ende der Monarchie nannte eine revidierte Form ${ }^{18}$ auch Lektoren als potentielle Vortragende ( $(13)$; ebenso durften Außenstehende verpflichtet werden. Der Einbezug auswärtiger Orte wurde allgemeiner formuliert ( $(\mathbb{1} 1)$. Die regionale Expansion bezog vor dem Ersten Weltkrieg in der Tat die ganze Steiermark ein. Zudem bedienten die Vortragenden, wie geplant, das historische Innerösterreich, Triest(e) bildete die äußerste Grenze. (Vgl. Tabelle 1.) Die Resonanz außerhalb des Universitätsstandortes variierte offensichtlich stark. Konkrete Klagen sprachen von ,nicht entsprechenden Lokale[n] und Vorbereitungen“. ${ }^{19}$ Praktisch gesehen funktionierte die geographische Ausweitung über lokale Honoratioren, die als Ansprechpartner fungierten. Im frühen Geschäftsjahr 1900/01 nannte eine Liste der sogenannten „Vertrauensmänner" in sieben steirischen Orten fünf Lehrer, einen Bürgermeister, einen Arzt sowie einen Kaufmann. ${ }^{20} 1908$ sollte der Volksbildungsverein die Aufstockung des Vermittlerkontingents unterstützen. ${ }^{21}$ Der Erste Weltkrieg bildete in dieser Ausdehnungsdimension einen besonders prononcierten Einschnitt. Zwar wurde während der Kampfhandlungen noch das frontnahe Capriva del Friuli auf der Landkarte der Universitätsausdehnung eingetragen. Nach dem Zusammenbruch der Monarchie beschränkten sich die Aktivitäten jedoch vorerst auf Graz. In diesem lokalen Rahmen sollte das Potential der Technischen Hochschule stärker aktiviert werden. $^{22}$ Von der Seite des Landes beziehungsweise des Staates wurde die neue Institution eines Landesreferenten für das Volksbildungswesen ins Spiel gebracht. ${ }^{23}$

16 Für Ansuchen nach dem Krieg: Sitzungsprotokoll, 12. Juni 1926.

17 Sitzungsprotokoll, 9. Mai 1931. Bericht 1907 5: Neben dem Unterrichtsministerium, der Landesregierung und der Stadtgemeinde Graz wurden auch der Volksbildungsverein und die Steiermärkische Sparkasse genannt.

18 Aus dem Jahr 1922, am gleichen Ort beigelegt wie die ursprüngliche Fassung. Vgl. auch: Sitzungsprotokoll, 18. November 1922.

19 Sitzungsprotokoll, 25. Januar 1910.

20 UAG, VV Ausschussakten 1900/01 o. Zl.

21 UAG, VV Ausschussakten, Verschiedene Vorakten, Normalien, Brief des Ausschusses an den Volksbildungsverein, 23. Oktober 1908.

22 Zuletzt offiziell niedergelegt, vgl. Sitzungsprotokoll, 5. Juli 1922.

23 Für die Zusammenarbeit: Sitzungsprotokoll, 31. Mai 1920. Sitzungsprotokoll, 27. Januar 1923. 
Die Ausdehnung über Graz hinaus in zentrale Orte der Steiermark und das Umland der Landeshauptstadt wurde erst ab 1922 wieder forciert, fruchtete jedoch kaum. (Vgl. Tabelle 2.) Ein Spezifikum stellte eine Veranstaltungsreihe über das neu in den Staatsverband integrierte Burgenland dar. $^{24}$ Lehrpersonen aus dem Burgenland konnten andererseits 1931 beispielsweise das forensische Institut besichtigen. ${ }^{25}$

Als der Rundfunk in der Zwischenkriegszeit ebenfalls eine Bildungsschiene etablierte, schloss sich die Universität dieser neuen Initiative an. Der Grazer Filiale der RAVAG wurden 1925 Kostproben geliefert. ${ }^{26}$ Vier Jahre später willigte der Sender Graz ein, das universitäre „Programm wöchentlich einmal zu verlautbaren“. ${ }^{27} 1930$ beschloss die RAVAG allerdings, die Vortragstätigkeit auf steiermarkrelevante Themen zu beschränken. ${ }^{28}$ Verstärkt wurde nun auch das Pressewesen als Multiplikationsfaktor genutzt. ${ }^{29} 1927$ versuchte der Ausschuss, eine Pressekurzmeldung über jeden Vortrag einzufordern. ${ }^{30}$ Publikationsmöglichkeiten für Vorträge wurden erwogen. ${ }^{31}$ Eine Drucklegung ausgewählter Vorträge wurde 1927 durch die Buchhandlung Leuschner und Lubensky in Aussicht gestellt. Der Verlag handelte dabei im eigenen Interesse und auf eigene Kosten, ${ }^{32}$ ließ jedoch anscheinend keine Taten folgen.

Lehrer- und Arbeiterschaft wurden im Rahmen der Zehnjahresbilanz von 1907 explizit als Interessentengruppen genannt; in weiterer Folge hoffte der Ausschuss auch, die „Landwirte“ zu erreichen. ${ }^{33}$ Neben den traditionellen Multiplikatoren sollten also auch bildungsferne Schichten direkt angesprochen werden. Der Vorsatz, den „Arbeitern“ Bildung zuteil werden zu lassen, wurde ,in Principe ${ }^{\text {‘34 }}$ bereits 1903 vertreten. Eine Besonderheit in der Ausdehnung auf die Arbeiterschaft stellte die Kooperation mit der Firma Böhler \& Comp. A.-G. in Kapfenberg dar. Sie übernahm in vorbildlicher Weise alle Kosten und besorgte das infrastrukturelle Umfeld. ${ }^{35}$ In der Ersten Republik stand hinsichtlich der Arbeiterschaft die Zusammenarbeit mit der 1920 installierten Arbeiterkammer im Mittelpunkt. ${ }^{36}$ Die Strategie sah außerdem die Aufnahme der Vortragsankündigungen in das Presseorgan Arbeiterwille vor. ${ }^{37}$ Nachlässe beim Kartenkauf sorgten für leichtere Erschwinglichkeit. ${ }^{38}$ Die Bauernschaft blieb im

24 Sitzungsprotokoll, 14. Juni 1922.

25 Sitzungsprotokoll, 8. Juli 1931.

26 Sitzungsprotokoll, 23. Mai 1925. Vor allem Sitzungsprotokoll, 17. Oktober 1925. Vgl. insbesondere für Mediziner auch: UAG, VV Ausschussakten Zl. 164 ex 1925 (Rudolf Polland, Adolf Tobeitz, Heinrich Schrottenbach, Paul Widowitz, Karl Laker).

27 Sitzungsprotokoll, 8. Juni 1929.

28 Sitzungsprotokoll, 15. März 1930.

29 Sitzungsprotokoll, 25. Februar 1922.

30 Sitzungsprotokoll, 18. Juni 1927.

31 Sitzungsprotokoll, 24. Mai 1933.

32 Sitzungsprotokoll, 18. Juni 1927.

33 Bericht 1907 3f. Die Besucherzahlen wurden im entsprechenden Protokoll nur in Einzelfällen soziologisch genauer aufgeschlüsselt. Die Statistiken in den Berichten beruhen auf freiwilligen Angaben des Auditoriums, vgl. Bericht 1907 23-25. Insgesamt besteht der Eindruck, dass es sich bei den runden Pauschalangaben in den Akten um Schätzungen handelt, die sich am Fassungsvermögen der Lokalitäten orientierten.

34 Sitzungsprotokoll, 11. Juli 1903. Zudem insbesondere die Positionen der Vortragenden im Sitzungsprotokoll, 22. Februar 1910.

35 Bericht 1913 3f.

36 Sitzungsprotokoll, 23. Mai 1925, und vor allem Sitzungsprotokoll, 17. Oktober 1925. Für erste Konsultationen: Sitzungsprotokoll, 7. November 1924.

37 Sitzungsprotokoll, 31. März 1925.

38 Sitzungsprotokoll, 18. Juni 1927, vgl. auch Sitzungsprotokoll, 13. Oktober 1927. 
Gegensatz zur Arbeiterschaft weiterhin ein Desiderat, abgesehen von personellen Verknüpfungen. Nach dem Ersten Weltkrieg wurde ihr Bildungsbedürfnis insbesondere in St. Martin in der Nähe von Graz institutionalisiert. ${ }^{39}$ Das auch schon vor dem Ersten Weltkrieg erfasste studentische Publikum wurde schließlich ebenfalls mit Rabatten im Ausmaß der Unterstützung für die Arbeiterschaft begünstigt. ${ }^{40}$ Überdies sollten die Studierenden ab 1925 via Beilagen in den Vorlesungsverzeichnissen informiert werden. ${ }^{41}$ Den Titeln zufolge handelte es sich zum Teil um Überschneidungen mit den Vorlesungen für die Hörerschaft aller Fakultäten, die im Studienjahr 1904/05 eingeführt worden waren und quasi eine Ergänzung der allgemeinen Bildungsbestrebungen ,nach innen “ darstellten. ${ }^{42}$

Die höheren bürgerlichen Schichten blieben letztendlich stets im Fokus. Die vor dem Ersten Weltkrieg für Graz erhobenen Daten sprechen diesbezüglich eine klare Sprache. ${ }^{43}$ (Vgl. Graphik 1.) Zusätzlich fällt die Nähe zu bürgerlichen Bildungsinstitutionen auf. Die Verbindungen zum 1870 gegründeten Steiermärkischen Volksbildungsverein, ${ }^{44}$ dem Flaggschiff der deutschnationalen, liberalen Volksbildung, gestalteten sich recht enge; in gewisser Weise bildete seine Tätigkeit ein Substrat für die Bemühungen vonseiten der Universität. Nachdem diese Vorreiterorganisation im Ersten Weltkrieg ihre Bedeutung eingebüßt hatte, musste sich der Ausschuss mit der neu begründeten Urania ${ }^{45}$ arrangieren; personell gesehen gehörte der Ausschussobmann Rudolf Klemensiewicz auch zum Vorstand der Urania. ${ }^{46}$ Insgesamt lehnte die neue Organisation ihre Tätigkeit an wissenschaftliche Standards an, ${ }^{47}$ die Nachfrage wurde jedoch klarer von außen an die Wissenschaft herangetragen.

39 KOJALEK, Volksbildung 36f. Im Allgemeinen hielt sich die Professorenschaft, wie Kojalek ebenda ausführte, jedoch an die Urania. Vgl. allgemein auch: Judith LELLECK, Bäuerliche Volksbildung in der Zwischenkriegszeit am Beispiel von St. Martin und Hubertendorf. Philosophische Diplomarbeit (Graz 1989).

40 Sitzungsprotokoll, 18. Juni 1927.

41 UAG, VV Ausschussakten Zl. 117 ex 1925.

42 Vgl. die entsprechenden Rubriken in den Lehrveranstaltungsverzeichnissen.

43 Bericht 1907. Bericht 1910. Bericht 1913.

44 Vgl. http://www.adulteducation.at/de/historiografie/institutionen/265, 02. 11. 2011: 1870 - 1938. Vgl. allgemein Martin MOLL, Politische Organisationen und öffentlicher Raum in der Steiermark. In: Helmut RUMPLER, Peter URBANITSCH (Hg.), Die Habsburgermonarchie 1848-1918. VIII: Politische Öffentlichkeit und Zivilgesellschaft. Teilband 1: Vereine, Parteien und Interessenverbände als Träger der politischen Partizipation (Wien 2006) 397-449. Zu Vereinen im Spektrum der Lebensreform, die im Umfeld der medizinischen Wissensvermittlung von Bedeutung ist, speziell: Reinhard FARKAS, Geschichte der Lebensreform in der Steiermark. In: Zeitschrift des Historischen Vereines für Steiermark 91/92 (2000/01) 541-570. Über Arbeitervereine: Eduard STAUDINGER, Die Bildungs- und Fachvereine der Arbeiter in der Steiermark von 1848 bis 1873. Philosophische Dissertation (Graz 1977). DERS., Die andere Seite des Arbeiteralltags. Sozialdemokratisches Vereinswesen in der Steiermark, 1918 - 1934. In: KURATORIUM der Wanderausstellung „Für Freiheit, Arbeit und Recht“ (Hg.), Für Freiheit, Arbeit und Recht. Die steirische Arbeiterbewegung zwischen Revolution und Faschismus (1918 - 1938) (Graz 1984) 133-185.

45 NB. die jüngste Festschrift, dort insbesondere den Beitrag des Historiographen der Urania: Kurt KOJALEK, Die Grazer Urania 1919-1938. In: Caesar Walter ERNST, Markus JAROSCHKA (Hg.), Zukunft beginnt im Kopf. Festschrift 75 Jahre Urania (Graz 1994) 120-134. Für die Kenntnisnahme durch die Universitätsausdehnung: Sitzungsprotokoll, 6. Februar 1919. Laut Kojalek stellte die Universität auch Räumlichkeiten zur Verfügung, vgl. KOJALEK, Urania 128.

46 KOJALEK, Urania 124.

47 Kojalek zufolge teils als Zugpferd, teils lediglich großsprecherisch, vgl. KOJALEK, Urania 129. 
Mit Veranstaltungen für Kinder ${ }^{48}$ beschrieben die Bildungsbestrebungen zudem einen weiteren Bogen. In der unterschwelligen, inoffiziellen politischen Ausrichtung positionierte sich die Urania - wie der Volksbildungsverein - im deutschnationalen Umfeld, in weiterer Folge wurde die Nähe zum Nationalsozialismus ${ }^{49}$ evident. Die Institution bespielte mit ihren Veranstaltungen in der Zwischenkriegszeit nicht zuletzt nicht weniger als 67 steiermärkische Orte ${ }^{50}$ und kann in diesem Zusammenhang als Nachfolgerin der regional breiten universitären Volksbildung vor dem Ersten Weltkrieg angesehen werden. Bemerkenswert ist im Gefüge der konkurrierenden staatlichen und nicht-staatlichen Bildungsschienen und ihrer jeweiligen Zielgruppe schließlich die resolute Haltung der Ausschussmitglieder gegenüber den Repräsentanten des weltanschaulich differierenden autoritären Ständestaates. Eine im Rahmen der Vaterländischen Front angesiedelte Organisation namens „Neues Leben“ wurde nämlich damit abgespeist, dass Ermäßigungen nur bei einer finanziellen Beteiligung der Trägerorganisation möglich wären. ${ }^{51}$ Erst der nationalsozialistischen Machtübernahme war die Universität nicht mehr gewachsen. Sogenannte Jedermann-Vorlesungen ${ }^{52}$ sollten die Universitätsausdehnungsbewegung beerben.

Inhaltlich wurden durch den Ersten Weltkrieg zwei Grundlinien in Frage gestellt. Der zuvor zum Teil heftig umkämpfte ${ }^{53}$ Ausschluss des Religiösen wurde verwässert. ${ }^{54}$ Federführend wirkte in diesem Zusammenhang der Theologe Johannes Ude. Sein Kampf gegen Gesellschaftsdrogen und für eugenische Zielrichtungen tangierte das Feld der Medizin. Gleichzeitig wurden ethische Fragen mit religiösen Untertönen wiederum von Ude - in die Debatte reklamiert. ${ }^{55}$ Neben der Lehrerschaft wurde in der Zeit des Umbruchs explizit auch die Geistlichkeit als Publikum und als Multiplikationsfaktor berücksichtigt. ${ }^{56}$ Aus gegebenem Anlass wurde zudem das politische Tabu gebrochen. ${ }^{57}$ Im November $1915^{58}$ suchte der Ausschuss nach Wissensvermittlern, ,die in der Lage wären, Vorträge ₹u halten, die mit Rücksicht auf die Kriegszeit besonders aktuell sind." Dieses Feld besetzten vor allem Geo- und Historiographen sowie Literaturwissenschafter.

48 KOJALEK, Urania 130.

49 Ebd. insb. 131-133.

50 Ebd. 131.

51 Vgl. Sitzungsprotokoll, 17. November 1936.

52 UAG, Rekt. Zl. 3503 ex 1939/40.

53 Zum Beispiel Sitzungsprotokoll, 29. Januar 1903. Seit 1908 wurden die Theologen nicht mehr zur Teilnahme eingeladen, vgl. UAG, VV Ausschussakten, Verschiedene Vorakten, Normalien, Anfrage wegen Theologen.

54 Vor allem forciert ab Sitzungsprotokoll, 25. Juni 1914. Zur Zulassung von Theologen letztendlich: Sitzungsprotokoll, 23. März 1920.

55 Thomas MAYER, Eugenik in Graz oder Grazer Eugenik? Versuche über eine Standortbestimmung eugenischer Positionen und Aktivitäten in der Zwischenkriegszeit. In: Virus. Beiträge zur Sozialgeschichte der Medizin 7 (2008) 117-129, hier 123f. NB. zum Beispiel Udes Vortrag im Jahr 1932: Das Christentum und das Sexualproblem.

56 Sitzungsprotokoll, 6. Februar 1919.

$57 \mathrm{Zu}$ Wien: Klaus TASCHWER, Friedliche Volksbildung? Ergänzungen zur Geschichte der Wiener Erwachsenenbildung vor, während und nach dem Ersten Weltkrieg. In: Spurensuche. Zeitschrift für Geschichte der Erwachsenenbildung und Wissenschaftspopularisierung 7/2 (1996) 12-31.

58 Sitzungsprotokoll, 15. November 1915. NB. die lange Pause nach der Eintragung am 2. Juli 1914. 


\section{Mitglieder der Medizinischen Fakultät als führende Proponenten der Universitätsausdehnungsbewegung}

Von der Professorenschaft der Medizinischen Fakultät gingen wesentliche Impulse aus. Alexander Rollett $(1834-1903)^{59}$ und Rudolf Klemensiewicz, einer seiner Schüler, spielten leitende Rollen im Ausschuss. Rollett hatte sich zuvor schon um den Steiermärkischen Volksbildungsverein verdient gemacht. 1893 hielt er als Obmann desselben einen allgemeinen Vortrag „Ueber Volksbildung“6 ${ }^{60}$ Die letztendlich gemeinnützigen Ideale der Institution, „Wabrbeit, Bildung und Aufklärung“61 standen im Mittelpunkt und wurden pathetisch vorgetragen. International wettbewerbsfähige ,fortschrittsfreundliche Deutsche ${ }^{662}$ gaben die Marschrichtung an; „eine echte, kernige, deutsche Bildung des Volkes in allen Schichten und in seiner ganzen Masse"63 galt als Ziel. Die Förderung der heimischen dezidiert laikalen Schulen bildete das zentrale Anliegen. „Orts- und Volksbibliotheken", Publikationen, „Wanderversammlungen" und Vorträge mussten auf dieser Grundlage aufbauen. ${ }^{64}$ Sogar bereits vor der Gründung des Vereines hatte der Physiologe in der Wissenspopularisierung mitgewirkt. Das „Programm der populär-wissenschaftlichen Vorträge, welche in der Fastenzeit 1865 im Saale der Ressource zu Graz, gehalten werden ${ }^{665}$ gibt darüber Auskunft. Der Mediziner referierte „Ueber die Wirkungen eingeathmeter Luftarten auf den Organismus“. Inhaltlich zeigte sich bereits ein Vorläufer der Volkstümlichen Vorträge. Institutionell und konzeptionell erinnerten die Bestrebungen etwa noch an die „Fastenpredigten“des Arztes Franz Anton $\mathrm{Mai}^{66}$ in den $1790 \mathrm{er}$ Jahren. Auch Rolletts politisches Engagement ist greifbar. ${ }^{67}$ Klemensiewicz $^{68}(1848$ - 1922) zeichnete sich neben seiner regen Vortragstätigkeit dadurch aus, dass er den ganzen Krieg hindurch den Ausschussvorsitz führte. Seine eigenen militärischen Erfahrungen müssen besonders betont werden.

Durch sein regelmäßiges Wirken über dreißig Jahre hinweg verdient auch Wilhelm Prausnitz $^{69}$ (1861 - 1933) Erwähnung. Als Professor der Hygiene stand er an der

59 Erster Commissionsobmann 1898 - 1901. Studium in Wien, 1857 - 1863 Assistent (bei Ernst Wilhelm Brücke); Ordinarius und quasi Begründer der Physiologie und Histologie in Graz 1863; Präsident des Vereines der Ärzte in der Steiermark, Obmann des Städtischen Gesundheitsamtes, Mitglied des Grazer Gemeinderates, Obmann des Steiermärkischen Volksbildungsvereines.

60 AUSSCHUSS des steiermärkischen Volksbildungsvereines (Hg.), Die in Fürstenfeld am 4. Juni 1893 abgehaltene Wander-Versammlung des steiermärkischen Volksbildungsvereines (Graz 1893) 6-16.

61 Ebd. 6.

62 Ebd. 7.

63 Ebd. 16.

64 Ebd. 12.

65 Vgl. das Exemplar in UAG, Nachlass Rollett 15. Die zuvor genannte Rede ist ebenfalls dort enthalten.

66 Eduard SEIDLER, Lebensplan und Gesundheitsführung. Franz Anton Mai und die medizinische Aufklärung in Mannheim (Mannheim 1975).

67 Reinhold AIGNER, Der Physiologe Alexander Rollett als Abgeordneter im Grazer Gemeinderat und Steiermärkischen Landtag. In: Historisches Jahrbuch der Stadt Graz 4 (1971) 107-128.

68 Im Ausschuss ab 1903, Ausschussvorsitzender 1907/08 - 1921/22, insgesamt 64 Vorträge. Studium in Graz und Wien, 1870/71 Militärdienst, 1871 Dr. med., 1872 Dr. Chir., Assistent bei Alexander Rollett 1871, Habilitation 1875, Forschung in Zürich, Bern, Genf, Straßburg, Wien; Oberarzt im Bosnienfeldzug 1878; Extraordinarius für allgemeine und experimentelle Pathologie 1878, Ordinarius 1885.

691901 - 1929 vierzig Vorträge, zudem Führungen und Kurse um die Mitte der 1920er. Studium in Heidelberg, Leipzig, Wrocław (Breslau), Freiburg im Breisgau, München, 1885 Dr. med., Assistent in München und Göttingen, Habilitation 1890; Extraordinarius der Hygiene 1894, Ordinarius 1899, auch Leiter der bakteriellen Untersuchungsanstalt; Lehrveranstaltungen zur Rassenhygiene ab 1920, Anregung einer Eheberatungsstelle der Stadt Graz 1922. 
Schnittstelle zwischen akademischer Medizin und gesellschaftlicher Anwendung. Neben seiner Vortragstätigkeit fielen weitere relevante Aktivitäten im Umfeld auf. 1912/13 stand er als erster Obmann dem Spielausschuss vor. Dieser koordinierte suprafakultär die sportlichen Betätigungen an der Universität. Die Vorlesungen für Hörer aller Fakultäten waren ebenfalls ein Werk des Hygienikers. ${ }^{70}$ Dementsprechend regelmäßig fanden ab 1904/05 facheinschlägige Veranstaltungen in diesem Rahmen statt, an denen sich neben Prausnitz auch andere Mitarbeiter des Instituts (Hans Hammerl, Paul Theodor Müller) beteiligten. Außerdem waren die Lehrveranstaltungen zur Schulhygiene, die Dozent Oskar Eberstaller, seines Zeichens auch Stadtphysikus, für Lehramtsstudierende abhielt, am Institut angesiedelt. Sie begannen 1898, also zur Zeit der Geburt der Volkstümlichen Vorträge. Hans Prausnitz, Wilhelms Sohn, gehörte schließlich zu den Funktionären des Deutschen akademisch-technischen Abstinenten-Vereines. Im Zuge der Erwähnung dieses Vereines und einer Nachfolgeunternehmung kann an dieser Stelle nur auf die Existenz weiterer Vereine auf akademischem Boden hingewiesen werden, die der Körperkultur im engeren oder weiteren Sinne dienten. ${ }^{71}$

Überhaupt blieben nicht nur die Leitungsfunktionen, sondern auch die Vorträge eine Domäne der Professorenschaft. (Vgl. Graphik 3.)Für den speziellen Fall der Mediziner muss außerdem bedacht werden, dass auch die Privatdozenten zuweilen leitende Positionen in Krankenhäusern bekleideten. Die Situation stellte sich also insgesamt wohl anders dar als jene der Geistes- und Naturwissenschafter. ${ }^{72}$

\section{Inhalte und Motive der populärmedizinischen Vorträge}

Inhaltlich schlugen die „Medizinische[n] Wissenschaften“ laut einer internen Bilanz von $1910 \mathrm{zu}$ dieser Zeit mit etwa 27 Prozent zu Buche. ${ }^{73}$ Im Vergleich kamen in der generell „,bewährten Verteilung" die Rechts- und Staatswissenschaften auf sieben Prozent, die Naturwissenschaften inklusive Mathematik auf 28 Prozent, die geographischen, historischen und kunsthistorischen Inhalte auf 34 Prozent und der Bereich Philosophie und Philologie auf vier Prozent. In den offiziellen Berichten bildete die Medizin mit den Naturwissenschaften eine gemeinsame Kategorie. $^{74}$ Die hier pragmatisch praktizierte Beschränkung auf die Medizinische Fakultät verschleiert also zugegebenermaßen allgemeinere Sichtweisen auf den Menschen. Die Zoologie steuerte etwa Auseinandersetzungen mit Charles Darwin und mit der Deszendenztheorie bei. ${ }^{75}$ Punktuell standen auch die Vererbung und Insekten als Überträger von Krankheiten im Mittelpunkt. ${ }^{76}$ Die Paläontologie brachte ebenfalls entwicklungsgeschichtliche

70 Vgl. für den Antrag im Senat: UAG, Rekt. Senat, Sitzungsprotokoll, 19. November 1903. Vgl. zudem die Lehrveranstaltungsverzeichnisse und Personalstände.

71 UAG, Rekt. Vereinswesen, Zl. 132: Abstinenten-Verein, [Deutscher] akadem[isch]-techn[ischer] (1902 - 1922). Ebd. Zl. 106: Deutsche Gemeinschaft für alkoholfreie Kultur, akad[emische] Gruppe (1922 1937).

72 Für Wien zuletzt allgemein: Klaus TASCHWER, Ende der Aufklärung? Die Entwicklung der volkstümlichen Universitätskurse in Wien zwischen 1918 und 1937. In: Spurensuche. Zeitschrift für Geschichte der Erwachsenenbildung und Wissenschaftspopularisierung 10 (1999) 108-128, hier 113.

73 Anträge des Dreier-Ausschußes (Bauer - Fritsch - Zoth), nach Sitzungsprotokoll, 12. April 1910.

74 Bericht 1913 10, 12.

75 Vor allem Ludwig Böhmig, auch Artur Ritter von Heider.

76 Ludwig Böhmig. 
Aspekte über den Menschen ein ${ }^{77}$ und auch in der botanischen Wissensvermittlung spielte die Vererbung eine Rolle. ${ }^{78}$ Die Physik setzte sich marginal mit dem Phänomen Blitz auseinander. ${ }^{79}$ Es blieb jedoch nicht bei diesen schon offiziell angedeuteten Überschneidungen. Darüber hinaus ergeben sich Verbindungen zu der in Graz um 1900 aus der Philosophie erwachsenden Psychologie. ${ }^{80}$ Die Positionen des Theologen Ude wurden bereits erwähnt. Schließlich klärten Vertreter der Rechts- und Staatswissenschaften über die Arbeiterversicherung auf. ${ }^{81}$

Die Häufigkeit der beteiligten Fächer spiegelt einerseits deutlich das Engagement einzelner Lehrender wider. Die Stärke der allgemeinen und experimentellen Pathologie vor dem Ersten Weltkrieg verdankt sich zu einem Gutteil der Präsenz Klemensiewicz'. Die Physiologie verlor insbesondere durch die Abstinenz Oskar Zoths nach 1918 an Bedeutung. Ähnlich verhielt es sich mit der Inneren Medizin, die in der Vorkriegszeit vom Bemühen Theodor Pfeiffers und Wilhelm Scholz' profitierte. Pfeiffer tat sich mit einer regelrechten Tournee durch nicht weniger als neunzehn Orte hervor und brachte somit sein Wissen um die Tuberkulose unters Volk. Max Stolz als Repräsentant der Geburtshilfe und Gynäkologie verhalf diesem Fach zur entsprechenden Evidenz. In der Zwischenkriegszeit sorgten vor allem der nach wie vor aktive Julius Kratter sowie Fritz Reuter dafür, dass die Gerichtsmedizin an der Spitze stand. Der Aufschwung des Faches Dermatologie/Venerologie stand mit Rudolf Pollands Aktivitäten in Zusammenhang. Der Bereich Psychiatrie/Neurologie verdoppelte sich durch leicht überdurchschnittliches Niveau mehrerer Venieninhaber. Allerdings lassen sich neben diesen Schwankungen allgemeinere Kontinuitäten ausmachen. Kinderheilkunde und Hygiene schnitten konstant im oberen Bereich ab. Insgesamt zeigt sich neben gewissen Häufungen auch die Breite der Beteiligung der Medizinischen Fakultät. (Vgl. Graphiken 4 und 5.)

Die Inhalte können zumeist nur annäherungsweise über die Titel erschlossen werden. Deutlich dominierte durchgängig die Auseinandersetzung mit Krankheiten. Abgeschlagen folgte die Erhaltung der Gesundheit, reine anatomisch-physiologische Wissensvermittlung bildete einen dritten Themenbereich. Aufgrund der Herangehensweise über die Krankheit und ihre Ursachen können die Vorträge insgesamt wohl als Leistungsschau der akkreditierten Heilkunde interpretiert werden; die Fortschritte der naturwissenschaftlichen Grundlagenforschung und ihre klinischen Anwendungen standen im Vordergrund. Auch die hier aufgeführten Präventionsmöglichkeiten, die vor dem Krieg eine bedeutende Stellung einnahmen, leiteten sich direkt von den Krankheitszuständen und von der Betrachtung der Krankheitsursachen ab. Es handelte sich in diesem Bereich dezidiert nicht um ein kurzgefasstes, allumfassendes Kompendium der Krankheitsvermeidung. Als starker Gegenpol stand der Prävention außerdem die akkreditierte Heilung gegenüber. Die Auseinandersetzung mit Infektionskrankheiten, insbesondere mit ansteckenden Kinderkrankheiten und mit der Tuberkulose, spiegelte die Probleme der Zeit wider. Gleiches galt für das nachgereihte Thema des Alkoholmissbrauchs. Die unterschiedliche Präsenz einzelner Krankheitsbilder, also der Geschlechtskrankheiten, der chirurgischen Notfälle und ihrer

\footnotetext{
77 Vinzenz Hilber.

78 Karl Linsbauer.

79 Ernst Kielhauser.

80 Vor allem Stephan Witasek, auch Otmar Sterzinger, Viktor Benussi.

81 Rudolf Bischoff, Ernst Mischler.
} 
Versorgung sowie der psychiatrisch-neurologischen Störungen, ergab sich aus dem bereits oben thematisierten unterschiedlichen Engagement der Lehrenden. Die relative Stärke des Komplexes Krebs in der Zwischenkriegszeit erwuchs aus der Durchführung einer speziellen Reihe zu dieser Thematik, für die Krankenpflege galt vor dem Krieg das Gleiche. Richtiggehende Tourneen, wie etwa jene des Tuberkulosespezialisten Theodor Pfeiffer oder die ebenfalls ausgedehnte Reisetätigkeit des Pädiaters Adolf Tobeitz, zeugen vom Einsatz für eine umfassende Information der Bevölkerung vor Ort vor dem Ersten Weltkrieg. Ob das Muster der Orte mit Mortalitäts- und Morbiditätsstatistiken korrespondiert, wäre noch eine interessante Fragestellung. Die Vernachlässigung der Peripherie in der Zwischenkriegszeit dürfte neben den personellen Schwerpunktsetzungen wohl auch ein Grund für Schwankungen gewesen sein. Der Bereich Prävention nahm etwa weniger Raum in den Titeln ein. Auffällig ist auch die Betonung allgemeiner pathologischer Mechanismen, deren Explizierung sich eher an ein gebildetes städtisches Publikum gewandt haben könnte. (Vgl. Graphiken 6, 7 und 8.)

Der humanitäre Gedanke der Wissensvermittlung verknüpfte sich vor diesem Hintergrund vielleicht nicht zuletzt mit Bestrebungen, die potentielle Patientenschaft $\mathrm{zu}$ überzeugen und zu vergrößern. Ein zwiespältiges Beispiel am Rande der Geburtsphase der Volkstümlichen Vorträge illustriert diese Spekulation. Karl Nicoladoni, Professor für specielle chirurgische Pathologie und Therapie, machte sich für Erleichterungen für Patientinnen und Patienten stark, die in der kalten Jahreszeit aus der Obersteiermark nach Graz anreisen mussten. Der offizielle Antrag an das Ministerium für Cultus und Unterricht lautete philanthropisch:

„Es möge das löbliche Professoren-Collegium bei den dabei mitinteressirten hohen Ministerien dabin vorstellig werden, daß für die von Selzthal nach Graz abzweigenden Züge ein directer Wagen II. und III. Classe für Graz eingestellt werde und den mit ärztlicher Weisung versehenen Kranken eine Preisermässigung gewährt werden möge. " 82

Intern äußerte Nicoladoni zudem die Beobachtung, dass das viermalige Umsteigen die Leidenden nach Wien trieb, das direkt erreicht werden konnte. Dies bedingte aus der kühlen technokratischen Sicht des Chirurgen, „daß [das] Klin.-Material aus Ob[er]-Steier eine große Einbuße erleidet." Nebenbei bemerkt war es gerade die Eisenbahn, die eine Niederlage der akademisch akkreditierten Medizin eindrucksvoll exemplarisch demonstrierte. Die Schmalspurbahn Preding - Wieselsdorf - Stainz, der nicht zufällig sogenannte „Flascherlzug“" ${ }^{33}$ führte nämlich bequem zum vielbesuchten Urinbeschauer und Konkurrenten Höllerhansl (1866 - 1935).

Die eigentliche Gesundheitspflege wandte sich kontinuierlich der adäquaten Kinderversorgung zu. Väter und vor allem Mütter wurden in die Pflicht genommen. Hinzu kamen allgemeinere Themen der physischen Lebensführung. Die vorzügliche

82 UAG, Med[izinische] Fak[ultät] Zl. 64 ex 1897/98. Vonseiten der Eisenbahn wurde die Beschwerde hinsichtlich der Verbindungsqualität anerkannt, vage versprach die maßgebliche Stelle, die komplizierten Probleme im Hintergrund beheben zu wollen; eine Fahrpreisermäßigung kam jedoch nicht in Frage, vgl. UAG, Med. Fak. Zl. 848 ex 1897/98.

83 STEIERMÄRKISCHES LANDESMUSEUM JOANNEUM, Abteilung Schloß Stainz (Hg.), Flascherlzug. 100 Jahre Stainzer Bahn (= Schriftenreihe des Steiermärkischen Landesmuseums Joanneum, Abteilung Schloß Stainz und des Museumsvereines Stainz 4, Stainz 1992). Bernd E. MADER, Der Höllerhansl. Leben und Wirken des Naturheilers Johann Reinbacher (Graz/Wien/Köln 1997). Für Probleme bei der Konsultation von Ärzten, die am Land hauptsächlich an Sonn- und Feiertagen stattfand, andeutungsweise: UAG, Nachlass Rollett, Briefe 1893, Ivo Hütter an Alexander Rollett, 24. Oktober 1893. 
Sorge galt den Zuständen in den Städten. Institutionen, die mit der Gesundheitspflege in Verbindung standen, scheinen nur in der Vortragsstatistik bis 1914 auf. Nach dem Krieg wurde diese Thematik anschaulicher durch Führungen vermittelt. Prausnitz zeigte der Interessentenschaft im zweiten Anlauf - zunächst war das Interesse im Sommersemester $1924 \mathrm{zu}$ gering gewesen - 1925 das Landeskrankenhaus und das Wasserwerk, 1926 führte er durch das Impfstoffwerk Graz-Triesterstraße und die Arbeiterbäckerei Eggenberg. (Vgl. Graphiken 9 und 10.)

Abschließend sollen noch Schlaglichter auf die Konkurrenz in der medizinischen Wissensvermittlung geworfen werden. In der Vortragstätigkeit der Urania spielte der Bereich „Medizin, Gesundheit, Ernährung“ eine prominente Rolle. Von den 1616 Vorträgen von 1919 bis 1938 entfielen 152 auf dieses Feld. ${ }^{84}$ Damit rangierte es an zweiter Stelle, gleichauf mit der Thematik „Kulturgeschichte, Völkerkunde“, jedoch abgeschlagen hinter geographischen Inhalten, die mit 293 Einträgen zu Buche schlugen. Dazu kamen - analog zu den oben geäußerten Beobachtungen - wohl noch einige physische und psychische Aspekte aus den Gebieten Biologie, Psychologie, Sport, oder auch aus der erwähnten „Völkerkunde“. Insgesamt blieb die Zahl der medizinisch einschlägigen Vorträge hinter der Masse der Volkstümlichen Vorträge zu dieser Thematik aber zurück. Die im universitären Rahmen vernachlässigte körperliche Praxis wurde allerdings auf Wanderungen und an „,[m] usisch-gymnastische[n] Abende[n]“ gepflegt. ${ }^{85}$ Als Verbindung zum katholisch-bäuerlichen Volksbildungszweig der Ersten Republik in St. Martin in der Nähe von Graz ist beispielsweise der Grazer Ordinarius für Kinderheilkunde Franz Hamburger evident. ${ }^{86}$ Hinsichtlich der Arbeiterschaft kann Prausnitz' Vortragstätigkeit in der Mitte der 1920er Jahre ins Treffen geführt werden.

Im Sozialbereich entfaltete die Fürsorge insbesondere nach dem Ersten Weltkrieg stärker ihr Wirken. Ein Vortrag Hamburgers wurde 1924 dezidiert „im Rahmen des Vereins für Kinderpflege ${ }^{\text {c87 }}$ angesiedelt und gibt Auskunft über konkrete Verknüpfungen. Die 1924 gegründete Steiermärkische Caritas ${ }^{88}$ widmete sich beispielsweise unter anderem der Kinder- und Jugendfürsorge sowie der Alkoholismusbekämpfung. Kranke wurden ab 1926 auch im Rahmen einer Hauskrankenpflege betreut. Damit erhebt sich die Frage, ob inoffizielle Wissensvermittlung auf diese Weise stattfand. Potentiell geschah dieser Transfer näher am betroffenen Individuum als die Bemühungen der Universität.

\section{Aspekte der Politisierung}

Angesichts der oben zitierten Positionen, die Rollett im Rahmen des Volksbildungsvereines vertrat und die sich aufgrund der personellen und strukturellen Verbindungen wohl auch auf die Universitätsausdehnung übertrugen, können die universitären Bestrebungen dem liberalen, deutschnationalen Umfeld zugeordnet werden. Eine

\footnotetext{
84 KOJALEK, Urania 129.

85 Vgl. ebd. 130. Zum Teil mit weltanschaulichem Hintergrund laut ebd. 133.

86 KOJALEK, Volksbildung 37.

87 Sitzungsprotokoll, 4. April 1924.

88 Elfriede Maria HUBER-REISMANN, Krankheit, Gesundheitswesen und Armenfürsorge. In: Walter BRUNNER (Hg.), Geschichte der Stadt Graz. II: Wirtschaft - Gesellschaft - Alltag (Graz 2003) 239-356, hier 350f. Vgl. allgemeiner jüngst: Andreas WEIGL, The rise and fall of the Fürsorgerin (female welfare worker) in Austrian public health policies. Theory and practise of a professional link within a changing social and epidemiological framework. In: Robert JÜTTE, Martin DINGES (Hg.), The transmission of health practices (= Medizin, Gesellschaft und Geschichte, Beiheft 39, Stuttgart 2011) 117-133.
} 
außergewöhnliche soziopolitische Stellungnahme bereits kurz vor dem Ersten Weltkrieg soll eingangs als Detail ebenfalls nicht unerwähnt bleiben. Paul Mathes, Privatdozent für Geburtshilfe und Gynäkologie, befasste sich im Studienjahr 1913/14 im Kärntnerischen Wolfsberg nämlich mit ,biologischen Grundlagen der modernen Frauenemanzipation“. Die allgemeine politische Radikalisierung kann vor allem am Aufstieg rassenhygienischer Inhalte festgemacht werden. Interesse an rassekundlichen Aspekten kann an der Grazer Medizinischen Fakultät grundsätzlich schon früh nachgewiesen werden. 1883 hatte Emil Zuckerkandl, der Grazer Ordinarius für descriptive und topografische Anatomie, „Beiträge zur Craniologie der Deutschen in Österreich" verfasst und dabei unter anderem Vergleiche mit der „,alten Hallstätter Race «89 angestellt. 1884 folgten „Craniologische Untersuchungen in Tirol und Inner-Oesterreich“"90 Zuckerkandl nahm in Graz diesbezüglich anscheinend eine Vorreiterrolle ein. Zumindest für die historischen Disziplinen teilte der Archäologe Wilhelm Gurlitt ${ }^{91}$ Josef Szombathy mit, dass es Anfang 1884 keine nennenswerten Ambitionen gäbe. Der Psychiater Gabriel Anton, dessen Schüler eugenische Bestrebungen in Graz mitgestalteten, ${ }^{2}$ brachte die Vererbung von Krankheiten 1898/99 in einem der ersten volkstümlichen Vorträge prominent ins Spiel. Oskar Zoth betonte zwar im Studienjahr 1905/06 die Schaffung eines Umfeldes für die Zeugung ausgezeichneter Nachkommenschaft im Rahmen seiner Ausführungen über die „Fortpflanzung des Menschen“. "Qualität" und „erstklassige Nachkommenschaft" waren die Ziele. Die Eltern hatten nicht zuletzt Verpflichtungen zur „Erbaltung der Art", dem „Volke“ und der „Rasse“ gegenüber. Die praktische Umsetzung, das „Wie“, hielt er jedoch dezidiert für eine „Privatsache “. ${ }^{93}$ Prausnitz trug 1903 in Eisenerz über „Volkshygiene“ vor, 1925 referierte er vor einem zahlreichen Grazer Arbeiterschaftsauditorium ausführlich in vier Einheiten über die „Grundzüge der Rassenhygiene“. Auch sein Nachfolger Heinrich Reichel bediente sich übrigens noch beider Diktionen. Im Sommersemester 1920 befasste sich Wilhelm Prausnitz zusammen mit seinem Assistenten Johann Hammerschmidt erstmals explizit in einer akademischen Lehrveranstaltung mit Rassenhygiene. In weiterer Folge wurde diese Veranstaltung auch für die gesamte Hörerschaft der Universität zugänglich. ${ }^{94}$

Rudolf Pollands weitreichendes Engagement hatte sich vor 1930 vorwiegend an der Urania abgespielt. ${ }^{95}$ Polland und auch dem im Rahmen der Volkstümlichen Vorträge unterrepräsentierten Leopold Löhner eröffnete sich so ein Forum außerhalb der universitären Allgemeinbildungsschiene. Erst ab 1930 nahmen Pollands volkstümliche Vorträge verstärkt und fast ausschließlich Bezug auf Rassenlehre und Eugenik. Auch insgesamt nahmen einschlägige Fragestellungen ab dem Beginn der 1930er Jahre zu.

89 E[mil] ZUCKERKANDL, Beiträge zur Craniologie der Deutschen in Österreich. In: Mittheilungen der Anthropologischen Gesellschaft in Wien 13 (1883) 1-30, hier 8f.

90 Beide in der Sonderdrucksammlung in UAG, Nachlass Carla Zawisch-Ossenitz 8. Die Sammlung stammte wohl zum größten Teil aus den Beständen Otto Draschs, eines Vorgängers der Nachlasserin.

91 Vgl. UAG, Nachlass Wilhelm Gurlitt, Josef Szombathy an Wilhelm Gurlitt, 19. Februar 1884.

92 MAYER, Eugenik 119. Es handelt sich hier also zunächst als Nukleus um das Bestreben und die Interessen von Fachvertretern, zudem kann die Bildung von Schulen als Verfestigung interpretiert werden. Die Schüler und auch die akademischen Nachfolger, die ihrerseits andere Quellen und Wurzeln einbrachten, beteiligten sich schließlich an der propagandistischen Ausweitung auf weitere Bevölkerungskreise und in Richtung offizielle Politik.

93 UAG, Nachlass Rudolf Rigler, O. Zoth Vorlesungen, Ms. 19 V. 8.

94 Zum Beispiel im Sommersemester 1923.

95 KOJALEK, Urania 132. 
Als Zäsur im Bereich der Volkstümlichen Vorträge ist also wie im Allgemeinen in letzter Konsequenz wohl auch die Weltwirtschaftskrise anzusehen. ${ }^{96}$ Im Rahmen der einschlägigen Vortragsreihe zum Überbegriff „Volk“ brachten sich Friedrich Standenath und Heinrich Reichel ein. Sie behandelten die Teilbereiche „Volk und Medizin“" respektive „Volkshygiene““97 Für den Herbst 1936 wurde ein Zyklus über „Vererbung und Mensch“ konzipiert, der fast vollständig von Medizinern getragen wurde. $^{98}$ Zuletzt, bereits nach dem Anschluss, sollte „Das Blut“ im Mittelpunkt stehen. ${ }^{99}$ Neben diesen Bestrebungen verblassten die medizinisch-praktischen Zyklen. Im Herbst 1931 konnte ein „Krebs-Cyclus“ durchgeführt werden; ${ }^{100}$ die Veranstaltungsreihe „Der gesunde und kranke Mensch (Hygiene des Lebens)“" im Herbst 1933 galt bezeichnenderweise als enttäuschend schlecht besucht. ${ }^{101}$ Veranstaltungen zu Infektionskrankheiten fanden Anfang 1938 statt. ${ }^{102}$

\section{Vorträge der Mitglieder der Medizinischen Fakultät im Ersten Weltkrieg}

Der Erste Weltkrieg wurde bis hierher allgemein als Wasserscheide und durch den Systemwechsel bedingter Einschnitt betrachtet. Als Abschnitt in der Vortragstätigkeit der Mediziner soll seine Bedeutung in weiterer Folge umrissen werden. Die Zahl der einschlägigen Vorträge sank drastisch auf insgesamt fünfzehn, die maximale Mehrfachbelastung bestand neben der Volksbildung aus akademischer Lehre und Lazarettdienst. Das Engagement hatte bereits Tradition, Personal und Räume der Universität waren regelmäßig in militärische Planungen einbezogen worden. Klemensiewicz hatte beispielsweise als aktiver Militärarzt den Bosnienfeldzug von 1878 mitgemacht und seinen Lehrer Rollett durch Briefe auf dem Laufenden gehalten. ${ }^{103}$ Statt der Weitergabe von Wissen waren die fachliche Anwendung des Wissens sowie die Heranbildung von Fachleuten gefragt. An der Medizinischen Fakultät nahm sich der Privatdozent für Neurologie und Psychiatrie sowie Gerichtsarzt Heinrich di Gaspero ab dem Wintersemester 1915/16 ${ }^{104}$ als erster seines Faches und in weiterer Folge regelmäßig einzelner „Erkerankungen des Nervensystems im Kriege“ an. Die angekündigten Demonstrationen dürften sich wohl auf in Graz behandelte Patienten bezogen haben. ${ }^{105}$ Außerdem finden sich etwa „keriegsärztliche Demonstrationen“ Fritz Hartmanns (Sommersemester 1916), ${ }^{106}$ seines Zeichens ordentlicher Professor der Psychiatrie und Nervenpathologie sowie Vorstand der Klinik für Geistes- und Nervenkrankheiten. Außeruniversitär wirkte er ebenfalls als Gerichtsarzt. Lediglich im darauf folgenden Wintersemester spezifizierte der Ordinarius, dass seine Vorführungen

96 Vgl. zu dieser Zäsur auch MAYER, Eugenik 125.

97 Sitzungsprotokoll, 26. Juni 1934.

98 Sitzungsprotokoll, 26. März 1936.

99 Sitzungsprotokoll, 14. Juni 1938. Zur Vortragsreihe auch noch (das letzte) Sitzungsprotokoll, 21. Juni 1938.

100 Sitzungsprotokoll, 9. Mai 1931; Sitzungsprotokoll, 8. Juli 1931; Sitzungsprotokoll, 26. November 1931.

101 Sitzungsprotokoll, 9. März 1933; Sitzungsprotokoll, 24. Mai 1933; Sitzungsprotokoll, 12. September 1933; Sitzungsprotokoll, 12. Dezember 1933.

102 Sitzungsprotokoll, 23. November 1937.

103 http://gams.uni-graz.at:8080/fedora/get/o:wgroll-1878/bdef:TEI/get/, 02. 11. 2011. NB. zudem auch die Briefe Otto Draschs, eines weiteren Schülers.

104 Unausgesetzt Wintersemester 1916/17 bis Wintersemester 1918/19.

105 NB. Hans-Georg HOFER, Nervenschwäche und Krieg. Modernitätskritik und Krisenbewältigung in der österreichischen Psychiatrie (1880-1920) (Wien/Köln/Weimar 2004).

106 Auch noch in den Sommersemestern 1917, 1918. 
sowohl für Militärärzte als auch zivile Fachvertreter gedacht waren. Sie fanden nicht nur im Hörsaal, sondern auch in der „Übungsschule für Sprachkeranke und andere Gebirnverletżte" statt. Im Wintersemester 1917/18 folgte ein Collegium publicum über Zusammenhänge zwischen „Krieg und Nervenleiden“. Im Wintersemester 1915/16 fand auch die Kriegschirurgie erstmals explizite Berücksichtigung im Lehrveranstaltungsverzeichnis. Sie wurde durch den Titular Extraordinarius Josef Hertle ${ }^{107}$ repräsentiert und in weiterer Folge auch durch den Ordinarius Viktor von Hacker ${ }^{108}$ vertreten. ${ }^{109}$ Schließlich informierte Privatdozent Otto Burkard im Wintersemester 1918/19 mittels „Exkursionen und Demonstrationen“ über die Kriegsinvalidenfürsorge. ${ }^{110}$ Arnold Wittek ${ }^{111}$ nahm in den beiden Semestern des Studienjahres 1918/19 speziell auf die Kriegsorthopädie Bezug.

Die genannten fachlichen Schwerpunkte flossen auch in die klinische Versorgung der in Mitleidenschaft gezogenen Soldaten ein. Überdies tat sich die Fakultät mit dem Betrieb eines Reservespitals hervor. ${ }^{112}$ Dieses beanspruchte sowohl die Aula als auch zwei Hörsäle, ebenfalls im ersten Stock des Hauptgebäudes. Im Laufe des Krieges spezialisierte es sich auf Kieferverletzte. Eine Einrichtung an der Chirurgischen Klinik und eine orthopädische Anstalt komplettierten das Angebot. Zudem wurde der Einsatz von Chirurgen in Frontnähe systematisch organisiert. Ein zweiter Schwerpunkt bestand in der Betreuung von Nervenkranken. Für sie wurden eine MilitärNervenheilanstalt sowie eine Schule für "sprachkeranke und gebirnverletżte Militärpersonen“" geschaffen. Der schon gewürdigte Wilhelm Prausnitz setzte Maßnahmen zur Bekämpfung von Epidemien in Internierungslagern. ${ }^{113}$ Nicht zuletzt sorgte sich der Hygieniker um die Ernährungslage. Klemensiewicz gründete als Rektor des Jahres 1915/16 eine Einrichtung zur Sachversorgung Universitätsangehöriger. 1918/19 stand er auch der Kriegsküche deutscher Hochschüler vor, die im Jahr darauf von Fritz Pregl weitergeführt wurde.

Privatdozent Burkard informierte schließlich nicht nur Studierende, sondern im Studienjahr 1917/18 auch ein allgemeines Deutschlandsberger Publikum über die Kriegsinvalidenfürsorge in der Steiermark. Klemensiewicz besuchte im gleichen Studienjahr und im Jahr darauf mit einem seiner Hauptthemen, dem Blutkreislauf, die frontnahen Lokationen Gorica/Gorizia (Görz) und Capriva del Friuli. Am aktivsten zeigte sich der Ordinarius für Gerichtsmedizin Julius Kratter. Er hielt im Studienjahr 1917/18 drei Vorträge in Graz, begab sich in der gleichen Periode nach Mürzzuschlag, um, wie auch vor dem Krieg, über Berufskrankheiten zu berichten, und wagte sich schließlich später, als sich der Krieg schon dem Ende nahte, ebenfalls nach Capriva del Friuli. Bezeichnenderweise informierte er dort über das insgesamt singuläre Thema

\footnotetext{
107 Vgl. Franz SPATH, Zur Geschichte der Chirurgie an der Karl-Franzens-Universität Graz. Aus dem Nachlaß herausgegeben, ergänzt und fortgeführt von Walter Höflechner (= Publikationen aus dem Archiv der Universität Graz 18, Graz 1986) 56. Auch Wintersemester 1916/17, 1917/18 und 1918/19. 108 Vgl. SPATH, Geschichte 46-54.

109 Sommersemester 1916, 1917, 1918 und Studienjahr 1918/19.

110 Auch Sommersemester 1919.

111 Vgl. SPATH, Geschichte $54 f$.

112 Nach HÖFLECHNER, Baumeister 99-101.

113 Vgl. zum Lager Thalerhof neuerdings: Nicole-Melanie GOLL, „... Dass wir es mit zwei Kriegen zu tun haben, der eine ist der Krieg nach außen, der andere nach innen“. Die Ruthenen und das k.k. Zivilinterniertenlager Thalerhof bei Graz 1914-1917. In: Historisches Jahrbuch der Stadt Graz 40 (2010) 277-303.
} 
Vergangenheit, Gegenwart und Zukunft der Feuerbestattung. Etwa zur gleichen Zeit brachte sich Rudolf Polland in Graz mit drei Vorträgen zu Geschlechtskrankheiten ein.

Oskar Zoth recycelte quasi zwei volkstümliche Vorträge über das Blut und seine Verrichtungen sowie über Schutzeinrichtungen des Körpers. Gleich nach dem Ausbruch des Krieges las er sie in Graz im Rahmen eines Krankenpflegerinnenkurses. ${ }^{114}$ In einer Vortragsreihe während des Krieges sprach der gleiche Ordinarius vom Hunger. ${ }^{115}$ Dieses eindrucksvolle Beispiel soll am Ende stehen. Deutlich zeigt es letztendlich auf, was sich hinter einem einfachen Titel inhaltlich tatsächlich verbergen konnte. Einleitend unterstrich Zoth die Relevanz seiner Ausführungen,

„[s] teht ja die Frage, wie heute wohl von keiner, auch der blödesten Seite, mehr gelengnet werden kann doch sozusagen und einigermaßen auf der Tagesordnung! Zwar sagt ein altes Sprichwort: ,Man soll den Teufel nicht an die Wand malen!' Aber dieses Sprichwort ist, wie selten eines, grundfalsch.“

Danach folgten Stichworte, denen zufolge dem Auditorium der Teufel, oder auch sein lokaler Vertreter, der „Nikolobartl“, lebhaft vor Augen geführt worden sein dürfte. Gleichsam als Regieanweisung kam die Bemerkung: „Lachen“. Die zweite Anmerkung fuhr mit Ernsterem fort: „2. Noch allg. [emein] gefürchtet: Tod!“ Der ausgeführte Gedanke relativierte jedoch: „Je mehr man darïber nachdenkt, ihn studiert und beobachtet, - mit ihm umgeht - Feldgraue!! desto mehr verliert er von seinem Schrecken, Bruder: Schlaf! Erlöser, ob wir uns Vernichtung oder Fortleben des Ichs vorstellen." An den Rand notiert fand sich in der Originalsprache zudem die klassische Formulierung Epikurs. Schließlich folgte als dritter Anstoß: ,Jede Gefahr: ins Auge schauen! Törichte - Vogel Strauß!“ Die Conclusio der Anfangsbetrachtung konnte daher lauten:

„Und so wollen wir sehen, ob es mit dem gefürchteten Hunger nicht eine ähnliche Bewandtnis hat wie mit Tod und Teufel und wir wollen ibn nun in kennzeichnenden Zügen wabrheitsgemäß, an die Wand malen', beobachten, studieren und aus allem zum Schluße praktische Folgerungen für unser Verhalten in solchen Zeiten, wie die jetzigen, ziehen."

Über Fakten aus Tierversuchen oder auch aus der Auseinandersetzung mit Hungerkünstlern und verunglückten Bergleuten, über Statistiken und praktische Regeln kam Zoth zum Schluss. Besondere Beachtung verdient der lamentierende Hinweis auf die „,Ernährungs-Behörden ${ }^{*}$. Diese hätten ,ja die ,Vertheilung' wieder in die Hand genommen, wie im Vorjabr." Die folgenden Streichungen sprechen Bände: „,

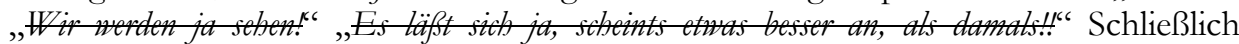
steigerte sich Zoth wortgewaltig zum großen Finale:

„Aber dafür wollen wir eines Spruches zum Schluße und binfort gedenken, bei jedem kargen Mabl und jeder ausgefallenen Mablzeit - in Grimm und Groll, in Haß und Hohn, des Spruches, den unsere tapferen Grauen in den Schützengräben Flanderns querst geprägt haben und seither als bitteren Gruß sich zurufen und den wir forterben wollen auf die jetzt mitleidenden Kinder:

Des Fluches gegen den alten nimmersatten [!], gewissen- und ruchlosen Ausbeuter der Menschbeit und Anzetteler des jetzigen Weltkrieges, in dem bis heute schon über 10 Millionen Menschen hingeopfert und mehr als 12 Millionen zu Krüppeln gemacht worden sind:

Des Fluches gegen die durch unser verbissenes, Durchbalten' und durch den qielbewußt mit der Sicherheit eines mathematischen Exempels geführten U-boot-Krieg schon heute in der Weltgeschichte für alle Zeiten bis auf die Knochen blamierten ,Aushungerer':

114 UAG, Nachlass Rigler, Zoth Vorlesungen, Mss. 12 und 18 (18. August 1914 und 17. August 1914). Zuvor gehalten in Maribor (Marburg an der Drau) 1899, Übelbach 1902, mit Regieanweisungen und Angaben zur Visualisierung, respektive in Deutschlandsberg 1901, Weiz 1905 und Eisenerz 1909.

115 UAG, Nachlass Rigler, Zoth Vorlesungen, Ms. 30 (7., 14. und 21. Oktober 1917). 
Laut!! ,Gótt / stráfe / Englánd!' (Pause!)

und wir wollen binzufügen (leiser und bedenken genau, wen wir alles meinen):

Laut!! ,und / seine / Helfershelfer.'! - "

Vor dem Hintergrund dieser Tirade stellt sich natürlich auch die Frage, ob die anderen Mediziner ihre Vorträge in ähnlicher Weise in den Dienst der Agitation stellten.

\section{Zusammenfassung und Schlüsse}

Die Beteiligung der Medizinischen Fakultät an der Grazer Universitätsausdehnung fiel also durchaus beträchtlich aus. Von Beginn an zeigte sich das Engagement nicht nur in der regelmäßigen Abhaltung von Vorträgen. Auch Funktionärstätigkeiten waren deutlich wahrnehmbar. Zum Teil erstreckten sich diese auf Vorläufer, Konkurrenten und ergänzende Initiativen. Insgesamt prägten vor allem Professoren die Aktivitäten. Die Inhalte kamen aus einem reichen Repertoire medizinischer Fächer. Überschneidungen vor allem mit den Naturwissenschaften müssen noch genauer expliziert werden. Krankheiten und deren Behandlung durch die akademisch akkreditierte Medizin beanspruchten breiteren Raum als allgemeine vorbeugende Maßnahmen. Die Befassung mit Infektionskrankheiten spiegelte die Sorge für die Allgemeinheit wider. Summa summarum zeigen sich sowohl Motive der philanthropischen Wissenspopularisierung als auch Facetten, die auf professionellen Eigennutz schließen lassen. Die in der Zwischenkriegszeit erwachsene Konkurrenz deckte einerseits jene Bevölkerungsschichten ab, deren Einbezug der Universitätsausdehnung nicht überzeugend gelungen war; namentlich handelte es sich um die Arbeiterschaft und insbesondere um die Bauernschaft. Die „bürgerliche“ Konkurrenz der Urania zeigte zudem praktischere Herangehensweisen. Dies traf vielleicht auch auf die informelle Wissensvermittlung durch soziale Dienste zu. Eine politische Zuordnung kann schon für den Beginn der Bewegung vorgenommen werden. Deutschnationale und liberale Positionen überwogen. Die Radikalisierung vor allem in der Form rassenhygienischer Inhalte setzte am Ende des Ersten Weltkrieges ein und intensivierte sich in den 1930er Jahren. Das Engagement im Ersten Weltkrieg selbst stand der einschlägigen Lehre und der praktisch-medizinischen Tätigkeit gegenüber. Das Fallbeispiel Oskar Zoth zeigt schließlich, wie auch die Medizinische Fakultät in die Agitation eingriff. Zudem deutet es an, mit welchen Mitteln die Anschaulichkeit gewährleistet werden sollte.

\section{Autoreninformation}

Mag. Dr. phil. Andreas Golob, Historiker, Wissenschaftlicher Mitarbeiter des Universitätsarchivs der Karl-Franzens-Universität Graz. Postadresse: Universitätsplatz 3/TG, 8010 Graz, Österreich. Mail: an.golob@uni-graz.at 


\section{Tabellen und Grafiken}

Tabelle 1: Häufigkeit von medizinischen Vorträgen nach Orten - vor dem Ersten Weltkrieg

\begin{tabular}{|c|c|c|c|}
\hline Ort & Anzahl & Ort & Anzahl \\
\hline Graz & 126 & Frohnleiten & 4 \\
\hline Kapfenberg & 25 & Köflach & 4 \\
\hline Celje/Cilli & 15 & Ptuj/Pettau & 4 \\
\hline Bruck an der Mur & 14 & Übelbach & 4 \\
\hline Eisenerz & 14 & Wolfsberg in Kärnten & 4 \\
\hline Leoben & 14 & Feldbach & 3 \\
\hline Eggenberg & 13 & Kindberg & 3 \\
\hline Voitsberg & 12 & Klagenfurt & 3 \\
\hline Weiz & 12 & Neudau & 3 \\
\hline Deutschlandsberg & 9 & Fohnsdorf & 2 \\
\hline Maribor/Marburg/Drau & 9 & Fürstenfeld & 2 \\
\hline Bad Radkersburg & 8 & Ljubljana/Laibach & 2 \\
\hline Judenburg & 8 & Stainz & 2 \\
\hline Neuberg & 8 & Trieste/Trst/Triest & 2 \\
\hline Villach & 8 & Ljutomer/Luttenberg & 1 \\
\hline Hartberg & 6 & Mürzzuschlag & 1 \\
\hline Mautern & 6 & Peggau & 1 \\
\hline Fehring & 5 & Veitsch & 1 \\
\hline Gleisdorf & 5 & Vordernberg & 1 \\
\hline Knittelfeld & 5 & Windisch Feistritz & 1 \\
\hline Brežice/Rann & 4 & Zeltweg & 1 \\
\hline
\end{tabular}

Tabelle 2: Häufigkeit von medizinischen Vorträgen nach Orten - nach dem Ersten Weltkrieg

\begin{tabular}{|c|c|}
\hline Ort & Anzahl \\
\hline Graz & 190 \\
\hline Fürstenfeld & 2 \\
\hline Kapfenberg & 2 \\
\hline Krieglach & 1 \\
\hline
\end{tabular}


Graphik. 1: Soziale Ausdebnung auf der Basis ausgewählter Beispiele nach den Berichten in Prozent:

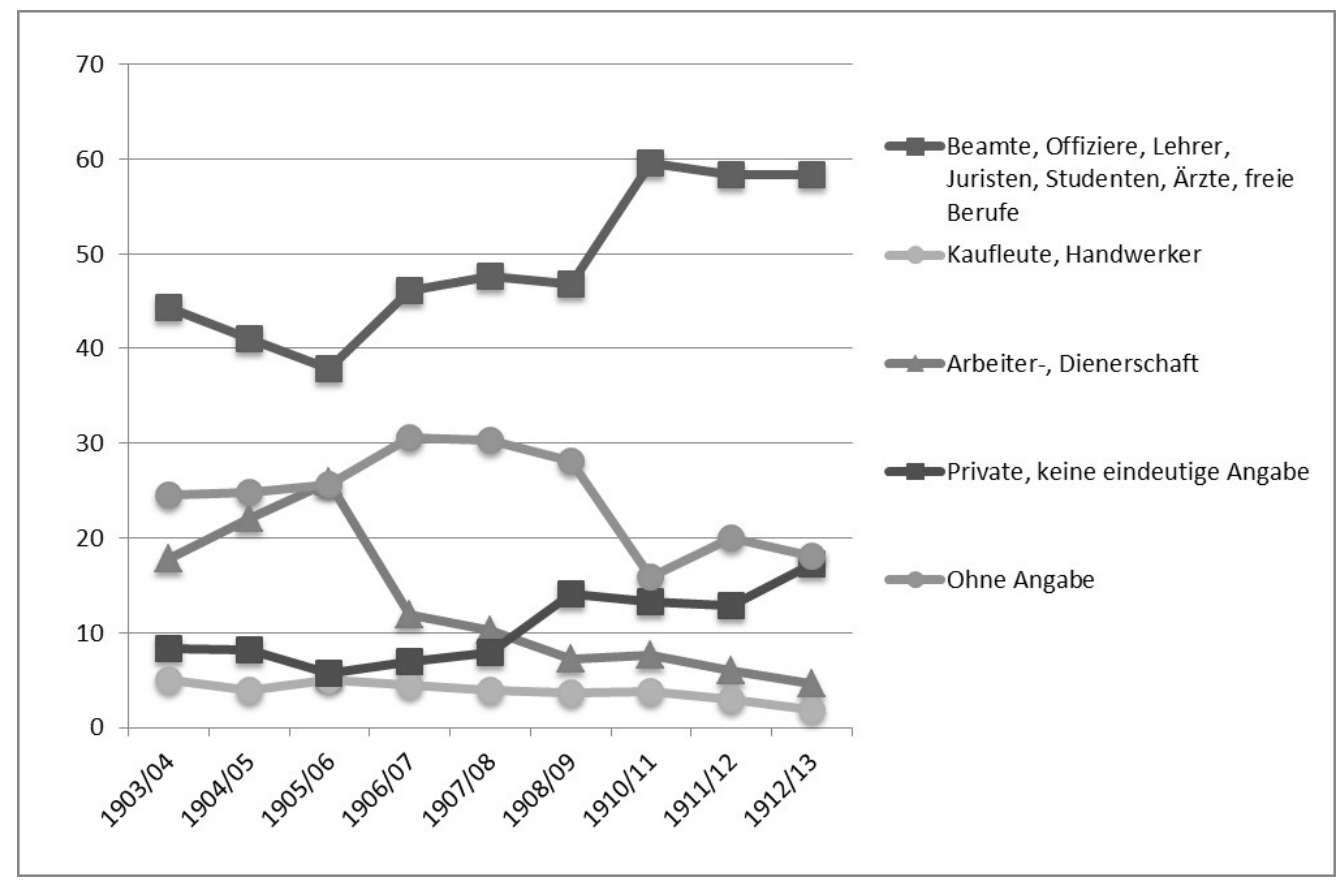

Graphik. 2: Geschlechterverteilung auf der Basis ausgewählter Beispiele nach den Berichten in Prozent:

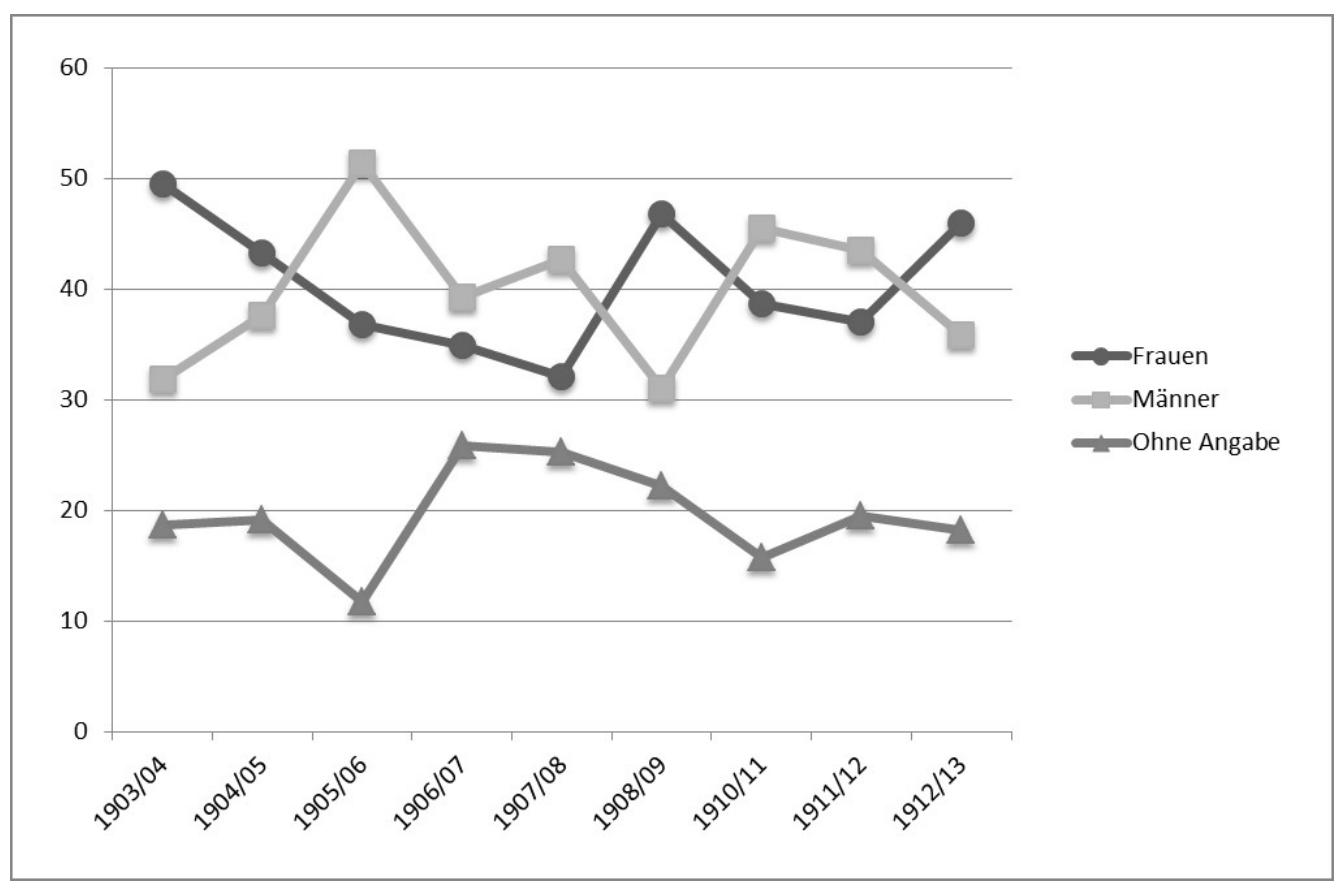


Graphik 3: Stellung der Vortragenden zum Zeitpunkt des Vortrages (vor/nach dem Ersten Weltkrieg):
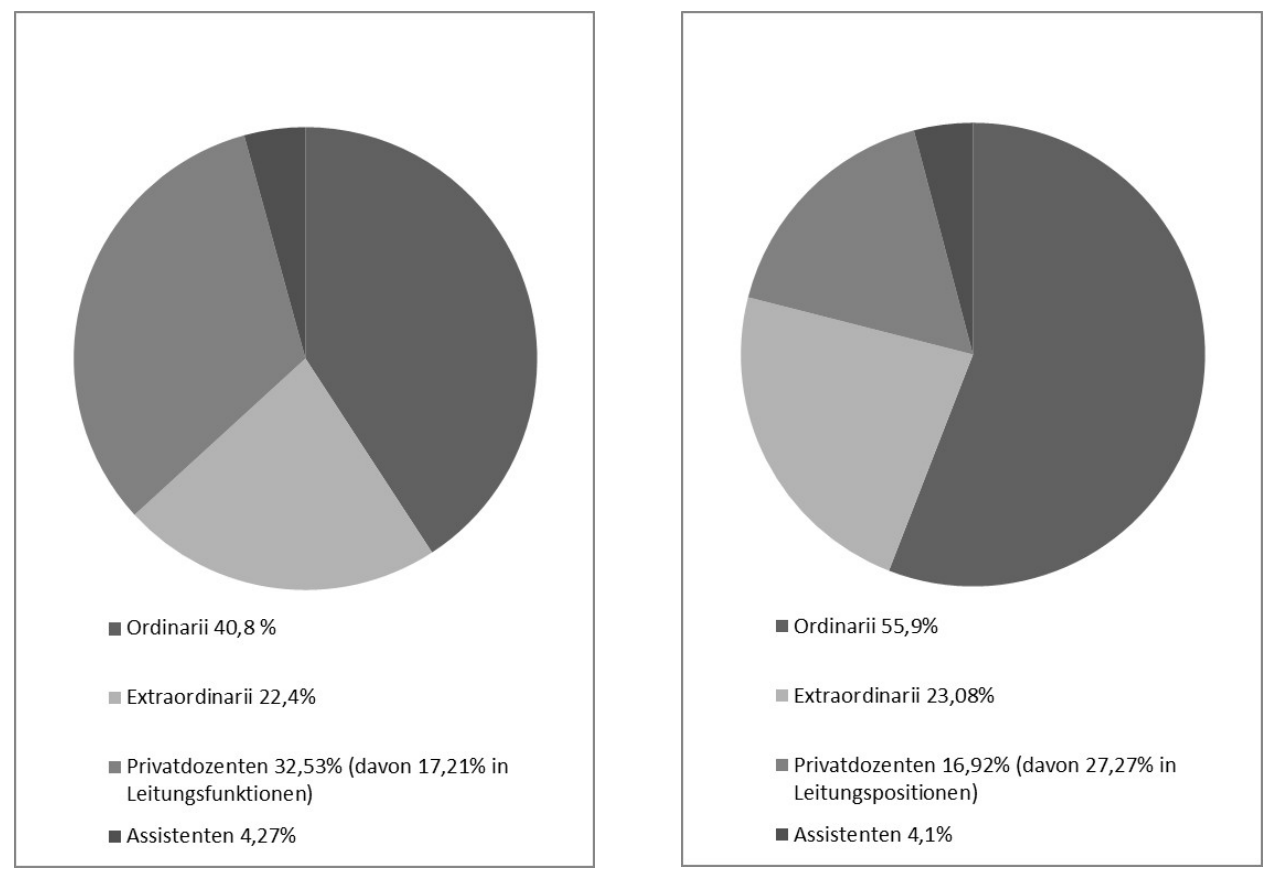

Graphik 4: Anteile ausgewäblter Fächer in Prozent bis zum Studienjabr 1913/14 (Insgesamt 375 Vorträge):

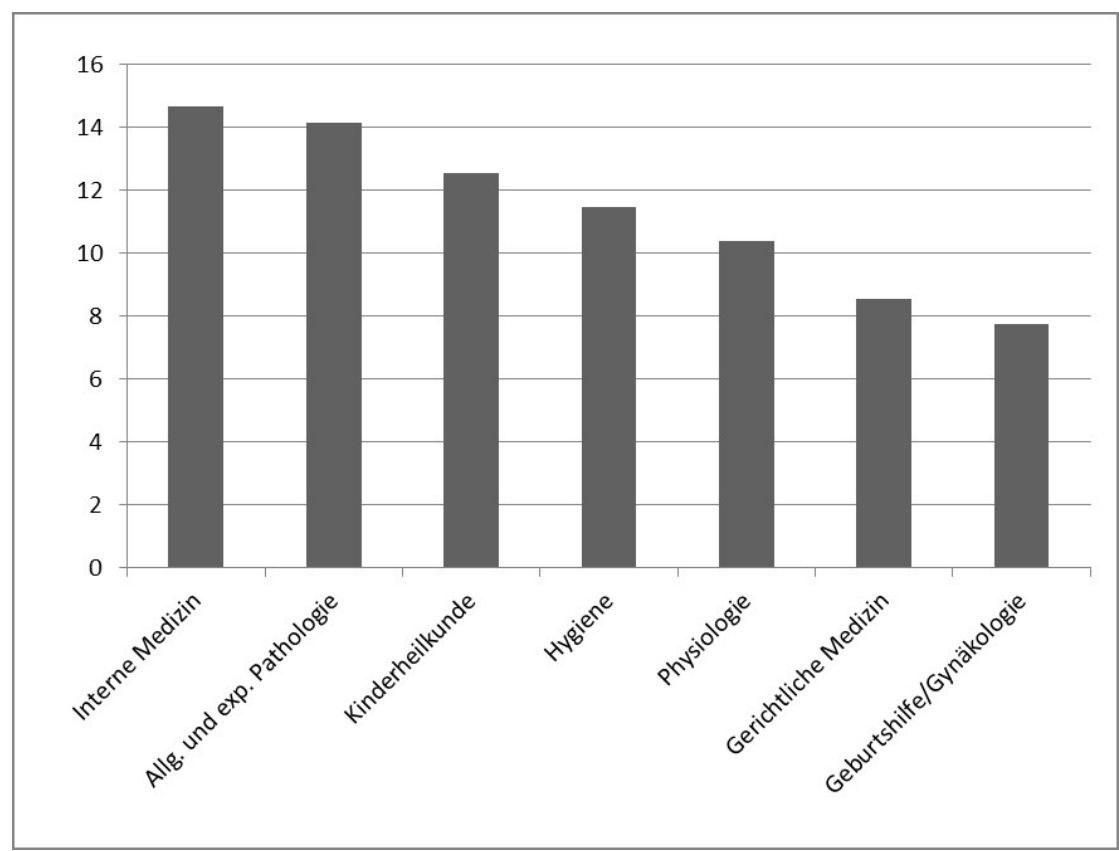


Graphik 5: Anteile ausgewäblter Fächer in Prozent, Studienjabre 1919/20 bis 1937/38 (Insgesamt 195 Vorträge):

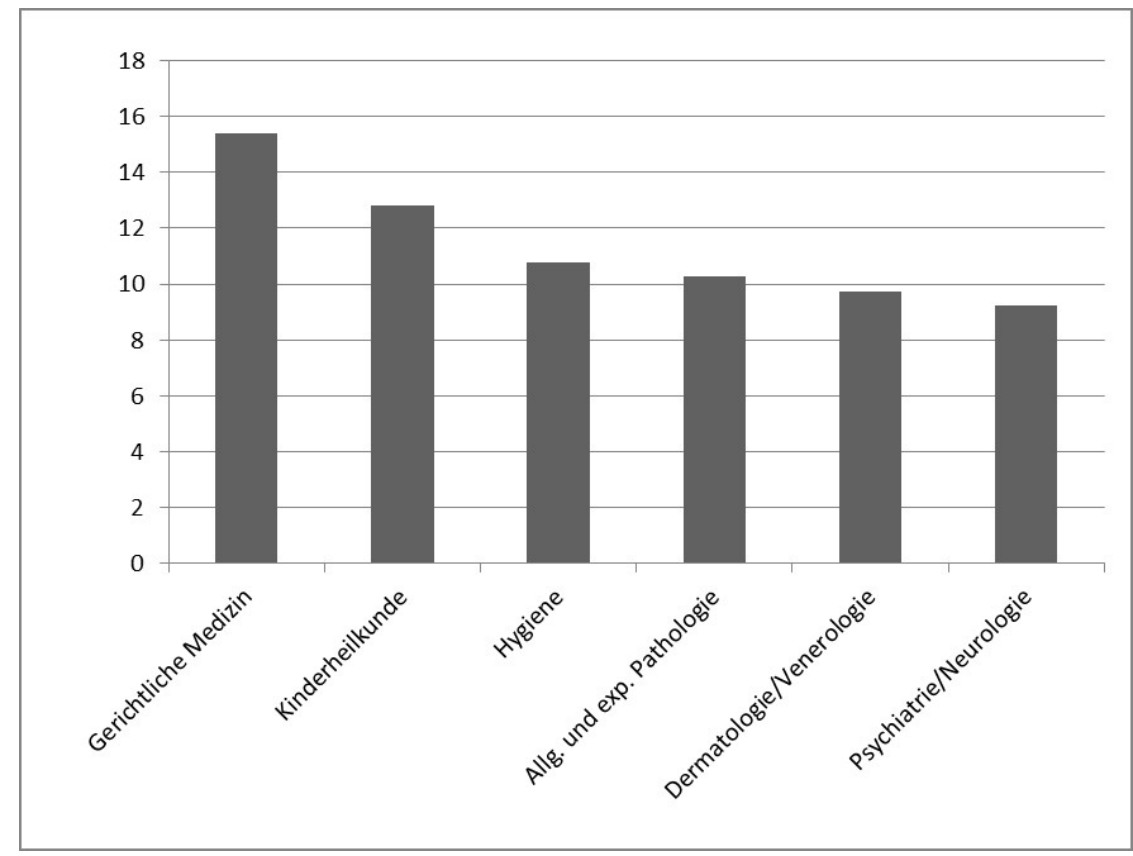

Graphik 6: Inhalte auf der Makroebene in Prozent (375 bzw. 195 Vorträge):

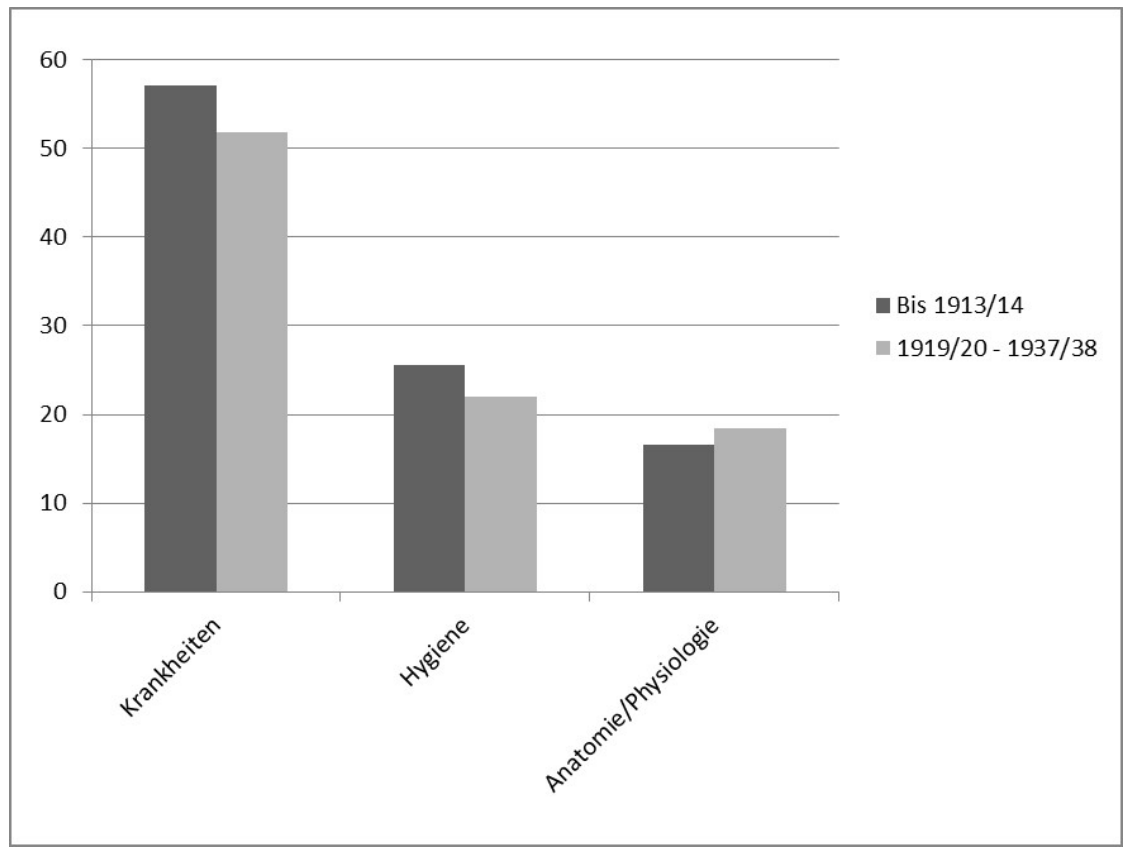


Graphik 7: Krankbeiten: Ausgewäblte Inbalte in Prozent bis zum Studienjahr 1913/14

(Insgesamt 214 Vorträge):

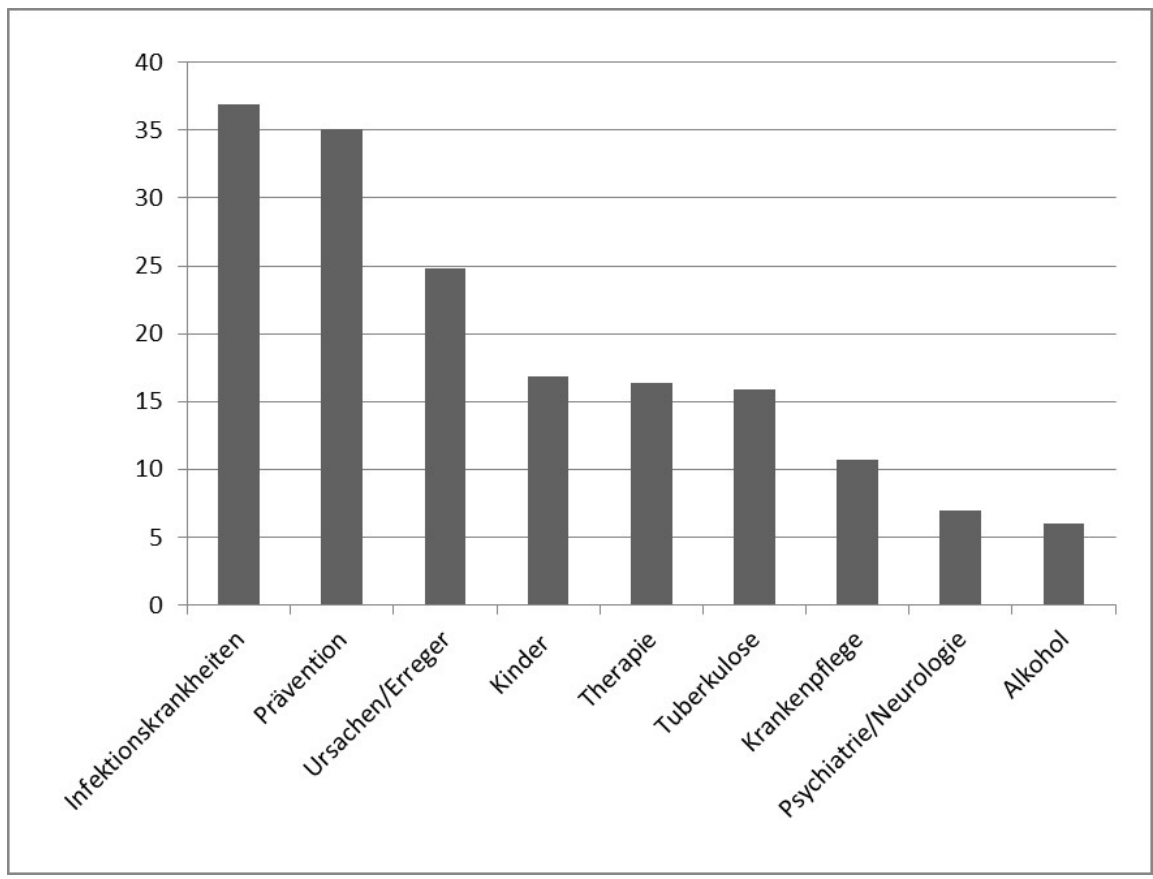

Graphik 8: Krankheiten: Ausgewählte Inhalte in Prozent, Studienjabre 1919/20 bis 1937/38 (Insgesamt 101 Vorträge):

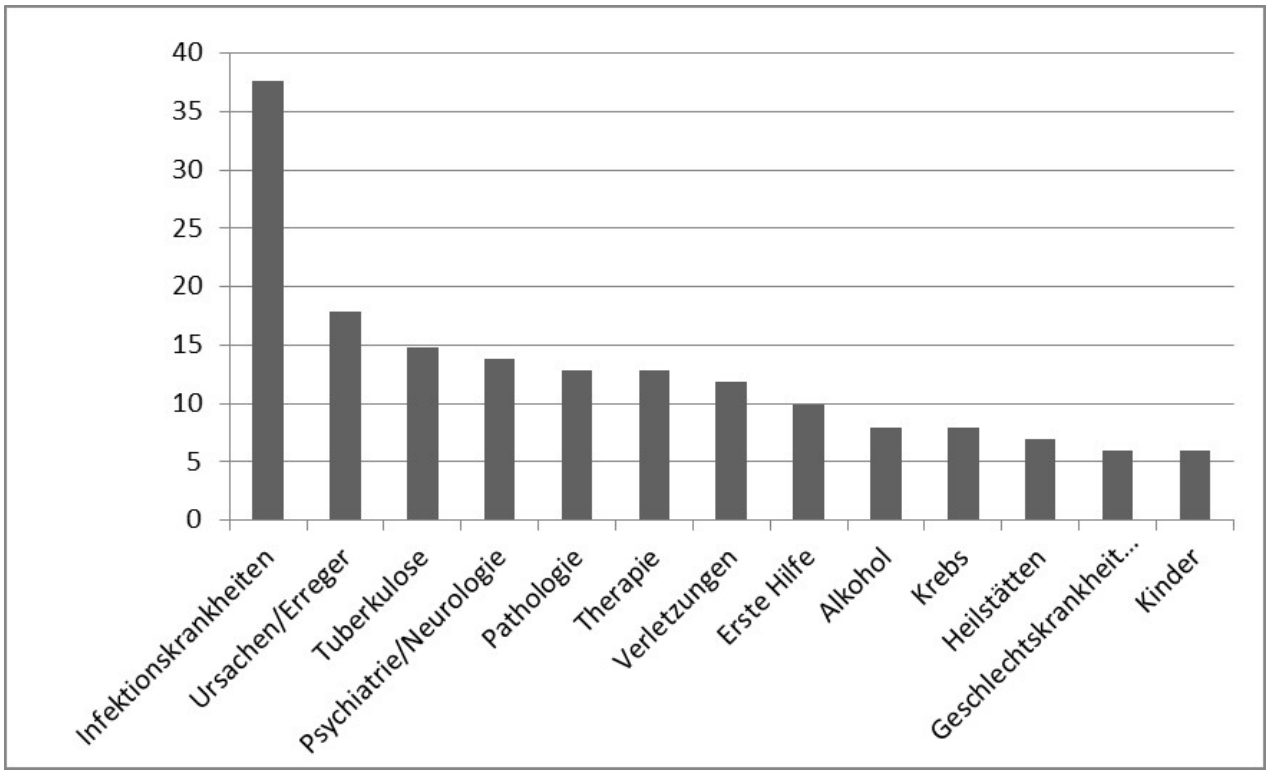


Graphik 9: Hygiene: Ausgewählte Inhalte in Prozent bis zum Studienjahr 1913/14

(Insgesamt 96 Vorträge):

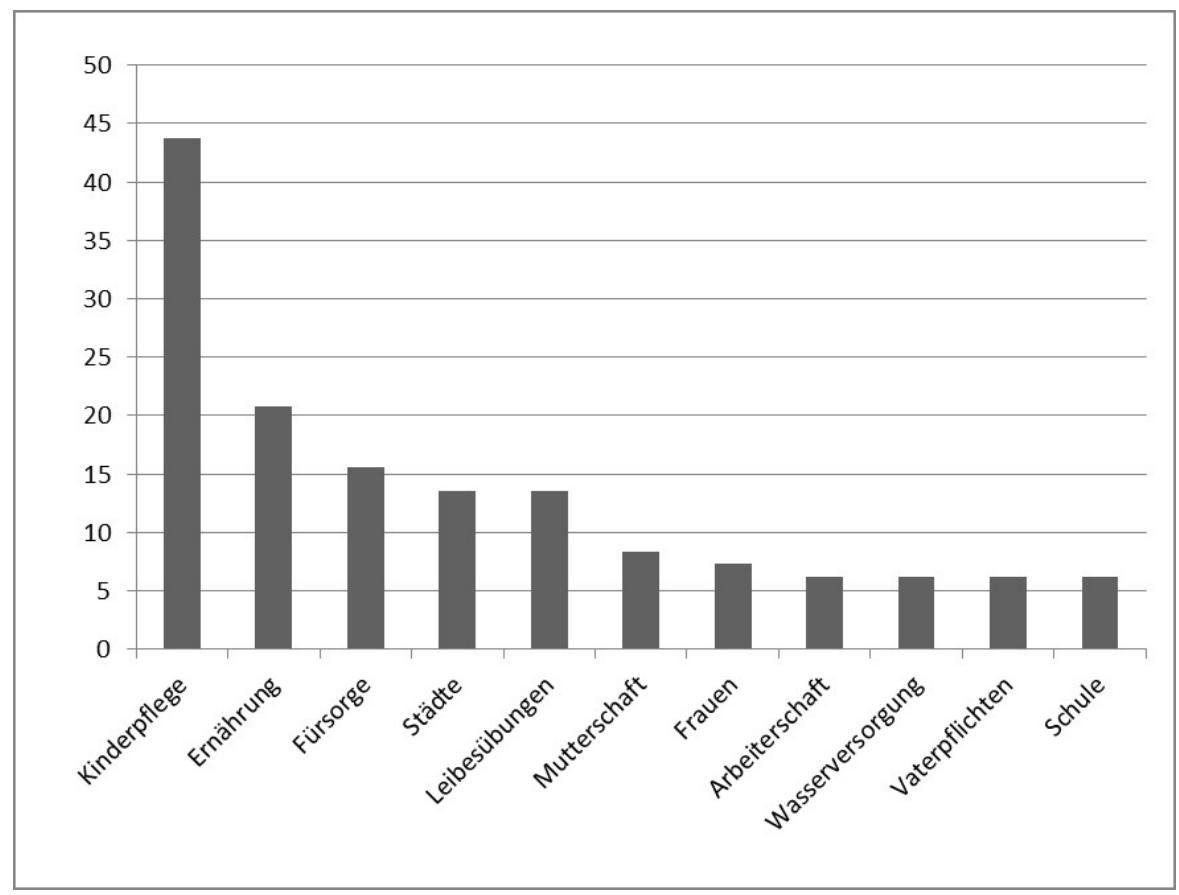

Graphik 10: Hygiene: Ausgewäblte Inhalte in Prozent, Studienjabre 1919/20 bis 1937/38 (Insgesamt 43 Vorträge):

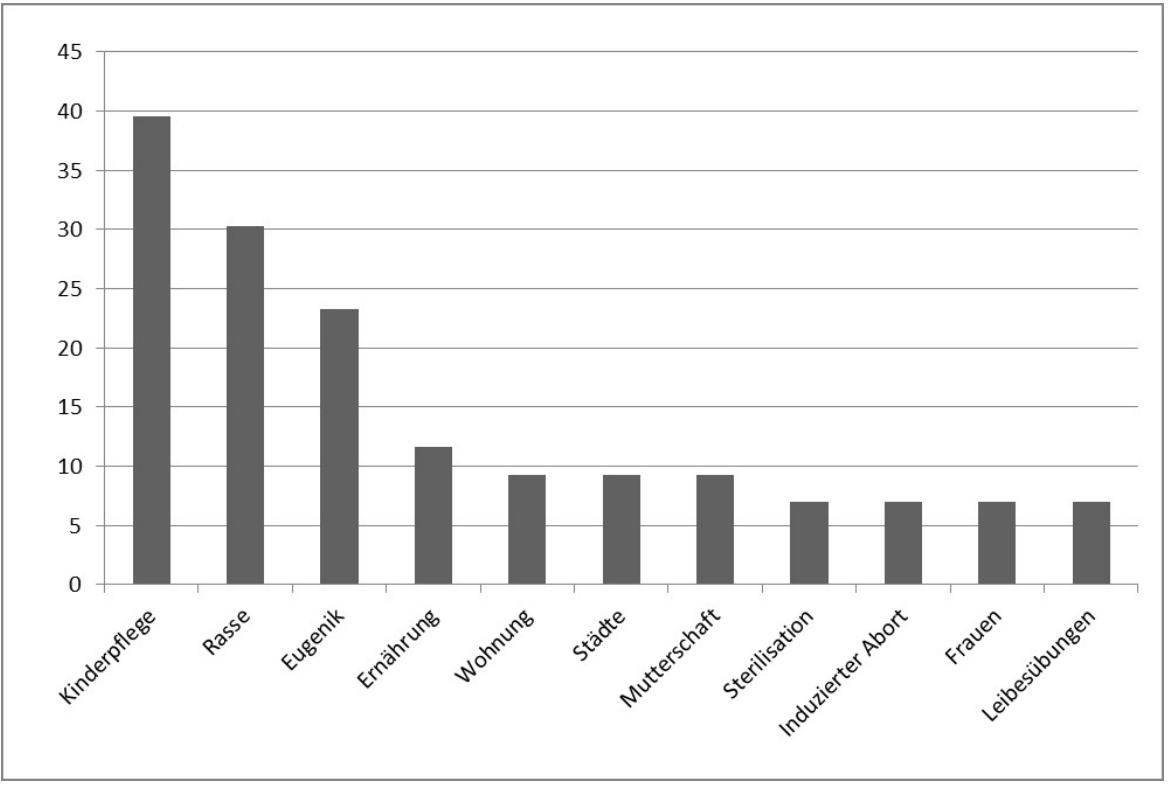





\section{„Absender: Dr. Johann W., auf ein Jahr für ein Narr erklärt“. Die Konfliktfelder Politik, religiöse Bewegung und Psychiatrie im Tirol der 1930er Jahre am Beispiel des Franziskanerpaters W.}

\section{English Title}

„Absender: Dr. Johann W., auf ein Jahr für ein Narr erklärt“. Politics, religious movements and psychiatry as areas of conflict in Tyrol in the 1930s - the example of the Franciscan Father W.

\section{Summary}

Based on the case history of the Tyrolean Franciscan Father W. this paper wishes to illustrate how difficult it was to draw a clear distinction between disciplining and treating the mentally ill or those individuals seen as socio-politically querulous and overly critical. The admission of Father W. in the Tyrolean Mental Asylum known as the "Landes-Heil- und Pflegeanstalt für Geisteskranke" in 1831 caused public unrest which found expression in several newspaper campaigns - especially in the interest of the political parties - and was discussed among religious congregations as well as the intellectual elite of Tyrol.

\section{Keywords}

$20^{\text {th }}$ century, Hall in Tyrol, mental illness, history of psychiatry, mental asylum, religious congregation, psychiatry in Austria, religious movements, Hall i.Tirol, history of psychiatry

\section{Vorbemerkungen}

Die Tiroler „Landes-Heil- und Pflegeanstalt für Geistes- und Nervenkranke“ - das heutige „Psychiatrische Krankenhaus (PKH)“ in Hall in Tirol - ist in diesem Beitrag Schauplatz des Geschehens. Eine Institution, die damals wie heute in der breiten Öffentlichkeit bekannt ist, im Volksmund aber teils immer noch als „,berüchtigt“ gilt. Der Stadtname findet sich auch heute noch als Synonym für Wahnsinn, Verrücktheit und Andersartigkeit in der Tiroler Alltagssprache. 1930, also im Zeitraum dieser Betrachtung, feierte die „Landes-Heil- und Pflegeanstalt" ihren 100. Geburtstag. 
Gegründet wurde sie als „k. k. Provinzial-Irrenanstalt" auf dem Grundareal des ehemaligen Klarissinnenklosters als Spezialinstitution zur Heilung, Pflege und Verwahrung psychisch Kranker mit einem Stand von anfänglich 30 Betten. 1930 verfügt die Anstalt über 400 Betten, die Gesamtzahl der im Jubiläumsjahr verpflegten Patientinnen und Patienten betrug 1.018. ${ }^{1}$ Als bedeutender Bestandteil der Geschichte des Hauses gingen immer wieder Strategien in der Öffentlichkeitsarbeit hervor, die darauf abzielten, das „gelbe Häusl" in der Bevölkerung von den bestehenden Vorurteilen zu befreien. Die negative Konnotation der psychiatrischen Anstalt stand auch in Zusammenhang mit ihrer Funktion als Verwahrort zur Disziplinierung verhaltensauffälliger Individuen. Nach einem Inspektionsbericht des Landes-Sanitäts-Direktors Paul Daser von 1929 diente die Anstalt zu dieser Zeit „hauptsächlich Verwahrungszwecken“", wobei - abgesehen von Arbeiten in der Landwirtschaft, in den Werkstätten und im Haus - „eine zielbewusste Therapie wenig oder gar nicht betrieben“ wurde. Der allgemeine Pessimismus der Anstaltspsychiatrie war gewiss auch ein Grund dafür, weshalb die Institution auch dieser Zeit in der Öffentlichkeit als „Schreckensasyl“ stigmatisiert wurde. $^{2}$ Am Beispiel des Franziskanerpaters W. soll im Folgenden veranschaulicht werden, welche Schwierigkeiten sich für die medizinisch-wissenschaftliche Fachdisziplin Psychiatrie ergeben können, wenn es darum geht, Konstrukte religiöser und weltanschaulicher Natur in der Psyche eines Menschen zu verorten und zu deuten. Zudem soll verdeutlicht werden, wie diffizil in der Anstaltspsychiatrie der 1930er Jahre eine klare Trennung zwischen Disziplinierung und Therapierung von psychisch Erkrankten, aber auch gesellschaftskritisch und sozialpolitisch querulierenden Individuen vollzogen bzw. dargestellt werden kann.

Das hierfür verwendete Quellenmaterial besteht aus Sanitäts-Akten des Amtes der Tiroler Landesregierung ${ }^{3}$, aus Aktenbeständen der Volksgesundheit des Bundesministeriums für soziale Verwaltung im Österreichischen Staatsarchiv (ÖSTA) ${ }^{4}$ sowie dem Kranken- und Verwaltungsakt des Patienten W. im Historischen Archiv im PKH Hall in Tirol.

\section{Die Einlieferung Pater W.s in die Heil- und Pflegeanstalt. Oder: Konflikte um den „Widerspruch zwischen Christi klaren Worte und der durch Gesetz sanktionierten Worte ${ }^{65}$}

W. wurde am 28.10.1931 um 20.30 Uhr von der Rettungsgesellschaft in die „LandesHeil- und Pflegeanstalt für Geistes- und Nervenkranke“" in Hall eingeliefert. Aus den ersten Sätzen in der Krankengeschichte geht hervor, dass er sich an besagtem Abend in „gehobener Stimmung" befand, den Arzt freudig begrüßte und sich gesprächig gab. Nach einem kurzen Aufnahmegespräch war er dem Arzt „willig“ auf die Abteilung gefolgt.

1 Vgl. zur Geschichte der „Landesirrenanstalt“ in Hall u. a. die Dissertationsarbeit Angela GRIESSENBOECK, Die Landesirrenanstalt in Hall in Tirol und ihre Patientinnen und Patienten (1882-1919). Dissertation Geschichte, Innsbruck 2009.

2 Tiroler Landesarchiv (TLA), Amt der Tiroler Landesregierung 1931, Abt. IIb, 44 - X - 47, Bericht des Landes-Sanitäts-Direktors über die Inspizierung der Landes-Heil- und Pflegeanstalt für Geisteskranke in Hall i. T. am 26., 27. und 28. Februar 1929.

3 TLA, Amt der Tiroler Landesregierung 1932, Abt. II b, 140-X-47.

4 Österreichisches Staatsarchiv (ÖSTA), AdR, Bundesministerium für soziale Verwaltung 1931, Volksgesundheit, Kt. 2031, Zl. 108.904, W., Franziskanerpriester, Einlieferung in die Landes-Heil- und Pflegeanstalt in Hall.

5 Historisches Archiv im PKH, Patientenakte W., Brief W. an den Dekan Franz Schwarz, Flauring 1931. 
Bei seiner Aufnahme war W. 41 Jahre alt, Franziskanerpater, Professor der Theologie und trug zivile Kleidung. Seine Herkunft aus dem Kloster war äußerlich nur an den Franziskanersandalen an seinen Füßen zu erkennen. ${ }^{6}$

Wie der Akte zu entnehmen ist, war der Einlieferung ein Telefonat aus dem Franziskanerkloster in Schwaz vorangegangen, worin dem Haller Anstaltsdirektor Ernst Klebelsberg mitgeteilt wurde, dass Pater W. sich „derartig verhalte, dass man ibn im Kloster nicht mehr recht haben könne“. Wie lange die „Krankheitsstörung“ des W. bereits bestand, war für Klebelsberg ,aus diesem Telefongespräch nicht herauszubringen“. W. hatte einige Stunden zuvor vor seinen Mitbrüdern im Refektorium „im pathetischem Tone " eine lange Abschiedsrede gehalten und angekündigt, er habe nun die „richtige Religion" gefunden. Er habe eine „hohe, von Gott gesandte Person" kennen gelernt, der er sich anschließen wolle, ihre Lehre studieren und anschließend verbreiten wolle. Wie der Krankenakte zu entnehmen ist, schien ,im Anbetracht des Umstandes, dass im Kloster sich die jungen Theologen "befanden, „ein weiterer Aufenthalt [...] [desselben] nicht mehr ratsam". Nach seiner Abschiedsansprache zog W. sich in Bewachung zweier Pater in seine Zelle zurück, um die Koffer zu packen. In dieser Zeit war bereits der Rettungswagen vorgefahren, um den „Verwirrten “in die Anstalt zu bringen. ${ }^{7}$

Das Erstgespräch zwischen Primar Klebelsberg und Patient W. fand am darauf folgenden Tag statt. Dem Protokoll der Patientenakte zufolge sprach W. „vollkommen rubig und geordnet", entwickelte logische Gedankengänge, war mitteilsam und „offenherzig“. W. berichtete von den inneren Konflikten, unter denen er in den letzten Jahren als katholischer Priester und Theologielehrer gelitten hatte, und aufgrund derer er eigentlich in der Anstalt sei. Der Patient erklärt, er habe die ganze „Heuchelei“ nicht mehr länger aushalten können. Er sei ,zur Einsicht gekommen, dass nicht die römischkatholische Kirche, sondern die griechische Kirche [...] dem ursprünglichen Christentum bedeutend näher" stünde und bezeichnete die ,römisch-katholische Kirche als abwegig[e] und gefälscht [e]" Version der ursprünglichen christlichen Glaubenswahrheit. In seinen Ausführungen wendete sich W. vor allem, „gegen das Papsttum [und] gegen den großen weltlichen Pomp, der in der kath[olischen] Kirche herrsche". Daher trete er für das "wabre, ursprüngliche Christentum" ein und damit auch für ,den Sozialismus im christlichen Sinne“. Durch diese innere Bekehrung hätte er es sich als neue Lebensaufgabe gesetzt, künftig als urchristlicher Missionar tätig zu sein, und zwar nicht unter den ,heidnischen Völkern, sondern vorwiegend hier unter dem sich von der Katholischen Kirche abwendenden Proletariat". Patient W. äußert sich erleichtert darüber, dass er nun endlich die Kraft aufgebracht habe, um „mit dem äußeren Zwang zu brechen und den neuen Weg zu beschreiten". Daher erklärte er sich in dem Erstgespräch bereit, einige Zeit in der Haller Anstalt zu bleiben, „um sich hier auf neutralem Boden fassen und sammeln zu können“. Zudem „äußert $[e]$ er den Wunsch nach irgendeiner Beschäftigung zum Zeitvertreibe und zeigt [e] sich bereit, jede Arbeit auf der Abteilung anzunehmen".8

Am selben Tag, den 29.10.1931, war auch Pater Jakob D. aus dem Franziskanerkloster in Schwaz als Referent in die Anstalt geladen worden, um nähere Auskünfte über den Patienten zu geben. D. kannte W. seit der Studienzeit. Nach seinen Ausführungen war

6 Historisches Archiv im PKH, Patientenakte W., Eintrag Aufnahmeprotokoll in der Krankengeschichte vom 28.10.1931.

7 Ebd.

8 Historisches Archiv im PKH, Patientenakte W., Eintragung Erstgespräch W. mit Klebelsberg am 29.10.1931. 
W. bereits als Student außerordentlich strebsam und tieffromm gewesen, seine Mitbrüder hätten ihn deshalb scherzhaft sogar den „Heiligen“ genannt. Allerdings sei W. in seinen Anschauungen immer auch sehr eigensinnig und fanatisch gewesen, in „seinen Handlungen sebr impulsiv, etwas unberechenbar, in Extremen sich bewegend" und sogar etwas „neuerungssü̈chtig“. Als Student war W. ein begeisterter Anhänger von Prof. Dr. Friedrich Heiler gewesen, der ihn vor allem auch für den Protestantismus begeistert konnte. Heiler lehrte zu dieser Zeit an der evangelisch-theologischen Fakultät der Universität in Marburg allgemeine und vergleichende Religionsgeschichte. Daraus war eine gute Freundschaft erwachsen. An der Universität in Breslau hatte W. bei Prof. Joseph Wittig studiert. Mit ihm stand er ebenfalls noch in regem brieflichen Kontakt. Nach Aussagen des Paters Jakob D. war W. durch Wittigs Ideen aber regelrecht „inficiert" worden, er ergriff leidenschaftlich Partei für ihn und lernte seine Schriften nahezu auswendig. Das war insofern problematisch, da Wittig im Jahr 1926 auf Grund diverser kirchenkritischer Schriften, in denen er vor allem Reformen in der katholischen Kirche forderte, exkommuniziert worden war - ein Ereignis, das W.s Grundfeste des Vertrauens in die Kirche tief greifend erschüttert hatte. W. bezeichnete den Index Librorum Prohibitorum seither als „die grösste Gaunerei" und als „ein typisches Zeugnis römischer Brutalität", wodurch solche Talente - wie eben Wittig - nur ,wie unmündige Kinder niedergehalten und mundtot gemacht würden“. Für W. war es daher „der römische Terror, der jedes freie und selbständige Denken unterbinde". Der Anlass, der W. aber letztendlich zum Austritt aus der katholischen Kirche bewog, lag nach Ansicht des Paters D. in der Bekanntschaft W.s mit Bischof Pater Timotheos, seinerseits „Apostolischer Missionär der altchristlichen Gemeinde Österreichs und Wanderbischof".? Timotheos war in der „Szene“ der Religionswissenschaftler vor allem als „Reliquien-“ und „Katakombenforscher" bekannt, er veröffentlichte unter seinem bürgerlichen Namen „Alois Stumpfl“ zahlreiche Artikel in wissenschaftlichen Kirchenzeitschriften. Er lebte zu dieser Zeit mit seiner Gefolgschaft in Going in Tirol und brachte sich offiziell als Bibelbote im Dienste der „Österreichischen Bibelgesellschaft“ durch. ${ }^{10}$

Nach dem Bericht des Pater Jakob D. hatte W. Timotheos vor geraumer Zeit trotz anfänglicher Startschwierigkeiten kennen gelernt. Das Interesse dafür sei in erster Linie von Timotheos ausgegangen, dieser habe nämlich gehört, dass W. ein ,freierer" Priester sei. Timotheos übte auf W. bald „den grösseren Einfluss aus als Prof. Wittig“. W. habe dem Referenten sogar einmal anvertraut, ,dass dieser Timotheus einen fast unheimlichen, unwidersteblichen Einfluss auf ibn ausübe". Nach Pater Jakobs Bericht wollte W. ab dieser Zeit

„von Rom nichts mehr wissen, schwärmt [e] für die Ideen des Kommunismus, [...] benahm sich den Vorgesetzten gegenüber nicht mehr in der üblichen Weise des Gehorsames und Respektes, [...] [sprach] jeden Pater, so auch den Provinzial [...] mit ,Du Bruder' [an] und [...] [bielt] vor den Mitbrüdern ,fulminant' Reden. W. [blieb] obne Erlaubnis vom Kloster weg, verkehrt [e] in proletarischen Kreisen, wo er bereits einen kleinen Anhang gefunden hat [te]. Hat [te] seinen Habit mit Zivilkleidern vertauscht [und] wollte noch am Tage seiner Einlieferung eine kommunistische Versammlung besuchen. "11

Spätestens nach dieser Unterredung wurde Klebelsberg bewusst, dass die Informationsquellen aus dem Kloster zur Erörterung der tatsächlichen Tatbestände,

9 Historisches Archiv im PKH, Patientenakte W., Unterredung mit Pater Jakob D. am 29.10.1931.

10 Otto WINKLER, Bischof Pater Timotheos Alois Stumpfl, Diplomarbeit Theologie, Linz 1979, 25-38.

11 Historisches Archiv im PKH, Patientenakte W., Unterredung mit Pater Jakob D. am 29.10.1931. 
die zu dem „manischen Erregungszustand“ des W. geführt hatten, sehr einseitig und parteilich waren. ${ }^{12}$ In der Folge nahm er Kontakt zu anderen Bekannten W.s auf, um den Konflikt mit der Kirche, welcher im „Nervenzusammenbruch“W.s gipfelte und zur Einweisung in die „Irrenanstalt“ geführt hatte, aus unterschiedlichen Kontexten zu untersuchen.

Am 31.10.1931, also drei Tage nach der Einlieferung, fand die Unterredung des Patienten W. mit dem Primararzt statt, worin interessante Aspekte der Anamnese beleuchtet wurden. Dadurch konnte W. eine Gegendarstellung zu den Aussagen des Paters Jakob D. vorbringen. Demnach war W. mit 13 Geschwistern in bescheidenen Verhältnissen einer Kleinhäusler-Familie im Tiroler Paznauntal aufgewachsen. Eine familiäre Heredität geht aus der Befragung des Patienten nicht hervor. Von 1919 bis 1922 studierte er Theologie in Innsbruck, München und Breslau und promovierte 1923 „summa cum laude“. Nach Befragung zu dem „nervenaufreibenden“ Konflikt mit der katholischen Kirche äußerte sich W. kritisch über ihre hierarchisch-autoritäre Struktur: In ihrem Dienste heiße es nur „dienen...Maulhalten...und weiter dienen “. Ausführlich protokolliert ist W.s Aussage über die politische Bedeutung der Kirche:

„Jeder heutige, römische Geistliche duldet alles, wenn nur einer sich Rom unterwirft. Da sei es ganz. gleich, ob einer Ehebrecher, Defrandant oder ein anderer Gauner ist, wenn er nur in die Kirche gebt und heuchelt, so genügt es ibnen, dann heisse es gleich, das ist ein unsriger, der gehört zu unserer Partei." "3

W.s systemkritische Auffassungen waren, wie der Referent Jakob D. angab, in den letzten Jahren durchaus bekannt:

„Auch war $[\ldots][\mathrm{W}$.$] schon in Rom denunqiert worden, doch hat sein Ordensprovinzial immer vor$ einer Maßregelung durch Rom schützen können. Immerbin hatte sein Konflikt [...] [noch nie zuvor] eine solche Zuspitzung erreicht, dass er sich mit dem Gedanken eines Austrittes aus dem Orden und aus der römischen Kirche trug. " 14

Weiters protokollierte Klebelsberg, der Patient sei von der Richtigkeit seines Weges überzeugt, spreche davon, den Papst künftig nur mehr als Bischof von Rom anzuerkennen, dass er nun ,in der urchristlichen Fülle“ die Eucharistie in beiderlei Gestalt in der „Liturgie des Morgenlandes" zu sich nehmen werde und des gläubigen einfachen Volkes wegen „unbedingt für den deutschen Gottesdienst" eintrete, auch wenn sich dies von der Ostkirche unterscheide. Über die Schwierigkeiten, die in der Bewältigung seines künftigen Weges liegen würden, war W. sich in dem Arztgespräch durchaus bewusst: „Sagt, er wisse wohl, dass sein Amt kein leichtes sein wird und dass er vielleicht Widerwertigkeiten ertragen werden müsse. [...] [Aber] erst dann, wenn alle die irrgläubigen Kirchen zur Ostkirche zurückgefunden haben werden, erst dann wird das wabre Reich Christi auf Erden entstehen. "15

Noch am selben Tag wird ein rechtskräftiges Formular ausgestellt, in dem „der Gefertigte"W. offiziell um die ,freiwillige"Aufnahme in die Anstalt bittet. ${ }^{16}$

12 Historisches Archiv im PKH, Patientenakte W., Abschrift des Briefes von Klebelsberg an Friedrich Heiler vom 24.12.1931.

13 Historisches Archiv im PKH, Patientenakte W., Unterredung Klebelsberg mit dem Patienten vom 31.10.1931.

14 Historisches Archiv im PKH, Patientenakte W., Unterredung mit Pater Jakob D. am 29.10.1931.

15 Historisches Archiv im PKH, Patientenakte W., Unterredung Klebelsberg mit dem Patienten vom 31.10.1931.

16 Historisches Archiv im PKH, Patientenakte W., Unterzeichnetes Gesuchformular zur freiwilligen Aufnahme in die Anstaltspflege vom 31.10.1931. 


\section{Die Pathologisierung des „Unbekannten“. Oder: Der „Heilige“ und Bischof Timotheos, die „Wurzel allen Übels“}

In den darauf folgenden Tagen nahm Klebelsberg Kontakte zu Personen aus dem nächsten Umfeld W.s auf, um Rückschlüsse über die als „krankhaft" gedeutete ideologische Wandlung des Patienten ziehen zu können. Zudem wurden zahlreiche Befragungen der Besucher W.s in der Krankenakte protokolliert, es handelte dabei vorwiegend um Persönlichkeiten aus der höheren Bildungsschicht. Es wurde vermerkt, dass von nahezu allen BesucherInnen, die von außerhalb des Klosters kamen, zwar eingestanden wurde, W. neige in manchen Anschauungen zu Fanatismus, von einer „Geisteskrankheit" könne aber nicht die Rede sein. Dem Protokoll der Pfleger in der Patientenakte ist zu entnehmen, dass W. fast täglich mehrere BesucherInnen, die aus der Familie, vorwiegend aber aus seinem Bekannten- und Freundeskreis stammten, empfing. Dabei handelte es sich um vergleichsweise ungewöhnlich hohe Besucherfrequenzen für einen Anstaltspatienten. Aus den teils unabhängig und getrennt von einander geführten Unterredungen sowie dem Briefverkehr Klebelsbergs mit dem nächsten „Umfeld“ W.s kristallisierte sich nahezu einhellig die Meinung heraus, dass W.s derzeitiger Zustand in erster Linie durch Bischof Timotheos ausgelöst worden sei. Sämtliche „Referenten“ gaben an, dass dieser Timotheus ,eine starke Suggestion, wenn nicht gar hypnotischen Einfluss auf W. ausübe". Timotheos habe ihn, nach der Meinung von W.s Bekannten „stud. phil“ Ignaz Zangerle, „durch eine Art persönlichen Magnetismus ganz. börig gemacht". Timotheos mache auf Zangerle „einen etwas keänklichen Eindruck“, er sei ihm bereits lange Zeit zuvor in der Universitätsbibliothek in Innsbruck ,durch sein beständiges Hüsteln" aufgefallen. Aber auch seine Gefolgschaft in Going sei nicht gesund: „Timotheos Frau sei herzkrank, die Ehe kinderlos. In der Gemeinschaft lebe noch ein Diakon, ein geheilter Trinker, dessen Frau sei ebenfalls nervös und kränklich; auch diese Ehe wäre kinderlos. Zudem lebe die Gemeinschaft in Going vegetarisch und betreibe Naturbeilkunde. "17

Direktor Klebelsberg erhielt auch von dem Religionswissenschafter Friedrich Heiler aus Marburg wichtige Informationen über Bischof Timotheos. Klebelsberg stand während des Aufenthaltes von W. in Hall und noch längere Zeit darüber hinaus in regem Briefverkehr mit Heiler. Nach dessen Beschreibungen verfügte Timotheus, den Heiler persönlich gut kannte, „über eine ausgedehnte theologische Bildung" mit höchsten wissenschaftlichen Qualitäten, die er sich aber größtenteils als Autodidakt angeeignet hatte. Allerdings mache er auch „Propaganda gegen die römisch-katholische Kirche" und polemisierte sie gelegentlich heftig. Weiters besaß Timotheos „altsprachliche Kenntnisse“, war Experte auf den Gebieten der ,altchristlichen Archäologie und Liturgiegeschichte wie der Geschichte der östlichen, zumal syrischen Kirche" und publizierte diverse Aufsätze in theologischen Zeitschriften, wodurch er - nach Heilers Einschätzung - W. imponiert haben mochte. Allerdings praktiziere der Bischof ,einen gewissen religiösen Fanatismus, der auf weichere Naturen wie W. faszinierend und [gleichzeitig] zwingend wirken " mochte. ${ }^{18}$ Heiler warnte daher vor weiterem Kontakt W.s mit Timotheos, vor allem für die Zeit nach der Stabilisierung seines psychischen Zustandes: „Timotheos, den ich in vielem schätre, ist übrigens selbst nervenkrank [...]. Er leidet an einer hemmenden nervösen Krampfsucht. Da ihm ein gewisses Querulantentum nicht abzusprechen ist, ist zu befürchten, dass $W$. bei einer Zusammenarbeit

17 Historisches Archiv im PKH, Patientenakte W., protokollierte Unterredung Direktor Klebelsberg mit Ignaz Zangerle vom 9.11.1931.

18 Historisches Archiv im PKH, Patientenakte W., Brief Friedrich Heilers an Direktor Klebelsberg vom 9.11.1931. 
mit ihm sehr bald in Konflikt geraten werde."19 Heiler war daher ernsthaft „, besorgt, dass ein definitiver Austritt P[ater]. W.s aus dem [Franziskaner-]Orden und ein ,missionarisches' Arbeiten nach der Art von Bischof Timotheos und an seiner Seite zu einer völligen Katastrophe führen werde. "20 Trotz des immer wieder thematisierten querulierenden Verhaltens des strenggläubigen, chronisch-kranken Timotheos, gaben aber nahezu alle befragten Personen an, dass der Druck, den die Kirche auf W. ausgeübt habe, primärer Grund für die „Zerrüttung“ seiner Nerven war. Für Joseph Wittig, den exkommunizierten Theologen aus Neurode in Deutschland, stellte der Fall des W. nur eine weitere Bestätigung der Repressionen der katholischen Kirche dar. Wie er in einem Brief an Klebelsberg schrieb, ziehe man bei W. eben eine offizielle „Entmündigung im Narrenhaus" der Exkommunikation vor. Wittig, der mit W. auch während seines Anstaltsaufenthaltes in regem Briefkontakt stand, sprach lediglich von einem „Zustand starker religiöser Begeisterung", die durch Timotheos hervorgerufen worden seien, doch trotz aller Vorkommnisse „niemanden“ berechtige, ,ibn mit Gewalt in eine Anstalt qu bringen“.21

Friedrich Heiler sah den Sachverhalt komplexer und wies Klebelsberg ausdrücklich auf die allgemeine Problematik übersteigerter Religiosität hin:

„Die Grenzen zwischen dem Gesunden und Krankhaften sind gewiß im religiösen Leben äußerst schwer zu bestimmen und werden, je nach der religiösen und weltanschaulichen Einstellung des Forschers, verschieden bestimmt. Ich selber gehöre gewiß nicht zu jenen, welche religiöse Erlebnisse leichter Hand unter die Kategorie des Pathologischen stellen. Dennoch glaube ich einen krankhaften Einschlag in den jüngsten Selbstbekenntnissen von W. nicht abstreiten zu können. '22

Seiner Ansicht nach lagen die Grenzbereiche von Theologie, Spiritualität und Psychiatrie bei Menschen mit stark ausgeprägter Frömmigkeit nicht weit von einander entfernt. Nach Heilers ,Ferndiagnose', die er u.a. durch die zahlreichen Briefe aus der Anstalt stellte, befand sich W. in einem krankhaft überhitzten „Enthusiasmus“, wodurch seine klare religiöse Urteilskraft beeinträchtigt sei. ${ }^{23}$ Aus seiner langjährigen beruflichen Praxis schilderte Heiler Klebelsberg, wie bei persönlichen Krisen von Geistlichen im Konflikt mit der Kirche am besten vorzugehen sei:

„Ich habe reiche Erfahrung mit römisch-katholischen Priestern und Ordensleuten, die einen ähnlichen Weg gegangen, da solche sich häufig an mich wenden. Nach einem jahrelangen Aufenthalte im Kloster ist der Übergang in die ,Welt', selbst bei einer Fortführung des, geistlichen Berufes' ein gefährliches Wagnis, das in der Mehrzahl der Fälle mit einer seelischen oder moralischen Katastrophe endet, wenn der Betreffende nicht rechtzeitig wieder den Weg ins Kloster zurückfindet. Ich stelle dies einfach als Tatsache fest, trotzdem ich für die religiösen und sonstigen Konflikte von römisch-katholischen Priestern und Ordensleuten volles Verständnis habe, trotzdem ich in vielem das römisch-katholische System durchaus nicht gutheiße und auch, trotzdem ich weiß, daß es Ausnabmen von der Regel gibt. Ich pflege solchen Leuten stets den Rat zu geben, von zwei unvermeidlichen Uebeln das kleinere zu wäblen und im Kloster zu bleiben. '24

19 Historisches Archiv im PKH, Patientenakte W., Brief Friedrich Heilers an Direktor Klebelsberg vom 9.11.1931.

20 Ebd.

21 Historisches Archiv im PKH, Patientenakte W., Brief Joseph Wittig an Direktor Klebelsberg vom 28.11.1931.

22 Historisches Archiv im PKH, Patientenakte W., Brief Friedrich Heilers an Direktor Klebelsberg vom 9.11.1931.

23 Ebd.

24 Historisches Archiv im PKH, Patientenakte W., Brief Friedrich Heiler an Direktor Klebelsberg am 9.11.1931. 
Sowohl die „Totale Institution“ des Klosters als auch die der „Heil- und Pflegeanstalt“ für psychisch Erkrankte hatten die Funktion als geschützte Bereiche zu erfüllen, als eine Art „Lebenshilfe“ zur Verwahrung für längere Zeit bzw. für „lebenslänglich“.25

\section{Das Urteil der gerichtlichen Kommission und die medialen Konsequen- zen. Oder: „Absender: Dr. Johann W., auf ein Jahr für ein Narr erklärt.“}

Nach der ersten Woche in Hall begann W. damit, seiner anfänglich als „freiwillig“ postierten Entscheidung, einige Zeit in der Anstalt zu verbringen, zu widersprechen. Er forderte, in derselben ,freien Entscheidung “ zu Timotheos ziehen zu können oder zur weiteren Genesung zu seiner Familie ins Paznauntal überstellt zu werden. Ab dieser Zeit wurden in der Krankengeschichte zahlreiche Drohungen vermerkt, worin W. kundgab, sich aufgrund der ,unrechtmäßigen Anbaltung" in der Anstalt an die Zeitungen zu wenden. ${ }^{26} \mathrm{Da}$ die ärztliche Leitung von einer sofortigen Entlassung abriet, bekam W. Unterstützungen des „linken Lagers“. Ausgehend von Schwazer Kommunisten bekam W. das Angebot, sich unentgeltlich von den sozialdemokratischen Rechtsanwälten Höflinger und Uffenheimer aus Innsbruck vertreten zu lassen. Nach längerer Bedenkzeit und umfangreichem Briefverkehr mit den Anwälten lehnte der Patient diese Option aber ab, da er sich nach Beratung mit Bischof Timotheos darauf berief, sich nicht von politischen Interessen vereinnahmen zu lassen. ${ }^{27}$

Am 17. November 1931 fand die kommissionelle gerichtliche Untersuchung W.s durch den Privatdozenten der psychiatrisch-neurologischen Klinik in Innsbruck, Helmut Scharfetter, und Landessanitätsdirektor Paul Daser statt. Klebelsberg rechtfertigte sich über diesen Schritt, der zur Konstatierung der Zurechnungsfähigkeit W.s gesetzt worden war, in einem Brief an Heiler folgendermaßen: „In den ersten Tagen gab mir mein Schützling [W.] selbst zu, dass er [...] eine Art Nervenzusammenbruch erlitt und erklärte sich auch mit dem freiwilligen Aufenthalt in der Anstalt einverstanden. Einige Tage später aber, nabm er diese freiwillige Erklärung zurück, sodass ich nach den bestehenden Gesetzen ihn bei Gericht zur Konstatierung der Zulässigkeit der Anbaltung in einer geschlossenen Anstalt anzeigen musste. "28

Zur Beweisführung für das Gutachten wurden neben der Krankengeschichte auch sämtliche Korrespondenzmaterialien W.s. an die „Außenwelt" und an die Haller Ärzteschaft verwendet, die allesamt in mit der Schreibmaschine abgetippten Abschriften im Kranken- und Verwaltungsakt gesammelt und hinterlegt wurden. Interessanterweise wurden aber auch Briefe, die von auswärts kamen - etwa Korrespondenzen aus dem Schwazer Kloster, die an den Patienten gerichtet waren abgeschrieben. In der gerichtlichen Untersuchung wurde der Beschluss gefasst, die „Anhaltung des $W$. in einer geschlossenen Anstalt für die Dauer von einem Jahr" als zulässig zu entscheiden. Die Begründung hierfür ist im Vergleich zu anderen gerichtlichen Entscheidungen in Fragen der Anhaltung außerordentlich lang. Die Quintessenz war: Eine Internierung W.s sei nicht unbedingt notwendig, da die Erkrankung zur Zeit der gerichtsärztlichen Untersuchung nur mehr in geringem Maße bestehe und er sich auf

25 Vgl. Erving GOFFMAN, Asyle. Über die soziale Situation psychiatrischer Patienten und anderer Insassen, Frankfurt am Main 1972.

26 Historisches Archiv im PKH, Patientenakte W.

27 Historisches Archiv im PKH, Patientenakte W., Brief W. an Rechtsanwalt Dr. Uffenheimer vom 27.11.1931.

28 Historisches Archiv im PKH, Patientenakte W., Brief Direktor Klebelsberg an Friedrich Heiler am vom 25.11.1931. 
dem Weg der Besserung befinde, aber aufgrund der äußeren Bedingungen für den Kranken werde das als beste Lösung gesehen. Klebelsberg rechtfertigte die Ergebnisse der kommissionellen Untersuchung in einem Brief an Heiler folgendermaßen:

„Ich habe, wie ich Ihnen wie ich glaube schon schrieb, es abgelehnt bei dieser Kommission beteiligt zu sein und habe von Anfang an dem Gericht vorgeschlagen den Dozenten Dr. Scharfetter der psychiatrischen Klinike Innsbruck zu bestellen. Heute babe ich vom Gericht die Mitteilung erhalten, dass der Begutachter feststellen konnte, dass es sich bei Dr. W. um einen manischen Erregungszustand handelt. Es ist natürlich deshalb keineswegs gesagt, dass er deshalb in der Anstalt bleiben muss, sondern es wurde nur ausgesprochen, dass die Einweisung nicht eine Art Freibeitsberaubung war und die Anhaltung infolge Geisteskerankheit zulässig erklärt wurde. "29

Nach Verkündung des „Urteils“ waren der zuvor sehr zuversichtliche W. und seine Unterstützer geschockt. Ein darauf folgender medialer Aufruf des Protests ließ die Wogen hoch gehen. W. war es gelungen, mittels eines Besuchers einen Brief aus der Anstalt zu schmuggeln, der dann in der ,Volks-Zeitung“veröffentlicht wurde. W. nutzte das Medium, um seine ,Version’ von der Einlieferung in die „Irrenanstalt“ klarzulegen. Von Beginn der Kampagne an trat der Patient namentlich und somit in seiner ganzen bürgerlichen Identität in Erscheinung. In seiner Beschreibung des Tatherganges äußert sich W. über die Einlieferung:

„Tatsächlich waren meine Nerven durch die fortwährenden theologischen Streitigkeiten mit meinen Klosterbrüdern stark ermüdet - aber sicher ist dies kein Grund gewesen, mich binter Schloß und Riegel eines Narrenhauses zu stecken! Will man mich nach mittelalterlicher Praxis etwa, wie es schon manch anderem romflüchtigen Priester ergangen ist, auf diese Weise unschädlich machen? '30

Die „freiwillige“" Aufnahme in der Anstalt, die ihm letztendlich den Freiheitsentzug brachte, thematisierte W. in der Zeitungserklärung folgendermaßen: „Um nicht vor den Aerz̨ten als verrückt zu erscheinen - bekanntlich behauptet jeder Narr, er wäre kein Narr - sagte ich unter dem Drucke des äußeren Zwanges, leider eine, Jesuitenlüge' gebrauchend: ,Mir scheint, ich habe eine Art Nervenzusammenbruch erlitten!' [...] [Nur] aus Furcht vor Weiterem gab ich die Erklärung ab, vorläufig freiwillig bleiben zu wollen, da man mir sagte, das wäre in meiner Sache das Klügere! $" 31$

Österreichweit erschienen in sozialdemokratischen Blättern Berichte darüber, dass Pater W. unrechtmäßig als „verrückt" in Hall angehalten werde: Dieser Fall sei ein Paradebeispiel dafür, dass die römisch-katholische Kirche das Organ zur Aufrechterhaltung der hierarchischen Ordnung und der Repression gegenüber dem mündigen Volk in Tirol sei. Seine Ankündigung zum Kirchenaustritt sowie seine Gesinnung als „gläubiger Sozialist" hätten ausgereicht, um ihn seitens der Kirche in die „Irrenanstalt" einliefern zu lassen, damit er für das „System“ keine Gefahr mehr darstelle. ${ }^{32}$ Die unverhohlen als „Narrenhaus" benannte Anstalt in Hall wurde somit als repressives Instrument der Obrigkeiten von Kirche, Land und Staat gedeutet. Tatsächlich wusste W. aber auch die politischen Interessen der Sozialisten in der Presse zu nutzen:

29 Historisches Archiv im PKH, Patientenakte W., Brief Direktor Klebelsberg an Friedrich Heiler vom 25.11.1931.

30 N.N., Die Verschleppung eines Franziskanerpaters in das Irrenhaus. In: Neueste Zeitung, Nr. 270, 25.11.1931, 3 .

31 Ebd.

32 N.N., Die Verschleppung eines Franziskanerpaters in das Irrenhaus. In: Neueste Zeitung, Nr. 270, 25.11.1931, 3-4; N.N., Hetze und immer nur Hetze. In: Zweigroschenblatt, Wochenflugschrift für Recht und Wahrheit, Nr. 50, 13.12.1931, 1-2. 
„Merkwürdig ist [für mich] auch folgende Tatsache: Die Franziskaner können auf Grund eines eigenen Privilegs ,ibre Narren' auf Landeskosten hier im Irrenhause verpflegen lassen, die ,Hochwürdigen' in 2. Klasse - und die ,Ehrwürdigen' in 3. Klasse; also aus Steuergeldern des Volkes! Auch ich werde als ,Franziskaner' bier verpflegt. Da ich aber keiner mehr bin, verstehe ich nicht, wieso mich die Franziskaner auf Landeskosten (!) hier verpflegen lassen können. "33

Der Grundtenor, in welchem er viele weitere Unterstützer gewinnen konnte, lautete: „[...] ich protestiere hiermit öffentlich gegen die widerrechtliche Beraubung meiner persönlichen Freibeit und bitte auf diesem Wege alle meine Freunde und rechtlich denkenden Menschen, für diese Wiedererlangung meines primitivsten Menschenrechtes - der Freibeit - einzutreten. "34

Dass viele Menschen von diesem Aufruf betroffen waren, lässt sich an der Post an Klebelsberg, die sich ebenfalls in der Krankenakte befindet, erkennen. Etliche Menschen, die W. noch nicht einmal persönlich kannten, erkundigten sich bei der Direktion über das Befinden des Paters, und darüber, wie lange er noch in der Anstalt bleiben müsse. ${ }^{35}$

Im Gegenzug wurde in der katholischen Presse von einer „gelungenen Zusammenarbeit“ des ,sektierenden" Bischofs Timotheos mit den Sozialdemokraten und Kommunisten gesprochen: W. leide nach ärztlicher Diagnose an einer „schweren Geistesstörung“, einer „akuten religiösen Manie“, und sei daher zu Recht nach Hall gebracht worden. W. sei ein „Allesnörgler" und „Querulant". Der eigentliche Skandal an der Affäre liege aber darin, dass die „sozialistische Presse“ aus der Geschichte des Unglücklichen für sich Kapital schlage. Rücksicht auf den eigentlich betreffenden W. werde dabei nicht mehr genommen. Man spreche in den ,roten Blättern“von Abwegigkeiten wie dem „Terror des Mittelalters", den die Kirche angeblich gegen kritische, abtrünnig gewordene Mitglieder verhänge. ${ }^{36}$ Es sei vor allem das „Wiener sozialdemokratische[...] Hauptorgan“, welches die Sachverhaltung des W. für sich zu nutzen wisse:

„Wer einmal in das Netz der klerikalen Kreuzspinne geraten ist, entkommt nicht so leicht; die Fäden schlingen sich immer enger um ihn, die Spinne spritzt ibr Gift gegen ihn, die Hölle wird zur Wirklichkeit [...] Selten gewinnt man Einblick in die Lemurenwelt, in diese schwarze $V$ ergangenheit, die immer noch Gegenwart ist - aber manchmal, wenn eine Luke aufgestoßen wird, schlägt der Verwesungsgeruch empor. "37

Regelrecht ,zerrissen“ wurde in der Presse auch das nächste Umfeld W.s. Etwa der „religiöse ,Sozialist" Bischof Timotheos, der ,ursprünglich Bauernknecht [gewesen sei], später eine Handelsschule besucht hatte und dann obne weitere Studien [...] zum Bischof geweiht worden war", und nun mit Gefolgschaft von ,dessen Frau und drei anderen Sektierern" diese ",ganz, unbekannte Sekte" leite; 38 vor allem wurde auch an ihrer, Glaubwürdigkeit' gekratzt, da weder Timotheos noch die „sozialdemokratischen Anwälte“ die rechtliche Verantwortung für ihn übernehmen wollten bzw. konnten: „[...] aber den Revers, der seine

33 N.N., Die Verschleppung eines Franziskanerpaters in das Irrenhaus. In: Neueste Zeitung, Nr. 270, 25.11.1931, 4 .

34 Ebd.

35 Historisches Archiv im PKH, Patientenakte W., Brief des L. Schneebauer aus Wien an Kleblesberg vom 3.12.1931.

36 N.N., Ueble Geschäfte auf Kosten eines Geisteskranken. Der Fall W. von Schwaz - die Ausbeutung der Geschichte eines Unglücklichen zu einer Hetze. In: Reichspost, Nr. 328, 28.11.1931, 2. N.N., Hetze und immer nur Hetze. In: Zweigroschenblatt, Wochenflugschrift für Recht und Wahrheit, Nr. 50, 13.12.1931, 1-2.

37 Zitiert in: N.N., Ueble Geschäfte auf Kosten eines Geisteskranken. Der Fall W. von Schwaz - die Ausbeutung der Geschichte eines Unglücklichen zu einer Hetze. In: Reichspost, Nr. 328, 28.11.1931, 2.

38 Ebd. 
Entlassung aus der Anstalt gebracht bätte, wenn damit die Verantwortung für den Kranken übernommen worden wäre, unterschrieben seine ,Befreier' nicht!' 39

Die von Klebelsberg bereits zuvor geäußerten Befürchtungen, welche W.s „Opferrolle“ in dem Lagerkonflikt betrafen, waren eingetreten:

„[...] ich stehe nicht an zu erklären, dass es mir hauptsächlich darum zu tun ist, dass Dr. W. unter eine entsprechend rubige Fübrung kommt; ibn in seinem Zustand allein in die Welt binaus zu lassen, in der es heute nach allen Seiten hin rebelliert, schiene mir wirklich nicht recht rätlich, denn ich glaube mit Recht annehmen zu dürfen, dass man ibm zum Schlusse ausnützt und am Ende, wie es schon öfters vorgekommen ist, wenn man seiner nicht mehr bedarf, fallen lässt. " 40

In Österreich blieben die journalistischen Schlammschlachten hauptsächlich auf politische Interessensebenen beschränkt. Anders in Deutschland: Der Fall W. füllte auch deutsche Zeitungen, wurde darin aber hauptsächlich von Anhängern Wittigs, die seine Geschichte dadurch auch wieder in Umlauf bringen konnten, forciert.

\section{Sanktionierungen von inner- und außerhalb der Anstalt. Oder: W., ein „Nestbeschmutzer“, oder nur Opfer des „Wiener Hauptorgans der Kirchenfeinde'?}

Von Seiten der Schwazer Franziskaner, die aufgrund der Zeitungskampagnen tatsächlich um Rufschädigung fürchteten, wurde Direktor Klebelsberg eine Reihe von Rechtfertigungsschreiben überreicht, die bezeugen sollten, dass W. durch anormales Verhalten bereits längere Zeit vor seiner Einweisung aufgefallen sei. Diese Bezeugungen, die von den Patern handschriftlich unterschrieben wurden, nahmen teilweise recht groteske Züge an: „Herr Pfarrer von Breitenbach erfubr von Augenzengen, dass $W$. im Sommer bei einer Bergwanderung gesehen wurde in folgendem Aufzuge: den Habit über die Schultern gestülpt, dementsprechend die Unterhosen freigelegt. Die Leute hätten die Köpfe geschüttelt. " 11 Wie in den Zeitungen breitgetreten, war es vor allem die „Gottlosenpresse“, die mittels W. „so viel Schmutz auf die Kirche und ihre Diener geworfen " habe, „dass es geradezu Wunder [...] [annehme], wenn [...] die Priester [...] [sich] auf den Straßen [...] noch blicken lassen dürfen, ohne offen angeflegelt, angespucket und tätlich angegriffen zu werden" 42.

Nach den Zeitungskampagnen begann für W. der ,Terror' in der Anstalt. Spätestens jetzt war auch in Hall das Potential des Falles W. erkannt worden, das für den Ruf der Anstalt in der Öffentlichkeit nicht förderlich war, aber auch den „Frieden“ in der Anstalt beeinträchtigte. Zudem liefen behördliche Ermittlungen von Landes- und Staatlicher Seite über die Geschehnisse in der Anstalt. ${ }^{43}$ Wie in der Krankenakte beschrieben wurde, war es Patient W. ab dieser Zeit untersagt, am geschlossenen Gelände des Anstaltsareals spazieren zu gehen. Sein Kontakt zu anderen Patienten,

39 N.N., Ueble Geschäfte auf Kosten eines Geisteskranken. Der Fall W. von Schwaz - die Ausbeutung der Geschichte eines Unglücklichen zu einer Hetze. In: Reichspost, Nr. 328, 28.11.1931, 2.

40 Historisches Archiv im PKH, Patientenakte W., Brief Direktor Klebelsberg an Friedrich Heiler vom 25.11.1931.

41 Historisches Archiv im PKH, Patientenakte W., Kommentarsammlung von Vertretern des Franziskanerklosters Schwaz, 2.

42 N.N., Hetze und immer nur Hetze. In: Zweigroschenblatt, Wochenflugschrift für Recht und Wahrheit, Nr. 50, 13.12.1931, 1.

43 Österreichisches Staatsarchiv (ÖSTA), Archiv der Republik (AdR), Bundesministerium für soziale Verwaltung 1931, Volksgesundheit, Kt. 2031 (Irrenwesen), Zl. 108.904, W., Franziskanerpriester, Einlieferung in die Landes-Heil- und Pflegeanstalt in Hall. TLA, Amt der Tiroler Landesregierung 1932, Abt. II b, 140 - X - 47, Pater W. 
aber auch zum Anstaltspersonal wurde teilweise unterbunden. Zudem hatte er, wie aus einem Zitat der Krankenakte vom 15.12.1931 hervorgeht, neue ,Verhaltensregeln’ zu beachten:

„[Der Patient] Geht seit einiger Zeit mit ärztlicher Erlaubnis im Anstaltsgebiete alleine spazieren. Es wurde berichtet, dass Dr. W. bei dieser Gelegenheit mit Gartenarbeiter [sic!] über religiöse Dinge spricht und über die römische Kirche loszieht. Er wurde deshalb beute abends vom Abt [eilungs-]. Aræte daran erinnert, dass er s[einer].Z[eit]. dem Anstaltsleiter versprochen hatte hier dem Personal und den Patienten gegenüber nicht über Religion zu sprechen. Auf diese in höflich gesuchter Form erfolgte Ermahnung wurde Pat[ient]. sofort erregt, fubr in die Höhe, erklärte er füblte sich an dieses gegebene Versprechen nicht gebunden, weil dasselbe erzwungen gewesen sei. Verlangte vom Arzt in kategorischer Weise die Beantwortung der Frage: ,Wo steht es geschrieben, dass es einem Anstaltspatienten untersagt ist über religiöse Dinge zu sprechen?' Wiederholte diese Frage mehrmals Wort für Wort mit Nachdruck aussprechend, klopfte dabei diktatorisch mit dem Zeigefinger auf den Tisch, steigerte sich selbst immer mehr in Erregung binein, schlug mit der Faust auf die Tischplatte. Gab sich dann mit der gegebenen Erklärung (dass bei manchen innerlich unrubigen Kranken die Religion das Einzige ist, was Halt gibt und dass man sie daber im Glauben an diese wahre Religion nicht auch noch wankend machen soll) zufrieden, berubigt sich augenblicklich und sagt: ,Ja bätten Sie mir das doch gleich gesagt!' Zeigt sich dann gleich wieder gemütlich und freundlich [...]. "44

Was sollte nun mit W. geschehen? Ihn in der Anstalt zu behalten, lag nicht im Interesse Klebelsbergs. Er war darum bemüht, baldigst einen seriösen und geeigneten „Gewährsmann“ für W. zu finden, der den Rekurs bezahlen und ihn zu sich nehmen konnte. Weder Bischof Timotheos, der selbst bettelarm war, noch Wittig oder Heiler kamen aus diversen Gründen dafür in Betracht. Von politischer Seite aus betrachtet etwa im Schreiben des Tiroler Landeshauptmannes Franz Stumpf an das Bundministerium für Soziale Verwaltung - wurden Bedenken bezüglich der Übernahme W.s durch Timotheos angeführt:

„Genannter Timotheus will Dr. W. zu sich nehmen, es besteht aber vorerst noch Bedenken, dass W., der während der Anbaltung Aesserungen[sic!] machte, dass er sich den Kommunisten anschlösse, in der gegenwärtig aufgeregten Zeit unter der Landbevölkerung mit seinen gegen Besitz, und teilweise Autorität gerichteten Lehren argen Unfug anrichten könnte. “45

W. selbst plädierte in seinen Briefen an den Direktor sowie an den gerichtlichen Gutachter Scharfetter dafür, zu seiner Familie ins Paznaun gehen zu dürfen. In den Briefen versuchte er Klebelsbergs Bedenken darüber zu entkräften:

„Aber sie fürchten, dass ich dort missioniere? Glauben Sie mir, Herr Doktor! In der Klinik, ja nicht einmal im Narrenhaus bin ich [...] so gezwungen zu schweigen wie in einem ganz römischen Dorf, wo man mich von früher her gut kennt. Da werde ich den Leuten so viel als möglich ausweichen - um nicht gefragt zu werden und sie werden wahrscheinlich auch dem , abgefallenen Priester' scheu aus dem Wege gehen, höchstens hinter dem Rücken tuscheln. "46 W. wollte, wie er in einem Schreiben an Scharfetter formulierte, ,weit weit weg von der Stadt in die Berge, aufs einfache Dorf. In die Heimatluft. Dann körperliche Arbeit. Nicht Rube beilt meine Nerven, sondern Abwechslung zwischen körperlicher Arbeit und vor allem vollständiger $W$ ablfreibeit. Das habe ich nirgends so wie bei meinen Brïdern in Flirsch. " 47

44 Historisches Archiv im PKH, Patientenakte W., Eintragung von der Visite am 15.12.1931.

45 ÖSTA, AdR, Bundesministerium für soziale Verwaltung 1931, Volksgesundheit, Kt. 2031, Z1. 108.904, W., Franziskanerpriester, Einlieferung in die Landes-Heil- und Pflegeanstalt in Hall.

46 Historisches Archiv im PKH, Patientenakte W., Brief W. an Direktor Klebelsberg vom 19.12.1931.

47 Historisches Archiv im PKH, Patientenakte W., Brief W. an Dr. Helmut Scharfetter vom 18.12.1931. 
Dieser Brief an Scharfetter wurde übrigens nicht abgesendet. Er ist einer der wenigen Dokumente, die sich im Original in der Krankenakte in Hall befinden.

Tatsächlich lehnte aber auch W.s Familie, vor allem seine Brüder, seine Übernahme gegen Revers strikt ab: Die betagte Mutter würde es nicht ertragen, ihren Sohn mit dieser Karriere vor sich zu sehen. Nach all den medialen Vorfällen sei ein friedliches Zusammenleben in dem Tiroler Dorf im Paznaun für W. nicht mehr möglich. ${ }^{48}$

Schließlich fand sich Dr. Manjeri, ein Bekannter W.s aus Salzburg, der von Seiten Klebelsbergs als geeignet betrachtet wurde, und den Revers für W. dann erstattete. Am 18.12.1931 wurde W. aus der Anstalt als "gebessert" entlassen und zu Manjeri nach Salzburg transferiert, um dort in „Familienpflege“" versorgt zu werden. ${ }^{49}$

\section{Konsequenzen des Falls W. für die Anstalt in Hall}

Nach der Entlassung schrieb Klebelsberg nochmals einen Brief an Prof. Heiler, in welchem er ihn über W.s Aufenthaltsort informierte und schilderte, welche Konsequenzen er aus dem Fall W. für die Haller Anstalt zog:

„Ich muss schon offen gestehen, dass ich mit Dr. W. reichlich genug habe. Sie werden es begreifen, wenn ich dem lebhaften Wunsche Ausdruck gebe, mit Theologen möglichst wenig mehr zu tun zu baben. [...] Wenn Sie sehr verehrter Herr Professor diese ganze Serie von schriftlichen und mündlichen Auseinandersetzungen, Telephongesprächen, Vorsprachen bei der Tiroler Landesregierung etc. bier mitgemacht hätten, dann würden Sie es verstehen, wenn ich eben sage, dass ich mehr derartige Patienten hier nicht mehr haben möchte. "50

Er resümierte dann noch einmal die verschwörungstheoretisch angehauchten Konfrontationen von W.s Sympathisanten und Bischof Timotheos gegen die Anstaltsleitung:

„Timotheus hat ja sogar einmal mit dem Aufmarsch von 300 Kommunisten gedroht und erklärt, dass dieselben Dr. W. gewaltsam aus der Anstalt heraus holen wollen. Wie weit die falschen Ideen gehen, können Sie daraus ermessen, dass Bischof Timotheos allen Ernstes befürchtet hat, es könnten eines Nachts gewissermaßen vermummte Gestalten kommen und Dr. W. im Auto verschleppen und ibn irgendwo in ein italienisches Kloster bringen, wo man ibn dann eingesperrt bätte. Ich babe Mühe gehabt, den Bischof von diesen Wabnideen abzubringen und war genötigt ibm zu sagen, dass ich gewissermaßen persönlich für den biesigen Aufenthalt des Dr. W. bürge. "

Zudem äußerte er sich über die in Deutschland publizierten kirchenkritischen Artikel, die den Fall W. sarkastisch aufbereitet und der „Heil- und Pflegeanstalt“ in Hall ein schlechtes Image verpasst hatten:

„Ich füble mich Ihnen gegenüber [...] gewissermaßen verpflichtet festzustellen, dass wir hier keinesfalls etwa die Organe eines Inquisitionstribunale sind. Vielleicht haben Sie Gelegenheit in dieser Hinsicht in Deutschland aufkelärend zu wirken und das Land Tirol von dem Vorwurf zu befreien, das hier noch etwas mittelalterliche Zustände berrschen. "51

Im vorliegenden Beitrag wurde veranschaulicht, welche Auseinandersetzungen durch die medialen Aufbereitungen der Geschichte des Paters W. in der Psychiatrie von Seiten unterschiedlicher politischer und geistlicher Interessengemeinschaften

48 Vgl. Historisches Archiv im PKH, Patientenakte W., Briefe der Familie des Patienten an W. und an die Direktion.

49 Vgl. Historisches Archiv im PKH, Patientenakte W., Eintragung vom 18.12.1931.

50 Historisches Archiv im PKH, Patientenakte W., Abschrift des Briefes von Klebelsberg an Friedrich Heiler vom 24.12.1931.

51 Ebd.. 
verursacht wurden. Weiters wurde dargestellt, dass im Falle des W. sowohl die „Landes-Heil- und Pflegeanstalt“ als auch das Kloster als „Totale Institutionen“ auftraten und sowohl als geschützte Bereiche als auch als reglementierende Systeme fungierten. Weiters wurde demonstriert, dass Psychiatrie und Theologie als fließende Grenzbereiche auftreten können, was sich u. a. an der Pathologisierung des Unbekannten, hier etwa am Beispiel des Bischof Timotheos, gezeigt hat. Schlussendlich wurde anhand des Falles W. auch ein Beispiel dafür gegeben, wie repräsentativ die Deutung der „Irrenanstalt“ als repressives Instrument der Obrigkeit zur Verstummung politisch unliebsamer Individuen in der Bevölkerung - wenn auch zu politischen Zwecken missbraucht - vorherrschte.

\section{Autoreninformation}

Mag. Dr. Angela Grießenböck, Historikerin und Projektmitarbeiterin im Interreg IV Projekt „Psychiatrische Landschaften. Die Psychiatrie und ihre Patientinnen und Patienten im historischen Raum Tirol-Südtirol von 1830 bis zur Gegenwart" in Innsbruck. Postadresse: Institut für Geschichtswissenschaften und Europäische Ethnologie, Innrain 52, 6020 Innsbruck. Mail: angela.griessenboeck@uibk.ac.at 


\section{Zwischen Front und Heimat: Deutungen des Ersten Weltkrieges in Krankenakten am Beispiel des Bremer St. Jürgen-Asyls}

\section{English Title}

Between front and home: Interpretations of First World War in patients' records - the example of the St. Jürgen-Asyl in Bremen

\section{Summary}

World War I is known for being the first industrialized war. More than 600,000 soldiers, who had served in the German army, suffered from psychic diseases, and even many women, who had remained at home during the war, were affected by such mental illnesses. Psychiatrists, who were not only working at the "homefront" but also at the battleground, were in both situations confronted with these diseases. However, they did not only analyse and diagnose the patients but they also interpreted the war and its influence on the individuals. This article deals with these interpretations of the war by examining patient records of male and female, civil and soldier patients of the St.Jürgen-Asyl in Bremen (Germany). The psychiatrists of the Bremer St.Jürgen-Asyl tended to see no causal relationship between the experiences that their patients had made during the "Great War" and their psychic diseases as they were convinced that genetic predisposition would cause mental illness. Only in a few patient records an explicit connection between the experiences that the soldiers had made during the war and their resulting mental illnesses can be found. Against the background of the traditional gender role models of that time, the psychiatrists were of the opinion that only men fighting at the front were involved and affected by the war. According to the public opinion men and women would have a specific obligation towards society (especially during war), which they could not provide when mentally ill. Therefore psychiatrists interpreted mental health as an obligation that every efficient member of the society had to fulfil.

\section{Keywords}

First World War, patients records, St.Jürgen-Asyl, Bremen, psychiatry 
Im Juli des Jahres 1916 wurde der 25jährige Soldat Willi S. in das St.Jürgen-Asyl, das städtische psychiatrische Krankenhaus in Bremen, eingeliefert. ${ }^{1}$ Seine Diagnose lautete Hysterie, eine häufig im Ersten Weltkrieg gestellte Diagnose für seelisch erkrankten Soldaten. ${ }^{2}$ Willi S. war im November 1915 zum Kriegsdienst eingezogen worden und im Frühjahr 1916 an die Westfront gekommen. Hier wurde er im Schützengraben eingesetzt. In der klinischen Untersuchung während seines mehrwöchigen Aufenthaltes im bremischen psychiatrischen Krankenhaus beschrieb er für ihn einschneidende Erlebnisse dieser Zeit:

„Vor 8 Tagen wurden wir angegriffen von Franzosen und unsere Kompanie wurde aufgerieben. ich wurde verschüttet. Verletzung? Nein. W arum hier? Ich weiss nicht. Krank gemeldet? Ich bin herunter gekommen. Ins Lazarett? Ich weiss nicht wann. Angriff? Am 15. Nach dem Angriff kam die $V$ erschüttung. Wann wieder heraus? Ein paar Minuten. Wir liefen alle hin und her. Ich versuchte über die Deckung nach vorn wegzulaufen unterwegs traf ich einen Verwundeten den hab ich mitgenommen. Die Granaten schlugen ein und nahm [sic] den Kopf des Kameraden mitnahm [sic]. ich kam dann in einen Graben binein, wo alle tote [sic] lagen auch Schwarze. Ich lief immer wieder bin und her und ein Kamerad kam dann dort [sic] und hat mich mitgenommen. dann habe ich die Erinnerung verloren."

Im Folgenden kam Willi S., vermittelt über ein Lazarett und ein anderes Krankenhaus, in das bremische St.Jürgen-Asyl. Hier wurden seine Kriegserlebnisse psychiatrisch eingeordnet, beispielsweise musste beurteilt werden, ob der Krieg tatsächlich die Ursache der Krankheit des Patienten sei. Indem sie diese und ähnliche Fragen beantworteten, unternahmen die Bremer Ärzte jedoch nicht nur eine individuelle Krankheitsdeutung dieses einen Patienten. Mit der Einordnung und Beurteilung der Kriegserlebnisse von Willi S. machten sie nichts weniger, als den Krieg selbst zu deuten.

1 Die folgenden Angaben beziehen sich, soweit nicht anders angegeben, auf die Krankenakte des Patienten: Alt-Archiv am Klinikum Bremen-Ost, A 100/13, Krankenakte Willi S. Der folgende Beitrag stellt Ergebnisse meiner 2010 beendeten kulturhistorischen Dissertation vor, in der ich die Krankenakten von 396 weiblichen und männlichen, zivilen und militärischen PatientInnen des St.Jürgen-Asyls analysiert habe, die während des Ersten Weltkrieges dort aufgenommen wurden. Auf diese 396 Krankenakten beziehen sich die folgenden Prozentangaben.

2 Im öffentlichen militärpsychiatrischen Diskurs der Kriegszeit entstand eine Debatte um die Benennung der seelischen Erkrankungen von Soldaten mit der Diagnose Hysterie oder traumatische Neurose. Diese Debatte wurde auf der so genannten Kriegstagung des „Deutschen Vereins für Psychiatrie“ und der „Gesellschaft deutscher Nervenärzte“ im September des Jahres 1916 in München dahingehend entschieden, dass man sich darauf einigte, seelisch erkrankten Soldaten im Krieg die Diagnose Hysterie zu stellen. Damit konnte einerseits die Annahme des bereits im Begriff der traumatischen Neurose enthaltenen Kausalzusammenhangs zwischen psychischer Krankheit und Kriegsgeschehnissen vermieden werden; die Annahme eines entsprechenden Kausalzusammenhangs hätte bedeutet, dass den erkrankten Soldaten eine Rente hätte gezahlt werden müssen. Dies galt es für militärtreue Psychiater zu vermeiden. Andererseits konnten aufgrund der Einbettung der Diagnose Hysterie in ihren Diskurszusammenhang - die Hysterie als spezifisch weibliche Krankheit - die erkrankten Soldaten diffamiert werden: „Eigentlich“, so die Auffassung, die hiermit propagiert wurde, erkrankte der „deutsche Mann“ nicht im Krieg. Die Diagnose Hysterie hatte für den öffentlichen militärpsychiatrischen Diskurs zwischen 1914 und 1918 somit eine hohe Bedeutung. Vgl. zur Debatte um Hysterie oder traumatische Neurose: Paul LERNER, Hysterical Men. War, Psychiatry, and the Politics of Trauma in Germany, 1890-1930 (Ithaca, London 2003) und Paul LERNER, „Ein Sieg deutschen Willens": Wille und Gemeinschaft in der deutschen Kriegspsychiatrie. In: Wolfgang U. ECKART, Christoph GRADMANN (Hg.), Die Medizin und der Erste Weltkrieg (Herbolzheim 2003) 85-107.

3 Alt-Archiv am Klinikum Bremen-Ost, A 100/13, Krankenakte Willi S. 
Der folgende Beitrag befasst sich mit diesen Deutungen des Ersten Weltkrieges in Krankenakten am Beispiel des Bremer St.Jürgen-Asyls. Das St.Jürgen-Asyl ist ein psychiatrisches Krankenhaus, das zwischen 1900 und 1904 im dörflichen Ellen bei Bremen erbaut wurde. Dem Ende des 19. Jahrhunderts populär gewordenen „NoRestraint-System" folgend, war es als dörfliche Anlage konzipiert worden, in welcher die Kranken nicht das Gefühl bekommen sollten, eingesperrt zu sein. Eigentlich war das St.Jürgen-Asyl ein ziviles Krankenhaus, im Ersten Weltkrieg wurden jedoch auch Soldaten aufgenommen. Im Oktober des Jahres 1916 erfolgte die Einrichtung eines eigenen Reservelazaretts auf dem Gelände des Krankenhauses. Zur Versorgung der erkrankten Soldaten wurden die zivilen Ärzte des St.Jürgen-Asyls herangezogen, Unterstützung bekamen sie durch einen Stabsarzt. Die Krankenakten aller, der zivilen und der soldatischen, PatientInnen sind noch erhalten. Die in diesem Beitrag gestellte Frage nach Deutungen des Ersten Weltkrieges in Krankenakten wird im Folgenden anhand der Krankenakten dieser verschiedenen Patientengruppen, d. h. ziviler und militärischer, männlicher und weiblicher PatientInnen, erörtert. Nur so können die Besonderheiten ärztlicher Krankheitsauffassungen im Krieg bei den einzelnen Patientengruppen aufgezeigt werden. Die Frage nach Deutungen des Krieges meint einerseits, ob bei psychiatrischen Krankheitskonstruktionen in Krankenakten die ärztliche Annahme eines kausalen Zusammenhangs zwischen Kriegsgeschehnissen und psychischer Krankheit zum Ausdruck kommt. Andererseits befasst sich dieser Beitrag damit, was in der Auffassung der Ärzte des St.Jürgen-Asyls psychische Gesundheit im Krieg ausmachte.

Mit der hier vertretenen Auffassung, mit psychiatrischen Krankheitsauffassungen erfolgten Deutungen des Ersten Weltkrieges, wird ein kulturhistorisches Krankheitsverständnis zugrunde gelegt, das sich erst seit den 1990er Jahren etabliert hat. ${ }^{4}$ Psychische Krankheit wird hier nicht mehr als internes Forschungsgebilde der Psychiatrie, sondern antiessentialistisch als historisch kontingent verstanden. Mit psychiatrischen Diagnosen wurden demnach nicht objektiv vorhandene Krankheiten lediglich festgestellt, sondern diese erst konstruiert. Auch die Wahrnehmung spezifischer Verhaltens- und Denkweisen eines Menschen als Symptom einer seelischen Erkrankung ist demnach abhängig vom jeweiligen Diskurszusammenhang und den jeweiligen historischen Rahmenbedingungen, in dem und unter denen sie erfolgt. Die Ärzte griffen bei ihren Krankheitskonstruktionen ebenso auf innermedizinische Diskurse, etwa den Sozialdarwinismus, wie auf gesamtgesellschaftliche Diskurse bspw. zu erwünschtem Geschlechterrollenverhalten von Männern und Frauen im Krieg zurück.

Der Erste Weltkrieg ist als erster industrialisierter Massenkrieg in die Geschichtsschreibung eingegangen. Das vorangestellte Zitat aus der Krankenakte des Willi S. veranschaulicht Erlebnisse der an diesem Krieg beteiligten Soldaten gut. Unter diesen Bedingungen des Krieges erkrankten allein beim Feldheer des Deutschen Reiches 313.399 Soldaten an so genannten Krankheiten des Nervengebietes, beim Feld- und

4 Dieses Krankheitsverständnis wird beispielsweise in den Arbeiten von Volker Roelcke und HansGeorg Hofer zu Grunde gelegt. Vgl. Volker ROELCKE, Krankheit und Kulturkritik. Psychiatrische Gesellschaftsdeutungen im bürgerlichen Zeitalter (1790-1914) (Frankfurt/Main, New York 1999) sowie Hans-Georg HOFER, Nervenschwäche und Krieg. Modernitätskritik und Krisenbewältigung in der österreichischen Psychiatrie (1880-1920) (Wien, Köln, Weimar 2004). 
Besatzungsheer zusammen waren es über 600.000.5 Auf diese - tatsächlich unerwarteten, vor 1914 war stets die „Nervenstärke“ des deutschen Volkes propagiert worden - Massen an psychisch kranken Soldaten mussten die Psychiater im Folgenden reagieren. Sie entwickelten radikale Behandlungsmethoden, so mit elektrischen Strömen oder Hypnose, die den Kranken zurück an die Front zwingen oder ihm die Irrealität seiner Krankheit zeigen sollten. ${ }^{6}$

Neben der Entwicklung neuer, radikaler Behandlungsmethoden stand die Frage der Verursachung seelischer Krankheit von Soldaten im Krieg im Fokus des öffentlichen militärpsychiatrischen Diskurses. Diese militärrechtliche Frage der Dienstbeschädigung musste auch in Reservelazaretten der „Heimatfront“ beantwortet werden.

In den Krankenakten des St.Jürgen-Asyls wurde die Frage der Verursachung einer jeweiligen psychischen Krankheit durch Kriegsgeschehnisse üblicherweise im Anschluss an die klinische Untersuchung eines Patienten im Rahmen einer Auflistung seiner Krankheitssymptome beantwortet. Bei Willi S. begann diese Auflistung mit der Erwähnung, die beiden Schwestern des Patienten seien nervös, er selbst sei zwar begabt, aber körperlich schwächlich. ${ }^{7}$ Diese ärztlichen Annahmen der hereditären Belastung des Patienten und seiner schwächlichen Konstitution sind Ausdruck bereits Ende des 19. Jahrhunderts in der Psychiatrie angewandter sozialdarwinistischer Deutungsmuster. Die Selbstverständlichkeit sozialdarwinistischer Auffassungen für die psychiatrische Beurteilung von PatientInnen im bremischen Krankenhaus bereits bei seiner Eröffnung 1904 zeigen die den Untersuchungen zu Grunde liegenden Formulare: Bei der Anamnese eines Patienten wurde zunächst seine/ihre hereditäre Belastung thematisiert, bei der Untersuchung des körperlichen und nervlichen Zustandes als erstes seine/ihre Konstitution und etwaige Degenerationszeichen. Der Blick der Ärzte orientierte sich somit immer schon an sozialdarwinistischen Deutungsmustern. Wesentliche Merkmale des sozialdarwinistischen Diskurses waren damit die Annahmen der biologischen Ungleichheit von Menschen und der Vererbbarkeit negativer Eigenschaften (als eine solche wurde psychische Krankheit verstanden). Diese lagen auch im Ersten Weltkrieg der praktischen Psychiatrie des St.Jürgen-Asyls zu Grunde.

Eine hereditäre Belastung wurde hier bei weiblichen und männlichen, zivilen und militärischen PatientInnen jeweils in über 60 Prozent der Fälle festgestellt. Die ärztliche Annahme einer hereditären Belastung ersetzte im bremischen psychiatrischen Krankenhaus zudem meist die Annahme einer Verursachung der Erkrankung durch den Krieg. Die Bedeutung dieser Übernahme sozialdarwinistischer Deutungsmuster für ärztliche Deutungen des Krieges ist eindeutig: Weniger der Krieg als solches sei es, der psychische Erkrankungen auslöse, als vielmehr die hereditäre Belastung des Patienten. Die „Schuld“ für die psychische Erkrankung wurde damit im Betroffenen selbst verortet.

5 Vgl. Sanitätsbericht über das Deutsche Heer (Deutsches Feld- und Besatzungsheer) im Weltkriege 1914/1918 (Deutscher Kriegssanitätsbericht 1914/18), 3. Band: Die Krankenbewegung bei dem Deutschen Feld- und Besatzungsheer im Weltkriege 1914/1918 (Berlin 1934) 145-148.

6 Diese Systematisierung von Behandlungsmethoden der Militärpsychiatrie im Ersten Weltkrieg stammt von Paul Lerner. Vgl. Paul LERNER, Rationalizing the Therapeutic Arsenal: German Neuropsychiatry in World War I. In: Manfred BERG, Geoffrey COCKS (Eds.), Medicine and Modernity. Public Health and Medical Care in Nineteenth- and Twentieth-Century Germany (Washington 1997) 121-148, hier 131.

7 Vgl. Alt-Archiv am Klinikum Bremen-Ost, A 100/13, Krankenakte Willi S. 
Betrachtet man die ärztliche Beschreibung der Krankheitssymptome des vorgestellten Patienten Willi S. genauer, so fällt noch etwas auf. Die Zeit des Patienten beim Militär wurde auf nur wenige Worte reduziert, hier hieß es:

„Mit 25 Jahren vor 8 Monaten Soldat. Vor 4 Monaten ins Feld. Vor 2 Monaten Gasangriff, darnach [sic] Gedächtnisschwäche und Kopfweh. Vor 10 Tagen nach 5tägigem Trommelfeuer bei eiserner Portion in sehr schwerem Kampf nicht verletzt aber etwas kopflos geworden. Für die folgende [sic] etwa 48 Stunden etwas traumbaftes unzuverlässiges Gedächtnis, darnach [sic] allmählich klarer."

Die Erlebnisse des Willi S. an der Front, die eingangs vorgestellt wurden, finden hier hingegen keine Erwähnung. Auch gibt es in der Krankenakte keine Hinweise darauf, dass diese Fronterlebnisse in therapeutischen Gesprächen vor Ort verarbeitet worden wären. Der Patient wurde mittels der Arbeitstherapie behandelt und nach einigen Wochen als gebessert in ein Heimatlazarett entlassen.

Die Arbeitstherapie war eine der bedeutendsten Behandlungsmethoden im bremischen psychiatrischen Krankenhaus auch während des Krieges. Hier wurden wie in der Vorkriegszeit etwa 50 Prozent aller, der weiblichen und männlichen, zivilen und soldatischen PatientInnen mit der Arbeitstherapie behandelt. ${ }^{8}$ Die Möglichkeiten zur Anwendung der Arbeitstherapie waren bereits bei der Konzeption des Krankenhauses berücksichtigt worden, dieses war als wirtschaftlich autonomer Komplex mit Handwerksbetrieben, Landwirtschaftseinrichtungen, Feldern, Gärten, sogar einer eigenen Energieversorgung angelegt worden. Doch nicht nur aufgrund ihrer häufigen Anwendung kam dieser Therapieform im St.Jürgen-Asyl während des Krieges eine hohe Bedeutung zu. Auch wurden in der Arbeitstherapie über die Bestellung der anstaltseigenen Felder und die Bewirtschaftung der Gärten und des Bauernhofes Nahrungsmittel erwirtschaftet. Die bessere Versorgung mit Nahrungsmitteln führte dazu, dass es im St.Jürgen-Asyl im Ersten Weltkrieg erst später als in anderen psychiatrischen Anstalten zu einer erhöhten Sterblichkeit von PsychiatriepatientInnen kam: Während das so genannte Hungersterben, wie Heinz Faulstich ${ }^{9}$ zeigte, in anderen psychiatrischen Krankenhäusern des Deutschen Reiches bereits 1915 einsetzte, stieg im St.Jürgen-Asyl erst im so genannten Steckrübenwinter 1916/1917 die Sterblichkeit stark an. ${ }^{10}$

Das eigentliche Ziel der Arbeitstherapie war jedoch die Ablenkung des Patienten von seinen „pathologischen Denkinhalten“ und damit im Krieg gerade die Vermeidung einer Auseinandersetzung mit seinen Kriegserlebnissen. ${ }^{11}$

Auch in anderen Krankenakten des St.Jürgen-Asyls wurde von den konkreten Erlebnissen der soldatischen Patienten an der Front abstrahiert. Dies zeigt die geringe Bedeutung der Kriegserlebnisse eines Patienten nicht nur für die psychiatrische Behandlung, sondern auch für die psychiatrische Krankheitskonstruktion im St.JürgenAsyl. Diesen Erlebnissen wurde kein Einfluss auf die seelische Gesundheit der Betroffenen zugestanden. Wenn die Bremer Ärzte einen kausalen Zusammenhang

8 Die im öffentlichen militärpsychiatrischen Diskurs der Kriegszeit entwickelten radikalen Methoden der Behandlung psychisch kranker Soldaten wurden hier hingegen nur in wenigen Fällen angewandt.

9 Vgl. Heinz FAULSTICH, Hungersterben in der Psychiatrie 1914-1949. Mit einer Topographie der NSPsychiatrie (Freiburg im Breisgau 1998) 61.

10 Vgl. Ärztliche Berichte über die Wirksamkeit des St.Jürgen-Asyls für Geistes- und Nervenkranke in Ellen (Bremen) bei Hemelingen (o. O. 1904-1919).

11 Vgl. Gerda ENGELBRACHT, Achim TISCHER, Das St. Jürgen-Asyl in Bremen. Leben und Arbeiten in einer Irrenanstalt 1904-1934 (Bremen 1990) 57. 
zwischen psychischer Erkrankung und Kriegsgeschehnissen annahmen, so galten stets besondere Ereignisse als hierfür verantwortlich, die meist im Zusammenhang mit einer körperlichen Verletzung standen, so beispielsweise Verschüttungen. Erlebnisse der Patienten wurden nicht als krankheitsverursachend wahrgenommen. Dies ist Ausdruck des zeittypischen körpermedizinischen Krankheitsverständnisses, das in allen Krankenakten des St.Jürgen-Asyls zum Vorschein kommt.

Für ärztliche Auffassungen der Verursachung seelischer Erkrankungen im Krieg ist ein weiterer Aspekt von Bedeutung. In den Krankenakten einiger weniger soldatischer Patienten des bremischen Krankenhauses ist von den Strapazen die Rede, die die Soldaten an der Front hätten aushalten müssen. ${ }^{12}$ Die Erwähnung von Strapaz̨en an der Front lässt jedoch auf die ärztliche Annahme schließen, an der Front habe es auch einen Zustand obne Strapazen gegeben, einen Normalzustand. Der Alltag an der Front und in den Schützengräben wurde so zur Normalsituation umdefiniert. Auch deshalb wurden psychische Erkrankungen im Krieg stets auf besondere Ereignisse zurückgeführt. Der Krieg an der Front wurde zur Normalität, ihn nicht aushalten zu können, zum Symptom einer „Geisteskrankheit“.

Die Selbstverständlichkeit, die der Situation des Krieges von den Bremer Ärzten beigemessen wurde, zeigt auch ihr Umgang mit den Patienten des St.Jürgen-Asyls, die fahnenflüchtig geworden waren. 18 Prozent der im St.Jürgen-Asyl untergebrachten soldatischen Patienten waren während des Ersten Weltkrieges fahnenflüchtig geworden. Vergleicht man diese Zahlen mit von Christoph Jahr für das gesamte deutsche Heer angenommenen, so wird deutlich, dass im St.Jürgen-Asyl sehr viele desertierte Soldaten untergebracht waren: Jahr geht von einer Desertionsrate von ein bis zwei Prozent aus. ${ }^{13}$

Desertion wurde in den Krankenakten des bremischen Krankenhauses entweder als Symptom einer „Geisteskrankheit“ perzipiert oder zur Begründung der Erkrankung oder der Degeneration eines jeweiligen Patienten herangezogen. So hieß es im psychiatrischen Gutachten des soldatischen Patienten Stanislaus J.:

"J[...] gebört, wie die Mehrzabl der wegen unerlaubter Entfernung Angeklagten, zu den psychopathischen disharmonisch entwickelten Persönlichkeiten, die niemals das Gleichmass [sic] in ibrem Seelenleben finden und in einer plötzlich auftauchenden Stimmung kritiklos davonlaufen, obne dass ibnen die Strafbarkeit ihrer Handlung klar zum Bewusstsein kommt." "14

Das militärisch deviante Verhalten der Desertion wurde somit im St.Jürgen-Asyl psychiatrisiert. Seelische Gesundheit im Krieg bedeutete den Bremer Ärzten zufolge damit militärische Pflichterfüllung und Gehorsamsbereitschaft. Sie bedeutete, sich in die Verhältnisse des Krieges zu fügen und diese auszuhalten.

Sich mit den Verhältnissen des Krieges zu arrangieren implizierte jedoch ein spezifisches Verhalten eines Menschen. Dieses stand (im Gegensatz beispielsweise zu seinem Erleben) wie schon zuvor auch zwischen 1914 und 1918 im Fokus der Krankheitskonstruktionen auch im bremischen psychiatrischen Krankenhaus. Während des Krieges wurde in den Krankenakten etwa 50 Prozent aller PatientInnen

12 Vgl. Alt-Archiv am Klinikum Bremen-Ost, A 111/16, Krankenakte August M. et al.

13 Christoph JAHR, „Der Krieg zwingt die Justiz, ihr Innerstes zu revidieren“. Desertion und Militärgerichtsbarkeit im Ersten Weltkrieg. In: Ulrich BRÖCKLING, Michael SIKORA (Hg.), Armeen und ihre Deserteure. Vernachlässigte Kapitel einer Militärgeschichte der Neuzeit (Göttingen 1998) 187 222, hier 199. Vgl. zur Desertion im Ersten Weltkrieg auch Christoph JAHR, Gewöhnliche Soldaten. Desertion und Deserteure im deutschen und britischen Heer 1914-1918 (Göttingen 1998).

14 Alt-Archiv am Klinikum Bremen-Ost, A 112/14, Krankenakte Stanislaus J., Hervorhebung M. H. et al. 
des St.Jürgen-Asyls - auch der männlichen zivilen und der weiblichen - die Verhaltensweise der Unrube als Krankheitssymptom erwähnt, und zwar tendenziell unabhängig von der gestellten Diagnose. Unruhe jedoch war bei Männern und Frauen im Krieg eine unerwünschte Verhaltensweise. Hans-Georg Hofer beschreibt dies für Soldaten mit den Worten:

„Im Präzisionskrieg technischer Waffensysteme war der nervenkranke Soldat nicht braucbbar; eine ängstliche, zitternde Hand am Abrug, ein von Kopfsausen, Lähmungen und Scbüttelkrämpfen geplagtes Nervenbündel - mit solchen Männern konnte kein Krieg gewonnen werden. "15

Auch bei Frauen war Unruhe im Krieg nicht erwünscht. Von Frauen an der so genannten Heimatfront wurde bedingungslose Unterstützung ihrer Väter, Ehemänner, Brüder etc. an der Front erwartet, sie selbst hätten die Verhältnisse ohne Murren zu ertragen. Voraussetzung hierfür war ihr ruhiges, unaufgeregtes Verhalten.

Die häufigen Verweise auf das Krankheitssymptom der Unruhe im St.Jürgen-Asyl - es handelt sich hierbei um das am häufigsten während des Krieges in den Krankenakten des bremischen Krankenhauses notierte Krankheitssymptom - zeigen die hohe Bedeutung, die die Bremer Ärzte dieser Verhaltensweise beimaßen. Indem bei weiblichen und männlichen PatientInnen häufig das Krankheitssymptom der Unruhe festgestellt wurde, wurde in den Krankenakten die Auffassung formuliert, seelische Gesundheit im Krieg äußere sich in ruhigem den Erfordernissen des Krieges entsprechenden Verhalten. Ein solches Verhalten wurde von PatientInnen aller Patientengruppen erwartet. Tatsächlich unterschieden sich die Krankheitsbilder männlicher und weiblicher, ziviler und militärischer PatientInnen des St.Jürgen-Asyls auch hinsichtlich anderer Krankheitssymptome im Krieg nicht grundsätzlich voneinander. Spezifisch war lediglich ihre Einbettung in den Kontext je unterschiedlicher gesamtgesellschaftlicher präskriptiver Geschlechterrollenbilder, die sich an „kriegswichtigem" Verhalten von Männern und Frauen im Krieg orientierten.

Die bereits thematisierte ärztliche Wahrnehmung des Ersten Weltkrieges als Normalzustand kommt auch in den Krankenakten der weiblichen Patienten des St.Jürgen-Asyls zum Vorschein. Der Erste Weltkrieg kann tendenziell als totaler Krieg verstanden werden, die gesamte Heimat richtete sich hier an den Bedürfnissen der Front aus. ${ }^{16}$ Die Auswirkungen des Krieges wurden damit für die Menschen auch in Bremen, fernab der Front, spürbar.

15 Hans-Georg HOFER, „Nervöse Zitterer“. Psychiatrie und Krieg. In: Helmut KONRAD (Hg.), Krieg, Medizin und Politik. Der Erste Weltkrieg und die österreichische Moderne (Wien 2000) 15-134, hier 23-24.

16 Vgl. hierzu Karen Hagemann: „Die Heimat wird im doppelten Sinne zur Front: zur ,Heimatfront‘, ohne deren Unterstützung der Krieg nicht zu gewinnen ist, und zur ,Kampffront ${ }^{e}$, die selbst durch den Krieg bedroht wird, sowohl durch die angreifenden Bombenflieger als auch durch die einmarschierenden Bodentruppen des Gegners“. Karen HAGEMANN, ,Jede Kraft wird gebraucht“. Militäreinsatz von Frauen im Ersten und Zweiten Weltkrieg. In: Bruno THOSS, Hans-Erich VOLKMANN (Hg.), Erster Weltkrieg - Zweiter Weltkrieg. Ein Vergleich. Krieg, Kriegserlebnis, Kriegserfahrung in Deutschland (Paderborn u. a. 2002) 79-106, hier 81. Letzteres trifft für das Deutsche Reich im Ersten Weltkrieg jedoch nur bedingt zu. Vgl. zum Begriff des ,totalen Krieges“ Roger CHICKERING, Der totale Krieg. Vom Nutzen und Nachteil eines Begriffs. In: Roger CHICKERING (Hg.), Krieg, Frieden und Geschichte. Gesammelte Aufsätze über patriotischen Aktionismus, Geschichtskultur und totalen Krieg (Stuttgart 2007) 241-258. 
Dieser Aspekt wird allerdings in den Krankenakten des St.Jürgen-Asyls nicht thematisiert. Als Beispiel kann die Krankengeschichte der Elisabeth Z. ${ }^{17}$ herangezogen werden. Die 24jährige Elisabeth Z. wurde im Dezember des Jahres 1916 erstmals in das St.Jürgen-Asyl aufgenommen. Bei ihrer Einlieferung war sie in mehrfacher Hinsicht mit dem Krieg in Berührung gekommen: Sie arbeitete in einem Reservelazarett in Bremerhaven, ihr Ehemann und ihr Vetter waren im Krieg, ihr Ehemann wurde dort schwer verwundet. Die Verwundung des Ehemanns und die Tätigkeit der Patientin in einem Reservelazarett fielen zeitlich mit dem Ausbruch der Erkrankung zusammen. Und dieser Ausbruch, so wurde immer wieder notiert, erfolgte Ende des Jahres 1916 ,plötglich“. Für die Krankheitskonstruktion der Elisabeth Z. spielten diese Kriegserlebnisse ${ }^{18}$ der Patientin jedoch keine Rolle. Die in ihrer Krankenakte verwendete Sprache zeigt Gründe hierfür auf.

Elisabeth Z. war bei ihrer Aufnahme in das St.Jürgen-Asyl seit einiger Zeit in einem Reservelazarett in Bremerhaven tätig. In der Krankenakte wurde ihre Tätigkeit als „Helferin“ beschrieben: „Helferin seit 2-3 Monaten“, wurde bei der Frage nach dem Beruf der Patientin im Anamnesebogen notiert; hinzugefügt wurde „im Reservelazarett". Dies ist eine Berufsbezeichnung: Z. war nicht als ausgebildete Krankenschwester, sondern als Aushilfe im Reservelazarett tätig. Doch verwendete der Direktor des bremischen psychiatrischen Krankenhauses, Anton Delbrück, wenn er in anderen Zusammenhängen von entsprechenden MitarbeiterInnen im eigenen Lazarett sprach, den Ausdruck der „Hilfskeraft". ${ }^{19}$ Die Verwendung des Ausdrucks der „Helferin“" in der Krankenakte der Patientin stellt somit andererseits die ärztliche Bezugnahme auf ein populäres zeitgenössisches Bild der Tätigkeit von Frauen in Lazaretten dar. Dieses Bild wurde auch in zeitgenössischen Zeitschriften und auf Abbildungen auf Feldpostkarten verbreitet. Gabriele Haefs und Klaus Gille geben die Erinnerungen einer jungen Frau wieder, die sich 1914 freiwillig zur Tätigkeit in einem Lazarett meldete: „Wie alle anderen jungen Mädchen hatte ich mir die Verwundetenpflege romantisch vorgestellt: Limonade reichen, Kissen richten, kü̈le Hände auf Fieberstirnen legen, Vorlesen, mit Genesenden spazierengehen. "20 Diese Vorstellungen entsprachen jedoch keinesfalls der Wirklichkeit: „Der Übergang in diese Wirklichkeit war jäh: Sie bedeutete Schweiß- und Uringeruch, bedeutete das hilflose Wimmern von Männern, die als Helden ausgezogen waren und jetzt nach ihrer Mutter, ihrer Frau riefen."21 Dazu kamen die hier nicht erwähnten unzähligen Verletzungen und Verstümmelungen der Soldaten, die gerade in einem Reservelazarett an der „Heimatfront" unübersehbar waren. ${ }^{22}$

17 Die folgenden Angaben beziehen sich, soweit nicht anders angegeben, auf die Krankenakte der Patientin: Alt-Archiv am Klinikum Bremen-Ost, Jahrgang 1929, Krankenakte Elisabeth Z. geb. R.

18 Der Begriff des Kriegserlebnisses ist hier gerechtfertigt, da es sich um Erlebnisse der Patientin handelt, die in unmittelbarem Zusammenhang mit dem Krieg standen, auch wenn sie nicht an der Front stattfanden.

19 Vgl. Ärztlicher Bericht von 1915.

20 Gabriele HAEFS, Klaus GILLE, Von Sittenstrenge und Aufbegehren. Die Wilhelminische Zeit (Hamburg 1994) 217.

21 HAEFS, GILLE, Von Sittenstrenge und Aufbegehren, 217.

22 Reservelazarette waren der Ort in der Heimat, an dem am unmittelbarsten die Verletzungen zum Vorschein kamen, die der Krieg mit sich brachte. Entsprechende Lazarette fernab der Front nahmen meist schwer verwundete Soldaten auf, deren weiterer Einsatz im Krieg noch nicht absehbar oder nicht möglich war, deren Gesundheitszustand sich allerdings so weit gebessert hatte, dass man sie von der Front weg transportieren konnte. Krankenschwestern und Ärzte waren somit hier unmittelbar mit der Realität des Krieges konfrontiert. Vgl. Wilhelm ROSENBAUM, Das Krankentransportwesen im 
Es ist anzunehmen, dass auch Elisabeth Z. diese Realität des Krieges im Reservelazarett kennengelernt hatte. Doch das mittels des Ausdrucks der „Helferin“ von den Bremer Ärzten in ihrer Krankenakte vermittelte Bild war ein anderes. Lediglich der positive, der öffentlich propagierte Aspekt einer Tätigkeit als Hilfskrankenschwester wurde hier rezipiert. So konnte die Tätigkeit der Patientin im Reservelazarett als unwesentlich für die Entstehung ihrer Krankheit wahrgenommen werden. Sie interessierte im bremischen Krankenhaus nur insofern, als es sich hierbei um ihre aktuelle berufliche Tätigkeit handelte, nach der im Anamnesebogen gefragt wurde. Von der Erfahrung selbst wurde abstrahiert. Die Krankheit der Elisabeth Z. wurde schließlich auf eine Blinddarmentzündung und die anschließende Operation zurückgeführt, vorbereitet sei diese Erkrankung durch die hereditäre Belastung der Patientin gewesen.

Die Rückführung der Erkrankung der Elisabeth Z. auf körperliche Ursachen und auf ihre vermeintliche hereditäre Belastung zeigt die hohe Bedeutung sozialdarwinistischer Erklärungsansätze im Ersten Weltkrieg in der zivilen Psychiatrie. Die Rückführung der seelischen Erkrankungen auch von Soldaten im Krieg auf ihre vermeintliche hereditäre Belastung ist damit nicht primär Ausdruck eines vorauseilenden Gehorsams der Ärzte gegenüber dem Militär. ${ }^{23}$ Vielmehr „passten“ zeitgenössische psychiatrische Theorien genau zu den Erfordernissen des Militärs im Ersten Weltkrieg. Im St.Jürgen-Asyl wurde eine Verursachung seelischer Erkrankung durch Kriegsgeschehnisse sogar am ehesten bei soldatischen Patienten wahrgenommen: Bei 4 Prozent der weiblichen und 6 Prozent der männlichen zivilen, aber bei 23 Prozent der männlichen militärischen Patienten wurde eine Verursachung ihrer Erkrankung durch den Krieg angenommen. Nicht nur die Situation an der Front, auch die Kriegssituation an der so genannten Heimatfront wurde von den Bremer Ärzten zur Normalsituation umdefiniert. So wurde die zentrale Alltagsproblematik des Krieges in der Heimat, die Nahrungsknappheit, nur selten und primär in den Krankenakten weiblicher Patienten erwähnt. Die kriegsbedingte Nahrungsknappheit wurde ausschließlich als Sorge der betroffenen Patientin um die Versorgung der eigenen Familie mit Lebensmitteln gelesen; diese Sorge wurde als Krankheitssymptom bezeichnet. Sich trotz der bestehenden Verhältnisse nicht um die Versorgung der eigenen Familie mit Lebensmitteln zu sorgen, wurde so zum Merkmal seelischer Gesundheit während des Krieges. Die Bremer Ärzte erwarteten von Frauen im Krieg damit ein Verhalten zu den Bedingungen von vor 1914.

Auch dies ist aufschlussreich für ärztliche Deutungen des Krieges. Der Krieg fand, so die Wahrnehmung der Bremer Ärzte, an der Front statt, nicht in der Heimat. Sich selbst verorteten sie in der Heimat, einem normativen unpolitischen Raumkonstrukt.

Damit konstruierten sie eine fundamentale Diskrepanz zwischen Front und Heimat, nahmen den Ersten Weltkrieg nicht als totalen Krieg wahr. Die Wahrnehmung einer Verursachung seelischer Krankheit durch den Krieg primär bei soldatischen Patienten ist durch diese Konstruktion einer fundamentalen Diskrepanz zwischen Front und Heimat zu erklären. Ärztliches Handeln im Krieg findet jedoch tatsächlich (hierauf hat Johanna Bleker als eine der ersten aufmerksam gemacht) niemals unabhängig vom

Weltkriege. In: Wilhelm HOFFMANN (Hg.), Die deutschen Ärzte im Weltkriege. Ihre Leistungen und Erfahrungen (Berlin 1920) 315-342.

23 Vgl. zu dieser Auffassung Peter RIEDESSER, Axel VERDERBER, „Maschinengewehre hinter der Front“. Zur Geschichte der deutschen Militärpsychiatrie (Frankfurt/Main 1996). 
Krieg statt. ${ }^{24}$ Nicht nur die Notwendigkeit der Beurteilung der Dienstbeschädigung erkrankter Soldaten zeigt, dass der Aufgabenbereich auch der Bremer Ärzte im Ersten Weltkrieg zwischen Front und Heimat verortet werden muss.

Krankenakten als das Quellenmaterial, auf dessen Grundlage in diesem Beitrag ärztliche Deutungen des Ersten Weltkrieges erarbeitet wurden, sind krankenhausinterne Medien der wissenschaftlichen Kommunikation und Dokumentation. Untersuchungen der in den Krankenakten verwendeten Sprache ergeben, dass in den Akten selbst keine Begründungen von Anschauungen erfolgen. Nichtsdestotrotz kommen hier Deutungen des Krieges durch die Ärzte zum Vorschein. Der Krieg wurde an der Front und in der Heimat zur Normalsituation umdefiniert, eine Verursachung einer seelischen Erkrankung konnte demnach nur durch außerordentliche Ereignisse zustande kommen, ärztliche Auffassungen seelischer Gesundheit selbst orientierten sich bei Männern und Frauen an als „,kriegswichtig“ bezeichnetem Verhalten. Diese in den Krankenakten verschlüsselten Deutungen des Krieges durch die Bremer Ärzte lehnten sich an herrschende medizinische Diskurse der Vorkriegszeit an. Doch lassen sich die gerade erarbeiteten Deutungen des Krieges nicht nur in militärpsychiatrischen Zeitschriften auffinden, wo sie bislang meist untersucht wurden, sondern auch in Krankenakten selbst (als Spiegel der psychiatrischen Praxis) mittels psychiatrischer Krankheitskonstruktionen. Es waren diese psychiatrischen Krankheitskonstruktionen, die die PatientInnen und den ärztlichen Umgang mit ihnen im Krankenhaus stets unmittelbar betrafen.

\section{Autoreninformation}

Maria Hermes, Dr. des., Kulturwissenschaftlerin. Postadresse: Hegelstraße 34/36, 28201 Bremen, Deutschland. Mail: Maria-Hermes@gmx.de

24 Vgl. Johanna BLEKER, Einleitung. Medizin im Dienst des Krieges - Krieg im Dienst der Medizin. Zur Frage der Kontinuität des ärztlichen Auftrages und ärztlicher Werthaltungen im Angesicht des Krieges. In: Johanna BLEKER, Heinz-Peter SCHMIEDEBACH (Hg.), Medizin und Krieg. Vom Dilemma der Heilberufe 1865 bis 1985 (Frankfurt/Main 1987) 13-28. 


\section{Blinde Menschen unter dem NS-Regime in der „Ostmark“ - Eine Problematisierung}

\section{English Title}

Blind persons under the NS-regime in the "Ostmark" - a problematisation

\section{Summary}

This article presents various aspects of my doctoral thesis "Zwischen Integration, Kooperation und Vernichtung - Blinde Menschen unter dem NS-Regime in der ,Ostmark." This doctoral thesis presents various aspects of the circumstances of blind people's lives in the "Ostmark" under the Nazi regime, such as the economic and social situation. Legal, medical and gender aspects are also taken into consideration. The aim was to gain detailed insight into the living conditions of blind people of that time. Under the Nazi regime blind people were separated into three main groups: the civilian blind, the war blinded and blind people of Jewish origin. Even since the time of the First World War there had been a two-class system of the civilian blind and blinded ex-serviceman. Due to the Nazi regime's anti-Jewish policy, the civilian blind and blinded veterans of Jewish origin were persecuted. In addition to that there was a strong segregation among blind people under the Nazi regime. This article deals with some main problems concerning the research about the life of blind people.

\section{Keywords}

National socialism, Austria, blindness, the war blinded, disability, 1938-1945

In diesem Aufsatz werden einige Aspekte der von der Autorin im Jänner 2010 fertiggestellten Dissertation vorgestellt. Die Dissertation ${ }^{1}$ trägt den Titel „Zwischen Integration, Kooperation und Vernichtung - Blinde Menschen unter dem NS-Regime in der ,Ostmark " "und wird in einer leicht überarbeiteten und gekürzten Version im Dezember 2011 im Studienverlag veröffentlicht werden. Die Arbeit stellt die Lebensumstände blinder Menschen in der „Ostmark“ in verschiedenen Teilaspekten, wie ihre ökonomischen und sozialen Verhältnisse, dar. Rechtliche-, medizin-, und geschlechterspezifische Gesichtspunkte wurden soweit der lückenhafte Quellekorpus dies zuließ, mitberücksichtigt. In diesem Aufsatz sollen einige der Probleme in der Auseinandersetzung mit dem Thema Blindheit diskutiert werden.

1 Barbara HOFFMANN, Zwischen Integration, Kooperation und Vernichtung: Blinde Menschen in der „Ostmark“ 1938-1945 (Diss. [Manuskript]) (Innsbruck 2010). 


\section{Einführung}

Unter dem NS-Regime verteilten sich blinde Menschen auf drei verschiedene Hauptgruppen: Zivilblinde, Kriegsblinde und blinde Menschen jüdischer Herkunft. Bereits seit dem Ersten Weltkrieg hatte es ein Zweiklassensystem von Zivil- und Kriegsblinden gegeben. ${ }^{2}$ Der Lebensstandard von Kriegsblinden im Gegensatz zu Zivilblinden war bereits in der Zwischenkriegszeit wesentlich höher gewesen. Zivilblinde hatten keinen generellen Rentenanspruch, viele waren arbeitslos. Dies machte sie in einem hohen Masse abhängig von privaten und staatlichen Sozialleistungen. Die Politik der bevorzugten Versorgung Kriegsblinder setzte sich unter dem NSRegime fort. Kriegsblinde galten als „Helden der Nation“ und genossen einen privilegierten gesellschaftlichen Status. ${ }^{3}$

Die Verfolgung von Menschen jüdischer Herkunft führte dazu, dass Zivil- und Kriegsblinde, die als Jüdinnen und Juden galten, zu einer dritten Klasse wurden. Nur wenige blinde Menschen jüdischer Herkunft überlebten den NS-Terror. ${ }^{4}$

1938 lebten rund 4.000 blinde Menschen in der „Ostmark“, etwa 300 von ihnen waren im Ersten Weltkrieg erblindet. Rund 200 Zivil- und Kriegsblinde galten nach den „Nürnberger Rassegesetzen“ als Jüdinnen und Juden. Über diese drei Klassen von blinden Menschen hinaus kam es zu einer starken Segregation unter blinden Menschen zwischen 1938 und1945. Nicht nur die Herkunft, auch die Ursache einer Erblindung, das Geschlecht sowie die Beurteilung des Arbeitspotentials beeinflusste ihre Lebensbedingungen enorm.

Die NS-Machthaber gingen prinzipiell davon aus, dass blinde Menschen über ein „nutzbares“ Arbeitspotenzial verfügten. Initiativen, die einer beruflichen Integration von blinden Menschen dienten, wurden daher gefördert, da darin ein volkswirtschaftlicher Gewinn gesehen wurde. Die NS-Fürsorgegesetzgebung war dementsprechend utilitaristisch ausgerichtet. Die berufliche Integration, in der NS-Propaganda, bezeichnenderweise als „Brauchbarmachung“ tituliert, war das Hauptziel der NSPolitik in Bezug auf blinde Menschen. Für die Zivilblinden hieß dies, dass die „Berufsfürsorge“ der wichtigste Aspekt staatlicher Unterstützung war. Das Postulat einer „produktiven“ Fürsorge legte die NS-Regierung unter anderen in den „Reichsgrundsätzen über Art und Maß der öffentlichen Fürsorge“ (RGS) ${ }^{5}$ fest. Neue Berufsfelder, wie beispielsweise in Industriebetrieben, Büroberufen oder als MasseurInnen sollten für Zivilblinde etabliert werden. Dabei waren allerdings diese Bemühungen für Kriegsblinde neue Betätigungsfelder zu finden bzw. auszubauen wesentlich weiterreichender als jene für Zivilblinde.

Charakteristisch für die NS-Politik war es dabei, das Anspruch und Praxis zum Teil weit auseinander klafften: Die neuen Berufsfelder etablierten sich nur schleppend. So war es ein dezidiertes Ziel der NS-Machthaber, die Anzahl blinder HandwerkerInnen $\mathrm{zu}$ reduzieren, da diese Branche als wirtschaftlich unrentabel galt. Da aber eine Ausbildung in einem Blindenhandwerk im Vergleich etwa zu einem Lehrgang für

2 Barbara HOFFMANN, Kriegsblinde in Österreich. Die Entstehung eines „Zwei-Klassen-Systems“ von blinden Menschen, In: Virus. Beiträge zur Sozialgeschichte der Medizin 6 (2007) 75-84.

3 Vgl. René SCHILLING, Die „Helden der Wehrmacht - Konstruktion und Rezeption, In: Rolf-Dieter MÜLLER, Hans-Erich VOLKMANN (Hg.), Die Wehrmacht. Mythos und Realität (München 1999) 550-572.

4 HOFFMANN, Blinde Menschen „Ostmark“, 273-280.

5 Vgl. GBlÖ, Nr. 397/1938, Verordnung über die Einführung fürsorgerechtlicher Vorschriften im Lande Österreich vom 3. September 1938. 
Büroberufe nach wie vor wesentlich kostengünstigster und in kürzerer Zeit durchführbar war, wurden beispielsweise die im Zweiten Weltkrieg erblindeten Soldaten und Zivilpersonen, um die Kosten für deren aufwendige Rehabilitation gering zu halten, weiterhin in großer Anzahl zu HandwerkerInnen ausgebildet. Um diese zu beschäftigen, gab es unter der NS-Diktatur sogar Maßnahmen zur Existenzsicherung blinder HandwerkerInnen, wie beispielsweise Wehrmachtsaufträge.

Die Bemühungen um die sogenannte „Brauchbarmachung“ blinder Menschen unter der NS-Diktatur trieb zumindest aus heutiger Sicht seltsame Blüten: So gab es Versuche, blinde Menschen als Flakhelfer einzusetzen, was sich allerdings nach einigen Testläufen als unmöglich herausstellte. ${ }^{6}$

Auch die nationalsozialistische Kriegsopferversorgung war utilitaristisch geprägt. Für Kriegsblinde galt ein Dasein als reine Rentenempfänger verpönt. Sowohl nach dem RVG (Reichsversorgungsgesetz) für die Kriegsopfer und Kriegshinterbliebenen des Ersten Weltkrieges als auch ab 1940 nach dem WFVG (Wehrmachtsfürsorge- und Versorgungsgesetz), welches für die Angehörigen der so genannten ,neuen deutschen Wehrmacht“" am 26. August 1938 erlassen worden war, ${ }^{7}$ bezogen Kriegsblinde die höchst möglichen Rentenzahlungen. Trotzdem sollten die Kriegsblinden möglichst vollständig in die Arbeitswelt integriert werden. ${ }^{8}$ Sogenannte „Berufsberatungskommissionen" von denen die Kriegsblinden, also die Betroffenen selbst, zunächst ausgeschlossen waren, fällten in den Reservelazaretten ${ }^{9}$ die Entscheidung über die berufliche Zukunft für die im Zweiten Weltkrieg erblindeten Soldaten. ${ }^{10}$

Der NS-Wohlfahrtsstaat zeigte darüber hinaus den von Marie Luise Recker bereits 2001 aufgezeigten Charakter als „Woblverhaltensstaat" anstatt eines Wohlfahrtsstaates. ${ }^{11}$ Ein an die NS-Ideologie angepasstes Verhalten war Voraussetzung für verschiedene Versorgungsleistungen. Darüber hinaus sah die Gesetzgebung beispielsweise Gratifikationen für berufstätige Zivilblinde vor, wie etwa steuerliche Vergünstigungen

6 Vgl.[Franz] BÖGGE, Die Aufgabe der [sic!] Bannes B unter Berücksichtigung der besonderen Lage im deutschen Blindenwesen, In: Nationalsozialistische Deutsche Arbeiterpartei Hitler-Jugend Bann B (Blinde) (Hg.), Bericht über die Führertagung des Bannes B (Blinde) vom 11. Dezember bis 13. Dezember 1937 (Hannover o. J.) 1-7 hier 4; Bertram SAUER, Zur Situation blinder Jugendlicher 19331945 (Manuskript) (Hamburg 1989) 60; Vgl. Wolfgang DRAVE, „Hier riecht's nach Mozart und Tosca“. Blinde Menschen erzählen ihr Leben (Würzburg 1996).

7 Vgl. GBlÖ, Nr. 411/1938, Fürsorge- und Versorgungsgesetz für die ehemaligen Angehörigen der Wehrmacht und ihrer Hinterbliebenen (WFVG) vom 26. August 1938.

8 Anton SCHANZER, Rückführung und Einsatz der Kriegsversehrten in die Wirtschaft, (Diss. Manuskript) (Wien 1944) 63.

$9 \mathrm{Zu}$ den Reservelazaretten existieren im Militärarchiv des Bundesarchives in Freiburg nur noch Schriftgutreste. Vgl. weiterführend: Roland MÜLLER, Wege zum Ruhm. Militärpsychiatrie im Zweiten Weltkrieg, Das Beispiel Marburg (=PapyRossa-Hochschulschriften 35) (Köln 2001) 52-72; Hubert FISCHER, Der deutsche Sanitätsdienst in den ersten Kriegsmonaten des Jahres 1939, In: Wehrmedizinische Monatsschrift 26 (1982), 26-27; MA, RH 55, Sanitätsdienststellen und Reservelazarette im Heimatkriegsgebiet und in besetzten Gebieten.

10 Vgl. u. a. OBERKOMMANDO DER WEHRMACHT (Hg.), Merkblatt. Ärztliche Fürsorge für erblindete Soldaten; [D] RGBl., Teil I, Verordnung über die Fürsorge für Kriegsblinde und hirnverletzte Kriegsbeschädigte vom 28. Juni 1940, 937 Oberkommando der Wehrmacht (Hrsg.), 91. Richtlinien für die ärztliche und Berufsbetreuung der in den Sammellazaretten befindlichen erblindeten Soldaten [OKW S In (WFV)/W Vers. 20.3.42 - 30 p. 11.10 - Nr. 1473/42)] , abgedruckt in: Ders. (Hg.), Wehrmachtsfürsorge- und -versorgungsbestimmungen (Fürs. U. Verf. Best.), Blatt 8, 6 (1942), 77-80.

11 Marie-Luise RECKER, Sozialpolitik, in: Wolfgang BENZ, Hermann GRAML, Hermann WEISS (Hg.), Enzyklopädie des Nationalsozialismus (München ${ }^{42001)}$ 123-134 hier 130. 
oder Ermäßigungen bei der Benutzung der Reichsbahn für berufliche Zwecke. In der Lohnsteuergesetzgebung konnten Zivilblinde sogar eine Gleichstellung mit Kriegsblinden erreichen. ${ }^{12}$ Die nationalsozialistische Ideologie räumte den nach ihren Wertmaßstäben „leistungsbereiten und -fähigen“, „geistig normalen" und „erbgesunden“ Zivilblinden die Aussicht auf Integration in die "Volksgemeinschaft" und Mitgliedschaft in NS-Organisationen, wie dem „Reichsbann B“ der „Hitler-Jugend“, der SA und der NSDAP, ein.

Nach dem „Anschluss“ kam es zu einer Ausrichtung des gesamten Blindenwesen nach Maßgabe der NS-Wohlfahrtspolitik: Der Stillhaltekommissar in der „Ostmark“ beendete sämtliche freie Vereinstätigkeit. ${ }^{13}$ Unter Aufsicht der NSV agierten für Zivilblinde nur mehr zwei Dachorganisationen, der „Deutsche Blindenfürsorgeverband“ (DBV) und der „Reichsdeutsche Blindenverband“ (RBV). Alle NSBlindenorganisationen führten den Arierparagraphen ein. Die Funktionäre des DBV und die selbst blinden Funktionäre des RBV mussten sich ideologischen Schulungen unterziehen. Funktionsträger die sich nicht entsprechend den NSV-Zielvorgaben verhielten, wurden durch regimetreue ausgetauscht. Maßgeblich für die Kriegsblinden war die NSKOV „Fachabteilung erblindeter Krieger“, welche die Kriegsblinden in der „Ostmark“ fast vollständig erfasste. Als Funktionäre fungierten Kriegsblinde des Ersten Weltkrieges.

Eine Aufgabe der NS-Blindenorganisationen war die Verbreitung der NS-Ideologie unter blinden Menschen. Die auf Kriegsblinde gezielte Propaganda suggerierte beispielsweise ein besonders hohes Verständnis des Regimes für ihre Anliegen und präsentierte etwa Adolf Hitler als „Schicksalsgenossen“ der Kriegsblinden. Hitler selbst inszenierte seine im Ersten Weltkrieg durch „Senfgas“ hervorgerufene Bindehautentzündung als vorübergehende Kriegserblindung. ${ }^{14}$

Kriegsblinde und Zivilblinde sollten in möglichst großer Zahl zu AnhängerInnen der NS-Ideologie werden. Davon versprachen sich die NS-Machthaber eine bereitwilligere Umsetzung ihrer Maßnahmen zur Produktivitätssteigerung und in Bezug auf die Zivilblinden unter anderem eine Befürwortung der Rassenhygiene. Diesem Zweck diente beispielsweise die Verbreitung von öffentlichen Aufrufen von regimetreuen Zivilblinden zur freiwilligen Sterilisation, die allerdings weitgehend ohne Erfolg blieben. ${ }^{15}$ Zur Zwangssterilisierung verurteilte Personen wehrten sich teilweise heftig gegen diese Eingriffe.

12 Vgl. [D] RGBl, Teil I, Zweite Verordnung zur Durchführung des Steuerabzuges vom Arbeitslohn (Zweite LStDVO) vom 6. Februar 1938, S. 149-180, J 26, 158-161; [Bruno] GERL, Steuervergünstigungen, In: Peter Th. MEURER (Hg.), Ratgeber für Blinde. Zugleich eine Einführung in die Blindenkunde für Fürsorge, Berufsberater und Augenärzte (Berlin 1939) 90-96, hier 91.

13 Vgl. Verena PAWLOWSKY, Edith LEISCH-PROST, Christian KLÖSCH, Vereine im Nationalsozialismus. Vermögensentzug durch den Stillhaltekommissar für Vereine, Organisationen und Verbände und Aspekte der Restitution in Österreich nach 1945, (= Veröffentlichungen der Österreichischen Historikerkommission. Vermögensentzug während der NS-Zeit sowie Rückstellungen und Entschädigungen seit 1945 in Österreich, 21.1) (München 2004) 13-14.

14 Vgl. u. a. Ian KERSHAW, Hitler. 1889-1936 (Stuttgart 1998) 143-146; Adolf HITLER, Mein Kampf (München 1939) (=Jubiläumsausgabe anlässlich der Vollendung des 50. Lebensjahres) 202-206.

15 Vgl. Mohammad Reza MALMANESH, Blinde unter dem Hakenkreuz. Eine Studie über die Deutsche Blindenstudienanstalt Marburg und den Verein der blinden Akademiker Deutschlands e. V. unter dem Faschismus (=Marburger Schriftenreihe zur Rehabilitation Blinder und Sehbehinderter, 13) (Marburg 2002) 173; Gabriel RICHTER, Blindheit und Eugenik (=Freiburger Forschungen zur Medizingeschichte, Neue Folge, 15) (Freiburg 1986). 
Ein Weiterbestand jüdischer Blindenverbände und Institutionen war grundsätzlich nicht geplant. Dies galt auch für das international renommierte „Israelitische Blindeninstitut" auf der Hohen Warten in Wien. Nach dem „Anschluss" kam es zunächst zur Liquidation von kleinen jüdischen Blindenorganisationen. Die größte, der „Hilfsverein der jüdischen Blinden“, wurde quasi als eine Art Übergangslösung in das „Israelitische Blindeninstitut“" eingegliedert. Das Gebäude auf der Hohen Warte wurde von der IKG als „Altersheim mit Blindenabteilung“ weiterhin genutzt und blieb bis 1942 die wichtigste Anlaufstelle und Unterkunft für blinde Menschen jüdischer Herkunft aus der „Ostmark“. Bis 1941 wurden blinde Menschen jüdischer Herkunft ihrer Existenzgrundlage beraubt, aus ihren Wohnungen vertrieben und verarmten völlig. Auf Grund ihrer Beeinträchtigung hatten sie zudem nur geringe Chancen zur Flucht. Bereits 1941, im Wesentlichen aber 1942, erfolgten die Zwangsdeportationen blinder Menschen aus Wien. Sie kamen in großer Anzahl nach Theresienstadt.

\section{Definition Blindheit}

Ein Problem bei der Erfassung blinder Menschen ist die Frage, wie „Blindheit“ definiert wird. Weit verbreitet in der Bevölkerung ist der Irrglaube, dass Personen die „blind“ sind, überhaupt keinen Lichtschein wahrnehmen. Dies ist historisch wie aktuell unrichtig, da sowohl im Untersuchungszeitraum wie heute, Personen als „blind“ gelten, auch wenn sie schwache Lichtempfindungen haben. Die Möglichkeit beispielsweise hell und dunkel zu unterscheiden, ist zwar für die Betroffenen bei der Orientierung durchaus hilfreich, zur Alltagsbewältigung werden aber auch in diesem Fall entsprechende Hilfsmittel, Schulungen und/oder fallweise fremde Hilfe benötigt. Im 20. Jahrhundert hat sich der Begriff „Blindheit“ daher sinnhaft um Formulierungen wie ,„sozialblind", ,praktischblind" oder auch ,erwerbsblind"16 erweitert. Diese Gegebenheiten wurden von der Sozialgesetzgebung bereits in der ersten Hälfte des 20. Jahrhunderts berücksichtigt. Dies geschah aber nicht einheitlich und führte dazu, dass die Festlegungen von „Blindheit“ in privat-, schul-, versicherungs- und versorgungsrechtlichen Bestimmungen voneinander abwichen. ${ }^{17}$

\section{Statistische Erfassung von blinden Menschen}

Die Frage, wie viele blinde Menschen in Österreich zwischen 1938 und 1945 lebten, kann nicht exakt beantwortet werden. Dies liegt zum Einen daran, dass nur wenige Quellen existieren, die konkrete Informationen liefern können. Zum Anderen birgt die statistische Erfassung blinder Personen generell Interpretationsprobleme. Da es keine einheitlichen Anerkennungskriterien und -verfahren bei der Definition von Blindheit gab, ist es schwierig, bei einer Erhebung Personen als blind oder als sehbehindert einzustufen.

Bei der Interpretation des Datenmaterials zu Blindheit muss daher immer hinterfragt werden, welche Kriterien für die Definition von Blindheit verwendet wurden. Häufig lassen sich dazu allerdings keine Hinweise finden. Weiter muss beachtet werden, wer die Angaben machte: Wurden die Betroffenen von Ärzten als „blind“ diagnostiziert oder beruhen die Aussagen auf eigenen Einschätzungen? Tatsächlich verfügen viele

16 Max SCHÖFFLER, Der Blinde im Leben des Volkes. Eine Soziologie der Blindheit (Leipzig, Jena 1956) 32.

17 Vgl. Christhard SCHRENK, Rudolf Kraemer. Ein Leben für die Blinden 1885-1945 (=Quellen und Forschungen zur Geschichte der Stadt Heilbronn, 14) (Heilbronn 1992) 15-16. 
blinde Menschen noch über ein Empfinden von hell und dunkel oder über einen minimalen Sehrest. Dies kann dazu führen, dass sie sich selbst als „sehbehindert“ einschätzen, auch wenn sie medizinisch gesehen als „praktisch blind“ gelten müssen. Betroffene können außerdem unter Umständen mit dem eigenen Schicksal besser umgehen, wenn sie sich nicht als „vollblind“, sondern als „sehbehindert“ wahrnehmen. Da das Vorliegen einer Behinderung auch eine negative Stigmatisierung bedeutete und immer noch bedeutet, versuchen Betroffene, diese zu vertuschen. Es stellt sich daher die Frage, wie ehrlich Betroffene selbst über ihre Sehbehinderung Auskunft geben, wenn die Angaben nicht von einer Medizinerin bzw. einem Mediziner oder einer anderen Instanz überprüft werden. Statistische Erhebungen über blinde Menschen zeigen daher bestenfalls Größenordnungen.

Die hier erwähnten Schwierigkeiten bei der statistischen Erhebung von blinden Menschen spielten schon im zeitgenössischen Diskurs des 20. Jahrhunderts eine nicht unwichtige Rolle. ${ }^{18}$ Viktor Gehrmann beschäftigte sich im Jahr 1919 in seinem Aufsatz über das Ergebnis der „Gebrechlichenzählung“ im Rahmen der Volkszählung 1910 ausgiebig mit den Problemen der Erfassung von blinden Menschen bei Volkszählungen. Insbesondere verwies er auf die eigentlich notwendige ärztliche Überprüfung der durch die Volkszählung gewonnenen Ergebnisse. Trotzdem wurde diese bei dieser Volkszählung nicht durchgeführt. ${ }^{19}$ Auch das Problem der Definition von Blindheit und die Abgrenzung zur Sehbeeinträchtigung beschrieb Gehrmann: „Sind nur auf einem oder beiden Augen blinde Personen zu zäblen? Wo bört Schwachsichtigkeit auf, wo beginnt Blindheit?" 20

1910 wurde für die sogenannten „Alpenländer“ eine Zahl von 5.578 blinden Menschen ermittelt. $^{21}$ Diese Zahl, wurde allerdings von Siegfried Altmann, dem damaligen Direktor des „Israelitischen Blindeninstituts“ auf der Hohen Warte in Wien, in seinem 1930 publizierten Aufsatz über das Blindenwesen ${ }^{22}$ in Österreich, als zu hoch eingeschätzt. Er verweist in diesem Zusammenhang auf die Umstände der Volksbefragung. Die Rubrik ,blind“ auf den Zählbögen sei nicht näher erklärt und daher seien wohl auch Personen mit verschiedenen „Gebrechen“ zu dieser Kategorie

18 Vgl. A. CRZELLITZER, Blindenwesen, in: Alfred GROTJAHN, Ignaz KAUP, Handwörterbuch der sozialen Hygiene Band I (Leipzig 1912) 163-171, hier 163-164. [Zur Problematik bei der Erstellung der ersten Blindenstatistik in der Habsburger Monarchie im Rahmen der allgemeinen Volkszählung 1869 vgl. auch die dort angegebene Literatur: Corinna WOLFFHARDT, Das Israelitische Blindeninstitut Hohe Warte. Ein historischer Abriß über Entstehen, Wirken und Einfluß auf das österreichische Blindenwesen (Dipl. [Manuskript]) (Wien 1999) 9-10.]

19 Vgl. Viktor GEHRMANN, Die Blinden und Taubstummen am Ende des Jahres 1910, In: Statistische Monatsschrift 3/1 (1919) 1-104, hier 9-12.

20 GEHRMANN, Blinden und Taubstummen, 1-104, hier 3.

21 Vgl. GEHRMANN, Blinden und Taubstummen, 1-104, hier 14. Für die Anzahl blinder Menschen in den „Alpenländern“ wurden die Angaben der Länder Niederösterreich, Oberösterreich, Salzburg, Steiermark, Kärnten, Tirol und Vorarlberg herangezogen.

22 Verstanden werden darunter nicht nur die blinden Menschen selbst, sondern alle Personen, Gruppen, Einrichtungen und Initiativen, die sich für sie einsetzen und schließlich sämtliche Gesetze und Verordnungen, die sich direkt oder indirekt mit blinden Personen befassen. Diese Formulierung wird in seiner ursprünglichen Bedeutung bis heute verwendet, ist allerdings unter Fachleuten umstritten. Vgl. MALMANESH, Blinde unter dem Hakenkreuz, 14; Karl SOBOTKA, Das deutsche Blindenwesen vom Gesichtspunkt der Wohlfahrtspflege und Sozialpolitik (Borna 1936) 1, zitiert in: RICHTER, Blindheit und Eugenik, 10. 
gezählt worden. ${ }^{23}$ Nach Altmann gab es nach 1910 keine neue, spezielle amtliche Blindenzählung mehr. ${ }^{24}$ Trotzdem nannte Altmann 1930 eine Gesamtanzahl von 3.663 Zivilblinden für Österreich. Zu diesem Ergebnis kam er durch eine private Erhebung aus dem Jahr 1928. ${ }^{25}$ Auch hier fehlt eine Erläuterung, wie diese zustande gekommen ist und welche Kriterien für die Ermittlung von „Blindheit“ verwendet wurden.

$\mathrm{Zu}$ der Anzahl blinder Menschen in Österreich konnte darüber hinaus nur eine weitere statistische Angabe aus dem Jahr 1938 recherchiert werden. Bei der 194. Sitzung der „Tarifkommission der Deutschen Eisenbahnverwaltung“ im Dezember 1938 in München wurde ein Antrag auf Ermäßigungen der Tarife für Zivilblinde gestellt. Zur Berechnung des zu erwartenden Einnahmeausfalles wurde angegeben, dass für Österreich eine Gesamtzahl von 4.000 blinden Menschen angenommen werde. Diese Daten sollen auf einer Auskunft des Reichsdeutschen Blindenverbandes (RBV) beruhen. ${ }^{26}$ Der RBV war nach dem „Anschluss“ 1938 auch für die „Ostmark“ zuständig. In dieser Zahl sind allerdings rund 350 Kriegsblinde mit eingerechnet. Die Interessensvertretung blinder Menschen, der RBV, ging also von der gleichen Zahl wie Altmann aus. In Ermangelung weiterer Quellen muss daher die Anzahl von 3.650 Zivilblinden zur Zeit des „Anschlusses“ für Österreich als ungefähre Größenordnung angesehen werden.

\section{4. „Erbliche Blindheit“ nach dem GzVeN}

In einigen der bisher veröffentlichten wissenschaftlichen Arbeiten über blinde Menschen unter dem NS-Regime wird davon ausgegangen, dass Personen, die wegen der GzVeN Diagnose „erbliche Blindheit“ vor dem Erbgesundheitsgericht standen, tatsächlich blind waren. ${ }^{27}$ Dies ist allerdings eine Fehleinschätzung. Nach dem GzVeN kam es auch zu Verfahren vor einem Erbgesundheitsgericht wegen der Diagnose „erbliche Blindheit“ obwohl keine völlige oder auch nur praktische Blindheit vorlag. ${ }^{28}$ Die Annahme der Erblichkeit einer vorhandenen Sehbehinderung war das ausschlaggebende Kriterium, nicht deren Ausmaß. Für eine Zwangssterilisation kamen dementsprechend auch sehbehinderte Menschen in Frage. Martin Bartels, Leiter der Städtischen Augenklinik Dortmund, schrieb dazu 1939 im „Ratgeber für Blinde“:

23 Vgl. Siegfried ALTMANN, Das Blindenwesen in Österreich, In: Carl STREHL (Hg.), Handbuch der Blindenwohlfahrtspflege. Teil II. Europa und Nordamerika (Marburg 1930) 146-162, hier 149.

24 Vgl. ALTMANN, Blindenwesen, 146-162, hier 149.

25 Vgl. ALTMANN, Blindenwesen, 146-162, hier 149.

26 Vgl. Bundesarchiv Berlin-Lichterfelde, Reichsverkehrsministerium, R 5/3048, Auszug 194. Sitzung der ständigen Tarifkommission der Deutschen Eisenbahnverwaltung in München vom 6., 7., 8.12.1938, 141.

27 Vgl. u. a. RICHTER, Blindheit und Eugenik, 147-151; Ludwig BECKENBAUER, Sterilisation in Bayern, In: Blinde unterm Hakenkreuz. Erkennen, Trauern, Begegnen, Seminar im November 1989 in Berlin-Wannsee und Materialien zum Thema (zusammengestellt von Martin Jaedicke, Wolfgang Schmidt-Block) (=Marburger Schriftenreihe zur Rehabilitation Blinder und Sehbehinderter 8) (Marburg 1991) 50-58; Henry FRIEDLANDER, Holocaust Studies and the Deaf Community, in: Donna F. RYAN, John S. SCHUMACHER (Hg.), Deaf People in Hitler's Europe (Washington 2002) 15-31.

28 Vgl. u. a. Stefan LECHNER, „Deshalb bitte ich, [...] mir dieses Unglück nicht anzutun.“ NSZwangssterilisationen, in: Rolf STEININGER, Sabine PITSCHEIDER (Hg.), Tirol und Vorarlberg in der NS-Zeit (=Innsbrucker Forschungen zur Zeitgeschichte 19) (Innsbruck, Wien 2002) 231-250, hier 234. 
„Andererseits will das Gesetz unter Blindheit nicht nur völlige, sondern auch praktische Blindheit verstanden wissen und überhaupt jede Herabsetzung des Sehvermögens, die so beträchtlich ist, daß sie die Leistungsfähigkeit des Erbkranken wesentlich vermindert." ${ }^{29}$

Die Zwangssterilisation von Menschen, die bei einer erblich bedingten Augenerkrankung noch über einen Sehrest verfügten, war laut Arthur Gütt, Ernst Rüdin und Falk Ruttke sogar besonders dringend. Ihrer Auffassung nach war bei sehbehinderten im Gegensatz zu blinden Menschen die Gefahr der „Weiterverschleppung der Krankheit" besonders groß, weil sie auf Grund ihres Sehrestes „noch Ehepartner finden, während die Gefahr bei vollständig Blinden nicht so groß" sei. ${ }^{30}$ Es war ein „Hauptdogma“31 der NS-Zeit, Menschen zu sterilisieren, die als leichtere Fälle galten.32 Opfer der NSSterilisationspolitik waren in erster Linie so genannte „Fortpflanzungsfähige“ bzw. „Fortpflanzungsgefährliche“.

$\mathrm{Ob}$ bei einer diagnostizierten „erblichen Augenerkrankung“ eine Zwangssterilisation anzuordnen war oder nicht, wurde in Kommentar zum GzVeN von Gütt, Rüdin und Ruttke festgelegt. ${ }^{33}$ Weiter ausgeführt wurden diese Indikationen im fünften Band des 1938 von Arthur Gütt herausgegebenen „Handbuch der Erbkrankheiten“.34 Ausschlaggebend für die Empfehlung für oder gegen eine Zwangssterilisation war die Einschätzung, inwieweit eine ,erblich bedingte Augenerkrankung“ die „Berufsfähigkeit“ der Betroffenen einschränkte. Nach Auffassung von Gütt, Rüdin und Ruttke konnten erblich bedingte Sehbehinderungen zu einer ,schweren Berufsstörung “635 führen.

Es gab daher auch den umgekehrten Fall. Das heißt, Augenerkrankungen, die nach damaligem Wissensstand zwar als ,erblich“ galten, die aber keine Indikation für eine Zwangssterilisation oder ein Eheverbot darstellten, weil sie das Erwerbsleben der Betroffenen kaum beeinträchtigten. Als Beispiel kann hier das „Erbliche Augen₹ittern“36 (Nystagmus) genannt werden. Die Sehschärfe beim hereditären Nystagmus wurde vom 1. Assistenten der Universitätsklinik für Augenkrankheiten in Berlin, Heinrich Harms, als „recht gut" eingeschätzt. Die Berufsfähigkeit der Betroffenen sei daher nur ,in bestimmter Richtung “ 37 eingeschränkt. Dass die Bewertung einer Augenerkrankung nach ihren Auswirkungen auf die „Berufsfähigkeit“ unter Umständen sogar den Ausgang eines Verfahrens nach dem $\mathrm{GzVeN}$ beeinflussen konnte, wird durch die Arbeit von Gabriel Richter bestätigt. Unter den von Richter ausgewerteten Verfahren befindet sich beispielsweise ein Mann, bei dem „Retinitis Pigmentosa“ diagnostiziert wurde. Diese fortschreitende Erkrankung der Netzhaut kann zur Erblindung führen und galt in den

29 [Martin] BARTELS, Hygiene, in: Peter Th. MEURER (Hg.), Ratgeber für Blinde. Zugleich eine Einführung in die Blindenkunde für Fürsorge, Berufsberater und Augenärzte (Berlin 1939) 1-15, hier 12.

30 Vgl. Arthur GÜTT, Ernst RÜDIN, Falk RUTTKE, Gesetz zur Verhütung erbkranken Nachwuchses vom 14. Juli 1933 mit Auszug aus dem Gesetz gegen gefährliche Gewohnheitsverbrecher und über Maßregeln der Sicherung und Besserung vom 24. Nov. 1933 (München 1934) 110.

31 Gisela BOCK, Zwangssterilisation im Nationalsozialismus. Studien zur Rassenpolitik und Frauenpolitik (=Schriften des Zentralinstituts für sozialwissenschaftliche Forschung der Freien Universität Berlin, Bd. 48) (Opladen 1986) 308.

32 Vgl. LECHNER, NS-Zwangssterilisationen, 231-250, hier 234, 238.

33 Vgl. GÜTT, RÜDIN, RUTTKE, Gesetz zur Verhütung erbkranken Nachwuchses, 107-114.

34 Vgl. Arthur GÜTT (Hg.), Erbleiden des Auges (=Handbuch der Erbkrankheiten 5) (Leipzig 1938).

35 GÜTT, RÜDIN, RUTTKE, Gesetz zur Verhütung erbkranken Nachwuchses, 112.

36 Heinrich HARMS, Erbliches Augenzittern, in: GÜTT, Erbleiden des Auges, 287-297, hier 289.

37 Heinrich HARMS, Erbliches Augenzittern, in: GÜTT, Erbleiden des Auges, 287-297, hier 296. 
meisten Ausprägungen als erblich. ${ }^{38}$ Obwohl in diesem Fall eine familiäre Belastung bejaht wurde, kam es zu keiner angeordneten Zwangssterilisation, offenbar mit der Begründung, der betroffene, sehbehinderte Mann sei ,berufsfäbig ““. ${ }^{39}$

Auf Grund diese Problematik bei der Definition von Blindheit nach dem GzVeN ist es nicht möglich, auf Basis der wegen der Diagnose ,erbliche Blindheit" geführten Verfahren darauf zu schließen, wie viele blinde Menschen betroffen waren. Wie bereits erwähnt, fielen unter diese Diagnose nicht nur blinde Menschen, sondern auch sehbehinderte Personen, das heißt Menschen mit Sehrest. Es kann daher nur wiedergebgegeben werden, wie hoch der Anteil dieser Diagnose an der Gesamtzahl der Verfahren war und im Weiteren, wie viele Zwangssterilisationen auf Grund der GzVeN-Diagnose ,erbliche Blindheit“ angeordnet wurden.

Hinzu kommt, dass allgemein nicht bekannt ist, wie hoch die Anzahl von Zwangssterilisationen im „Deutschen Reich“ tatsächlich war. Hier können nur Schätzungen angegeben werden. Gisela Bock nimmt an, dass in den elf Jahren, die das GzVeN wirksam war, rund 400.000 Menschen sterilisiert wurden. ${ }^{40}$ Für Österreich schätzt 1992 Wolfgang Neugebauer 6.000 durchgeführte Zwangssterilisierungen an Frauen und Männern. ${ }^{41}$ Claudia Spring sieht diese Schätzung durch neuere Forschungsergebnisse ${ }^{42}$ bestätigt. ${ }^{43}$ Zählungen und Hochrechnungen für das gesamte „Deutsche Reich“ ergaben, dass 95 Prozent aller Zwangssterilisationen auf Grund der psychiatrischen Diagnosen „Schwachsinn“, „Schirophrenie“, „manisch-depressives Irresein“ und Epilepsie erfolgten.44 Der Anteil der Diagnose „erbliche Blindheit" an der Gesamtzahl der Verfahren war dabei vergleichsweise niedrig, was charakteristisch für die Verfahren an Erbgesundheitsgerichten im gesamten „Deutschen Reich“ war, auch wenn die Häufigkeit der einzelnen Diagnosen regional zum Teil stark variierte. ${ }^{45}$

In Wien sind nach den Erkenntnissen von Spring, wie bereits erwähnt, 14 Verfahren wegen der GzVeN-Diagnose ,erblicher Blindheit'46 durchgeführt worden. Das ergibt einen Anteil von 0,8 Prozent an der Gesamtzahl der überlieferten Verfahren. In zehn Fällen wurde eine Zwangssterilisation angeordnet.

38 Vgl. HOFFMANN, Blinde Menschen „Ostmark“, 50-52.

39 RICHTER, Blindheit und Eugenik, 148 [ Mann Nr. 6 in Tabelle Nr. 15]

40 Vgl. BOCK, Zwangssterilisation, 8.

41 Vgl. Wolfgang NEUGEBAUER, Zwangssterilisierungen und „Euthanasie“ in Österreich 1940-1945, In: Zeitgeschichte 19 (1992), 17-28, hier 19.

42 Vgl. LECHNER, NS-Zwangssterilisationen, 231-250, hier 243; Josef GOLDBERGER, NSGesundheitspolitik in Linz und Oberdonau 1938-1945. Die Umsetzung der gesundheitspolitischen Forderungen des NS-Staates durch die staatliche Sanitätsverwaltung, in: Fritz MAYRHOFER, Walter SCHUSTER (Hg.), Nationalsozialismus in Linz, Teil 1 (Linz 2001) 799-906, hier 857; NEUGEBAUER, Zwangssterilisierung und „Euthanasie“, 17-28, hier 18.

43 Vgl. Claudia Andrea SPRING, „Die Gauleiter der Ostmark fordern das Gesetz dringend.“ Zwangssterilisationen in Wien 1940-1945 (Diss. [Manuskript]) (Wien 2008), 54. [Publikation: Claudia Andrea SPRING, Zwischen Krieg und Euthanasie. Zwangssterilisationen in Wien 1940-1945 (Wien 2009).

44 Vgl. Josef GOLDBERGER, „Erb- und Rassenpflege“ in Oberdonau, In: Gerhard BAADER, Veronika HOFER, Thomas MAYER (Hg.), Eugenik in Österreich. Biopolitische Strukturen von 1900 bis 1945 (Wien 2007), 345-366, hier 355-356.

45 Jürgen SIMON, Kriminalbiologie und Zwangssterilisation. Eugenischer Rassismus 1920-1945 (Münster, New York, München (u. a.) 2001) 283.

46 Soweit das aus den vorliegenden Akten beurteilt werden kann, muss bei mindestens acht der vor dem Erbgesundheitsgericht angezeigten Personen davon ausgegangen werden, dass sie nicht blind, sondern sehbehindert waren. Vgl. HOFFMANN, Blinde Menschen „Ostmark“, 186-190. 
Einer von Wolfgang Neugebauer zitierten Quelle aus dem Steiermärkischen Landesarchiv zufolge lag der Anteil der Diagnosen ,erbliche Blindheit“ und „erbliche Taubheit" an den Zwangssterilisationen dort bei 6,5 Prozent. ${ }^{47}$ Dabei dürften mehr Verfahren zur Diagnose ,erbliche Taubheit“ geführt worden sein. Nach Spring wurden wegen angenommener ,erblicher Taubheit" am Wiener Erbgesundheitsgericht etwas mehr Verfahren geführt als wegen ,erblicher Blindheit'.48 Am Erbgesundheitsgericht Offenbach waren zwischen 1934 und 1944 von insgesamt 395 Verfahren nur vier auf Grund einer angenommenen ,erblichen Blindheit“ indiziert. Das entsprach 0,76 Prozent der Antragsdiagnosen. ${ }^{49}$ Nach einer Zusammenstellung von verschiedenen Erbgesundheitsgerichten in Deutschland ${ }^{50}$ von Christoph Braß ergab sich ein Anteil der Diagnose ,erbliche Blindheit“ an den Verfahren von 0,5 Prozent in Göttingen bis zu 3,3 Prozent in Marburg. ${ }^{51}$

Henry Friedlander gab in seinem Aufsatz über Gehörlose an, das 0,6 Prozent aller Zwangssterilisationen im Jahr 1934 auf Grund der GzVeN-Diagnose ,erbliche Blindheit* erfolgten. ${ }^{52}$ Insgesamt wurde in dieser Übersicht über die Durchführung des GzVeN aus dem Jahr 1934 von 201 Zwangssterilisationen wegen ,erblicher Blindheit“ ausgegangen. 126 Männer (0,8 Prozent) und 75 Frauen (0,5 Prozent) wurden auf Grund dieser Diagnose sterilisiert. ${ }^{53}$ Achim Thom und Horst Spaar schätzen, dass etwa 0,5 Prozent der Sterilisationen infolge der Diagnose „erbliche Blindheit“ durchgeführt wurden. ${ }^{54}$

Gabriel Richter kommt durch eine von ihm erstellte Hochrechnung zu der näherungsweisen Angabe, dass in Deutschland ohne dem Saargebiet zwischen 2.400 und 2.800 Menschen wegen der Diagnose ,erbliche Blindheit" sterilisiert worden seien. 55 Bei einer angenommenen Gesamtzahl von 400.000 Zwangssterilisierungen im „Deutschen Reich“ ergibt sich dadurch ein Anteil von 0,6 bis 0,7 Prozent.

In Hinblick auf die fragmentarische Quellenlage müssen alle diese Angaben als reine Näherungswerte angesehen werden. Es kann aber daraus geschlossen werden, dass maximal ein Prozent der angeordneten Zwangsterilisationen auf Grund der Diagnose „,erbliche Blindheit“ erfolgt sind. Bei einer geschätzten Anzahl von 6.000 Zwangssterilisationen in Österreich würde das bedeuten, dass höchstens bei 60 Personen, die nach dem GzVeN als ,erblich blind“" galten, der Beschluss zur Zwangssterilisation gefällt wurde.

47 Vgl. Landesregierung, 200 II E 6/1944, zitiert in: NEUGEBAUER, Zwangssterilisierung und „Euthanasie“, 17-28, hier 18.

48 Vgl. SPRING, Zwangssterilisationen in Wien, S. 235.

49 Vgl. HENNIG, Zwangssterilisation in Offenbach am Main 1934-1944, (=Mabuse-Verlag Wissenschaft, 43) (Frankfurt a. M. 2000) 111.

50 Diese gab es bis 1938 in Saar, Frankfurt, Hamburg, Köln, Marburg und Göttingen.

51 Vgl. Christoph BRASS, Zwangssterilisationen und „Euthanasie“ im Saarland 1935-1945 (Paderborn, München, Wien (u. a.) 2004) 91. [Der Wert für Marburg an der Lahn muss dabei als Ausnahme bewertet werden, weil dort die größte Blindenanstalt im „Deutschen Reich“ angesiedelt war und dementsprechend viele SchülerInnen dieser Einrichtungen dem dortigen Erbgesundheitsgericht gemeldet worden sein dürften.]

52 Vgl. BA Koblenz (BAK), R 18/5585, Übersicht über die Durchführung des Gesetztes zur Verhütung erbkranken Nachwuchses, zitiert in: FRIEDLANDER, Holocaust Studies and the Deaf Community, 15-31, hier 22.

53 Vgl. Henry FRIEDLANDER, The Origins of Nazi Genocide. From euthanasia to the final solution, .Chapel Hill (London [1996]) 29.

54 Vgl. Achim THOM, Horst SPAAR, Medizin im Faschismus (Berlin 1983) 180.

55 Vgl. RICHTER, Blindheit und Eugenik, 153-154 


\section{Ausmaß der Kriegserblindungen}

Auf Grund der lückenhaften Überlieferung zum Sanitätswesen der Wehrmacht und dem Fehlen eines Kriegssanitätsberichtes ${ }^{56}$ können auch keine exakten Werte über das Ausmaß von Kriegserblindungen für den Zweiten Weltkrieg eruiert werden. Fest steht allerdings, dass der Anteil der Augenverletzungen auf Grund von Kampfhandlungen in den Kriegen des 20. Jahrhundert im Vergleich zum Jahrhundert davor stark angestiegen ist. Vor allem die Weiterentwicklung der Waffentechnik und der Einsatz von Granaten waren dafür verantwortlich. ${ }^{57}$ Die Steigerung der Splitterwirkung von Bomben und Granaten sowie die „vermehrte Feuerdichte der modernen Kriegswaffen"58 führte zu einer Zunahme von Augenverletzungen. ${ }^{59}$

Daten über das Ausmaß von Augenverletzungen im Zweiten Weltkrieg sind allerdings von einem Nebenschauplatz, dem griechisch-italienischen Krieg von 1940 bis 1941 erhalten. ${ }^{60}$ Der Oberarzt der Universitäts-Augenklinik Athen, J. Fronimopoulos, gibt in einem 1943 publizierten Aufsatz an, dass der Anteil der Augenverletzungen an der Gesamtzahl der Kriegsverletzungen in dieser kriegerischen Auseinandersetzung auf griechischer Seite 9,9 Prozent betrug. Dabei handelte es sich nach seinen Angaben allerdings nur um einen groben Annäherungswert, da nicht alle zur Bestimmung dieses Wertes notwendigen Unterlagen vorgelegen hätten. ${ }^{61}$ Wie viele dieser verwundeten Soldaten dauerhaft erblindeten, ist nicht bekannt. Da nicht jede Augenverletzung zu einer völligen oder teilweisen Erblindung führte, geben solche Zahlen nur bedingt Auskunft über die Anzahl von Kriegserblindungen.

Die Anzahl von Augenverletzungen an der Gesamtzahl von Verwundungen ist immer auch abhängig von den spezifischen Gegebenheiten der Kriegsschauplätze und der Kampfführung. In einem Stellungskrieg, bei dem sich die Soldaten in Schützengräben gegenüberstehen, z. B. an der West- und Isonzofront im Ersten Weltkrieg, ist die Gefahr im oberen Körperbereich, im Gesicht oder an den Augen verletzt zu werden, sehr hoch. Auch die Bodenbeschaffenheit spielt eine Rolle. Kämpfe auf staubigen, steinigen und sandigen Böden führen meist zu einer hohen Anzahl von Augenverletzungen. ${ }^{62}$

56 Vgl. Günter ROTH, Vorwort, in: Ekkehart GUTH (Hg.), Sanitätswesen im Zweiten Weltkrieg (=Vorträge zur Militärgeschichte, 11) (Herford, Bonn 1990) 7-8.

57 Vgl. Tien Yin WONG, Benjamin SEE, Chong-Lye ANG, Eye Injuries in Twentieth Century Warfare. A historical perspective, In: Survey of Ophthalmology 6/41 (1997), 433-459, hier 435; W[ilhelm] UHTHOFF, Weitere persönliche Erfahrungen und Betrachtungen zur Kriegsblindenfürsorge (Stuttgart 1917) 3; Barbara HOFFMANN, Kriegsblinde im Ersten Weltkrieg 1914-1934 (=Veröffentlichungen des Ludwig Boltzmann-Instituts für Kriegsfolgen-Forschung 9) (Graz, Wien, Klagenfurt 2006) 31; J. FRONIMOPOULOS, Augenärztliche Erfahrungen aus dem griechisch-italienischem Krieg 1940-1941, In: Klinisches Monatsblatt Augenheillkunde 109 (1943), 542-550, hier 549.

58 FRONIMOPOULOS, Augenärztliche Erfahrungen, 542-550, hier 549.

59 Vgl. Jens Martin ROHRBACH, Augenheilkunde im Nationalsozialismus (Stuttgart 2007) 173. [Die Arbeit von Rohrbach ist für die Beantwortung medizinisch-historischer Fragen durchaus relevant, die Quellenangaben zu seinen Schilderungen insbesondere zum GzVeN sind allerdings mangelhaft.]

60 Vgl. FRONIMOPOULOS, Augenärztliche Erfahrungen, 542-550, 549; ROHRBACH, Augenheilkunde im Nationalsozialismus, 173.

61 Vgl. ROHRBACH, Augenheilkunde im Nationalsozialismus, 173.

62 Bei der Operation „Desert Strom“ der USA im Irak und Kuwait 1991 hatten die Augenverletzungen einen Anteil von 13 Prozent an allen Verwundungen. Zurückgeführt wird dies auf die Kampfbedingungen in der Wüste. Vgl. WONG, SEE, ANG, Eye Injuries, 433-459, hier 435-436. 
Nach dem Ersten Weltkrieg mussten in Österreich so viele Kriegsblinde versorgt werden wie noch nie zuvor. ${ }^{63}$ Am 1. Dezember 1938 lebten nach einer Angabe des „Ministeriums für Wirtschaft und Arbeit" in Österreich noch 336 ehemalige Soldaten, die zusätzlich zu ihrer Invalidenrente den Blindenzuschuss erhielten. ${ }^{64}$ Die NSBehörden gingen daher 1939 von rund 300 Kriegsblinden aus, für die nach dem „Anschluss“ die nationalsozialistische Kriegsopferversorgung zuständig war. ${ }^{65}$ In Deutschland lebten zu diesem Zeitpunkt noch rund 3.000 Kriegsblinde des Ersten Weltkriegs. ${ }^{66}$ Am 1. September 1939 griff NS-Deutschland Polen an, der Zweite Weltkrieg begann. Er sollte 512 Tage länger dauern als der Erste Weltkrieg. Nach Angaben von Otto Jähnl erblindete schon kurz nach Kriegsbeginn, am 15. September 1939, Othmar Topil als erster Österreicher im Zweiten Weltkrieg. Der 1917 geborene Wiener verlor als Soldat der Wehrmacht im Angriffskrieg gegen Polen sein Augenlicht. ${ }^{67}$ Noch vor dem Ausbruch des Zweiten Weltkrieges erlitt allerdings ein Tiroler so schwere Augenverletzungen, dass er spätestens ab 1941 versorgungsrechtlich als Schwerkriegsgeschädigter anerkannt wurde. ${ }^{68}$ Das SA-Mitglied Erhard W. hatte sich bei Böllerschüssen zur Verkündung der Ergebnisse der Volksabstimmung im Kreis Reutte im April 1938 derart verletzt, dass er erblindete. ${ }^{69}$ Das SA-Mitglied hatte sich schon in der so genannten „Verbotszeit" für die NSDAP betätigt und galt zwischen 1938 und 1945 als ,alter Kämpfer für den Nationalsozialismus“. Im Zuge der terroristischen Aktivitäten der ,illegalen NSDAP“ zwischen 1933 und 1938 hatten einige Parteimitglieder und Angehörige von der NSDAP angeschlossenen paramilitärischen Formationen dauerhafte körperliche Beeinträchtigungen erlitten. Sie sollten die gleichen Vergünstigungen wie Kriegsopfer erhalten. ${ }^{70}$ Ab 1938 war für ihre Versorgung dementsprechend die NSKOV zuständig. ${ }^{71}$ Die gesetzliche Grundlage für ihre Versorgungsansprüche bildete das „Gesetz über die Versorgung der Kämpfer für die nationale Erhebung“, das am 1. Oktober 1938 in der „Ostmark“ in Kraft trat und die Versorgung von Mitgliedern der NSDAP und der ihr angeschlossenen

$63 \mathrm{Zu}$ den Kriegserblindungen und deren Versorgung vor dem Ersten Weltkrieg vgl. Hoffmann, Kriegsblinde, 25-28.

64 Vgl. ÖStA, AdR, Bürckel-Materie, Kt. 56, eingelegt in: Zl. 1944, GZ. 551.087/Abt.1/1938, Versorgung der Kriegsopfer, Ministerium für Wirtschaft und Arbeit an den Reichskommissar für die Wiedervereinigung Österreichs vom 19.7.1938, Betreff: Versorgung der österreichischen Kriegsopfer.

65 Vgl. ÖStA, AdR, Bürckel-Materie, Kt. 197, Zl. 4351/18, GZ VW II 8/39 9164, RM d. I. an den Reichskommissar für die Wiedervereinigung vom 26.4.1939, Betreff: Antrag der Deutschen Kriegsblindenstiftung auf Ausdehnung der Genehmigung zur schriftlichen Geldspendensammlung auf das Land Österreich.

66 Vgl. BAB, Reichsverkehrsministerium, R 5/3048, Auszug 194. Sitzung der ständigen Tarifkommission der Deutschen Eisenbahnverwaltung in München vom 6., 7., 8.12.1938, 141.

67 Vgl. Otto JÄHNL, Die österreichischen Kriegsblinden der beiden Weltkriege (Wien, Köln, Weimar 1994) 114.

68 Vgl. ÖStA, AdR, Gruppe Landesverteidigung, HVA, Ostmark-Kriegsblinde, Kt. 4, Akten betreffend Soziale Fürsorge Erhard W.

69 Vgl. Kapitel III.1.2.4; ÖStA, AdR, Gruppe Landesverteidigung, HVA, Ostmark-Kriegsblinde, Kt. 4, Akten betreffend Soziale Fürsorge Erhard W.

70 Vgl. ÖStA, AdR, Bürckel-Materie, Zl. 2150, 2. Teil a Tabakregie, NSKOV Gauamtsleiter an Joseph Bürckel vom 2.12.1939, Betreff: Tabakgeschäfts-Lizenzen für Witwen nach „Gehenkten“.

71 In Deutschland war die NSKOV auch für die Versorgung der NSDAP-Mitglieder aus der Zeit vor der Machtübertragung an Hitler zuständig. Außerdem wurde für diese am 27. Februar 1934 das „Gesetz über die Versorgung der Kämpfer für die nationale Erhebung“ erlassen. Vgl. James M. DIEHL, Victors or Victims? Disabled Veterans in the Third Reich, In: The Journal of Modern History 4/59 (1987) 705-736, hier 716. 
paramilitärischen Formationen regelte, die sich vor dem 11. April 1938 für die NSBewegung betätigte hatten und sich dabei irreversible Verwundungen zugezogen hatten. Dementsprechend führten die versorgungsrechtlichen Bestimmungen zwischen 1938 und 1945 dazu, dass Erblindungen, die mit einem Kriegseinsatz nicht in Verbindung standen, trotzdem als Kriegserblindungen eingestuft wurden. Deren Anzahl dürfte allerdings sehr gering gewesen sein. Genaue Angaben dazu ließen sich nicht eruieren. Außer Erhard W. ließ sich aus den eingesehenen Quellen im ÖStA kein weiterer Fall eruieren.

Auch darüber, wie viele Menschen im eigentlichen Sinn, das heißt durch die unmittelbaren Auswirkungen der Kampfhandlungen, insgesamt bis zum Ende des Zweiten Weltkrieges erblindeten, liegen nur Schätzungen vor. Otto Jähnl ging von rund 1.000 neu erblindeten Menschen aus, die nach Kriegsende in Österreich lebten. Dazu kamen noch rund 200 Überlebende aus dem Ersten Weltkrieg. ${ }^{72}$ Nach einer in der von der „Zentralorganisation der Kriegsopferverbände Österreichs“ herausgegebenen Zeitschrift „Österreichs Kriegsopfer“ veröffentlichten Kriegsblindenstatistik bezogen mit Stichtag 1. Juli 1949 aber nur 736 der insgesamt 168.974 Kriegsinvaliden eine Blindenzulage. ${ }^{73}$ Der Kriegsblindenverband gab 1979 eine Zahl von 900 im Zweiten Weltkrieg erblindeten Personen an. ${ }^{74}$ Auf Grund dieser Angaben muss von rund 800 bis $1.000 \mathrm{im}$ Zweiten Weltkrieg erblindeten Personen ausgegangen werden.

Im Gegensatz zum Ersten Weltkrieg erblindeten im Zweiten Weltkrieg nicht nur Militärangehörige, sondern auch Zivilpersonen, darunter Kinder und Frauen, vor allem durch den sogenannten „Luftkrieg“. Das jüngste Mitglied des 1946 neu gegründeten österreichischen Kriegsblindenverbandes war dementsprechend erst drei Jahre alt. Das Kleinkind erlitt schwerste Verletzungen, als eine Bombe das Haus der Familie traf. ${ }^{75}$ Bedauerlicherweise ist der Anteil von ZivilistInnen an der Gesamtzahl der Kriegsblinden auf Grund der mangelhaften Quellenlage derzeit nicht eruierbar.

Im OOStA sind lediglich die Akten von 252 Kriegsblinden erhalten, ${ }^{76}$ die zwischen 1938 und 1945 in die Zuständigkeit des Hauptversorgungsamtes (HVA) „Ostmark“ fielen. 158 davon erblindeten im Zweiten Weltkrieg, 91 waren Kriegsblinde des Ersten Weltkrieges und bei drei Betroffenen sind die Akten so unvollständig, dass keine Zuordnung möglich war. Verwertbare statistische Angaben können aus diesem Datenmaterial kaum erhoben werden. Unter anderem auch deshalb, weil nicht feststellbar ist, nach welchem System diese Akten in den insgesamt fünf Kartons überliefert sind. So fällt auf, dass sich unter dem auswertbaren Quellenmaterial nur eine erblindete Zivilperson befindet, die zudem als Sonderfall gewertet werden muss, ${ }^{77}$ alle anderen stammten von erblindeten Soldaten. Es ist daher anzunehmen, dass im

72 Vgl. JÄHNL, Kriegsblinde, 187-188.

73 Vgl. N. N., Kriegsopferstatistik, In: Österreichs Kriegsopfer 2/3/5 (1949), 10.

74 Vgl. Alois POISEL, Festansprache, In: Verband der Kriegsblinden Österreichs (Hg.), 60 Jahre Verband der Kriegsblinden Österreichs, (=Sondernummer Nachrichten des Verbandes der Kriegsblinden Österreichs) (o. O. [1979]) 19-23, hier 21.

75 Vgl. JÄHNL, Kriegsblinden, 117-118.

76 Auch wenn alle dort registrierten Kriegsopfer als „Kriegsblinde“ tituliert wurden, waren nicht alle vollblind. Von den insgesamt 252 registrierten Personen ist bei 65 das Ausmaß der Augenverletzung nicht feststellbar. 159 müssen als vollblind oder praktisch blind gelten. Bei 27 scheint auf Grund des vorhandenen Aktenmaterials eine Sehbehinderung vorgelegen zu haben. Eine Person galt als nur „leicht" sehbehindert.

77 Dabei handelt es sich um die kriegsblinde Frau Maria T. Vgl. HOFFMANN, Blinde Menschen „Ostmark“, S. 358. 
Zweiten Weltkrieg erblindete Zivilpersonen getrennt erfasst wurden. Soweit dazu Angaben gemacht wurden, sind in diesem Bestand im ÖStA auch kaum Personen vermerkt, die in den letzten Kriegsmonaten verwundet wurden. Nur einer der dort vermerkten Soldaten erblindete nach einer Verwundung aus dem Jahr 1945. ${ }^{78}$ Dabei müsste eigentlich, folgt man den Angaben des Reichswirtschaftsministeriums, gerade zu dieser Zeit die Zahl der Kriegserblindungen besonders hoch gewesen sein. Denn in den letzten zwei Kriegsjahren 1944/45, als sich die Wehrmacht auf dem Rückzug befand, war die Anzahl der Toten und Verwundeten größer als in den vorangegangenen Kriegsjahren zusammen. ${ }^{79}$ Im Reichswirtschaftsministerium ging man daher im November 1944 davon aus, dass monatlich im ganzen „Deutschen Reich“ etwa 150 Soldaten erblindeten. ${ }^{80}$

\section{Probleme bei der Quantifizierung und namentlichen Erfassung blinder Menschen jüdischer Herkunft}

Wie hoch die Anzahl blinder Menschen jüdischer Herkunft in der „Ostmark“ 1938 war, ist ebenfalls nicht bekannt. 1910 wurden 223 blinde Jüdinnen und Juden in Wien sowie fünf in den „Karstländern“ gezählt. ${ }^{81}$ Aus dem Protokoll der Sitzung des „Kuratoriums der Jüd. Blindenanstalt, Taubstummen- u. Krüppelbilfe Hohe Warte“, das am 8. September 1940 zusammenkam, um die endgültige Auflösung dieser Einrichtung zu beschließen, gaben die Vertreter der „Selbsthilfegruppe jüdischer Blinder" Jakob Wald und Leo Demm an, dass diese Organisation die Interessen „von mehr als 150 Personen, die durch ibre Blindheit im besondere Masse [sic!] hilfsbedürftig sind" ganisation dieser Selbsthilfevereinigung, der „Hilfsverein der jüdischen Blinden“, zählte am 30. Juni 1938 insgesamt 187 Mitglieder. ${ }^{83}$ Auf Grund der Tatsache, dass die antijüdische NS-Politik zu einer völligen Verarmung blinder Menschen führte, dürften blinde Menschen jüdischer Herkunft in der „Ostmark“ von diesen Sozialorganisationen nahezu vollständig erfasst worden sein. Hinzu kam, dass nur wenige blinde Menschen auf Grund ihrer eingeschränkten körperlichen Möglichkeiten Chancen zur Flucht ins Ausland hatten. Dementsprechend kann davon ausgegangen werden, dass 1938 rund 200 blinde Menschen jüdischer Herkunft in der „Ostmark“ lebten.

Auf Grund des eingesehenen Quellenmaterials und diverser Listen, auf denen blinde und sehbehinderte Menschen erfasst wurden, konnte im Rahmen dieser Forschungsarbeit eine Liste von 260 Menschen, die nach den „Nürnberger Rassengesetzen“ als Jüdinnen und Juden galten und der Quellenangaben entsprechend vermutlich eine Sehbehinderung hatten, erstellt werden. ${ }^{84}$ Eine Abgrenzung zwischen blinden und

78 Vgl. ÖStA, AdR, Gruppe Landesverteidigung, HVA, Ostmark-Kriegsblinde, Kt. 2, Akten betreffend Soziale Fürsorge von S. [Vorname nicht registriert, Akt unvollständig].

79 Vgl. Ekkehart GUTH, Der Sanitätsdienst der Wehrmacht im Zweiten Weltkrieg. Ein Überblick, in: Ders. (Hg.), Sanitätswesen im Zweiten Weltkrieg (=Vorträge zur Militärgeschichte 11) (Herford, Bonn 1990) 11-24, hier 20.

80 Vgl. BAB, Reichswirtschaftsministerium, Abteilung 2, R 3101/11890, RTK III A 9 d, Reichsbeauftragte für Tabak und Kaffee an die Gruppenarbeitsgemeinschaft Tabak und Tabakwaren in der Reichsgruppe Handel vom 2.11.1944, Betreff: Sonderversorgung der Kriegsblinden mit Tabak.

81 Vgl. GEHRMANN, Blinden und Taubstummen, 1-104, hier 52.

82 WStLA, M. Abt. 119, A 32, Zl. 2308/22, Protokoll über die Sitzung des Kuratoriums der Jüd. Blindenanstalt, Taubstummen- u. Krüppelhilfe Hohe Warte vom 8.9.1940.

83 Vgl. ÖStA, AdR, Stiko Wien, AC 31, Kt. 564, Mappe L 14, Obmann Leo Demm, Bericht über die Tätigkeit und sozialen Einrichtungen vom 30.6.1938.

84 Vgl. HOFFMANN, Blinde Menschen „Ostmark“, 567-572. 
sehbehinderten Personen war auf Grund des vorliegenden Quellenmaterials allerdings nicht möglich. Diese Liste kann allerdings keinen Anspruch auf Vollständigkeit erheben. In vielen Fällen konnten beispielsweise keine Geburtsdaten oder weitere biographische Daten ermittelt werden. Diese Liste umfasst zwölf Namen von Kriegsblinden jüdischer Herkunft, deren Anzahl dürfte allerdings etwas höher gewesen sein. In einem Schreiben aus dem Jahr 1938 ist die Rede von zwölf Kriegsblinden jüdischer Herkunft, die Besitzer einer Trafik waren und die zwangsenteignet wurden. ${ }^{85}$ Es kann angenommen werden, dass es darüber hinaus noch einige wenige Kriegsblinde jüdischer Herkunft gab, die allerdings nicht Besitzer eines solchen Tabakwarengeschäftes waren.

\section{Quellenstand/Probleme bei der Bearbeitung}

Die Recherchen für diese Studie basieren auf einem umfangreichen Quellenkorpus, der in Österreich, Deutschland und Israel eingesehen wurde. Der Wert dieser Arbeit liegt darin, dass neue Bestände erschlossen und bereits bekanntes Archivmaterial unter neuen Gesichtspunkten interpretiert werden konnte. Bei der Erstellung meiner Studie konnten quellenspezifische Probleme und Forschungsdesiderate aufgedeckt werden. Darüber hinaus ist die Quellenlage fragmentarisch. Viele Dokumente gingen unter nicht näher bekannten Umständen verloren, etwa die Vereinsakten der NSBlindenorganisationen, wie dem RBV, dem DBV und der NSKOV „Fachabteilung erblindeter Krieger“. Im Zuge der Quellenarbeit konnten vor allem Dokumente die Umsetzung fürsorgerechtlicher Vorschriften und Beschlüsse betreffend, erstellt von NS-Behörden, NS-Organisationen, AutorInnen die der NS-Ideologie zuzuordnen waren oder beispielsweise der von den NS-Machthabern gelenkten IKG, konsultiert werden. Diese Archivalien sowie gedruckten Dokumente zeigen die Lebensumstände blinder Menschen also aus der Perspektive der Akteure und nicht die Sichtweise der Betroffenen. Die eingesehenen Akten und gedruckten Dokumente geben daher keine Auskunft darüber, wie blinde Menschen selbst ihr Leben unter dem NS-Regime beurteilten und bestritten. Soweit vorhanden, wurden daher publizierte Aussagen blinder ZeitzeugInnen herangezogen, auf die im folgenden Kapitel eingegangen wird. Außerdem wurde mit Hilfe der Oral-History-Methode ein Interview mit dem Kriegsblinden Bernhard Lindmayr am 15. September 2006 in seinem Haus in Kapfenberg und für die Publikation mit der Zivilblinden Emma Leichter, am 7. Juni 2010, die 1940 aus Sterzing an die Blindenschule in Innsbruck kam, geführt. Auf Grund des hohen finanziellen sowie zeitlichen Aufwandes für eine Oral-History-Studie mit blinden Menschen aus ganz Österreich, musste von weiteren ZeitzeugInnenbefragungen abgesehen werden.

\section{Autoreninformation}

Mag. Dr. Barbara Hoffmann, Historikerin und Akademische Medienfachfrau. Postadresse: Schusterbergweg 34/9, 6020 Innsbruck, Österreich. Mail: info@kriegsblinde.at

85 Vgl. ÖStA, AdR, Bürckel-Materie, Kt. 86, Zl. 2150/1, Mitglied der S. d. P. Ortsgruppe Troppau an Herrn Doktor vom 3.5.1938, Betreff: Gesuch und Verzeichnis von 12. Kriegsblinden und 2 Hilfslosen nichtarischen Trafikanten. 



\section{Im Zerrspiegel von Eugenik, Emanzipation und Sexualwissenschaft: Helene Stourzh-Anderle (1890-1966)}

\section{English Title}

Eugenics, emancipation and sexology: Helene Stourzh-Anderle (1890-1966)

\section{Summary}

In Austrian history sexology is primarily associated with Sigmund Freud and his companions. Apart from Freud and some other university professors, a few doctors were dealing with sexology like e. g. Helene Stourzh-Anderle (1890-1966). She started courses in sexual education in the 1920s, dealt with the female orgasm and hormone therapies from the 1930s to the 1960s and criticized common legislative proposals concerning eugenics. She based her studies primarily on biological analysis. Furthermore, her theories were far away from modern feminist approaches.

\section{Keywords}

Helene Stourzh-Anderle, sexology in Austria, sexual education, female orgasm, hormone therapies

Wenn von Sexualforschung in Österreich die Rede ist, scheint es jenseits von Sigmund Freud und seinen abgesprungenen Adepten wie Stekel oder Adler niemanden zu geben. Später dann eventuell noch der Querkopf Ernest Bornemann. Kritische Sozialmedizin? Da wird Julius Tandler genannt, vielleicht einer seiner Schüler. Und von der konservativen Seite winken die Geister von Albert Niedermeyer und Johann Ude. Niemals eine Frau und auch Niemand, der außerhalb des universitären oder zumindest akademischen Establishments stand. Beides ist bei Stourzh-Anderle gegeben, vielleicht zwei Gründe mehr, weshalb sie in Vergessenheit geriet.

Helene Anderle wurde am 17. Juni 1890 in Klosterneuburg geboren, ihr Vater war Ingenieur, die Familie gehörte zum mittleren Bürgertum. Sie hatte noch eine ältere Schwester namens Anna. Beide gehörten sie zur ersten Generation von Frauen, die in Österreich studieren durften, Anna entschied sich für Philologie, Helene hingegen für die Medizin, das Studienfach schlechthin für auf Selbständigkeit bedachte junge Frauen. Es waren ja gerade Ärzte gewesen, die bis in das erste Jahrzehnt des 20. Jahrhunderts hinein, Frauen kleinere Gehirne und daher geringere Geistesgaben zurechneten, weswegen sie vom Studium, insbesondere der Medizin ausgeschlossen 
werden sollten. ${ }^{1}$ Dagegen argumentierten gerade engagierte Frauen, dass nur der weibliche Arzt das „schwache Geschlecht“ korrekt erforschen könne. Helene Anderle studierte ab 1910 in Wien Medizin. Sie muss eine sehr gute Studentin gewesen sein, denn sie bekam einen der begehrten Hiwi-Jobs am Anatomischen Institut unter Julius Tandler. Der Ausbruch des ersten Weltkrieges beschleunigte ihre Karriere. Bis zu diesem Zeitpunkt konnten Frauen auch nur „Demonstrator“, also Hiwi werden, doch die männlichen Kollegen kämpften an der Front, so konnten auch weibliche Studierende zu Assistenzärzten aufsteigen. 1915 erhielt Helene Anderle ein entsprechendes Ausbildungsangebot vom Direktor der II. Universitätsfrauenklinik, Wilhelm Weibel und nahm an. Im Frühjahr 1920 jedoch kam der eigentliche Assistenzarzt aus der Kriegsgefangenschaft zurück und Helene Anderle wurde umgehend gekündigt. Sie fand sich auf einem überfüllten ärztlichen Arbeitsmarkt wieder, umgeben von unzähligen Kollegen, die alle um die mittlerweile materiell sehr ausgeblutete Kundschaft buhlten. 1921 erhielt sie die begehrte Kassenzulassung als Frauenärztin, 1928 die Zulassung als Allgemeinpraktikerin. ${ }^{2}$ Einer Rückkehr an die Universität wäre Anderle zwar theoretisch nicht abgeneigt gewesen, doch blieben Frauen trotz der nun gewährten offiziellen Zulassung als Assistenzärzte weiterhin extrem unterrepräsentiert. Bis 1937 sollten von den 135 Universitätsstellen nur 4 mit Frauen besetzt werden. ${ }^{3}$

Neben der Arbeit als gynäkologische Fachärztin betätigte sich Anderle auch noch als Autorin liberaler Zeitschriften. Unter diesen ragte die „Soziale Bereitschaft“ heraus, Publikationsorgan der 1913 gegründeten Organisation mit Namen „Die Bereitschaft. Verein für soziale Arbeit und zur Verbreitung sozialer Kenntnisse“. Hier engagierten sich Persönlichkeiten, die dem österreichischen Liberalismus zuzurechnen waren. Der Verein war sozialreformatorisch und pazifistisch ausgerichtet. ${ }^{4}$ In der „Bereitschaft“ publizierte auch ein aufstrebender Staatsphilosoph, Herbert v. Stourzh (1889-1941). Er stammte aus einer alten protestantischen Familie und war als Lehrer an der niederösterreichischen Landeswirtschaftsschule in Krems beruflich tätig. Er publizierte Artikel sowohl zu sexualwissenschaftlichen als auch sozialpolitischen Themen. Herbert v. Stourzh und Helene Anderle heirateten im Juli 1928. Ein Jahr später wurde das einzige Kind der Ehe, Gerald, geboren und evangelisch getauft. Die Familie ließ sich in der Hauptstadt nieder, wo Herbert v. Stourzh seit 1927 als „B-Beamter“ bei der niederösterreichischen Landesregierung in Wien tätig war.

In den 1920er Jahren zog die Wiener Gesundheitsverwaltung aufgrund ihrer Sozialprogramme europaweit Bewunderer an und viele Ärztinnen hofften dort auf eine Karriere. Parallel dazu entwickelten Psychoanalytiker und Individualpsychologen darunter zahlreiche Frauen - Programme zur Aufwertung der Frau. All diesen

1 Sonja STIPSITS, „...und so gibt es nichts Widerwärtigeres, als ein die gesteckten Grenzen überschreitendes Mannweib“. In: Birgit BOLOGNESE-LEUCHTENMÜLLER, Sonia HORN (Hg.), Töchter des Hippokrates. 100 Jahre akademische Ärztinnen in Österreich (Wien 2000) 27-44, hier 33.

2 Zur Problematik der Kassenzulassung für weibliche Ärzte siehe (bezogen auf Deutschland) Beate ZIEGELER, Weibliche Ärzte und Krankenkassen. Anfänge ärztlicher Berufstätigkeit von Frauen in Berlin 1893-1935 (Weinheim 1993) 96-98, 106.

3 Ingrid ARIAS, Die ersten Ärztinnen in Wien. Ärztliche Karrieren von Frauen zwischen 1900 und 1938. In: BOLOGNESE-LEUCHTENMÜLLER, HORN (Hg.), Töchter des Hippokrates 55-78, hier 64.

4 Friedrich STADLER, Spätaufklärung und Sozialdemokratie in Wien 1918-1938. In: Franz KADRNOSKA (Hg.), Aufbruch und Untergang. Österreichische Kultur zwischen 1918 und 1938 (Wien 1981) 441-474, hier 454. 
Überlegungen war ein latenter Hang zur Sozialdemokratie oder zumindest die Ablehnung des konservativen staatstragenden Katholizismus gemeinsam. Helene Stourzh-Anderle fand weder vor noch nach ihrer Heirat Anschluss an diese wissenschaftlichen Schulen, obwohl sie und ihre Ehemann ebenfalls der katholischen Reaktion ablehnend gegenüberstanden. Herbert v. Stourzh war nach dem traumatisierenden Erlebnis des ersten Weltkrieges Pazifist geworden. ${ }^{5}$ Seine Ehefrau unterstützte gemäßigte weibliche Emanzipationsarbeit, schloss sich 1930 der „Österreichischen Frauenpartei“" an ${ }^{6}$ und hielt zahlreiche Vorträge in der „Urania“.

Im Jahre 1925 erschien die Zusammenfassung mehrerer kürzerer Artikel über Sexualaufklärung aus der Zeitschrift „Die Quelle“ als eigenes kleines Buch: „Die sexuelle Aufklärung“ von Helene Anderle. ${ }^{7}$ Auf 20 Seiten verfocht die Autorin das Konzept einer unverkrampften Annäherung an die menschliche Sexualität. Erst die sexuelle Aufklärung versetze die Menschen nämlich in die Lage, ihr Leben im Sinne eines „biogenetischen Grundgesetzes“ korrekt zu gestalten. ${ }^{8}$ Diese Formulierung lässt ihre persönliche Orientierung am monistischen Weltbild von Ernst Haeckel erahnen. Auf der Basis dieses „Grundgesetzes“ unterschieden sich Männer und Frauen Europas auch von den „primitiven Völkern“ in Afrika und Ozeanien, die dieses Wissen nie selbst erlangen könnten, sondern dem Aberglauben anhingen. ${ }^{9}$ Besonderen Wert billigte Anderle den Studien von Sigmund Freud zu, der bewiesen habe, dass Kinder und Jugendliche keineswegs ,geschlechtslose“ Wesen seien. Naive Vorstellungen hätten zu lange dominiert, so der Glaube Rousseaus, dass es genüge, die Kinder von allen Reizen fern zu halten. ${ }^{10}$ Denn dadurch sei es langfristig zu einer verheerenden Entsexualisierung gekommen.

„Infolge des Bannes, mit dem alles Sexuelle seit Jabrhunderten belegt worden ist, haben es viele Erwachsene so weit gebracht, hinter dem natürlichen Streben des Kindes, das Schöpfungswunder zu enträtseln, etwas Schmutziges, sittlich Minderwertiges zu sehen, die Schnüffelei und Sensationslüsternheit der Großen wird den aus reinster Quelle stammenden kindlichen Fragen untergeschoben, die Großen schämen sich oft für die Fragen der Kleinen und weisen sie als Dummbeit aus oder falschem Schamgefühl ab. "11

Die Sexualaufklärung müsse darauf abzielen, die Kinder zu selbständig denkenden Menschen zu erziehen und von Fehltritten abzuhalten. ${ }^{12}$ Es gelte die „Reinheit des Charakters“ der Kinder zu nutzen, um sie altersgemäß und moralischen Grundsätzen folgend aufzuklären. Ziel müsse die Bereitmachung der jungen Menschen auf ihre große Aufgabe, die Bewältigung der Ehe sein. ${ }^{13}$ Die Autorin fügte dem Büchlein auch noch eine längere Literaturliste bei, in der Namen wie Friedjung, Förster, Freud, Forel, Ehrenfels, Rohleder oder Leute zu finden waren.

5 Herbert STOURZH, Volksgenosse oder Mitmensch ? In: Die Bereitschaft 5 (1924), Nr. 10, 7-8.

6 Zu dieser politischen Gruppierung siehe Jutta PINT, Die österreichische Frauenpartei 1929-1934. Ein Versuch bürgerlich-liberaler Frauen gesellschaftspolitischen Einfluss zu nehmen, Dipl. phil. Wien 1988.

7 Helene ANDERLE, Die sexuelle Aufklärung (=Bücherei der „Quelle“ Heft 26, Wien 1925).

8 Ebenda 1.

9 Ebenda 1-2.

10 Ebenda 8.

11 Ebenda 9.

12 Ebenda 13.

13 Ebenda 19. 
Dieser schmale Band beinhaltete ein enormes Sprengpotential. Helene Anderle hatte zwar korrekterweise Rousseau als Rückschritt angeführt. Schließlich hatte dieser nicht nur Frauen per se für minderwertig erklärt, sondern auch die absolut keusche Erziehung der Kinder verlangt. Aber indirekt implizierte die alleinige Konzentration auf Rousseau die Unterstellung, dass auch all jene, die ähnliche Ansätze vertraten, mit Rousseau vergleichbar waren und seine Ideen teilten - in Österreich beispielsweise die katholische Kirche, die so diskret in die Zeit vor der Französischen Revolution positioniert wurde. Dass die Autorin hinsichtlich ihrer Autorenauswahl in keiner Weise zufällig agierte, legt die Berufung auf Joseph Leute nahe. Leute war ein katholischer Ordensrenegat gewesen, der in einem aufsehenerregenden Werk mit der Sexualpädagogik der Kirche abgerechnet hatte. ${ }^{14}$ Des Weiteren hatte Anderle es gewagt, sämtliche damals in der sexualpädagogischen Diskussion aktiven Wiener Mediziner schlichtweg zu unterschlagen, alle Individualpsychologen beispielsweise. Sigmund Freud wurde lediglich mit einem Frühwerk angeführt. Stattdessen stützte sich die Autorin auf August Forel, Friedrich W. Förster, Christian v. Ehrenfels und Hermann Rohleder, die allesamt der älteren Generation von Sexualforschern zuzurechnen waren, die bereits vor 1914 mit eigenen Ansätzen hervorgetreten waren. Zugleich hatte die Autorin aber die Ausführungen neuerer, dem sich formierenden Nationalsozialismus oder dem Sozialismus positiv gegenüber stehenden Forschern nicht in ihre Abhandlung, die zuvor immerhin als Artikelserie in einer der meist gelesenen Magazine des Landes erschienen war, integriert. Auch hatte sie jeden Hinweis auf den in der medizinischen Philosophie weiterhin hoch geschätzten Otto Weininger unterlassen. Schließlich hatte sie sich ganz bewusst in ihrer Argumentation von Vergleichen mit Naturvölkern abgegrenzt; deren Verhältnisse seien nicht mit denen in Österreich vergleichbar. Damit folgte sie zwar den Überlegungen der neueren Anthropologie, entfernte sich aber weit von der Vorgehensweise der älteren weiblichen Emanzipationsbewegung, deren Vertreterinnen eben durch Hinweise auf die Lebensweise in anderen Erdteilen die Situation der Frauen in der Heimat zu bessern gesucht hatten. ${ }^{15}$

Helene Anderle setzte sich also wissentlich von mehreren Überlegungen der damals nicht nur in Wien - dominierenden Lehrmeinungen ab. Sie enthielt sich so bereits in ihrer ersten größeren sexualwissenschaftlichen Publikation jeder parteipolitischen Zuordnung. Dass die Sexualwissenschaft kein einmaliger Ausflug war, stellte sie durch die Teilnahme am IV. Internationalen Kongress für Sexualreform im September 1930 in Wien unter Beweis. ${ }^{16}$

Die 1930er Jahre waren für die Österreichische Wissenschaftsgesellschaft ein Jahrzehnt permanenter Veränderungen. Je nach politischer Großwetterlage wurden Lehrstühle neu besetzt, wechselten dominierende Lehrmeinungen einander ab. Helene StourzhAnderle zog sich nach der Machtergreifung Engelbert Dollfuß‘ 1933/34 aus der Arbeit in der Öffentlichkeit zurück, kümmerte sich verstärkt um ihren jungen Sohn. Ihr Mann hingegen schrieb in der Zeitschrift „Der christliche Ständestaat“ anti-nazistische

14 Josef LEUTE, Das Sexualproblem und die katholische Kirche (Frankfurt/M. 1908), insbesondere 198249. So bestehe die katholische Sexualpädagogik praktisch nur aus „hässlichem Geschimpfe über die moderne Gesellschaft“ (198).

15 Siehe z.B. Rosa MAYREDER, Zur Kritik der Weiblichkeit. Essays, 2. Auflage (Jena 1907) 55. Rosa MAYREDER, Geschlecht und Kultur, Essays (Jena 1923) 189.

16 Helene STOURZH-ANDERLE, Die sexuelle Aufklärung. In: Herbert STEINER (Hg.), Sexualnot und Sexualreform. Verhandlungen der Weltliga für Sexualreform. IV. Kongress abgehalten zu Wien vom 16 bis 23. September 1930 (Wien 1931) 630. 
Artikel und suchte durch eigene Publikationen einen christlichen Idealstaat staatsphilosophisch zu definieren. Helene Stourzh-Anderle nutzte die ersten Jahre des „Ständestaates“ zu Vorbereitungsarbeiten an größeren medizintheoretischen Forschungsarbeiten, 1937 begann sie mit einer langen Reihe von entsprechenden Publikationen.

Helene Stourzh-Anderle hatte mittlerweile ihre eigenen Konsequenzen aus dem Wust an medizinphilosophischen Einschätzungen und diagnostischen Interpretationen über Frauen gezogen. Sie hatte sich dafür entschieden, eine modifizierte Konstitutionslehre mit starken psychosomatischen Aspekten zu bevorzugen, wie sie in Wien von Julius Bauer vorgezeichnet worden war. ${ }^{17}$ In den Jahren nach 1920 war in enger Anlehnung an die Lehren des deutschen Psychiaters Ernst Kretschmer, der eigentlich nur mittels einer Körperbautypologie schizophrene von manisch-depressiven Männern trennen wollte, eine weibliche Konstitutionslehre entwickelt worden. ${ }^{18}$ Federführend war hier der Innsbrucker Gynäkologe Paul Mathes gewesen, dessen Ansichten in der Feststellung gipfelten, nur die Frau mit breitem Becken sei als Mutter und damit als wertvolles Wesen für die Gemeinschaft ideal. ${ }^{19}$ Hochgewachsene, schlanke Frauen mit männlichen Zielvorstellungen wie berufliche Selbständigkeit, seien hingegen „minderwertig“.

Diese Ansichten standen in direktem Gegensatz zu den sozialhygienisch motivierten Bestrebungen vieler Frauenärztinnen, die Selbständigkeit der Frau durch Freigabe der Abtreibung zu fördern. ${ }^{20}$ Auch diese Ärzte und Ärztinnen bedienten sich der Konstitutionslehre, nur eben interpretierten sie Beckenmaße und Kalorienverbrennung anders als ihre rassenhygienisch hysterisierten Antagonisten. In Wien war hier der Arzt Rudolf Allers von Bedeutung, der Sexualaufklärung und psychosomatische Beratung der Frauen in der Arztpraxis kongenial verknüpfte. ${ }^{21}$ Verkompliziert wurde die konstitutionsbiologische Diskussion noch durch die sukzessive erfolgende Entschlüsselung der Hormonwirkungen - scheinbar feststehende genetische Konstitutionen erwiesen sich als Produkt von Hormonausschüttungen.

Stourzh-Anderles Arbeit wurde auch nicht durch den Anschluss Österreichs an das Deutsche Reich behindert, ihr Mann hingegen erfuhr rasch genauere Überwachung durch die Behörden des Sicherheitsapparates. Er starb jedoch noch vor einer Verurteilung im Sommer 1941. Nach dem deutschen Einmarsch im März 1938 war die Zahl der frauenärztlichen Praxen radikal reduziert worden (Schließung der jüdisch

17 Julius BAUER, Die individuelle Konstitution als Grundlage nervöser Störungen. In: Oswald SCHWARZ (Hg.), Psychogenese und Psychotherapie körperlicher Symptome (Wien 1925) 70-85. Julius BAUER, Innere Sekretion. Ihre Physiologie, Pathologie und Klinik (Wien 1927).

18 Ernst KRETSCHMER, Körperbau und Charakter. Untersuchungen zum Konstitutionsproblem und zur Lehre von den Temperamenten (Berlin 1921).

19 Paul MATHES, Die Konstitutionstypen des Weibes, insbesondere der intersexuelle Typus. In: Josef HALBAN, Ludwig SEITZ (Hg.), Biologie und Pathologie des Weibes. Ein Handbuch der Frauenheilkunde und Geburtshilfe Bd. III (Berlin/Wien 1924) 1-112.

$20 \mathrm{Zu}$ diesem Diskurs siehe Cornelie USBORNE, Abtreibung. Mord, Therapie oder weibliches Selbstbestimmungsrecht? Der $\$ 218$ im medizinischen Diskurs der Weimarer Republik. In: Johanna GEYER-KORDESCH, Annette KUHN (Hg.), Frauenkörper - Medizin - Sexualität. Auf dem Wege zu einer neuen Sexualmoral (Düsseldorf 1986) 192-236.

Cornelie USBORNE, Ärztinnen und Geschlechtsidentität in der Weimarer Republik. In: Ulrike LINDNER, Merith NIEHUSS (Hg.), Ärztinnen-Patientinnen. Frauen im deutschen und britischen Gesundheitswesen des 20. Jahrhunderts (Köln 2002) 73-94

21 Rudolf ALLERS, Sexualpädagogik. Grundlagen und Grundlinien (Salzburg 1934) 171. 
geführten Praxen). So gab es 1940 nur noch vier, 1942 nur noch drei Frauenärztinnen in Wien. ${ }^{22}$ In der täglichen Praxisarbeit schuf sich Stourzh-Anderle durch Arbeit mit ihren zahlreichen Patientinnen ein immenses Reservoir potentieller Probanden für wissenschaftliche Studien. In der wissenschaftlichen Diskussion erlebte sie stets die unterschwellige Ablehnung durch männliche Kollegen. Einmal wurde in einer Fachzeitschrift ihr Name falsch gedruckt ${ }^{23}$ - während die korrekte Wiedergabe ausländischer Namen für die Redaktion kein Problem darzustellen schien. Ein anderes Mal wurden ihre Studien zwar vorgestellt, sie selbst aber nur als „Frauenarzt“ wahrgenommen. Dies ging so weit, dass sie real als Forscher männlichen Geschlechts vorgestellt wurde. ${ }^{24}$ In der wissenschaftlichen Diskussion jedoch wurden ihre Ansichten aus den 1920ern sukzessive bestätigt. Es waren ab 1940 gerade die vormals so sehr auf Keuschheit pochenden Universitätsgelehrten aus Berlin, München oder Prag, die eine umfassende Sexualaufklärung zur Steigerung der Geburtenrate forderten $^{25}$ - in den 1920er Jahren hatten viele von ihnen noch im so genannten „Ethik“-Bund sich vehement gegen jede Form von Sexualaufklärung ausgesprochen. ${ }^{26}$ Vor allem galten die zuvor als die starren Konstitutions- und Vorurteilsmuster gefährdenden Hormone nun als Allheilmittel, um noch der letzten sterilen Frau das Mutterdasein zu ermöglichen. ${ }^{27}$

Inmitten dieser konfusen Bemühungen zur Förderung der Geburtenziffer äußerte sich Helene Stourzh-Anderle zurückhaltend über die Verwendung der Sexualhormone und empfahl eine vorsichtigere Handhabung mit Berücksichtigung der jeweiligen Körperkonstitution der Patientin. ${ }^{28}$ Ebenfalls 1942 entwarf sie eine „biopsychologische Skizze“, worin sie den Kausalzusammenhang von Körperbau und Charakter betonte. ${ }^{29}$ Dies klang zwar sehr nach Kretschmer, aber das Pochen auf Kausalzusammenhängen hieß nichts anderes als Rassenspekulationen zu unterlassen. Zudem deutete StourzhAnderle die Ausführungen Ernst Kretschmers nicht biotypologisch, sondern psychisch und äußerte sich zur ,intersexuellen Spaltung“ der Person. Hierbei sah sie sich auf den Pfaden von Sigmund Freud und Arthur Kronfeld - nicht gerade die Kronzeugen der NS-Rassenhygiene. ${ }^{30}$ Zuletzt setzte sie sich auch noch von der angeblichen Gefahr der Rassendegeneration durch Vermischung ab und betonte stattdessen die stete Nähe von Genie und Psychopathie, die jenseits des Rasseprinzips bestehe. Indirekt bestritt sie

22 Karin WALZEL, Ärztinnen in Wien 1934-1938. In: BOLOGNESE-LEUCHTENMÜLLER, HORN (Hg.), Töchter des Hippokrates 113-116, hier 116.

23 26. Tagung der Deutschen Gesellschaft für Gynäkologie in Wien. Sitzung vom 28. bis 30. Oktober 1941. In: Zentralblatt für Gynäkologie 66 (1942) 277-279, hier 277.

24 Paul BERNHARD, Die Sterilität des Weibes. Diagnostik-Genese-Therapie-Prophylaxe. Leitfaden der Sterilitätsbehandlung (Stuttgart 1947) 133. Das Buch erschien zwar erst nach 1945, war jedoch bereits zuvor fertiggestellt worden, konnte aber aufgrund von Papiermangel und Kriegseinwirkungen nicht gedruckt werden.

25 Siehe u.a. Günter F.K. SCHULTZE, Der gegenwärtige Stand der Bekämpfung der weiblichen Unfruchtbarkeit. In: Deutsche Medizinische Wochenschrift 68 (1942) 997-1002, 1027-1032,hier 998.

26 Andreas FREWER, Medizin und Moral in Weimarer Republik und Nationalsozialismus. Die Zeitschrift „Ethik“ unter Emil Abderhalden (Frankfurt/M. 2000) 49-58.

27 Gabriele CZARNOWSKI, „Die restlose Beherrschung dieser Materie“. Beziehungen zwischen Zwangssterilisation und gynäkologischer Sterilitätsforschung. In: Zeitschrift für Sexualforschung 14 (2001) 226-246, hier 236.

28 26. Tagung der deutschen Gesellschaft 277-279.

29 Helene STOURZH-ANDERLE, Konstitution und Sexualität. In: Wiener Klinische Wochenschrift 56 (1943) 556-564,hier 556.

30 Ebenda 558f. 
damit den Sinn der Zwangssterilisation. Der Frau billigte die Autorin im Charakter Analogien zum männlichen Geschlecht zu, insgesamt stelle sie das „biologische Primat" dar, während dem Mann der ,geistige Primat" zufalle. ${ }^{31}$ Mit wenigen Sätzen war es Stourzh-Anderle gelungen die Ansichten ihrer männlichen Kollegen ad absurdum zu führen. Warum nur wurde sie auf die noch folgenden Fachtagungen der "großdeutschen Frauenheilkunde" nicht mehr eingeladen?

Ihre Kollegen bescheinigten ihr nach Kriegsende, dass sie sowohl charakterlich als auch hinsichtlich des Fachwissens einen exzellenten Ruf besitze. So begann sie bereits im Frühsommer 1945 wieder mit der Praxisarbeit. 1946 wurde sie Mitglied der Gesellschaft der Aerzte in Wien und leitete 1951/52 sogar als erste Frau die wissenschaftlichen Versammlungen. 1953 rückte sie in den Vorstand der Organisation der Ärztinnen Österreichs auf. Angesichts der Tatsache, dass sich nach dem Ende des Dritten Reiches in der Medizin relativ wenig änderte und auch forschungstechnisch keine Rückkehr zur Vielfalt der 1920er Jahre abzusehen war, entschloss sich Helene Stourzh-Anderle selbst aktiv zu werden. In einem ersten Aufsatz 1949 verwarf sie sämtliche Überlegungen der Gynäkologie und Psychologie zur Therapierung des Vaginismus, worin sie als erste österreichische Ärztin mit der Verkoppelung von Konstitution und Sexualität brach und zudem die Hormontherapie anstelle der Psychotherapie bewarb ${ }^{32}$. Dies war ein Kurswechsel im Vergleich zu ihren Einschätzungen vor 1945, der Grund dürfte einfach sein: Nun wurden Frauen nicht mehr von Ärzten gezwungen, Hormontabletten zu konsumieren, um Schwangerschaften zu erzwingen, die Frauen konnten selbst entscheiden und für Helene StourzhAnderle als Ärztin stand außer Frage, dass sie allein das Wohl ihrer Patientinnen im Auge hatte. In einem Folgeaufsatz bewertete sie die Körperbaulehre Ernst Kretschmers als unzulänglich, zudem ginge Kretschmer allein von psychisch kranken Menschen aus. ${ }^{33}$ Eine Übertragung auf die Seele geistig Gesunder komme also nicht in Frage. Doch sie war keine Feministin, wie man sich das heute vorstellen möchte und wie es manch österreichische Frauenforscherin in sie hineininterpretieren wollte. Für ein Medizinisches Hausbuch schrieb Stourzh-Anderle zur selben Zeit voller Überzeugung Sätze wie: „Beim Verkehr fällt dem Manne der tätige und daher kompliziertere Teil zu, während die Frau nur eine untätige Haltung einzunehmen hat". 34

Es folgten neben größeren und kleineren Artikeln zur sexuellen Aufklärung zwei umfangreiche Studien (1955, 1961). Die erste hieß „Sexuelle Konstitution. Psychopathie - Kriminalität - Genie“ und enthielt den Versuch einer Neubewertung der rassenhygienisch desavouierten Konstitutionslehren. ${ }^{35}$ Stourzh-Anderle zeigte sich hier als überzeugte Biologistin und Gegnerin der eigenen Disziplin. In Ihren Ausführungen zur Sexualität fehlt jeder Hinweis auf die Publikationen von

31 STOURZH-ANDERLE, Konstitution und Sexualität, 564.

32 Helene STOURZH-ANDERLE, Hormonale Therapie des Vaginismus. In: Wiener Klinische Wochenschrift 61 (1949) 502-505, hier 504.

33 Helene STOURZH-ANDERLE, Die sexuelle Konstitution. In: Soziale Berufe 4 (1952) 129-131, 146149, hier 130.

34 Helene STOURZH-ANDERLE, Die gesunde Frau in der Ehe. In: Heinrich WALLNÖFER, Heinz SCHEIBENPFLUG (Hg.), Ehe-Familie-Heim. Ein Hausbuch für Alle (Wien/München 1954) 43-70, hier 56.

35 Helene STOURZH-ANDERLE, Sexuelle Konstitution. Psychopathie - Kriminalität - Genie (=Wiener Beiträge zur Sexualforschung Bd. 1, Wien 1955). 
Frauenärzten. Ansonsten erwies sie sich als treue Leserin der Schriften von Konrad Lorenz, der Endokrinologen und Sigmund Freuds.

Überhaupt schienen in den Augen der Autorin die Gene die entscheidende Rolle zu spielen. Dieser Glaube gipfelte in der - heute lächerlich oder allenfalls ironisch wirkenden - Aussage: „Die erbliche Fixierung ist bei der Rasse ungeheuer auffallend. Zwei Weiße können kein Negerkind zeugen".36

Ansonsten unterschied sich das Werk in einem Punkt entscheidend von allen anderen Einschätzungen von Ärzten, Juristen oder Theologen: Helene Stourzh-Anderle vermied diffamierende Begriffe, wollte Sexualformen nicht in gesund und pathologisch trennen und bevorzugte die Separation in „Normo“ und „para“-Sexualitäten.

Die Rezensionen ließen nicht lange auf sich warten, waren häufig positiv, doch nur ein Nervenarzt erkannte, dass in dem Buch ein „Gespräch über die Sexualität des Menschen" in Gang gesetzt wurde, das sich von früheren Diskursen radikal unterschied. ${ }^{37}$ Der Name dieses Psychiaters war Hans Giese. In der von ihm mitverantworteten Reihe „Beiträge zur Sexualforschung“ sollte 1961 Helene StourzhAnderles zweite bedeutende Monographie erscheinen, zur Anorgasmie der Frau. ${ }^{38}$ Es war auch zugleich die erste entsprechende Studie überhaupt - jenseits der Psychoanalyse. Es erschien gerade zu der Zeit, als die Pille auf den Markt kam und somit ein wenig spät. Denn wie sich zeigen sollte, waren viele der Ängste von Frauen bezüglich ihrer Sexualität der Furcht vor einer Schwangerschaft geschuldet. Doch Stourzh-Anderle legte noch einmal eine umfassende Studie vor, die ganz dem Geist der alten Zeit mit Sexualfurcht und mangelnder Aufklärung geschuldet war. Nun, schon in ihren letzten Lebensjahren hatte Stourzh-Anderle offenbar kapituliert, sie wollte nicht mehr die Welt verändern, nur mehr den Patientinnen ein schmerzfreies Dasein bescheren. Das Buch war in Kooperation mit der II. Universitätsfrauenklinik in Wien entstanden. 1000 Fälle brachte Stourzh-Anderle selbst bei, 500 stammten aus der Klinik. Sie betonte den Zusammenhang von psychischen und endokrinen Störungen im Leben der Frau und verwarf die in der Medizin verwendeten frauenfeindlichen Ausdrücke, z.B. Frigidität (Kälte). ${ }^{39}$ Der sexuellen Konstitution und dem Körperbau billigte Stourzh-Anderle nur mehr periphere Bedeutung zu und folgte damit dem Trend ihres Faches, sich aus der Körperbaulehre zu entfernen ${ }^{40}$. Sehr wohl aber gebe es einen Konnex zwischen erfüllter Sexualität und Kinderwunsch bzw. günstigen sozialen Verhältnissen und Kinderwunsch ${ }^{41}$. Stourzh-Anderle sah in der Klitoris und nicht der Vagina das für den Orgasmus der Frau wichtigste Organ. ${ }^{42}$ Frauen, die sich unglücklich fühlten, empfahl sie eine Hormontherapie auf freiwilliger Basis.

Es gab ein paar Rezensionen, die Studie musste sogar nachgedruckt werden, so schnell war sie verkauft, doch dann verschwand das Interesse. Zitiert wurde Stourzh-Anderle so gut wie gar nicht.

36 STOURZH-ANDERLE, Sexuelle Konstitution, 1955, 120.

37 Hans GIESE, Stourzh-Anderle, Helene: Sexuelle Konstitution, Psychopathie, Kriminalität, Genie. In: Der Nervenarzt 26 (1955) 304.

38 Helene STOURZH, Die Anorgasmie der Frau (= Beiträger zur Sexualforschung Heft 23, Stuttgart 1961, 2. Auflage 1962).

39 Ebenda 5-9.

40 Ebenda 31.

41 Ebenda 64, 67.

42 Ebenda 35. 
Sie selbst zog sich immer mehr zurück, schied aus der von ihr 1954 mitbegründeten Österreichischen Gesellschaft für Sexualforschung aus, gab 1962 die Praxis auf. Noch immer waren ihre Ziele aus den 1920ern aktuell: Sexualaufklärung vor allem und die Befreiung der Frau von dümmlichen Konstitutionsmustern. Weiterhin tat sie sich mit Rezensionen hervor, ohne zu bemerken, dass die Forschung sich längst weiter entwickelt hatte. ${ }^{43}$ Ebenso wie ihre fachwissenschaftlichen Gegner hatte sich auch Stourzh-Anderle stets in biologistischen Denkmustern betätigt. Dies bezog sich sowohl auf ihre sexualaufklärerischen Überlegungen, als auch auf ihre Bücher zur sexuellen Auf die Tendenzen der angelsächsischen Forschung, die jenseits konstitutionsbiologischer Theoriemodelle und überholter gynäkologischer Denkmuster agierte, ging sie nur in der Neuauflage der „Anorgasmie“ kurz ein. Es wäre interessant gewesen, was Stourzh-Anderle zu den Konzepten von Masters/Johnson gesagt hätte, von Oswald Kolle ganz zu schweigen. Noch bevor eine neue, revolutionär auftretende Frauenbewegung die in der Gesellschaft tief verwurzelten medizinisch „,begründeten“ Vorurteile über das weibliche Geschlecht konterkarierte, starb Helene Stourzh-Anderle am 21. Februar 1966 in Wien. Sie erhielt einige zurückhaltende Nachrufe, in denen ihr Engagement jenseits der Gynäkologie auf dem Gebiet der Psychologie betont wurde. ${ }^{44}$ Danach geriet sie endgültig in Vergessenheit.

\section{Autoreninformation}

Florian G. Mildenberger, Dr. phil. PD, Historiker. Postadresse: Liverpooler Str. 12, 13349 Berlin, Deutschland. Mail: mildenberger1973@gmx.de

43 Helene STOURZH-ANDERLE, Buchbesprechung Hans Giese: Über die menschliche Fortpflanzung. In: Wiener medizinische Wochenschrift 112 (1962) 63.

Helene STOURZH-ANDERLE, Buchbesprechung Edith Kent: Vom Mädchen zur Frau. In: Ebenda 216.

Helene STOURZH-ANDERLE, Buchbesprechung Willhart S. Schlegel: Die Sexualinstinkte des Menschen. In: Ebenda 714-715.

Helene STOURZH-ANDERLE, Buchbesprechung Albert Ellis: Liebe als Kunst und Wissenschaft. In: Ebenda 809-810.

Helene STOURZH-ANDERLE, Buchbesprechung H. Bürger-Prinz und H. Giese: Erziehung zur Sexualität. In: Ebenda 922-923.

Helene STOURZH-ANDERLE, Buchbesprechung H. Giese und V.E. v. Gebsattel: Psychopathologie der Sexualität/2.Teil. In: Wiener medizinische Wochenschrift 113 (1963) 480-481.

Helene STOURZH-ANDERLE, Buchbesprechung Eberhard Schaetzing: Die verstandene Frau. In: Wiener medizinische Wochenschrift 114 (1964) 223.

Helene STOURZH-ANDERLE, Buchbesprechung A. Langelüddeke: Die Entmannung von Sittlichkeitsverbrechern. In: Ebenda 353.

Helene STOURZH-ANDERLE, Buchbesprechung Franz Klinger: Des Mannes Hörigkeit. In: Ebenda 367.

Helene STOURZH-ANDERLE, Buchbesprechung Maxine Davis: Die sexuelle Liebe in der Ehe. Wiener medizinische Wochenschrift 115 (1965) 1024.

44 Siehe z.B. Wolfgang DENK, Nachruf auf Frau Dr. Helene Stourzh-Anderle. In: Wiener klinische Wochenschrift 78 (1966) 202. 



\section{Die Ermordung und das „Sterben-Lassen“ von psychisch und physisch kranken ausländischen ZivilarbeiterInnen im „Gau Oberdonau“}

\section{English Title}

Homicide and "leaving dying" of mentally and physically ill foreign civil workers in "Gau Oberdonau"

\section{Summary}

In Second World War 8.4 million foreign civilian workers were used for labour in the German Reich, many of them were forced labourers. Civilian workers from Poland and the Soviet Union, who became mentally or physically ill and could not be cured in short time, were sent back to their home countries. In May 1943 the transports of mentally ill forced labourers to their home countries were stopped, as the National Socialist „euthanasia“ bureaucracy intervened and brought the labourers from "mental institutions" to special facilities where they were killed. In 1943 and 1944 several transports with mentally ill forced labourers from mental institutions in the area of Bavaria and Austria are documented. In most of these cases the destinations of the transports are unknown. The working hypothesis of this article is that the transports went to Hartheim castle, which served as "killing centre" from 1940 to 1944 . Physically ill civilian workers were detained in camps, where many of them died because of lack of food and medical care and because of the bad hygienic situation.

\section{Keywords}

Second World War, Austria, foreign civilian workers, euthanasia, Hartheim

Zwischen 1939 und 1945 wurden im Deutschen Reich rund 13,5 Millionen ausländische ZivilarbeiterInnen, Kriegsgefangene, Häftlinge und „Arbeitsjuden“ zur Arbeit eingesetzt. 80 bis 90 Prozent dieser Menschen waren ZwangsarbeiterInnen. Der Anteil der eingesetzten ZivilarbeiterInnen betrug 8,4 Millionen Menschen. ${ }^{1}$

1 Mark SPOERER, Zwangsarbeit unter dem Hakenkreuz - Ausländische Zivilarbeiter, Kriegsgefangene und Häftlinge im Deutschen Reich und im besetzten Europa 1939-1945 (Stuttgart/München 2001) 223. 
Der zeitgenössische Umgang mit ausländischen ArbeiterInnen bzw. ihre Arbeits- und Lebensbedingungen im NS-Regime waren von ihrer Einordnung im Rahmen der nationalsozialistischen Rassenideologie, aber auch von der Frage, in welchem Verhältnis das Herkunftsland zum Deutschen Reich stand (verbündeter, neutraler, vom Deutschen Reich besetzter oder feindlicher Staat), abhängig. Polinnen bzw. Polen und „Ostarbeiterinnen“ bzw. „Ostarbeiter“ (diese stammten aus der Sowjetunion), die als „slawische Untermenschen" galten, waren repressiven und diskriminierenden gesetzlichen Bestimmungen ausgesetzt, ${ }^{2}$ während Zivil- bzw. ZwangsarbeiterInnen und Kriegsgefangene aus Westeuropa einer vergleichsweise besseren Behandlung unterlagen. ${ }^{3}$

Auch das Geschlecht der ausländischen ZivilarbeiterInnen war maßgeblich für ihre Behandlung: Für schwangere „Ostarbeiterinnen“ und Polinnen sah der NS-Staat etwa die erzwungene Schwangerschaftsunterbrechung vor. Bereits geborene Kinder von polnischen und sowjetischen Zwangsarbeiterinnen wurden ihren Müttern weggenommen und in „Ausländerkinder-Pflegestätten“ untergebracht. Aufgrund der mangelnden Versorgung kamen zahlreiche Kinder in derartigen Einrichtungen zu Tode. ${ }^{4}$ Die Behandlung dieser Menschen war nur ein Aspekt des Umgangs des NSRegimes mit jenen, die nicht im Zuge des „Arbeitseinsatzes“ für die Zwangsarbeit ausgebeutet werden konnten. Ausländische ZivilarbeiterInnen, die an psychischen oder physischen Krankheiten litten, gerieten - ebenso wie als „lebensunwert“ eingestufte Angehörige des Deutschen Reiches - in den Fokus des NS-,,Euthanasie“-Apparates und wurden ermordet oder starben aufgrund miserabler hygienischer Verhältnisse sowie mangelnder medizinischer Behandlung und mangelnder Versorgung mit Lebensmitteln. Auch für den Umgang mit kranken ArbeiterInnen waren spezielle Maßnahmen vorgesehen. Der vorliegende Beitrag beschäftigt sich mit der Behandlung psychisch und physisch kranker ausländischer ZivilarbeiterInnen (vor allem jenen aus der Sowjetunion und Osteuropa) im NS-Regime und schwerpunktmäßig mit der Ermordung bzw. dem „Sterben-Lassen“ von kranken ZivilarbeiterInnen im „Gau Oberdonau“.

\section{Rücktransport von kranken ZivilarbeiterInnen in ihre Heimatländer}

Eine medizinische Behandlung wurde kranken polnischen und sowjetischen ZwangsarbeiterInnen in Krankenhäusern bzw. in den Krankenhäusern angeschlossenen Krankenbaracken im Deutschen Reich nur dann gewährt, wenn eine Aussicht auf baldige und dauerhafte Wiedererlangung der Arbeitsfähigkeit bestand. ZivilarbeiterInnen, die als längerfristig arbeitsunfähig erschienen, wurden in die „Ostgebiete“ zurückgebracht. ${ }^{5}$ Ihr weiteres Schicksal blieb in vielen Fällen unbekannt. Die Dauer der medizinischen Versorgung war von dem noch erhofften zukünftigen Nutzen aus der Arbeitskraft der betreffenden Person abhängig. Kranke galten dann als dauerhaft arbeitsunfähig, wenn die Behandlung als zu aufwändig eingeschätzt wurde - der bereits

2 SPOERER, Zwangsarbeit 25-26, 91-99.

3 Ebd. 15-16.

4 Vgl. Gabriella HAUCH, Ostarbeiterinnen - Vergessene Frauen und ihre Kinder. In: Fritz MAYRHOFER, Walter SCHUSTER (Hg.), Nationalsozialismus in Linz II (Linz 2001) 1271-1310.

5 Annette SCHÄFER, Durchgangs- und Krankensammellager im Zweiten Weltkrieg: Schnittstellen zwischen „Arbeit“ und „Vernichtung“ beim Zwangsarbeitereinsatz. In: Andreas FREWER, Günther SIEDBÜRGER (Hg.), Medizin und Zwangsarbeit im Nationalsozialismus - Einsatz und Behandlung von „Ausländern“ im Gesundheitswesen (Frankfurt/New York 2004) 203-230, hier 210. 
erwähnte Rücktransport war die Folge. ${ }^{6}$ Im Oktober 1941 wurde die bis dahin geltende maximale medizinische Behandlungsdauer für polnische ZwangsarbeiterInnen von zwei auf drei Wochen erhöht. ${ }^{7}$ Ein Jahr später, Mitte Oktober 1942, wurde die ebenfalls mit drei Wochen festgelegte Grenze für kranke „Ostarbeiter“ aufgrund des steigenden Arbeitskräftemangels schließlich auf acht Wochen festgelegt. Ziel war es nun, die Arbeitskraft der ZwangsarbeiterInnen möglichst wiederherzustellen, um sie weiter einsetzen zu können. ${ }^{8}$ Kranke, die für die Rückbeförderungen bestimmt waren, wurden von den Arbeitsämtern u. a. in „Rückkehrersammellagern“ untergebracht - in der Regel ohne medizinisch versorgt zu werden. ${ }^{9}$ Im Oktober 1942 wurde die Errichtung von „Krankensammellagern“, die als Unterkünfte für schwer- und infektionskranke ZwangsarbeiterInnen genutzt werden sollten, angeordnet. Die Aufnahmekapazitäten bereits bestehender derartiger Lager wurden nun erhöht zusätzlich wurden neue Lager errichtet. Die Notwendigkeit für diese Unterkünfte ergab sich aus der steigenden Zahl schwerkranker ZwangsarbeiterInnen, die aus den miserablen Lebens- und Arbeitsbedingungen - v. a. für osteuropäische ZivilarbeiterInnen - resultierte. Darüber hinaus erschwerte der Kriegsverlauf immer mehr die Rückbeförderungen von kranken „Ostarbeitern“ und polnischen ZwangsarbeiterInnen und verunmöglichte diese schließlich völlig. ${ }^{10}$ Die schlechte Versorgungssituation und die schlechten hygienischen Zustände in den „Krankensammellagern“ und „Rückkehrersammellagern“11 führten dazu, dass viele der Kranken nicht überlebten. ${ }^{12}$

\section{Die Ermordung von psychisch kranken und das „Sterben-Lassen“ von physisch kranken ausländischen ZivilarbeiterInnen}

Die Rückbeförderung von psychisch kranken, polnischen ZwangsarbeiterInnen wurde laut Hamann von den Arbeitsämtern und psychiatrischen Anstalten veranlasst. ${ }^{13} \mathrm{Ab}$ Ende des Jahres 1942 war - belegt für ZwangsarbeiterInnen, die in die hessische Anstalt Hadamar gebracht wurden - auch der Mordapparat der NS-,,Euthanasie“

6 Michael DAHL, „... werden die Ostarbeiter in Zweifelsfällen erneut auf ihren Arbeitswillen und ihre Arbeitsfähigkeit praktisch überprüft" - Zwangsarbeit und Krankheit aus der Perspektive der staatlichen Behörden sowie der Krankenkassen. In: Uwe DANKER, Annette GREWE, Nils KÖHLER, Sebastian LEHMANN (Hg.), „Wir empfehlen Rückverschickung, da sich der Arbeitseinsatz nicht lohnt" - Zwangsarbeit und Krankheit in Schleswig-Holstein 1939-1945 (= IZRGSchriftenreihe 6, Bielefeld 2001) 102-137, hier 126.

7 Annette GREWE, Ärzte in der Verantwortung: Zwangsarbeit und Krankheit in Schleswig-Holstein. In: FREWER/SIEDBÜRGER, Medizin und Zwangsarbeit 29-66, hier 33.

8 DAHL, Perspektive der staatlichen Behörden 126-127.

9 Mandy JAKOBCZYK, Das Tuberkuloseproblem bei Zwangsarbeitern in Schleswig-Holstein. In: DANKER/GREWE/KÖHLER/LEHMANN, Zwangsarbeit und Krankheit 243-272, hier 251.

10 SCHÄFER, Durchgangs- und Krankensammellager 211-212.

11 SCHÄFER, Durchgangs- und Krankensammellager 214; Matthias HAMANN, Die Morde an polnischen und sowjetischen Zwangsarbeitern in deutschen Anstalten. In: VEREIN ZUR ERFORSCHUNG DER NATIONALSOZIALISTISCHEN GESUNDHEITS- UND SOZIALPOLITIK E. V. (Hg.), Aussonderung und Tod - Die klinische Hinrichtung der Unbrauchbaren (= Beiträge zur Nationalsozialistischen Gesundheits- und Sozialpolitik 1, Berlin 1985) 121-157, hier 123-124.

12 SCHÄFER, Durchgangs- und Krankensammellager 214-215.

13 Dies traf auch auf ZivilarbeiterInnen aus anderen Staaten zu: Aus der Heil- und Pflegeanstalt Niedernhart in Linz wurden etwa in den Jahren 1942 und 1943 auch ukrainische sowie west- und süd(ost)europäische ZivilarbeiterInnen - zum Zweck der Abschiebung in ihre Heimatländer - vom Arbeitsamt abtransportiert. Siehe Oberösterreichisches Landesarchiv (OÖLA), Wagner-Jauregg Kh, Hauptbücher der Heil- und Pflegeanstalt Niedernhart. 
(etwa die Tarnorganisation „Gemeinnützige Krankentransportgesellschaft“ [Gekrat]) in die Rückführungsverfahren involviert. Die erkrankten ZwangsarbeiterInnen wurden statt der Rückbeförderung den aus diversen psychiatrischen Anstalten abgehenden Transporten mit deutschen AnstaltspatientInnen, die in der Anstalt Hadamar endeten, angeschlossen und dort ermordet. Nach Ende der „T4“"14 im August 1941 wurde in Hadamar im August 1942 die zweite Phase der „Euthanasie“ an Erwachsenen eingeleitet. Nicht nur psychisch kranke Deutsche und ausländische ZivilarbeiterInnen sondern auch angeblich tuberkulosekranke ZivilarbeiterInnen fielen den Morden in der Anstalt zum Opfer. ${ }^{15}$ Während der von 1940 bis 1941 durchgeführten „Aktion T4“ war die Ermordung von psychisch kranken ZwangsarbeiterInnen noch nicht vorgesehen gewesen. ${ }^{16}$ Im Rahmen der nun in Hadamar, aber auch in zahlreichen anderen psychiatrischen Anstalten erfolgten „dezentralen Euthanasie“ starben PatientInnen durch Hunger, Kälte, Vernachlässigung und/oder Medikamente. ${ }^{17}$ Vereinzelt wurden die „dezentralen“ Morde sogar noch im Zeitraum der „T4“ durchgeführt: In der Heil- und Pflegeanstalt Niedernhart etwa wurden im Februar 1941 sieben polnische ZwangsarbeiterInnen getötet (siehe dazu weiter unten).

In der ersten Jahreshälfte 1943 erfolgte eine bedeutende Änderung im Umgang mit psychisch kranken ausländischen ZivilarbeiterInnen: Am 21. Mai des Jahres wurde die Rückbeförderung von aufgrund von psychischen Erkrankungen arbeitsunfähigen polnischen und sowjetischen ZwangsarbeiterInnen offiziell eingestellt. Psychisch auffällige ZwangsarbeiterInnen, die als „dauernd nicht arbeitsfähig“ galten, sollten nun, nachdem sie von den Arbeitsämtern in Kooperation mit den psychiatrischen Anstalten dem Reichssicherheitshauptamt gemeldet wurden, in dessen „Sonderlager“ gebracht werden. Die „Sonderlager“ wurden von der „Reichsarbeitsgemeinschaft Heil- und Pflegeanstalten“ (einer „Euthanasie“-Tarnorganisation) zur Verfügung gestellt, auch war sie für den Transport in die „Sonderlager“ zuständig. ${ }^{18}$ Hinter dem Begriff „Sonderlager“ bzw. „Sammelstelle“ verbargen sich Tötungsabteilungen in psychiatrischen Anstalten und Einrichtungen, die beim Transport der ZwangsarbeiterInnen in Vernichtungsanstalten als Zwischenstation dienten. ${ }^{19}$

In den Jahren 1943 und 1944 wurden aus zahlreichen Anstalten psychisch kranke ZwangsarbeiterInnen - teilweise unter dem Vorwand einer Rückbeförderung in die Heimatländer - mit unbekanntem Ziel abtransportiert. Einige dieser Anstalten lagen im „Einzugsbereich“ der in Alkoven/Linz in „Oberdonau“ gelegenen Tötungsanstalt Hartheim, d. h. schon während der „Aktion T4“ waren - mit dem Ziel der Ermordung

14 Gasmordaktion an behinderten und psychisch kranken Menschen in den Tötungsanstalten Bernburg, Brandenburg, Hadamar, Hartheim, Grafeneck und Sonnenstein - benannt nach der Zentraldienststelle des „Euthanasie“-Apparates in der Tiergartenstraße 4 in Berlin.

15 HAMANN, Morde 135-137.

16 Uta GEORGE, Polnische und sowjetische Zwangsarbeitende als Opfer der NS-,,Euthanasie“Verbrechen - Das Beispiel Hadamar. In: FREWER/SIEDBÜRGER, Medizin und Zwangsarbeit 389406, hier 391.

17 Brigitte KEPPLINGER, NS-Euthanasie in Österreich: Die „Aktion T4“ - Struktur und Ablauf. In: Brigitte KEPPLINGER, Gerhart MARCKHGOTT, Hartmut REESE † (Hg.), Tötungsanstalt Hartheim (= Oberösterreich in der Zeit des Nationalsozialismus 3, Linz 2008) 35-62, hier 60.

18 HAMANN, Morde 137-138.

19 SCHÄFER, Durchgangs- und Krankensammellager 223; Laut Hamann waren die „Sonderlager“ selbst Tötungsanstalten, siehe Matthias HAMANN, Die Ermordung psychisch kranker polnischer und sowjetischer Zwangsarbeiter. In: Götz ALY (Hg.), Aktion T4 - 1939-1945 - Die „Euthanasie“Zentrale in der Tiergartenstraße 4 (Berlin 1989) 161-167, hier: 163. 
- Transporte mit PatientInnen aus diesen Anstalten nach Hartheim erfolgt. Bei manchen der Transporte mit ZwangsarbeiterInnen, die im Folgenden geschildert werden, sprechen darüber hinaus auch verschiedene Indizien dafür, dass Hartheim als mögliches Ziel in Frage kommt. In einem Fall ist dies definitiv belegt:

Am 27. Juli 1943 wurden drei ukrainische ZwangsarbeiterInnen (Demytri R., Mikoly L. und Ekaterina H.) aus der im „Gau Niederdonau“ gelegenen Heil- und Pflegeanstalt Gugging zur Tötung nach Hartheim gebracht. In den Krankenakten dieser Menschen und im Aufnahmebuch der Anstalt Gugging wurde das Transportziel mit dem selten so eindeutigen Eintrag „Landesanstalt Hartheim/Alkoven“ vermerkt. Der Amtsarzt von Gmünd hatte sich im amtsärztlichen Gutachten über Mikoly L. auf den Erlass vom 21. Mai bezogen und vorgeschlagen, dass er „bis zum Abtransport in ein Sammellager" in der Anstalt Gugging untergebracht werden sollte. Im Juni 1943 hatte der Direktor von Gugging in ärztlichen Gutachten bzw. Zeugnissen geschrieben, dass Ekaterina H. und Demytri R. in eine „heimatliche Irrenanstalt“ (bzw. „Anstalt ${ }^{\star}$ ) gebracht werden könnten. In einem dem Krankenakt von Demytri R. beigelegten Schreiben vom Juli 1943, mit dem die Anstalt Gugging eine Anfrage seines ehemaligen Arbeitgebers beantwortete, wurde festgestellt, dass ,,das Verfahren zwecks Rückversetzung in eine heimatliche Anstalt [...] bereits in die Wege geleitet" sei. ${ }^{20}$ Der angebliche Rücktransport in die Heimat war im Falle dieser drei Personen jedoch nur ein Vorwand.

Bei anderen Transporten gestaltet sich die Erforschung der Ziele und der Schicksale der betroffenen Menschen aufgrund der schlechten Quellenlage schwieriger. Die Tatsache, dass zumindest in einigen Fällen „Euthanasie“-Organisationen in den Abtransport dieser ZwangsarbeiterInnen aus den Pflegeanstalten involviert waren, lässt aber vermuten, dass sie ermordet wurden: Am 03. August 1943 etwa transportierte die „Reichsarbeitsgemeinschaft“ - in zeitlicher Nähe zu dem Transport aus Gugging drei aus Polen bzw. der Ukraine stammende ZwangsarbeiterInnen aus der Heil- und Pflegeanstalt Regensburg ab. ${ }^{21}$ Die in Bayern gelegene Heil- und Pflegeanstalt Mainkofen war mit einem Schreiben vom 23. August 1943 von der „Reichsarbeitsgemeinschaft Heil- und Pflegeanstalten“ (bzw. dem „Geschäftsführer“ der „T4“Zentraldienststelle Dietrich Allers) kontaktiert worden: Man habe vom Reichskriminalpolizeiamt (Berlin) mitgeteilt bekommen, dass sich in der Anstalt ,geisteskranke Ostarbeiter" befänden und man sei mit der „Rückfübrung“ dieser (insgesamt fünf namentlich genannten) PatientInnen beauftragt worden. In einem zweiten Schreiben am 24. August wurde ein weiterer polnischer Zwangsarbeiter genannt. Die „Reichsarbeitsgemeinschaft“ forderte die Anstalt Mainkofen in den Schreiben auf, die ZwangsarbeiterInnen in die Heil- und Pflegeanstalt Günzburg, die „zunächst Sammelanstalt“ sei, zu bringen.22 Am 31. August und 7. September 1943 wurden aus der Anstalt Mainkofen schließlich vier der genannten ZwangsarbeiterInnen (diese stammten aus Polen) - angeblich zum Zweck des Rücktransports in die „zuständige Heimatanstalt“ - in die Anstalt Günzburg, die wie erwähnt als „Sammelanstalt“ bzw.

20 Niederösterreichisches Landesarchiv (NÖLA), Aufnahmeprotokoll der Heil- und Pflegeanstalt Gugging; Krankenakte der Heil- und Pflegeanstalt Gugging von Demytri R. (Abgangs-Nr. 470/1943), Mikoly L. (Abgangs-Nr. 471/1943) und Ekaterina H. (Abgangs-Nr. 469/1943).

21 Clemens CORDING, Die Heil- und Pflegeanstalt Karthaus-Prüll/Regensburg. In: Michael VON CRANACH, Hans-Ludwig SIEMEN (Hg.), Psychiatrie im Nationalsozialismus - Die Bayerischen Heil- und Pflegeanstalten zwischen 1933 und 1945 (München 1999) 175-229, hier 222.

22 Archiv der Heil- und Pflegeanstalt Mainkofen, Krankenakte von Miescislaw D. (Reg.-Nr. M126/43) und Wiecenti G. (Reg.-Nr. M121/43). 
„Sammelplatz, zur Rückbeförderung der nicht mehr arbeitseinsat_fähigen Ostarbeiter" diente, transportiert. Die ZwangsarbeiterInnen wurden in Begleitung von PflegerInnen mit dem Zug nach Günzburg gebracht. ${ }^{23}$ Im Sommer 1943 wurden insgesamt 23 ZwangsarbeiterInnen in die seit diesem Zeitpunkt bestehende „Sammelanstalt" eingewiesen, ${ }^{24}$ vermutlich befanden sich unter ihnen auch die Mainkofener PatientInnen. Die 23 eingewiesenen ZwangsarbeiterInnen wurden schließlich im September 1944 angeblich in die Anstalt Kaufbeuren verlegt (siehe dazu auch weiter unten). ${ }^{25}$ Wiederum dürfte es sich also bei dem angeblichen Rücktransport um einen Vorwand gehandelt haben.

Die übrigen zwei ZwangsarbeiterInnen (ein Pole und eine „Sowjetrussin“"), die ebenfalls in einem der beiden Schreiben von Allers genannt wurden, waren bereits zuvor aus der Anstalt Mainkofen weggebracht worden. Am 5. August 1943 wurden sie - angeblich „zur Rückführung nach Polen“ - von einem „Beauftragten der Reichsarbeitsgemeinschaft der Heilund Pflegeanstalten" namens Rohloff „abgeholt" bzw. in eine „zuständige Heimatanstalt" in Polen ,̈̈berfübrt". In ihren Krankenakten ist vermerkt, dass sie „vorerst nach Wien" gebracht wurden. ${ }^{26}$ Der für die „Rück.ü̈hrung" zuständige „Beauftragte“ transportierte rund ein Jahr später auch aus der Anstalt Kaufbeuren zahlreiche ZwangsarbeiterInnen mit unbekanntem Ziel ab (siehe weiter unten).

Ein am 24. Jänner 1944 durchgeführter Transport mit 58 „Ostarbeiterinnen“ und „Ostarbeitern“, der aus der im Rheinland gelegenen Anstalt Galkhausen mit unbekanntem Ziel abging, ${ }^{27}$ endete zumindest für einige der ZwangsarbeiterInnen im „Gau Oberdonau“: Einen Tag nach dem Abtransport in Galkhausen trafen in der Heil- und Pflegeanstalt Niedernhart in Linz fünf ZwangsarbeiterInnen ein, die von einer „Transportgesellschaft“ (offenbar der Gekrat) überbracht wurden. ${ }^{28}$ Mindestens drei dieser Menschen (Zbignew B., Eugenie N. und Anastasia T.) stammten aus dem Transport von Galkhausen - sie wurden in Unterlagen, die im Archiv der Anstalt erhalten geblieben sind, namentlich erwähnt. ${ }^{29}$ Zbignew B. war laut Krankenakt vor der Einweisung in der Anstalt Galkhausen einige Monate lang in der Anstalt Haina bei Kassel untergebracht gewesen. Auch die übrigen beiden Personen (Anemie K. und Maria S.) wurden aus dem „Altreich“ in die Anstalt Niedernhart gebracht. Sie waren laut Krankenakt bei Bauern eingesetzt gewesen und hatten dort trotz anstrengender körperlicher Arbeit hungern müssen, was zu psychischen Problemen geführt hatte. Maria S. war bereits ein halbes Jahr in einer Anstalt im „Altreich“ behandelt worden.

23 Archiv der Heil- und Pflegeanstalt Mainkofen, Krankenakte von Pauline H. (Reg.-Nr. F97/43), Wiecenti G., Stanislaus Ch. (Reg.-Nr. M123/43) und Miescislaw D.

24 Michael VON CRANACH, Reinhold SCHÜTTLER, Heil- und Pflegeanstalt Günzburg. In: VON CRANACH/SIEMEN, Psychiatrie 249-264, hier 251; Laut einem Schreiben von Herrn von Cranach an den Autor vom 15.9.2009 wurden die Informationen zu den ZwangsarbeiterInnen den Jahresberichten der Anstalt Günzburg entnommen.

25 VON CRANACH/SCHÜTTLER, Heil- und Pflegeanstalt Günzburg 251.

26 Archiv der Heil- und Pflegeanstalt Mainkofen, Krankenakte von Wojcick Ch. (Reg.-Nr. M108/1943) und Ulijana D. (Reg.-Nr. F84/1943).

27 Matthias LEIPERT, Rudolf STYRNAL, Winfried SCHWARZER, Verlegt nach unbekannt Sterilisation und Euthanasie in Galkhausen 1933-1945 (= Dokumente und Darstellungen zur Geschichte der Rheinischen Provinzialverwaltung und des Landschaftsverbandes Rheinland 1, Köln 1987) 235.

28 OÖLA, Wagner-Jauregg Kh, Hauptbücher der Heil- und Pflegeanstalt Niedernhart.

29 Archiv der Rheinischen Kliniken Langenfeld, Listen mit den Namen der aus der Anstalt Galkhausen abtransportierten ZwangsarbeiterInnen. 
Die fünf ZwangsarbeiterInnen verblieben mehrere Wochen bzw. Monate in der Anstalt Niedernhart und wurden schließlich „gebessert", „geheilt" bzw. „obne Geistesstörung“ dem Arbeitsamt Linz übergeben. ${ }^{30}$ Der Grund für die Verbringung dieser Menschen nach Linz ist unbekannt - möglicherweise wurden sie aus einem Transport mit zur Ermordung vorgesehenen ZwangsarbeiterInnen heraus genommen, weil sie als noch für die Zwangsarbeit verwendbar erschienen. Das Schicksal der restlichen Personen, die aus Galkhausen abtransportiert wurden, ist ebenso fraglich: Möglicherweise starben sie in der nicht weit von Linz entfernten Tötungsanstalt Hartheim. Zumindest einer der fünf in Niedernhart eingewiesenen ZwangsarbeiterInnen, Zbignew B., überlebte die NS-Zeit: Er verstarb im Jahr 2003.31

Ein Jahr nach der (offiziellen) Einstellung der Rücktransporte und der Schaffung von „Sonderlagern“ für psychisch kranke ZwangsarbeiterInnen erfolgte eine neuerliche Änderung im Umgang mit diesen Menschen. Am 6. Mai 1944 bestimmte der Reichsinnenminister in einem Erlass, dass

„,die geisteskranken Ostarbeiter in eine ausserbalb des Reichsgaues gelegene Anstalt überfübrt werden [sollen]. Die Kranken sollen zu besonderen Transporten zusammengestellt und bei bestimmten Anstalten gesammelt werden, von wo der Abtransport erfolgt." ${ }^{\prime 2}$

Hinter dem Begriff „Abtransport" verbarg sich die Ermordung. Der Historiker Georg Lilienthal vermutet, dass das Reichssicherheitshauptamt nun seine bisherigen Aufgaben verlor, die „Reichsarbeitsgemeinschaft“ und die ebenfalls der „T4“ zugehörige „Zentralverrechnungsstelle“ übernahmen konstante Funktionen im Umgang mit den kranken ZwangsarbeiterInnen. ${ }^{33}$ Im Gau Salzburg berief sich das zuständige Arbeitsamt offenbar noch länger auf die Regelung, bei der das Reichssicherheitshauptamt Funktionen beim Mord an kranken ZwangsarbeiterInnen inne hatte: Das Arbeitsamt Salzburg hatte die Landesheilanstalt für Geistes- und Gemütskranke in Salzburg in einem Schreiben am 22. November 1943 über „Massnabmen bei Rückführung arbeitsunfähiger ausländischer Arbeitskräfte" informiert und die Namen von zwei in der Anstalt untergebrachten „Ostarbeiterinnen“ sowie eines polnischen Zwangsarbeiters genannt. Demnach seien ,nach den Weisungen des Herrn Generalbevollmächtigten für den Arbeitseinsatz [...] geisteskranke Polen oder Ostarbeiter, soweit sie dauernd arbeitsunfäbig sind und einer Anstaltspflege bedürfen, dem Reichssicherbeitshauptamt Berlin zu melden, da beabsichtigt ist, diese Geisteskranken in bestimmte Heilanstalten zusammenzulegen. Das Vorliegen einer Geisteskrankheit ist, sobald sie dauernd jeden Arbeitseinsatz verbindert, vom beratenden Arzt des Arbeitsamtes zu bescheinigen und vom leitenden Arzt des Amtes zu bestätigen."

Das Arbeitsamt forderte die Anstalt auf, ihm ,die Bescheinigungen über das Vorliegen einer Geisteskrankheit" für die genannten ZwangsarbeiterInnen zu übersenden, damit dem Reichssicherheitshauptamt Berlin eine „Meldung“ erstattet werden könne. ${ }^{34}$ In einem

30 Ö̈LA, Wagner-Jauregg Kh, Krankenakte von Zbignew (Zbigniew) B. (Stammnr. 17719), Anemie K. (Stammnr. 17721), Eugenie N. (Stammnr. 17722), Maria S. (Stammnr. 17723) und Anastasia T. (Stammnr. 17724); Hauptbücher der Heil- und Pflegeanstalt Niedernhart.

31 Schreiben von Herrn Kamil Wieczorek, Büro für Internationale Zusammenarbeit - Stiftung „PolnischDeutsche Aussöhnung" vom 12.6.2008.

32 Niedersächsisches Hauptstaatsarchiv Hannover, Hann 155 Lüneburg Acc 56/83 Nr. 8/II, zitiert nach: GEORGE, Zwangsarbeitende 397.

33 GEORGE, Zwangsarbeitende 397; Hamann geht hingegen davon aus, dass das Reichssicherheitshauptamt erst im September 1944 seine Aufgaben verlor, siehe weiter unten.

34 Archiv der Christian-Doppler-Klinik Salzburg, Krankenakt von Marie (Maria) H. (Hauptbuch Nr. 213); Neben Marie H. wurden auch Maria Sch. (Hauptbuch Nr. 244) und Heinrich P. (Hauptbuch-Nummer unbekannt) in dem Schreiben genannt. 
weiteren ähnlichen Schreiben vom 17. Dezember 1943 wurde eine weitere angeblich für die „Rückfü̈brung“ vorgesehene Zwangsarbeiterin (eine „staatenlose“ Polin) genannt. 35 Am 21. Juni 1944 (somit nach dem Erlass vom Mai 1944) wies das Arbeitsamt die Anstalt - nun hinsichtlich der „Ostarbeiterin“ Anna P. - darauf hin, dass ,geisteskranke Polen und Ostarbeiter [...] nach den Weisungen des Herrn Reichsarbeitsministers dem Reichssicherbeitshauptsamt zu melden" seien, „sobald eine dauernde Arbeitsunfähigkeit vorhanden ist oder stete Anstaltspflege notwendig" erscheine. Es wurde die „sofortige Übersendung eines eingehenden äratlichen Gutachtens mit Angabe, ob die Patientin mit oder obne Reisebegleitung reisefähig" sei, erbeten.

Die Anstalt befürwortete im Antwortschreiben vom 26. Juni die Abholung von Anna P., „da eine dauernde Arbeitsunfäbigkeit angenommen werden muss. “ Für die „Reise“ sei eine „Begleitung“ notwendig. ${ }^{36}$ Am 13. Juli 1944 wurden schließlich vier der genannten ZwangsarbeiterInnen (Marie H., Maria Sch., Anna P. und Sofia G.) ${ }^{37}$ aus der Anstalt weggebracht. Hinsichtlich des Transportziels wurden in verschiedenen Schriftstücken, die den Krankenakten beiliegen, unterschiedliche Angaben gemacht: Einerseits war bei allen vier Personen von einer Verbringung in eine ,heimatliche Anstalt" bzw. nach Polen oder in die Ukraine die Rede. ${ }^{38}$ Andererseits wurde in einem dem Akt von Maria Sch. beiliegenden Schreiben vom 1. November 1944, mit dem die Anstalt eine Anfrage ihres ehemaligen Arbeitgebers beantwortete, angegeben, sie sei „in die Anstalt Linz. transferiert worden" ${ }^{39}$ In der Heil- und Pflegeanstalt Niedernhart in Linz wurde jedoch zumindest offiziell - keiner dieser Menschen aufgenommen. ${ }^{40}$ Es muss davon ausgegangen werden, dass sie in Hartheim durch Gas ermordet wurden.

Am 06. September 1944 legte der Reichsinnenminister in einem Erlass elf „Sammelstellen“" (bzw. „Sammelanstalten") für ,geisteskranke Ostarbeiter" und Polinnen bzw. Polen in den verschiedenen Regionen des Deutschen Reiches fest. Die „Zentralverrechnungsstelle“, eine „Euthanasie“-Organisation, nahm den „Abtransport“ von in den „Sammelanstalten" untergebrachten Kranken, die als nicht kurzfristig wiederherstellbar galten, „in dem Heimatgebiet nahe gelegene besondere Anstalten“ vor. Der „Abtransport" bedeutete zum einen wie gehabt die Verbringung in Tötungsanstalten, teilweise wurde aber auch in den „Sammelstellen“ selbst gemordet. Die Arbeitsämter, Bezirksfürsorgeverbände und das Reichssicherheitshauptamt waren nun laut Hamann nicht mehr an den Verfahren zum Umgang mit (als „unheilbar“ eingestuften) psychisch kranken ZwangsarbeiterInnen beteiligt, darüber hinaus bedeutete auch die Einweisung/Verlegung von Kranken aus Anstalten bzw. direkt durch ÄrztInnen der Betriebe, der Arbeitsämter und Gesundheitsämter in die „Sammelstellen“ eine Vereinfachung der bürokratischen Abwicklung - von der Erfassung bis zur Tötung der Kranken. ${ }^{41}$

35 Archiv der Christian-Doppler-Klinik Salzburg, Krankenakt von Sofia (Zofja) G. (Hauptbuch Nr. 370).

36 Archiv der Christian-Doppler-Klinik Salzburg, Krankenakt von Anna (Hanna) P. (Hauptbuch Nr. 436).

37 Heinrich P. wurde dem Transport vom 13.7.1944 nicht angeschlossen, sondern am 18. Juli zur Polizei in Salzburg zurück gebracht, siehe International Tracing Service (ITS), Kriegszeit-Dokumente, Österreich, SK Salzburg, Ordner Nummer 39, Landesheilanstalt Salzburg, Liste der in der Landesheilanstalt Salzburg seit 1.9.1939 (bzw. 1.10.1938) in Behandlung gestandenen ausländischen Kriegsgefangenen, Zivildienstverpflichteten usw., 1.5.1946, 101.

38 Archiv der Christian-Doppler-Klinik Salzburg, Krankenakte von Anna P., Maria Sch., Marie H. und Sofia G.

39 Archiv der Christian-Doppler-Klinik Salzburg, Krankenakt von Maria Sch.

40 Dokumentationsstelle Hartheim, Hauptbücher der Heil- und Pflegeanstalt Niedernhart Linz (digitales Verzeichnis).

41 HAMANN, Morde 145-147. 
Ab Herbst 1944 sind mehrere ZwangsarbeiterInnen-Transporte - wiederum aus Heilund Pflegeanstalten auf bayerischem und österreichischem Gebiet und somit im geographischen „Einzugsbereich“ der Tötungsanstalt Hartheim - mit unbekanntem Ziel belegt. Ähnlich wie bei den bereits erwähnten Transporten in den Jahren 1943 und 1944 sprechen auch hier teilweise verschiedene Indizien für die These, dass die aus den Anstalten weggebrachten ZwangsarbeiterInnen in Hartheim ermordet wurden: Mitte August 1944 kündigte die „Reichsarbeitsgemeinschaft“ dem Anstaltsleiter der als „Sammelstelle“ fungierenden Heil- und Pflegeanstalt Kaufbeuren, Dr. Faltlhauser, in zwei Schreiben das Eintreffen eines Transports mit „Ostarbeitern“ an. Einige Tage später sollte der bereits erwähnte Rohloff, der hier als „Transportleiter" der „Reichsarbeitsgemeinschaft“ bezeichnet wurde, die kranken ZwangsarbeiterInnen „weiter verlegen“. Dieser „Verlegung“ sollten auch einige bereits in der Anstalt Kaufbeuren untergebrachte ZwangsarbeiterInnen angeschlossen werden. Den Schreiben waren Listen beigegeben, in denen alle Personen, die "in die Heimat" zurückgebracht werden sollten, namentlich genannt wurden. ${ }^{42} 14$ russische ZwangsarbeiterInnen - davon elf Personen aus dem „Krankensammellager“ GroßSachsenheim, zwei aus der Anstalt Lohr und eine aus der Anstalt Ansbach - wurden schließlich Ende August 1944 in Kaufbeuren eingewiesen. Kaufbeuren diente in diesem Fall lediglich als Zwischenstation. Bereits am 5. September 1944 wurden sie wie geplant mit fünf weiteren polnischen und russischen ZwangsarbeiterInnen, die sich bereits seit 1943 in der Anstalt befanden, angeblich ,in die Heimat" gebracht. ${ }^{43}$

Bei dem in den Unterlagen genannten „Transportleiter" namens Rohloff handelte es sich mit hoher Wahrscheinlichkeit um den deutschen Krankenpfleger Erwin Rohloff, dem im Rahmen von Ermittlungen der Staatsanwaltschaft Magdeburg im Jahr 1947 vorgeworfen wurde, Dr. Linden ${ }^{44}$ und anderen Tätern beim Mord an Erwachsenen und Kindern aus der Heil- und Pflegeanstalt Uchtspringe (Sachsen-Anhalt) in der Anstalt Meseritz-Obrawalde durch das Organisieren der Transporte in letztere Anstalt Hilfe geleistet zu haben. ${ }^{45}$ Rohloff war bis Kriegsbeginn als Krankenpfleger in einem Hospital in Berlin-Buch beschäftigt. 1940 wurde er vom Polizeipräsidenten für die „Reichsarbeitsgemeinschaft" dienstverpflichtet. Seine Aufgabe im Rahmen der „Euthanasie“-Morde war es etwa, auf Anweisung von Dr. Linden PatientInnen aus Heil- und Pflegeanstalten, die „umgelagert" werden sollten (dies bedeutete eine Verbringung in andere Anstalten und in vielen Fällen die Ermordung der PatientInnen), bürokratisch zu erfassen, auch begleitete er die „von Berlin" aus zusammengestellten und organisierten Transporte. ${ }^{46}$ Rohloff zeichnete somit nicht nur für die Transporte aus der Anstalt Uchtspringe, sondern auch aus anderen Anstalten

42 Schreiben der „Reichsarbeitsgemeinschaft Heil- und Pflegeanstalten“ vom 11.8.1944 und 15.8.1944 an Dr. Falthauser, zitiert nach: Klaus DÖRNER (Hg.), Der Nürnberger Ärzteprozeß 1946/1947 (Mikroform): Wortprotokolle, Anklage- und Verteidigungsmaterial, Quellen zum Umfeld (München 1999) 3. Anklagematerial/Dokumente 2343-2349.

43 Archiv des Bezirkskrankenhauses Kaufbeuren, Schachtel Fremdarbeiter, Restakten, Verzeichnis der am 5.9.1944 in die Heimat zurückzuführenden Kranken, Ostarbeiter; Mappe „Ausländer“, Liste der in Kaufbeuren aufgenommenen und entlassenen „Ausländer“.

44 Dr. Herbert Linden, Ministerialrat im Reichsministerium des Innern, Obergutachten der „T4“, ab Oktober 1941 „Reichsbeauftragter“ für Heil- und Pflegeanstalten.

45 Landeshauptarchiv Sachsen-Anhalt (Abteilung Magdeburg), 2 Ks 11/47, Vorgang einer Strafsache gegen Ärzte und Pfleger der Heil- und Pflegeanstalt Uchtspringe 22-23.

46 Landeshauptarchiv Sachsen-Anhalt (Abteilung Magdeburg), 2 Ks 11/47, Vorgang einer Strafsache gegen Ärzte und Pfleger der Heil- und Pflegeanstalt Uchtspringe 28-29. 
verantwortlich. Der „T4“-„,Geschäftsführer“ Allers schickte etwa im September 1943 seinen „Beauftragten“ Rohloff in die Anstalt Neuruppin (Brandenburg), um den Abtransport hunderter PatientInnen aus der Anstalt zu organisieren. ${ }^{47}$ Zwischen Ende Oktober 1945 und Ende Juni 1947 befand sich Rohloff in Haft und wurde im Rahmen eines Prozesses im Februar 1948 vom Schwurgericht des Landgerichts in Magdeburg freigesprochen, ${ }^{48}$ da ihm ,nach dem Verlaufe der Hauptverhandlung eine Schuld nicht nachgewiesen werden" konnte, ,dass er bei der Durchführung der Krankentransporte gewusst hat, dass diese Kranken der Vernichtung zugefübrt wurden."49 Jene ZwangsarbeiterInnen, die wie bereits erwähnt im September 1944 aus der Anstalt Günzburg abtransportiert wurden, dürften am angeblichen Ziel - der Anstalt Kaufbeuren - nie eingetroffen sein. Im Aufnahmebuch der Anstalt Kaufbeuren wurde dieser Transport nicht registriert, ${ }^{50}$ vermutlich wurden die Kranken in eine Tötungsanstalt gebracht.

Am 14. September 1944 wurden 24 ZwangsarbeiterInnen aus der Anstalt Regensburg angeblich in das „Durchgangslager“ Neumarkt (in der Oberpfalz) transportiert. Im Jahr 1946 erwähnte der zu diesem Zeitpunkt stellvertretende Direktor der Anstalt, Dr. Rudolf Karl, diesen Transport in einem Bericht an das Bayerische Staatsministerium des Inneren mit dem Betreff „Tötung von Geisteskranken“. In erhaltenen Unterlagen, die einige der abtransportierten ZwangsarbeiterInnen betreffen, finden sich u. a. Vermerke wie „Polen nach Linそ" und „Rücktransport Lin そ“. ${ }^{51}$ Diese Vermerke könnten bedeuten, dass diese Menschen in Hartheim durch Gas ermordet wurden.

Am 18. September 1944 verließ ein Transport mit 56 ZwangsarbeiterInnen die Anstalt Eglfing-Haar. Der damalige stellvertretende Direktor der Anstalt sagte 1946 im Zuge der Nürnberger Ärzteprozesse aus, dass diese „Verlegung" mit als ,geisteskrank“" und „arbeitsunfäbig" beurteilten ZwangsarbeiterInnen „auf Veranlassung des Arbeitsamtes München" und "vermutlich nach einer beimatlichen Anstalt" erfolgte. ${ }^{52}$ Am Tag des Transports wurde der „Sammelstellen“-Erlass im Rahmen einer „Ärzteconferen₹“" [sic!] in der Anstalt bekannt gemacht. ${ }^{53}$ In der laut Erlass zuständigen „Sammelanstalt“ Kaufbeuren wurden die ZwangsarbeiterInnen jedoch nicht aufgenommen. ${ }^{54}$ Unter den abtransportierten Personen befanden sich drei Zwangsarbeiterinnen, die erst sechs Tage zuvor - am 12. September 1944 - „über Auftrag der Arbeitsgemeinschaft der Heil- und Pflegeanstalten" von der Pflegeanstalt Solbad Hall in Tirol nach Eglfing verlegt worden waren. ${ }^{55}$ Am 14. November 1944 wurden 21 Menschen ${ }^{56}$ aus der „Sammelanstalt“

47 Dietmar SCHULZE, Die Landesanstalt Neuruppin in der NS-Zeit (Berlin 2004) 140.

48 Dick DE MILDT (Hg.), Tatkomplex: NS-Euthanasie - Die ost- und westdeutschen Strafurteile seit 1945 I (Amsterdam 2009) 311.

49 DE MILDT, NS-Euthanasie 322.

50 Archiv des Bezirkskrankenhauses Kaufbeuren, Zu- und Abgangsbuch der Heil- und Pflegeanstalt Kaufbeuren.

51 CORDING, Karthaus-Prüll 220-221.

52 Eidesstattliche Erklärung von Dr. Moritz Schnidtmann vom 8.11.1946, zitiert nach: DÖRNER, Nürnberger Ärzteprozeß, 3. Anklagematerial/ Dokumente 5451-5452.

53 Schreiben von Herrn Dr. Nikolaus Braun, Archiv des Bezirks Oberbayern (München) vom 19.6.2008. Der handschriftliche Vermerk „In Ärzteconferenz bekannt gegeben 18.9.44“ findet sich auf dem Schreiben, mit dem der „Sammelstellen“-Erlass des Reichsministers des Innern vom 6.9.1944 der Anstalt Eglfing übersendet wurde.

54 Archiv des Bezirkskrankenhauses Kaufbeuren, Zu- und Abgangsbuch der Heil- und Pflegeanstalt Kaufbeuren.

55 Historisches Archiv Psychiatrisches Krankenhaus Hall i. T., Krankenakte von Uljana T. (laufende Nummer: 20721), Pelagie (Pelagia) L. (20740 und 20836) und Liena N. (20690); Zu den Namen der am 
Mauer-Öhling im „Gau Niederdonau“ abtransportiert. Als offizielles Ziel wurde die Heil- und Pflegeanstalt Niedernhart in Linz angegeben. ${ }^{57}$ In Linz dürften diese Menschen jedoch nie angekommen sein, ihre Namen wurden im Hauptbuch der Anstalt nicht registriert. ${ }^{58}$ Am 13. Jänner 1945 beurkundete das in der Tötungsanstalt Hartheim untergebrachte Standesamt den Tod des Polen Adam C., der am 20. Dezember 1944 in „Hartheim No. 1“ verstorben sei. ${ }^{59}$ Zu diesem Zeitpunkt waren im Schloss Hartheim jedoch die Arbeiten zur Beseitigung der Spuren für den Massenmord in der Vernichtungsanstalt bereits in vollem Gange: Zwischen Oktober und Dezember 1944 wurden alle schriftlichen Unterlagen vernichtet, von Mitte Dezember bis Mitte Jänner 1945 versuchte man, die baulichen Spuren auszulöschen. ${ }^{60}$ Bis dato ist unbekannt, woher bzw. aus welcher Anstalt Adam C. nach Hartheim gebracht wurde.

Wie bereits erwähnt wurden nicht nur in Tötungsanstalten, sondern auch in psychiatrischen Anstalten - darunter einigen „Sammelanstalten“ - ZwangsarbeiterInnen ermordet. In die Heil- und Pflegeanstalt Mauer-Öhling wurden u. a. aus den psychiatrischen Anstalten in Graz, Klagenfurt, Salzburg, Wien (Psychiatrische Klinik des Allgemeinen Krankenhauses), Hall (Tirol) und aus den „Durchgangslagern“ in Linz und Wörgl sowie dem „Rückkehrersammellager“" Windberg (bei St. Valentin) psychisch kranke ZwangsarbeiterInnen gebracht. Darüber hinaus wurden auch Kriegsgefangene aus dem Kriegsgefangenenlager Krems-Gneixendorf eingewiesen. ${ }^{61}$ Im Rahmen der „dezentralen Euthanasie“ wurden in Mauer-Öhling ZwangsarbeiterInnen und Kriegsgefangene getötet. Offenbar in den Monaten November 1944 und April 1945 wurden Luft-Injektionen und Starkstromelektroschocks zur Ermordung von PatientInnen eingesetzt. ${ }^{62}$

In der Heil- und Pflegeanstalt Niedernhart in Linz starben zwischen Februar 1941 und Anfang Mai 1945 mindestens 39 ZivilarbeiterInnen unterschiedlicher Nationalität und ein englischer Kriegsgefangener. ${ }^{63}$ Im Februar 1941 wurden die ersten Zwangsarbeite-

18.9.1944 aus Eglfing-Haar abtransportierten ZwangsarbeiterInnen siehe DÖRNER, Nürnberger Ärzteprozeß, 3. Anklagematerial/Dokumente 1944-1946.

56 Es handelte sich um drei russische Kriegsgefangene aus dem Lager Krems-Gneixendorf sowie 18 ausländische ZivilarbeiterInnen aus Polen und der Sowjetunion: 13 Personen aus der Anstalt „Am Feldhof" in Graz, eine aus der Anstalt Hall/Tirol, zwei aus der psychiatrischen Klinik des AKH Wien IX. und zwei direkt nach Mauer-Öhling eingewiesene Personen, siehe Archiv des Landesklinikums Mostviertel, Mauer-Öhling, Standesprotokolle der Landes-Heil- und Pflegeanstalt Mauer-Öhling.

57 Archiv des Landesklinikums Mostviertel, Mauer-Öhling, Standesprotokolle der Landes-Heil- und Pflegeanstalt Mauer-Öhling.

58 Dokumentationsstelle Hartheim, Hauptbücher der Heil- und Pflegeanstalt Niedernhart Linz (digitales Verzeichnis).

59 Dokumentationsstelle Hartheim, Sterbeurkunde von Adam C.

60 Brigitte KEPPLINGER, Die Tötungsanstalt Hartheim 1940-1945, In: KEPPLINGER/MARCKHGOTT'T/REESE, Tötungsanstalt Hartheim 63-116, hier 111-112.

61 Archiv des Landesklinikums Mostviertel, Mauer-Öhling, Standesprotokolle der Landes-Heil- und Pflegeanstalt Mauer-Öhling.

62 HAMANN, Morde 148.

63 OÖLA, Wagner-Jauregg Kh, Hauptbücher der Heil- und Pflegeanstalt Niedernhart; Die verstorbenen ZivilarbeiterInnen stammten aus folgenden Nationen: Polen (elf Frauen, acht Männer - davon einer nach eigenen Aussagen „volksdeutscher Abstammung“, siehe Krankenakt von Johann R. [Stammnr. 16683, OÖLA, Wagner-Jauregg Kh]), Russland/Ukraine (sechs Frauen, drei Männer), Italien (zwei Männer), Griechenland (zwei Männer), Slowakei (ein Mann), Jugoslawien (eine Frau), Frankreich (ein Mann), Spanien (ein Mann), bei einem „Ostarbeiter“ ist die Herkunft unbekannt. Zwei weitere Zivilarbeiter (ein Rumäne und ein Russe) starben bei einem Luftangriff der Alliierten auf die Stadt Linz am 25.4.1945. 
rInnen getötet: Fünf Männer und zwei Frauen aus Polen wurden innerhalb weniger Tage auf eine „Durchzugs“- bzw. eine „Fürsorgeabteilung“ der Anstalt gebracht, kurze Zeit später wurde ihr natürlicher Tod verzeichnet. Für fünf dieser Menschen wurden zuvor noch „T4““-,Meldebögen“, die zur Erfassung für die Ermordung in den Vernichtungsanstalten dienten, ausgefüllt. ${ }^{64}$ Im Juli 1943 wurden zwei „Ostarbeiterinnen“ (bzw. Polinnen) und zwei „Ostarbeiter“ ermordet, die im selben Monat in Niedernhart eingewiesen worden waren. Sie starben bereits wenige Tage nach der Einweisung in die Anstalt, in den Krankenakten fanden sich keinerlei Hinweise auf eine medizinische Behandlung. ${ }^{65}$

Während als psychisch krank diagnostizierte ZwangsarbeiterInnen in psychiatrischen Anstalten und Tötungsanstalten ermordet wurden, starben physisch Kranke an der bereits erwähnten Unterversorgung mit Lebensmitteln und Medikamenten sowie den miserablen hygienischen Zuständen in „Krankensammellagern“. Auch im „Gau Oberdonau“ gab es ein ZwangsarbeiterInnen-Lager, das ab 1942 offenbar die Funktion eines „Krankensammel“- und Sterbelagers inne hatte: Im „Durchgangslager 39“ im Stadtteil „Bindermichl“ in Linz dürften in der Zeit von Anfang September 1942 bis Kriegsende mindestens 331 Menschen verstorben sein - sie stammten vor allem aus Polen und der Sowjetunion. Bemerkenswert hoch ist mit 148 Personen der Anteil der verstorbenen (Klein-)Kinder und Jugendlichen, hinzu zu zählen sind 14 Totgeburten. Viele der Kinder verstarben schon im ersten Lebensjahr. Bei den Erwachsenen ist die mit Abstand häufigste Todesursache Lungentuberkulose, gefolgt von Herzerkrankungen. Bei den Kindern wurden häufig u. a. „Dyspepsia“ [Verdauungsstörung], „Körper“- bzw. „Lebensschwäche“ und Lungenentzündung genannt. ${ }^{66}$

Auch in „Ausländerkinder-Pflegestätten“ bzw. „Fremdvölkischen Kinderheimen“, die zur Unterbringung von Kindern von ZwangsarbeiterInnen dienten, ${ }^{67}$ gab es zahlreiche Todesfälle. Im „Gau Oberdonau“ existierten zwölf dieser Einrichtungen. ${ }^{68}$ Für zumindest einige der Heime sind Todesfälle von Säuglingen und Kleinkindern aufgrund der schlechten hygienischen Zustände sowie der mangelhaften Ernährung und Versorgung belegt: Der dramatischen Unterversorgung im „Lindenhof“" in Spital am Phyrn ${ }^{69}$ fielen etwa 38 von 97 eingewiesenen Kindern zum Opfer (bei sechs weiteren Kindern ist davon auszugehen, dass sie ebenfalls nicht überlebten), ${ }^{70} \mathrm{im}$ Schloss Etzelsdorf in Pichl bei Wels starben $13^{71}$ und im Waldschloss in Schardenberg

64 OÖLA, Wagner-Jauregg Kh, Krankenakte von Michael B. (Stammnr. 15919), Anna D. (Stammnr. 15862), Jan L. (Stammnr. 15725), Regina L. (Stammnr. 15865), Josef O. (Stammnr. 15702), Anton R. (Stammnr. 15920) und Wladislav Z. (Stammnr. 15821); vgl. Dokumentationsstelle Hartheim, Sterbescheine der Heil- und Pflegeanstalt Niedernhart (digitales Verzeichnis); Die Angabe „Lin\%, Waldegg 82 (Durchzugsabt.) “ findet sich in den Krankenakten von sechs der sieben ZwangsarbeiterInnen, nur bei Anton R. wird „Fürsorgeabt. Ndh.“ angegeben. Hingegen wird im Hauptbuch der Anstalt bei allen sieben Personen die „Fürsorgeabteilung“ als Ziel der Verbringung genannt, siehe OÖLA, Wagner-Jauregg Kh., Hauptbücher der Heil- und Pflegeanstalt Niedernhart.

65 Ö̈LA, Wagner-Jauregg Kh, Krankenakte von Tatjana Sch. (Stammnr. 17380), Stanislava St. (Stammnr. 17379), Alexander K. (Stammnr. 17377), Petro W. (Stammnr. 17378).

66 Archiv der Stadt Linz, Gesundheitsamt, Sterbescheine 1942-1945.

67 HAUCH, Ostarbeiterinnen 1290.

68 Ebd. 1304.

69 Ebd. 1296-1300.

70 Ebd. 1301.

71 Martin KRANZL-GREINECKER, Die Kinder von Etzelsdorf - Notizen über das „Fremdvölkische Kinderheim“im Schloss Etzelsdorf, Pichl bei Wels (1944-1946) (Linz 2005) 22-23. 
fünf Kinder. ${ }^{72}$ Auch in einem Heim in Burgkirchen (Bezirk Braunau) dürften Kinder ums Leben gekommen sein: In einem Schreiben des Amtsarztes von Braunau an den Reichsstatthalter von „Oberdonau“ August Eigruber vom 21. März 1945, in dem es u. a. um die Einrichtung eines NSV-Entbindungsheimes geht, heißt es: „NSV Entbindungsheim krankt also von vorn herein an Ausstattungsschwierigkeiten. Hoffentlich nicht ähnlicher Mißerfolg wie Ost-Sänglingsheim Burgkirchen (kolossale Säuglingssterblichkeit)“. 73

\section{Fazit}

Im vorliegenden Beitrag wurde versucht, einige Aspekte des Umgangs der Nationalsozialisten mit psychisch und physisch kranken ausländischen ZivilarbeiterInnen (insbesondere jenen aus Polen und der Sowjetunion) im „Gau Oberdonau“ zu beleuchten. Die anfängliche Abschiebung von Kranken in ihre Heimatländer und schließlich die Tötung im Rahmen der „Euthanasie“ bzw. die Unterversorgung und das „Sterben-Lassen“ in diversen Lagern sind ein Ausdruck der menschenverachtenden und rassistischen NS-Politik, in der der Lebenswert dieser zu „Untermenschen“ Degradierten auf ihre Ausbeutungsfähigkeit innerhalb des bestehenden Zwangsarbeitssystems reduziert wurde. Die Erforschung der „Euthanasie“-Morde an ausländischen ZivilarbeiterInnen in „Oberdonau“ gestaltet sich aufgrund der schlechten Quellenlage, d. h. kaum oder nicht vorhandener Dokumente, äußerst schwierig: Somit kann etwa nur vermutet werden, dass die erwähnten Transporte von kranken ZwangsarbeiterInnen aus psychiatrischen Anstalten auf österreichischem und bayerischem Gebiet die Anstalt Hartheim zum Ziel hatten. Ein ähnlicher Befund ist hinsichtlich der „dezentralen“ Euthanasie und der bewussten Inkaufnahme des Sterbens von Kranken in Lagern und Kindern in Heimen festzustellen: Die Aktenlage ist auch hier äußerst spärlich, aber auch hier muss davon ausgegangen werden, dass viele dieser Menschen eines unnatürlichen Todes starben.

\section{Autoreninformation}

Mag. Markus Rachbauer, Begleiter am Lern- und Gedenkort Schloss Hartheim und in der KZ-Gedenkstätte Mauthausen. Postadresse: Lern- und Gedenkort Schloss Hartheim, Schlossstraße 1, 4072 Alkoven, Österreich. Mail: Markus.Rachbauer@gmx.at

72 Matthias HUBER, Das Schardenberger Waldschloss als „Ausländerkinder-Pflegestätte“ des Dritten Reiches. In: Der Bundschuh - Schriftenreihe des Museums Innviertler Volkskundehaus (= Heimatkundliches aus dem Inn- und Hausruckviertel 11, Ried im Innkreis 2008) 79-85, hier 84.

73 OÖLA, Landesregierung 1945, Sch. 289, IIIa/M, 134-1388, Dokument 443/20. 



\section{Der Erste Weltkrieg „,in“ den Patientenakten von Kieferschussverletzten der Österreichisch- Ungarischen Landstreitkräfte}

\section{English Title}

The First World War ,within' patients' records of jar-injured men from the AustroHungarian Armed Forces

\section{Summary}

The specific fighting and trench warfare of the First World War resulted in facial injuries, the extent of which shocked doctors. As a result, military leadership decided to reform the medical support provided in order to treat the facial injuries more efficiently. Confronted with a new situation, maxillofacial doctors developed treatment methods that made the largest number of soldiers fit for battle as quickly as possible. From that point, medical support was used as a quantifiable resource and was actively integrated in warfare. The pressure exerted by the military defined the scope and therapeutic goal of treatment of facial injuries. Simultaneously, doctors with optimistic forecasts turned wounded soldiers into calculable resources for the military. The potential ethical conflict of the instrumentalization of medicine during the war was not addressed. In fact the doctors discussed the benefits of war to the scientific and practical achievements in the area of maxillofacial surgery.

\section{Keywords}

First World War, Austria, Medical History, Patient History, Plastic surgery, Facial reconstruction

Die technologisierte Kriegsführung und das Kämpfen in Schützengräben während des Ersten Weltkrieges hatten Gesichtsschussverletzungen zur Folge, über deren Ausmaß sich selbst Ärzte erschrocken zeigten. ${ }^{1}$ Das Sanitätswesen, das anfänglich auf einen Bewegungskrieg ausgelegt war, musste daher schnell und effizient reformiert werden. Es entstand ein gestaffeltes System medizinischer Versorgung: Krankenträger brachten die Verwundeten zu frontnahen Verbandsplätzen wo sie erstversorgt wurden. Zur

1 Wilhelm PFAFF, Friedrich SCHÖNBECK, Kursus der zahnärztlichen Kriegschirurgie und Röntgentechnik (Leipzig 21916) 226. 
Weiterbehandlung überstellte man sie in Feldspitäler, Notspitäler und Kriegskliniken. ${ }^{2}$ Aus der medizinischen Notwendigkeit heraus entstanden im Etappenraum Einrichtungen, die sich auf die Therapie bestimmter Verletzungsarten spezialisierten. ${ }^{3}$ Eine davon war die „Kriegszabnklinik der k. u. k. 4. Armee", deren Schwerpunkt die Versorgung von Kieferschussverletzten darstellte. War eine schnelle Heilung und die damit in Verbindung stehende Wiedereinsatzfähigkeit an der Front nicht zu erwarten, wurden die Soldaten ins Hinterland in die dortigen Kliniken bzw., wenn medizinisch notwendig, in weitere Spezialheilanstalten überstellt.

An die ÄrztInnen ${ }^{4}$ in den Spezialheilanstalten wurde seitens des Militärs die Erwartung gestellt, dass sie effektive Behandlungsmethoden entwickelten, um möglichst schnell möglichst viele Soldaten wieder frontdiensttauglich zu machen. Das Militär konnte sich auf die Unterstützung der Ärzte verlassen, welche zielstrebig an neuen Behandlungsmethoden arbeiteten, um die Zahl der wieder Einsatzfähigen Soldaten zu erhöhen. Erfolgschancen von bis zu achtzig Prozent wurden vorhergesagt. ${ }^{5}$

Wenn in diesem Aufsatz am Beispiel Kieferschussverletzter eine spezielle Kriegsverletzung und ihre Behandlung fokussiert wird, so soll ärztliches Handeln dabei in einen größeren medizinsozialhistorischen, alltagsgeschichtlichen und politischen Kontext ${ }^{6}$ gestellt und nach den Rahmenbedingungen und der Umsetzung von Behandlungsmethoden unter spezifischen Umständen (in diesem Fall Krieg und Medizin) gefragt werden. Mit der Analyse der Perspektive von Patienten soll eine Forschungslücke in der Patientengeschichtsschreibung geschlossen werden. ${ }^{7}$

\section{Kieferchirurgen und der Erste Weltkrieg}

Wie der Historiker Hans Georg Hofer feststellte, war innerhalb der Ärzteschaft eine positive Haltung gegenüber der Kriegspolitik weit verbreitet. Dies lag unter anderem am naturwissenschaftlichen Selbstverständnis der Ärzte, aus dem sich eine sozialdarwinistische und rassehygienische Argumentationslinie für die Befürwortung ergab. ${ }^{8}$ So wurde gerade die Bedeutung des Versuchsfeldes Krieg mit dem daraus

2 Bestand der Sammlungen der Medizinischen Universität Wien (MUW), Patientenakten der Zahnärztlichen Abteilung der allgemeinen Poliklinik Wien (Patientenakten).

3 Gerhard HIRSCHFELD, Gerd KRUMREICH, Irina RENZ (Hg.), Enzyklopädie Erster Weltkrieg (Paderborn 2009) 812.

4 Juljan Zilz, Leiter der Kriegszahnklinik in Lublin, führte in seinem Sanitätstagebuch zwei Zahnarztpraktikantinnen an. ( (MUW, Nachlass Zilz). In den Berichten der Wiener Spezialheilanstalt für Kieferschussverletzte an das Armeeetappenkommando wird eine Ärztin angeführt, jedoch ohne Angabe ihres Tätigkeitsbereichs. (Österreichisches Staatsarchiv, Kriegsarchiv (KA), Militär-Ärzte (Millitärkommando Wien) [2]) Offen ist die Frage, ob es auch in anderen Sanitätsanstalten Frauen gab, die als Ärztinnen und Chirurginnen tätig waren. Da es sich bei den zitierten Fachleuten ausschließlich um Männer handelte, wird im Folgenden die männliche Form verwendet.

5 S. SCHAAR, Statistischer Jahresbericht aus dem k.u.k. Reservespital Nr. 17 (Spezialspital für Kieferverletzte). In: Emil STEINSCHNEIDER (Hg.), Beiträge zur Kieferschusstherapie. Aus Anlass des einjährigen Bestehens des k.u.k. Reservespitals Nr. 17 (Wien 1917) 263-268, hier 268.

6 Methodisch vergleiche hierzu: Volker ROELKE, Auf der Suche nach der Politik in der Wissensproduktion: Plädoyer für eine historisch-politische Epistemologie. In: Berichte zur Wissenschaftsgeschichte, 33 (2010) 176-192.

7 Eberhard WOLFF, Perspektiven der Patientengeschichtsschreibung. In: Norbert PAUL, Thomas SCHLICH (Hg.), Medizingeschichte: Aufgaben, Probleme, Perspektiven (Frankfurt am Main/New York 1998) 310-334.

8 Hans-Georg HOFER, Nervenschwäche und Krieg. Modernitätskritik und Krisenbewältigung in der österreichischen Psychiatrie (1880-1920) (Wien/Köln/Weimar 2004) 199. 
gewonnenen „Menschenmaterial" ${ }^{\star 9}$ - hervorgerufen durch die große Zahl der Verwundeten - für den Fortschritt in der Medizin betont. Gerechtfertigt wurde diese Vorgehensweise mit Hinweis auf den Nutzen des gewonnenen Wissens für die Menschheit in den Nachkriegsjahren. ${ }^{10}$ Der humanistische Gedanke in der Medizin stand daher in keinem Bezug zum Pazifismus, sondern stand ihm im Grunde diametral entgegen. ${ }^{11}$ Der Eid des Hippokrates und die damit einhergehende Pflicht zur Erhaltung des Lebens wurde mit dem Argument ausgehebelt, durch das Wirken der Ärzte würde ,dem Krieg ein humaneres Antlitr" gegeben werden. ${ }^{12}$

Vereinzelt gab es innerhalb der ärztlichen Profession bekennende Pazifisten und Opponenten. Diese stellten jedoch eine verschwindende Minderheit dar. Sie waren Anfeindungen von Seiten der offiziellen Ärztevertreter ausgesetzt und wurden meist ignoriert und diffamiert. Das hatte zur Konsequenz, dass sie innerhalb der Ärzteorganisation keinerlei Einfluss hatten.

Welche Erwartungshaltungen die Kieferchirurgen im Speziellen an den gegenwärtigen Krieg stellten, zeigen die folgenden Zitate. Das erste stammt aus dem Jahr 1917 vom Zahnarzt und Kieferchirurgen Juljan Zilz, der vom „k. u. k. 4. Armee-Etappenkommando“ damit betraut wurde eine Kriegszahnklinik an der Ostfront zu errichten:

„W Was auf dem militärischen Gebiete alles geleistet wurde, was die Technik in ibrem ungeabnten Fortschritt hergab, was in sanitären Neueinrichtungen und in bygienischen Massnabmen bei einem Grossbetrieb zur Entwicklung kam, darïber wird die Kriegsgeschichte zur Zeit unseres segenreichen Friedens viel zu berichten haben. "13

Standespolitisch, aus der Sicht eines Zahnarztes im Militärdienst formuliert, konnte dies 1916 folgendermaßen lauten:

„Unser Stand wird aus dem Weltkrieg den enormen Nutzen ziehen, dass die Notwendigkeit, Zahnärzte mit gewisser chirurgischer und allgemein medizinischer Bildung, wie sie eben nur Vollärzte haben können, zur Behandlung von Kieferschussverletzten heranzuziehen, unser Ansehen bei allen denen heben wird, die uns bisher etwas geringschätzig über die Achsel angesehen haben. "14

Oder 1916 aus der Perspektive eines Schweizer Beobachters:

„Eine eingehende Bearbeitung des Gebietes der Zabnheilkunde ist nach dem Kriege von den Leitern der Abteilung für Kieferverletate zu erwarten. Es harrt hier ein grosses wissenschaftliches Material, das täglich noch vermehrt wird, der Verarbeitung. "15

9 Zeitgenössischer Begriff für Forschungsdaten den Menschen betreffend.

10 H. SCHRÖDER, Über Schussverletzungen der Kiefer und ihre Behandlung. In: Fritz WILLIGER, H. SCHRÖDER, Die zahnärztliche Hilfe im Felde. Heft 1 (Berlin 1914) 15-82, hier 17; Juljan ZILZ, Pathologisch-anatomische Befunde bei Kieferverletzungen. In: Vierteljahresschrift für Zahnheilkunde. Sonderabdruck aus Heft 33/2 (Wien 1917) 1 ; Otto MÜLLER-WIDMANN, Über die Behandlung von Kieferschussfrakturen. (Bern 1916) 7f.; SCHAAR, Statistischer Jahresbericht, 21.

11 Herbert GRUNDHEWER, Die Kriegskrankenpflege und das Bild der Krankenschwester im 19. und 20. Jahrhundert. In: Johanna BLEKER, Heinz-Peter SCHMIEDEBACH (Hg.), Medizin und Krieg. Vom Dilemma der Heilberufe 1865 bis 1985 (Frankfurt am Main 1987) 135-152, 148.

12 Ingo TAMM, "ein Stand im Dienst der Nationalen Sache". Positionen ärztlicher Standesorganisationen zum Ersten Weltkrieg. In: Wolfgang U. ECKART, Christoph GRADMANN (Hg.), Die Medizin und der Erste Weltkrieg (Paffenweiler 1996) 11-22, hier 1.

13 ZILZ, Pathologisch-anatomische Befunde,1.

14 SCHWABE, Kommentar zum „Bericht über die chirurgische Behandlung.“ In: Vierteljahresschrift für Zahnheilkunde 32/3-4 (Wien 1916) 101-103, hier 101.

15 MÜLLER-WIDMANN, Kieferschussfrakturen, $7 \mathrm{f}$. 
In diesen Zitaten tritt, wie auch in anderen Schriften von Ärzten der Glaube an den Krieg als Katalysator ärztlichen Erkenntnisfortschritts zu Tage. Selbst nach dem verlorenen Krieg und den unzähligen Kriegsopfern hielt man an dieser Prämisse fest. ${ }^{16}$ Ein Umdenken hätte eine völlig neue Positionierung der Medizin innerhalb der wissenschaftlichen Praxis, wie auch einen Bruch mit der wissenschaftlichen Tradition bedeutet.

Im Folgenden soll daher anhand der Beispiele von Patientengeschichten mit Kieferschussverletzungen Fragen nach der Einflussnahme des Ersten Weltkrieges auf die Behandlung nachgegangen werden. Neben der Verletzungsart war es vor allem die Bemessung der Diensttauglichkeit, welche die Kriegssituation in den Akten vergegenwärtigte. Daraus ergeben sich folgende Fragen:

- Findet sich der vom Militär ausgeübte Druck in den Patientenakten wieder?

- War die Bewertung einheitlich oder lassen sich Unterschiede feststellen?

- Handelte das Militär gegen die ärztliche Expertise?

- Inwieweit zeigten sich die Ärzte den militärischen Interessen gegenüber kooperativ?

- Trafen die behandelten Ärzte die Entscheidung über Behandlungsmethoden, oder wurden diesbezügliche Entscheidungskompetenzen auch an Mitglieder der Assentierungskommission ${ }^{17}$ des Militärs übergeben?

Die hier analysierten Patientenakten sind Teil des Bestandes des Zahnmuseums in den Sammlungen der Medizinischen Universität Wien (MUW). Dieser bislang noch nicht erschlossene Bestand wurde im Zuge der Recherchen für die Arbeit erstmals gesichtet. Ergänzend zu diesem umfangreichen Quellenmaterial wurde der Bestand der „Neuen Feldakten" [NFA] des Kriegsarchivs im Österreichischen Staatsarchiv, insbesondere der Aktenbestand des Armeetappenkommandos ${ }^{18}$, der Abteilung für Sanitätswesen im Armeetappenkommando und der Aktenbestand der k. u. k. Sanitätsanstalten, gesichtet. Zusätzliche Angaben zu den Patienten selbst lassen sich, sofern sie von der jeweiligen Person erhalten geblieben sind, in den Superarbitrierungsakten ${ }^{19}$ und den Hauptgrundbuchblättern des Kriegsarchivs finden.

In den Patientenakten selbst wurden Angaben über den Patienten (z.B.: Geburtsort, Wohnort, Eltern, Religion, Staatsangehörigkeit ${ }^{20}$, Beruf, körperliche Beschaffenheit), detaillierte Daten über Behandlungsschritte und zahlreiche Anmerkungen von Ärzten notiert. Ebenfalls Teil des Patientenaktes sind Vormerkblätter mit Anweisungen an andere Abteilungen und Kliniken sowie militärärztliche Zeugnisse, die ausgestellt wurden, wenn ein Patient um Urlaub ansuchte oder als nicht geheilt entlassen wurde.

16 Vgl:: Otto von SCHJERNING (Hg.), Handbuch der ärztlichen Erfahrungen im Weltkriege, I-VIII (Leipzig 1921-22).

17 Feststellung der militärischen Tauglichkeit.

18 Mit Etappe ist das Gebiet hinter der Front, in dem sich Versorgungsdienste und -einrichtungen, Lazarette, Ersatztruppen sowie Verwaltungsbehörden wie das Armeeetappenkommando befanden. Räumlich erstreckte sie sich während des Ersten Weltkriegs von der Front- bis zur Reichsgrenze. Ab der Reichsgrenze begann das Hinterland. Vgl. dazu: Gerhard HIRSCHFELD, Enzyklopädie Erster Weltkrieg, 465.

19 Der Terminus „Superarbitrierung“ bezeichnet die Feststellung der militärischen Dienst- und bürgerlichen Erwerbsfähigkeit nach einer Verletzung im Einsatz für das Militär.

20 Behandelt wurden Soldaten aus allen Kronländern der Monarchie (darunter auch Zivilpersonen), aus dem Deutschen Reich und Kriegsgefangene (hier aus Russland). Vgl. dazu: Juljan ZILZ, Kriegszahnärztliche Beobachtungen und Erfahrungen. In: Österreichische Zeitschrift für Stomatologie. Sonderabdruck aus Heft 12/13 (Wien 1915) 9. 
In Bezug auf die Sichtbarkeit des Krieges in den Akten ist der Fragenkomplex 721 aus den vorgedruckten militärärztlichen Zeugnissen, die während des Ersten Weltkrieges unverändert blieben ${ }^{22}$, von Interesse:

„7 a) $\mathrm{Ob}$ Aussicht auf vollständige Heilung, d. i. auf Erlangung der Kriegsdiensttanglichkeit, vorhanden ist und in ungefähr welcher Zeit?

b) Ob und zu welcher Dienstleistung der Untersuchte gegenwärtig geeignet ist?

c) Ob der Untersuchte bürgerlich erwerbsfähig ist?'23

Die Beurteilung in den Zeugnissen setzte sich aus militärischen, gewerblichen und medizinischen Aspekten zusammen. Bei der gewerblichen Beurteilung wurde die Berufs-, beziehungsweise Erwerbsfähigkeit geschätzt. Eine eingeschränkte Erwerbsfähigkeit bedeutete nach Definition im militärärztlichen Zeugnis zugleich eine eingeschränkte Wehrfähigkeit. Auf Grund der verminderten Erwerbsfähigkeit hatte der Soldat Anspruch auf eine „Invalidenrente“. Als Maßstab für diesen Leistungsanspruch galten nicht militärische Faktoren, sondern Kriterien in Bezug auf den vor dem Militärdienst ausgeübten Beruf. ${ }^{24}$ Bei schweren Kieferschussverletzungen wurde die Einschränkung in der Regel mit fünfzig Prozent ${ }^{25}$ bemessen. Das Modell der Schätzung und Entschädigung entsprechend dem Grad des Verlustes der Erwerbsfähigkeit hatte seinen Ursprung nicht im Militär und der Ärzteschaft, sondern ging auf die seit 1888 in Österreich geltende Unfallversicherung zurück. Daraus ergab sich, dass die durch den Krieg hervorgerufenen Verletzungen ab 1915 als Art Arbeitsunfall behandelt wurden. ${ }^{26}$ Ohne über eine besondere Ausbildung zu verfügen, fühlten sich Ärzte selbstverständlich dafür zuständig, die Bewertungen der Wehr- und Erwerbsfähigkeit vorzunehmen. Eigeninitiierte Richtlinien ohne gesetzlichen Rahmen dienten als (freiwillig wahrgenommener) Maßstab der Bewertung und besaßen daher eher einen informellen Charakter. ${ }^{27}$

\section{Widersprüche in der Auffassung von Wehrfähigkeit}

Wie unterschiedlich daher die Bemessung der Wehrfähigkeit ausfallen konnte, zeigen die folgenden Patientengeschichten der Infanteristen Stefan T. und Franz Z..

Mit 21 Jahren wurde Franz Z. am 19. Oktober 1914 am San durch einen Granatsplitter im Gesicht schwer verwundet, bereits einen Monat nach dem ersten Einsatz seines Regiments in Zamość (Zamosch, Woiwodschaft Lublin, Polen). Kurz nach dem ersten

21 In den anderen Fragenkomplexen wurde gefragt nach: Angaben zur Person, Befund, Grund der Krankheit, Behandlungsorte, vorhandene Dokumente über die Erkrankung, Verlauf der Erkrankung, weitere Behandlungsschritte.

22 In einigen Fällen wurde der Punkt 7d: „In welchem Berufe will sich der Untersuchte fernerhin betätigen?" mit der Schreibmaschine hinzu gefügt.

23 MUW, Patientenakten, militärärztliche Zeugnisse.

24 In den militärärztlichen Zeugnissen wurde unter Punkt 7c angeben, ob der Soldat den bisherigen Beruf ausüben wolle und mit welchen Einschränkungen er zu rechnen hatte. MUW, Patientenakten der Poliklinik, militärärztliche Zeugnisse.

25 Gustav WUNSCHHEIM, Über Pseudarthrosen des Unterkiefers. In: Emil STEINCHNEIDER (Hg.), Kieferschußtherapie, 197.

26 Harald WENDELIN, Verwundeter Held oder beschädigter Bürger. Die Prinzipien der Kriegsbeschädigtenversorgung in Österreich nach dem Ersten Weltkrieg. Beitrag im Panel: Erinnern und/oder Entschädigen - Formen der Kriegsbewältigung. Kriegsopferversorgung und Denkmalkultur nach 1918; 7. Österreichischer Zeitgeschichtetag (Innsbruck 2008) 3.

27 WUNSCHHEIM, Pseudarthrosen, 197; Adolf DEUTSCH, Anleitung zur Feststellung der Erwerbseinbusse bei Kriegsbeschädigten (Wien 1920). 
Behandlungsurlaub, ging am 13. April 1916 in der "Zahnärəttlichen Abteilung der allgemeinen Poliklinike in Wien" (Poliklinik) ein Dienstzettel mit der Frage nach der Einsatzfähigkeit Franz Z. ein. Die dritte Abteilung des k. u. k. Reservespitals Nr. 17 drängte auf eine Wiedereingliederung in den aktiven Dienst, weil Franz Z. „eine Anstellung bei [der] K.u.K Marine, Flugzengstation in Pola, in Aussicht bätte."28 Der zuständige Arzt und Klinikvorstand, Gustav Wunschheim von Lilienthal, antwortete optimistisch: „Die Behandlung des Genannten wird beiläufig noch zwei Monate dauern. "29

Das bedeutet, man rechnete mit dem erfolgreichen Abschluss der Behandlung Mitte Juni 1916, zwei Jahre vor der tatsächlichen Entlassung. Die behandelnden Ärzte versprachen dem Militär nicht nur einen frühen Behandlungserfolg, sondern auch die Wiedereinsatzfähigkeit in den aktiven Dienst.

Zu diesem Zeitpunkt war man von einer zufriedenstellenden Heilung der Verwundung jedoch noch entfernt. Von Franz Z. wurden in dieser Behandlungsphase Gebissabdrücke angefertigt, und ihm wurden Galerieklammern für die künftige Prothese eingesetzt. Der Kieferknochen war nicht verheilt und eine plastische (bedeutete auch kosmetische) Korrektur der Narben und Weichteile stand ebenfalls noch aus. Eine selbständige und uneingeschränkte Ernährung war Zamecnik noch nicht möglich.

Auch bei Stefan T. wurde eine Pseudarthrose ${ }^{30}$ im Unterkiefer diagnostiziert. In seinem Fall war man bezüglich der Heilungschancen jedoch pessimistischer.

Stefan T. wurde am 29. August 1914 in St. Nicolaje (Galizien, Ukraine) von einem Schrapnell ${ }^{31}$ im rechten Unterkiefer getroffen. Nach der Erstversorgung wurde er in Saluvalia-Ujhely (Ungarn) behandelt, von wo aus er am 1. Oktober 1914 in das Reservespital Nr. 5 überstellt wurde. Von da an wurde er bis zur Entlassung am 18. Jänner 1918 in der Poliklinik behandelt. Mehr als ein Jahr vor der tatsächlichen Entlassung am 20. November 1916 wurde im militärärztlichen Zeugnis von Stefan T. hinsichtlich des Behandlungserfolgs ,vielleicht in mehreren Monaten “ eingetragen. Fünf Monate später zeigte man sich schon weniger optimistisch und der Eintrag zum vorläufigen Therapieende wurde auf „unbestimmter Zeit' verlängert. Grundsätzlich war man aber auch weiterhin von einem Erfolg überzeugt. ${ }^{32}$

Im Jänner 1918 wurde Franz Z. mit dem „Befund D [zu jedem Dienst ungeeignet]“ und mit einer Erwerbsfähigkeit von fünfzig Prozent aus der Behandlung entlassen und der Superarbitrierungskommission vorgestellt. ${ }^{33}$ Die Superarbitrierungskommission setzte jedoch die Bewertung der behandelnden Ärzte nicht um und verminderte mit dem Beschluss vom 9. August 1918 die Berufsunfähigkeit ${ }^{34}$ auf 25 Prozent. ${ }^{35}$ Zamecnik $^{2}$

28 MUW, Patientenakten, Franz Z., Dienstzettel, 13. April 1916.

29 Ebd.

30 Der Terminus „Pseudarthrose“ bezeichnet ein falsches Gelenk an der Bruchstelle bei nicht geheilten Knochenbrüchen.

31 Als Schrapnelle wurden Streugeschosse der Artillerie bezeichnet, die in ihrer Wirkung den Kugeln eines Schrottgewähres ähnelten. Dieter STORZ, Schrapnell. In: HIRSCHFELD, Enzyklopädie Erster Weltkrieg, 820.

32 MUW, Patientenakten, Stefan T..

33 Franz Z. willigte nach der Entlassung in eine weitere Operation (Knochentransplantation) ein, um den Behandlungserfolg zu verbessern. Mit demselben Resultat wurde schließlich am 7. Juni 1918 entlassen. MUW, Patientenakten, Franz Z..

34 Die Berufsunfähigkeit bezieht sich auf den erlernten bzw. den zuvor ausgeübten Beruf. Im Vergleich dazu bezieht sich die Erwerbsfähigkeit auf die Fähigkeit, berufstätig sein zu können, unabhängig vom zuvor ausgeübten oder erlernten Beruf. 
stand damit eine Invalidenpension von jährlich 72 Kronen sowie eine Verwundungszulage von jährlich 96 Kronen auf Lebenszeit zu. ${ }^{36}$ Stefan T. hingegen wurde mit derselben medizinischen Prognose im Juni 1918 mit dem „Befund C [zum Dienste ohne Waffe geeignet]“ aus der Behandlung entlassen. ${ }^{37}$ Die Angaben zur Erwerbsfähigkeit fehlen in den Akten, vermutlich weil er wieder in den aktiven Dienst gestellt wurde.

Wie es zu dieser unterschiedlichen Bewertung bei gleichem Dienstgrad ${ }^{38} \mathrm{kam}$, kann anhand der vorhandenen Quellen nur indizienhaft beantwortet werden. Der Grund lag möglicherweise an den unterschiedlichen Bewertungsmaßstäben der behandelnden Ärzte ${ }^{39}$, deren Ursache in den fehlenden gesetzlichen Bestimmungen zu finden ist. Diese Beurteilungen hatten jedoch weitreichende Konsequenzen für die Soldaten. Während Stefan T. weiterhin dienen musste, stand es Franz Z. offen in seine Heimat zurückzukehren, einen zivilen Alltag zu Leben und wieder Berufstätig zu werden.

\section{Restriktive Maßnahmen des Militärs gegenüber den Patienten}

Der Erste Weltkrieg, die totale Mobilmachung und das restriktive Verhalten des Militärs gegenüber den Soldaten werden besonders eindringlich im Patientenakt von Stefan Ry. sichtbar. Aufgrund der hohen Verluste - bis Ende 1915 bilanzierte man 400.000 gefallenen und in den Spitälern gestorbenen Soldaten und etwa zwei Millionen Verwundete oder Kranke - entstand ein Engpass an einsatzfähigen Soldaten. Weitere Musterungen konnten den Mannschaftsstand nicht mehr ausgleichen, daher wurde angeordnet, die Krankenabgabe möglichst gering zu halten. ${ }^{40}$

Stefan Ry. war 32 Jahre alt, als er am 20. Oktober 1914 in der Gegend von Przemyśl (Premissel, Woiwodschaft Karpatenvorland, Polen) durch einen Gewehrschuss (Durchschuss) am rechten Kiefer getroffen wurde. Wegen seines falschen Aufbisses wurde Stefan Ry. geröntgt, um die „Verbältnisse am rechten Kieferwinkel" festzustellen. ${ }^{41}$ Die Aufnahmen vom 2. Oktober 1915 ergaben folgendes: „Am rechten Unterkieferast ein grosses Stück feblend am aufsteigenden Ast am Längssprung Metallsplitter. " "2

Mit dieser Diagnose wurde er in die Poliklinik überstellt. Als am 14. Jänner 1915 die Behandlung aufgenommen wurde, waren die äußeren Wunden zwar „etwas eingezogen“, aber ansonsten ,vollkommen verheilt‘. Der Splitterbruch hingegen hatte sich zu einer Pseudarthrose entwickelt: „Patient kam zu spät in unsere Behandlung, so daß es trotz der sechsmonatelangen Schienung der gebrochenen Kieferteile nicht mehr gelang, eine knöcherne Vereinigung der Bruchstücke zu erzielen. Patient erbielt schließlich eine untere Prothese als Ersatz. der verloren gegangenen Zähne mit schiefer Ebene links, die das Zurücksinken des Unterkiefers in die falsche Stellung verbindert. Infolge der Pseudarthrose ist der Patient nicht imstande, ordentlich zu kauen." 43

35 KA, NFA, Superarbitrierungsakten, Karton-Nr. 1.354, Superarbitrierungsakt Franz Zamecnik, Superarbitrierungsliste.

36 Ebd.

37 MUW, Patientenakten, Stefan T., militärärztliches Zeugnis.

38 So hatten Offiziere leichteren Zugang zu Spezialnahrung, weshalb ihre militärische Wiedereinsatzfähigkeit höher bemessen wurde als vergleichsweise die von Infanteristen.

39 Franz Z. wurde von Frey und Stefan T. von Ornstein behandelt.

40 HOFER, Nervenschwäche, 340 f.

41 MUW, Patientenakten, Stefan Ry..

42 Ebd.

43 Ebd. 
Mit dem Gesuch, der Superarbitrierungskommision vorstellig zu werden, wurde Stefan Ry. am 19. Juli 1915 als nicht geheilt vom Klinikleiter Gustav Wunschheim von Lilienthal entlassen. Nach Einschätzung von Wunschheim war Stefan Ry. „zu keiner" Zeit mehr militärdiensttauglich. Aufgrund, „seine[r] selbstständige[n] soziale[n] Stellung“ wurde er als voll erwerbsfähig eingestuft. ${ }^{44}$ Gemeint war hiermit, dass es ihm als selbstständigen Landwirt möglich war, zeitlich und organisatorisch flexibel genug zu sein, um eine spezielle Nahrung zu sich nehmen zu können. ${ }^{45}$

Nach der Entlassung aus der Poliklinik sollte Stefan Ry. seine Superarbitrierung im „k.u.k. Barackenlager" in Gmünd (Niederösterreich) abwarten. Von dort wandte er sich am 3. September mit folgendem Anliegen an Wunschheim:

„Sehr geehrter Herr Professor!

Ich komme mit einer großen Bitte zum Herm Professor. Seit der Zeit wo mich Herr Professor zur Superarbitrierung bestimmt und vom Kader aus mich nach Gmünd geschickt haben, leide ich heftige Zahnschmerzen. Ich empfinde dadurch Schmerzen im ganzen Kopf und kann ganze Tage hindurch nichts essen. Ich wollte dem Herrn Professor nichts schreiben und habe bisher geduldig gelitten. Aber jetzt hat mich die k. u. k. Kommission assentiert, mein Leiden gar nicht berïcksichtigt und ich werde in Kürze wider einberufen. Darum ersuche ich höflichst den geebrten Herrn Professor um neue Zäbne, denn mit diesen kann ich absolut nicht essen. Ich bitte vielmals um Einsenden der Zähne denn am 14. dieses Monats fahre ich schon zum Kader.

Hochachtungsvoll verbleib

Stephan Ry.

Gmünd 3. XI. 1916"46

Wunschheim reagiert unverzüglich auf den Brief von Stefan Ry.:

„An das Kommando des k.u.k. Barackenlagers in Gmünd, N.Oe.

Beiliegendes Schreiben des in der dortigen Baracke 105 untergebrachten Korporals Stephan Ry. wurde von diesem an mich als Vorstand der Zabnärztlichen Abteilung der allgemeinen Poliklinik vorgestern gesendet.

Es wird dasselbe mit dem diensthöflichen Ersuchen übermittelt, die Angaben des Korporals ₹u prüfen. Falls sie sich bezüglich seines von uns vor einem Jahre angefertigten Gebisses als richtig erweisen sollten, sind wir gerne bereit, ibm ein neues Unterstück zu machen, doch müßte der Korporal hiezu nach Wien in das Reservespital Nr. 17, Wien, XVIII., Leitermayergasse 45, auf meine dortige Abteilung transferiert werden. Der Korporal stand vom 14. Jänner 1915 bis 19. Juli 1915 wegen einer schweren Splitterfraktur des rechten Unterkiefers an unserer Abteilung in ambulatorischer Behandlung und wurde, da die Fraktur mit einer Pseudarthrose endigte, als zu jedem Dienste ungeeignet mit einer unteren Prothese und beiliegendem Superarbitrierungszengnisse (Abschrift) entlassen. Nach dem klinischen Befunde bei der Entlassung ist es sebr unwabrscheinlich, daß die Pseudarthrose unterdessen von selbst zur knöchernen Verheilung gelangt sein sollte und ist daher seine Angabe, daß er wieder ,assentiert" worden sei, nicht recht glaubwürdig. " "47

Auch die Barackenverwaltung reagiert prompt: "Stefan $\mathrm{Ry}$. ist assentiert und rückt ein ".48 Das Krankenblatt endete am 19. Juli 1915, was bedeutete dass Stefan Ry. nach der zuvor zitierten Korrespondenz nicht mehr in die Behandlung in die zahnärztliche Abteilung aufgenommen wurde. Im Zusammenhang mit der klaren Aussage der

44 MUW, Patientenakten, Stefan Ry..

45 WUNSCHHEIM, Pseudarthrosen, 197.

46 Stefan Ry. verfasste den Brief auf Tschechisch, eine zeitgenössische Übersetzung liegt dem Akt bei. MUW, Patientenakten, Stefan Ry..

47 Ebd.

48 Ebd. 
Barackenverwaltung in Gmünd kann davon ausgegangen werden, dass Stefan Ry. mit einem nicht verheilten Kieferknochenbruch, der es ihm unmöglich machte schmerzfrei und „normal“ zu essen, und mit einer ungenügenden Prothese wieder in den Kriegsdienst geschickt wurde.

Dieses Beispiel aus dem Behandlungsalltag von Stefan Ry. zeigt sehr eindringlich, dass innerhalb des Militärs und dessen Verwaltung nicht die Interessen des Soldaten im Vordergrund standen, sondern militärische Befindlichkeiten. Dem Soldaten wurde die Macht und damit die Entscheidungsmöglichkeit und Verantwortung über den eigenen Körper genommen und vom Militär und den Ärzten während der Dienstzeit übernommen.

\section{Kooperationsbereitschaft der Ärzte}

Neben den zuvor skizzierten restriktiven Maßnahmen des Militärs kam es auch vor, dass Ärzte leichtfertig mit den Verletzungen der Soldaten umgingen.

Oberleutnant Johann St. wurde am 31. August 1914 bei Zamość (Zamosch, Woiwodschaft Lublin, Polen) von einer Gewehrkugel getroffen. Dabei erlitt er eine „doppelte komplizierte Unterkieferfraktur"49. Am 9. April 1915 wurde er mit folgender Diagnose aus der Behandlung entlassen: „Der Herr Oberleutnant ist gegenwärtig zu Kaderdiensten geeignet, für den Frontdienst jedoch noch nicht, da er noch immer eine Schwäche in den unteren Zäbnen als Folge der Schußverletzung hat, die ibm das Kauen harter Nabrung noch nicht erlaubt. Eine vollständige Heilung auch für den Frontdienst ist jedoch mit Sicherbeit an absebbarer Zeit zu erwarten. "50

Johann St. leiste darauf ein Jahr und drei Monate Frontdienst, bevor er wieder in Behandlung kam: „17. VII. [1916] Verlor beim Rückzug von der Strypa sein Unterstück. Klagt auch über gastrische Beschwerden. "51 In Bezug auf die Kieferverletzung und der Fähigkeit sich selbständig zu ernähren heißt es: „Patient besitz̧t im linken Unterkiefer genügend Zähne, um kauen zu können. [...] Das verlorene Unterstück wurde erneuert. Es ist für das Kangeschäft nicht unbedingt nötig und kann im Bedarfsfall von jedem [Hervorhebung im Original] zahntechnischen Laboratorium ausgebessert und erneuert werden. "52

Johann St.'s Magenprobleme wurden in einer anderen Abteilung der Klinik untersucht. Der dortige Arzt Bauer ${ }^{53}$ stellte fest, dass diese nicht im Zusammenhang mit der Kieferverletzung standen. Die Behandlung war damit beendet und Johann St. wurde vier Tage später wieder in den aktiven Dienst gestellt. ${ }^{54}$ Auf die individuellen Beschwerden und die dadurch entstehenden - auch im militärischen Kontext relevanten - physischen Einschränkungen wurde nicht Rücksicht genommen.

Franz Km. wurde am 31. Jänner 1915 in den Karpaten durch einen Streifschuss am Kiefer und am Schultergelenk verwundet. Der Splitterbruch am Unterkiefer wurde wegen der Schulterverletzung nicht rechtzeitig behandelt und führte so zu einer Pseudarthrose. ${ }^{55} \mathrm{Um}$ die Knochenenden wieder zu einer Verwachsung zu bringen, beschlossen die Ärzte eine Knochentransplantation durchzuführen. Knochentrans-

49 MUW, Patientenakten, Johann St..

50 Ebd.

51 Ebd.

52 Ebd.

53 Vorname unbekannt.

54 MUW, Patientenakten, Johann St..

55 Ebd. 
plantationen zählten während des Weltkrieges noch keinesfalls zu den Operationen, bei denen mit einem abschließenden Erfolg zu rechnen war. ${ }^{56}$ Trotzdem prognostizierte Ornstein ${ }^{57}$ Franz Km. im März 1917 eine Wehrfähigkeit in „mebreren Monaten“58. Hans Pichler übernahm im Februar 1917 die "lokale Knochenplastik mit Wangenplastik“". Im Juni 1917 zeichneten sich die ersten Erfolge der Behandlung ab und im September desselben Jahres stellte man schließlich die knöcherne Verheilung des Implantates fest. In den nächsten Monaten folgten die Nachbehandlungen. ${ }^{59}$ Franz Km. zählte zu jenen insgesamt 27 Fällen, bei denen Hans Pichler bis 1917 eine Knochentransplantation durchführte. Eine große Zahl der Patienten jedoch verweigerten die riskante und schmerzhafte Operation, was Hans Pichler als fehlenden „Willen zur Heilung"60 auslegte. Auf die Ängste und Bedürfnisse der Patienten ging er nicht ein, vielmehr unterstellte er ihnen mangelndes medizinisches Verständnis und unverhältnismäßige Genügsamkeit. ${ }^{61}$ Franz Km.’s Schulterverletzung betreffend diagnostizierte die Filiale des Reservespitals Nr. 17 in der Klostergasse folgende Wehrfähigkeit: „Zustand nach Steckschuss der linken Schulter. Einschränkung der Bewegungen im Schultergelenke, besonders des seitlichen Hebens. Schwäche das Faustschlusses. C Landsturmdienst obne Waffe. 1. Februar 1918“.62 Am 28. Mai 1918 wurde er zur Weiterbehandlung, die noch etwa zwei Wochen dauern sollte, wieder in die Behandlung von Hans Pichler übergeben, der an der 1. Chirurgischen Universitätsklinik (Klinik Eiselsberg) arbeitete. Ob und wann Franz Km. wieder in den aktiven Dienst gestellt wurde, geht aus den Quellen nicht hervor. Das für die Entlassung aus dem Militärdienst notwendige militärärztliche Zeugnis wurde von der zuständigen Klinik nicht ausgestellt, was einem erneuten Einsatz gleichkam.

Etwas anders gestaltet sich folgendes Beispiel: Ernst D. wurde am 11. August 1915 nach einer Schussverletzung bei Lwiw (Lemberg, Ukraine) in die Behandlung der Poliklinik aufgenommen. Nach einer erfolgreichen plastischen Operation und der Einpassung der Prothese wurde eine vollständige Heilung von den Ärzten diagnostiziert. Die Narbeneigenschaften waren jedoch noch verbesserungswürdig. Dies hatte nicht nur optische Auswirkungen, sondern erschwerte dem Patienten das Sprechen und Essen. Folgende Schlussbemerkung wurde im Krankenblatt verzeichnet: ,3. VIII. [1916] Dr. Pordes teilt auf eine Anfrage, ob die radiol. Behandlung der Keloid in der Wange Aussicht auf Erfolg bätte, mit, daß ein Erfolg wahrscheinlich ist, aber die Behandlung möglicherweise 3 Monate dauern könnte. Da der Mann geheilt ist, müßte er entweder obne radiol. Behandlung entlassen werden oder auf 3 Monate zu leichten Diensten in Wien untergebracht werden. "63 Die Entscheidung und somit die Verantwortung, ob Ernst D. eine aus dem medizinischen Standpunkt optimale Behandlung zukommen soll, oder ob er wieder gänzlich einsatzfähig geschrieben werden sollte, wurde an die Superarbitrierungskommision, die meist im Sinne des Militärs urteilte ${ }^{64}$, abgegeben.

56 MUW, Patientenakten.

57 Vorname unbekannt.

58 MUW, Patientenakten, Franz K..

59 MUW, Patientenakten, Franz K..

60 Hans PICHLER, Ueber die Knochenplastik am Unterkiefer. In: Vierteljahresschrift für Zahnheilkunde $33 / 3$ (1917) 348-385, hier 383

61 Ebd. 349.

62 MUW, Patientenakten, Franz K..

63 Ebd.

64 Adolf DEUTSCH, Zur Schätzung der Erwerbsverminderung bei Kriegsbeschädigten. In: Der Invalide 2/5 (1. März 1919) 2-3. 


\section{Schlussbemerkungen}

Aus den Patientenakten und den medizinischen Schriften geht hervor, dass eine Behandlung während des Krieges erst dann als erfolgreich angesehen wurde, wenn der Soldat wieder wehrdienstfähig war. Der vom Militär ausgeübte Druck, der unter anderem auch die Frage nach der Dauer der Behandlung und des zu erwartenden Erfolgs beeinflusste, legte den Spielraum und das Behandlungsziel der Ärzte fest. Gleichzeitig spielten Ärzte mit zu optimistischen Prognosen den Militärs in die Hände und machten Verletzte, wie die Beispiele zeigen, wieder zu kalkulierbaren Ressourcen für die Streitkraft. Aus den gesichteten Patientenakten lässt sich die Tendenz erkennen, dass Ärzte eher dazu bereit waren, dem Militär entgegenzuarbeiten, als sich oppositionell zu verhalten. Der Umgang mit den Verwundeten zeigt, dass Mediziner und Mitglieder des Militärs nicht nur auf die medizinischen Erfordernisse eines Krieges reagierten, sondern auch die Chancen eines entgrenzten Zustandes der Medizin genutzt haben, um neue Behandlungsmethoden zu entwickeln und zu erproben.

Zum anderen bedeutete eine erfolgreiche Behandlung zwangsläufig die Wiedereingliederung in den militärischen Apparat und damit die Gefährdung der Gesundheit und des Lebens des Soldaten. Ein möglicher ethischer Konflikt, der durch die Instrumentalisierung der Medizin durch den Krieg entstehen konnte, wurde nicht diskutiert. Vielmehr tauschte man sich über den Nutzen des Krieges und die dadurch gewonnen wissenschaftlichen und praktischen Errungenschaften in der Kieferchirurgie aus.

\section{Autoreninformation}

Mag. Melanie Ruff, Historikerin, Stipendiatin des Instituts für Geschichte der Medizin der Robert Bosch Stiftung. Postadresse: Institut für Geschichte der Medizin, Straußweg 17, 70184 Stuttgart, Deutschland. Mail: melanie.ruff@med-uniwien.ac.at 



\section{Eine typische österreichische Ärztebiographie? Annotationen zu Medizinalrat Dozent Dr. Edwin Albrich}

\section{English Title}

A typical biography of an Austrian physician? Annotations concerning Medizinalrat Dozent Dr. Edwin Albrich

\section{Summary}

This essay investigates the political biography of one of the leading Austrian post War internists. Edwin Albrich was an internationally acknowledged sanatorium doctor whose patients originated from many countries and from all classes, kings as well as farmers and workers. It is argued that it was the academic and professional medical training he received under Nazi rule that made his postwar professional career possible. To prolong his career in the Second Austrian Republic Albrich had to pass a few obstacles. He did this with the support of the new democrat establishment of which he became am member in due course.

\section{Keywords}

Austria, Euthanasia, Montafon, Nazi Medicine, Political Biography, World War II

Am 29. November 1967 schrieb Dr. Edwin Albrich an den Vorarlberger Landeshauptmann Dr. Herbert Kessler, um für den „wunderschönen Festakt zu danken“, der zwei Tage zuvor in der Landeshauptstadt Bregenz stattgefunden hatte und bei dem Albrich das Goldene Ehrenzeichen des Landes Vorarlberg verliehen worden war. ${ }^{1}$ Dieses wurde und wird an maximal 24 Personen vergeben, die ,hervorragende Verdienste um das Land Vorarlberg und auf Sachgebieten, die in der Volliziebung Landessache sind" aufweisen können. ${ }^{2}$ Im Ermittlungsverfahren, das solchen Verleihungen vorausgeht, war mit 8. August 1967 festgestellt worden, dass Dr. Albrich nicht nur wegen seiner medizinischen, sondern auch aufgrund seiner zahlreichen kulturellen, touristischen,

1 Amt der Vorarlberger Landesregierung, Abt. PrsR, Zahl LEZ-46/1966, Schreiben Albrich an Kessler vom 29.11.1967.

2 Vorarlberger Landesgesetzblatt 16 (1963), $₫ 1$ Abs. 1 und $₫ 2$ Abs. 1. 
ökonomischen und sozialen Verdienste besonders für eine Verleihung des erst wenige Jahre zuvor geschaffenen Landesehrenzeichens in Gold qualifiziert sei. ${ }^{3}$

Dem Bericht zum Ermittlungsverfahren ging eine kurze biographische Skizze des Ausgezeichneten voraus, welche die zentralen beruflichen Stationen seiner Karriere benannte. Er führte u. a. Folgendes aus:

„Dr. Edwin Albrich wurde am 13. 7. 1910 in Schruns als Sohn des Standestierarztes Dr. August Albrich geboren. Nach Ablegung der Reifeprïfung an der Realschule Dornbirn im Jabre 1928 studierte er Medizin an der Universität Innsbruck und wurde 1937 zum Doktor der Heilkunde promoviert. Anschließend war er an der I. Universitätsklinik in Wien tätig und wurde 1941 als Facharzt für innere Medizin anerkannt. 1943 ernannte ibn die Universität Wien zum Dozenten. Von 1943 bis 1945 wirkte Dr. Albrich an verschiedenen Webrmachtslazaretten. Im Jabre 1945 ließ er sich als Facharat für innere Medizin in Schruns nieder und übernahm die Leitung des Sanatoriums bzw. des heutigen Krankenhauses Maria Rast, die er bis zum 3.4.1964 inne hatte. Seit 1949 ist Albrich ärztlicher Leiter der Kuranstalt Montafon und seit 1959 ärz̨tlicher Leiter des medizinisch-chemischen Laboratoriums Schruns. ${ }^{\text {“4 }}$

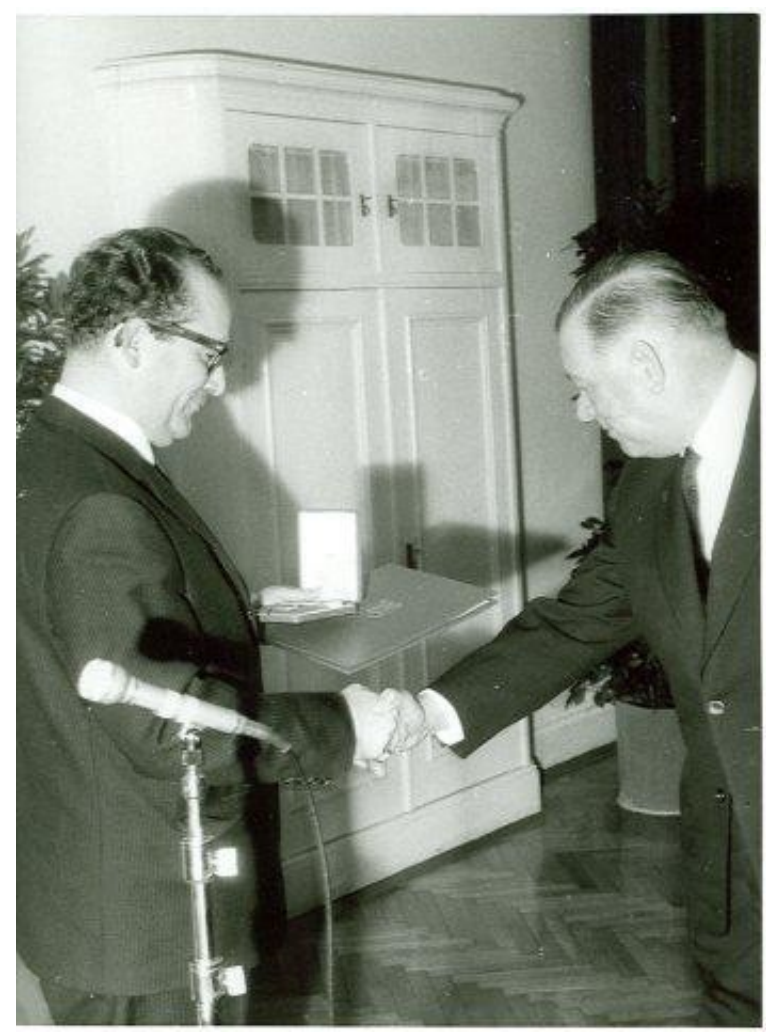

Abb. 1: Ehrenzeichenverleihung 1967: LH Kessler und MR Albrich

3 Amt der Vorarlberger Landesregierung, Abt. PrsR, Zahl LEZ-46/1966, Bericht über die Ergebnisse des Ermittlungsverfahrens vom 08.08.1967, 2.

4 Amt der Vorarlberger Landesregierung, Abt. PrsR, Zahl LEZ-46/1966, Bericht über die Ergebnisse des Ermittlungsverfahrens vom 08.08.1967, 1. 


\section{Unterschiedliche biographische Lesarten eines Lebensverlaufs}

Rund zwei Jahrzehnte zuvor war die Einschätzung des Amtes der Vorarlberger Landesregierung von Dr. Edwin Albrich von weniger Wertschätzung für seine Person geprägt gewesen bzw. legte sie den Fokus auf einen anderen Aspekt seiner Berufskarriere. Mit Wirkung vom 5. März 1946 untersagte sie ihm ,über Anordnung der Militärregierung besw. im Sinne Verbotsgesetzes [...] wegen nationalsozialistischer Betätigung die Ausübung Ibrer ärztlichen Praxis". ${ }^{5}$ Von diesem Berufsverbot waren zahlreiche weitere StandeskollegInnen von Albrich betroffen. Ihre Namen wurden so wie seiner in der Tagespresse veröffentlicht, ${ }^{6}$ nämlich: Siegfried Ausserer (Götzis), Oskar Bauer (Lech), Josef Bitschnau (Bludenz), Karl Blodig (Bregenz), Karl Brutmann (Bludenz), Ludwig Burtscher (Bregenz), Walter Bültemeyer (Sulzberg), Karl Dobnigg (Bregenz), Reinhold Ender (Lochau), Franz Feurstein (Feldkirch), Hermann Fieber (Dornbirn), Leonhard Gaßner (Rankweil), Hilde Hugl (Dornbirn), Adolf Nemecek (Bludenz), Norbert Pfurtscheller (Bludenz), Bruno Rhomberg (Dornbirn), Karl Sollgruber (Dornbirn), Josef Schedler (Dornbirn), Fritz Schinle (Rankweil), Franz von Stefenelli (Dornbirn), Karl Stöckl (Lustenau), Ernst Stolz (Bregenz), Viktor Thurnher (Dornbirn), Josef Vonbun (Rankweil), Hermann Waibel (Dornbirn), August Walser (Schruns). Manche dieser Ärzte etwa Karl Brutmann, Walter Bültemeyer und Josef Schedler waren als Ortsgruppenleiter Funktionäre der NSDAP gewesen. Andere wie Fritz Schinle oder Bruno Rhomberg, der während der NS-Diktatur Abtreibungen an Zwangsarbeiterinnen und Frauen mit geistigen Handicaps vornahm, waren direkt in NS-Verbrechen involviert. $^{7}$

Mit Edwin Albrich und Ernst Stolz wurden im März 1946 die beiden einzigen Internisten in Vorarlberg mit Berufsverbot belegt. Stolz war während der NS-Diktatur als Kreisärzteführer und Kreisamtsleiter für Volksgesundheit in leitender Position für den NS-Staat und die NSDAP tätig. Er galt als ,fanatischer Anbänger der Partei “. 8 Bereits 1933 war er als illegaler Nationalsozialist verhaftet und angeklagt worden, an der Ermordung des Heimwehrmannes Edwin King durch illegale Nationalsozialisten im November 1933 in Lochau am Bodensee beteiligt gewesen zu sein. Von diesem Verdacht wurde er in einer Verhandlung am Landesgericht Feldkirch freigesprochen. ${ }^{9}$ Stolz war nach 1945 und in Anwesenheit der alliierten Besatzungsmächte für eine Ausnahme vom politisch bedingten Berufsverbot zu exaltiert.

Bei Edwin Albrich waren sich die Vorarlberger Behörden über dessen NS-Engagement nicht klar, weil er zur Zeit der NS-Diktatur nicht im Land, sondern in Wien war. Daher gewährten sie ihm am 26. März 1946 eine Ausnahme vom Praxisverbot „bis zur

5 Vorarlberger Landesarchiv (in der Folge: VLA), AVLReg. II-G-133/1946, Bescheid vom 05.03.1946.

Verlautbarungen. In: Vorarlberger Nachrichten (16. März 1946).

$\mathrm{Zu}$ Vorarlbergs MedizinerInnen während der NS-Diktatur siehe: Wolfgang WEBER, Ärzte und Nationalsozialismus in Vorarlberg und im Bregenzerwald. In: Wolfgang WEBER, Kurt BEREUTER, Andreas HAMMERER (Hg.), Nationalsozialismus im Bregenzerwald unter besonderer Berücksichtigung der NS-,Euthanasie“ im Bregenzerwald (=Reihe Bregenzerwald 1, Rankweil 2008) 154-179. Wolfgang WEBER: Aspekte der administrativen Entnazifizierung in Vorarlberg. In: Wolfgang WEBER, Walter SCHUSTER (Hg.), Entnazifizierung im regionalen Vergleich, Linz 2004) 59-96.

8 VLA, AVLReg. IVb-331/1947, Schreiben Bürgermeister Landeshauptstadt an Landesregierung, politisches Gutachten Ernst Stolz vom 17.06.1946.

9 VLA, AVLReg. IVb-331/1947, Schreiben Bürgermeister Landeshauptstadt an Landesregierung, politisches Gutachten Ernst Stolz vom 17.06.1946. 
endgiltigen [sic] Klärung seiner politischen Tätigkeit",10 sicherten so zumindest eine teilweise internistische Versorgung des Landes und forderten am 26. April 1946 bei der Ärztekammer in Wien die Personalakte von Albrich an. ${ }^{11}$ Diese teilte der Landeshauptmannschaft in Bregenz am 10. Mai 1946 mit, dass Albrich in der einschlägigen Kartei der Kammer als NSDAP und SA Mitglied seit 1933 vermerkt sei. ${ }^{12}$ Als solches wurde Albrich in der Folge in den einschlägigen Vorarlberger Listen geführt und nach der Novellierung des Verbotsgesetzes aus dem Jahr 1945 als Nationalsozialistengesetz im Jahr 1947 galt er als minderbelasteter Nationalsozialist. ${ }^{13}$ Bereits am 9. August 1945 hatte das Staatsamt für Volksaufklärung, Unterricht und Erziehung in Wien Albrich wegen seiner NS-Aktivitäten als Dozent für innere Medizin an der Universität Wien entlassen. ${ }^{14}$ Das war im von der Bundeshauptstadt weit entfernten Vorarlberg jedoch nicht bekannt.

Minderbelastete Ärzte waren bis 30. April 1950 von der Berufsausübung ausgeschlossen. Von diesem Berufsverbot konnten sie jedoch durch eine Kommission beim Sozialministerium pardoniert werden. Edwin Albrich erhielt am 2. Juni 1947 durch den Leiter des Landesarbeitsamtes die Mitteilung über sein zeitlich beschränktes Berufsverbot ${ }^{15}$ und reichte am 10. September 1947 ein Gesuch um Ausnahme ein. Sie wurde ihm am 23. Juni 1948 bewilligt. ${ }^{16}$ Gegen seinen Assistenzarzt am Sanatorium Maria Rast, Harald Lehmann, wurde mit 10. Juni 1947 ebenfalls ein bis 1950 beschränktes Berufsverbot als minderbelasteter Nationalsozialist verhängt. ${ }^{17}$ Lehmann beeinspruchte es im Unterschied zu seinem Vorgesetzten jedoch erst ein Jahr später, am 2. Juni 1948, kurz bevor Edwin Albrich amnestiert wurde. Harald Lehmann wurde formell erst über einundeinhalb Jahre nach Ablauf seines ex lege verhängten zeitlichen Berufsverbotes, am 21. Dezember 1951, pardoniert. ${ }^{18}$

Die Einstufung von Edwin Albrich als minderbelasteter Nationalsozialist nach dem Nationalsozialistengesetz, die im Übrigen auch seinen Vater und seine Geschwister betraf, die am 14. November 1947 ebenfalls als minderbelastete Nationalsozialisten

10 VLA, AVLReg. II-G-133/1946, Bescheid vom 26.03.1946.

11 VLA, AVLReg. IVb-14-8/1946, Schreiben Landeshauptmannschaft an Ärztekammer Wien vom 26.04.1946.

12 VLA, AVLReg. IVb-14-12/1946, Schreiben Ärztekammer Wien an Landeshauptmannschaft vom 10.05.1946.

13 Diese Listen sind im VLA überliefert, so etwa eine Liste mit dem Betreff „Verzeichnis jener Ärzte die am 5. März 1946 vorläufiges Praxisverbot erhielten“ oder eine Liste mit dem Betreff „Ärzte, Standesübersicht" vom 01.05.1946, in der Albrich an erster Stelle des Bezirks Bludenz als Belasteter angeführt ist, siehe: VLA, AVLReg., IVb-331/1947.

14 Österreichisches Staatsarchiv (in der Folge: ÖStA), BM Unterricht, Personalakt Edwin Albrich, Schreiben Staatssekretär an Dekanat der medizinischen Fakultät vom 09.08.1946. Nach einer anderen Quelle soll die Entlassung bereits am 6. Juni 1945 erfolgt sein, siehe: ÖStA, BM Unterricht, Personalakt Edwin Albrich, Schreiben BM Wissenschaft an PVA Dornbirn vom 02.09.1977 in: GZ 186285/1 110/77. Vermutlich handelt es sich beim Datum 6. Juni jedoch um einen Schreibfehler, weil im Satz zuvor der 6. Juni 1945 als Veröffentlichungsdatum des Verbotsgesetzes als gesetzliche Grundlage für Albrichs Entlassung zitiert wird. Glaubwürdig ist die in diesem Schreiben zitierte Einstellung der Universitätsbezüge mit 30.06.1945.

15 VLA, AVLReg. II-G-133/1946, Bescheid vom 02.06.1947.

16 VLA, BH Bludenz, NS Registrierungsblätter 1947, Registrierungsblatt Edwin Albrich.

17 VLA, AVLReg. II-G-133/1946, Bescheid vom 10.06.1947.

18 VLA, BH Bludenz, NS Registrierungsblätter 1947, Registrierungsblatt Harald Lehmann. 
registriert wurden, ${ }^{19}$ ermöglichte ihm jene berufliche Karriere, für die er 1967 mit dem Goldenen Ehrenzeichen des Landes Vorarlberg ausgezeichnet wurde. Sein Berufskollege Ernst Stolz hingegen wurde erst in den 1950er Jahren amnestiert. Für ihn stellte das Jahr 1945 und die Befreiung von der NS-Diktatur tatsächlich eine berufliche und biographische Zäsur dar. Für Edwin Albrich hingegen waren die Jahre der NS-Zeit zumindest beruflich ausschlaggebend, denn in den Jahren des Zweiten Weltkrieges konnte er sich an einer der weltweit führenden internistischen Kliniken als Arzt, Forscher und Universitätslehrender etablieren. Dafür suchte und fand er die Nähe zur NSDAP und ihren Organisationen. Deren deutschnationale Ideologie war vermutlich der Andockpunkt, über den Albrich für den Nationalsozialismus rekrutiert wurde.

\section{Deutschnationale Sozialisation und Beginn der NS-Aktivitäten}

Edwin Albrich wurde im deutschnationalen Umfeld sozialisiert. Als Realschüler in seiner Vaterstadt Dornbirn war er Mitglied des Turnvereins Dornbirns, in dem der spätere illegale Vorarlberger Gauleiter und NSDAP Bezirksverbandsleiter Anton Plankensteiner zentrale Funktionen bekleidete und der zwischen 1933 und 1938 eine Plattform für die illegale NSDAP war. ${ }^{20}$ Plankensteiner war wie Albrich Absolvent der von Dornbirner Industriellen und Deutschnationalen initiierten Realschule. ${ }^{21}$

Als Student in Innsbruck trat Edwin Albrich dem Corps Gothia bei, einer durch Südtiroler Studenten im 19. Jahrhundert gegründeten deutschnationalen Verbindung mit Pflichtmensur, von denen er mehrere ausfocht. ${ }^{22}$ Nach Abschluss seiner medizinischen Studien trat er in deren "Altherrenconvent", die sogenannte Kameradschaft Gothia, über. ${ }^{23}$ Das war nach dem 31. Januar 1937. Damals war er bereits vier Jahre Mitglied der NSDAP und der SA. Das Datum des Beitrittes zu diesen beiden NS-Organisationen, welche Albrich 1942 im für sein Habilitationsverfahren eingereichten Lebenslauf angab, ist bemerkenswert. Er schrieb damals: „In die Partei trat ich im Juni 1933 ein, in der SA machte ich seit Oktober 1933 ununterbrochen Dienst. "24

Vier Jahre zuvor, im November 1938, hatte er im Zuge eines durch die SA urgierten Fragebogens diese Beitrittsdaten im Wesentlichen bestätigt. Damals gab er als Parteibeitrittsdatum den Mai 1933 und als SA Beitrittsdatum den Oktober 1933 an. ${ }^{25}$ Es muss daher als gesichert angenommen werden, dass Albrich zumindest der SA, vermutlich jedoch auch der NSDAP, zu einem Zeitpunkt beitrat, als die Hitlerschen

19 VLA, BH Bludenz, NS Registrierungsblätter 1947, Registrierungsblatt August Albrich, Registrierungsblatt Edwin Albrich, Registrierungsblatt Ernst Albrich, Registrierungsblatt Grete Albrich, Registrierungsblatt Guntram Albrich.

20 Zur Geschichte des TV Dornbirn siehe: Wolfgang WEBER, Zur Entwicklung und Bedeutung des TV Dornbirn 1862. In: Dornbirner Schriften. Beiträge zur Stadtkunde 10 (1990), 27-65. Wolfgang WEBER, Von Jahn zu Hitler. Politik- und Organisationsgeschichte des Deutschen Turnens in Vorarlberg 1847-1938 (=Forschungen zur Geschichte Vorarlbergs N.F. 1, Konstanz 1995).

21 Zur Geschichte der Dornbirner Realschule siehe: Wilhelm STÄRK, Geschichte der Dornbirner Realschule (Bregenz 1991).

22 Darauf verweist der von Albrich selbst ausgefüllte Personalfragebogen der SA vom 17.12.1938, in dem er unter besondere Kennzeichen anmerkte: „Mensurnarben an beiden Wangen“, vgl. dazu: Wiener Stadt- und Landesarchiv (in der Folge: WStLA), Gauakt 299.462 Edwin Albrich, Personalfragebogen für die Anlegung der SA-Personalakte vom 17.12.1938, 1.

23 ÖStA, BM Unterricht, Personalakt Edwin Albrich, Lebenslauf vom 21.10.1942, 1.

24 ÖStA, BM Unterricht, Personalakt Edwin Albrich, Lebenslauf vom 21.10.1942, 2.

25 WStLA, Gauakt 299.462 Edwin Albrich, Fragebogen vom 25.11.1938. 
Organisationen in Österreich verboten waren und er sich damit ex lege des Hochverrates schuldig machte. ${ }^{26}$

Nach eigenen Angaben war Edwin Albrich für diese beiden Organisationen auch tatsächlich illegal tätig. In einem ersten, am 17. Dezember 1938 durch ihn unterzeichneten SA Personalfragebogen, gab er an, dass er in der sogenannten Systemzeit „wegen Streitigkeiten mit C.V.ern" zu einer Geldstrafe von 20,- Schilling verurteilt worden war und als SA-Mann in Innsbruck von Oktober 1933 bis Juni 1937 „im Nachrichtenwesen“ tätig gewesen sei. ${ }^{27}$ Von Juli bis Dezember 1937 war er nach eigenen Angaben Mitglied der SS im ersten Wiener Gemeindebezirk, ehe er ab Januar 1938 als Arzt beim Sturmbann I/5 erneut für die SA tätig wurde. 1943 bestätigte der Führer der Standarte 5 in Wien Albrich in einem Personalantrag, ,sehr gute Arbeit für die $S A$ “ zu leisten, der er „im September 1931“ beigetreten und in der er ,auch in der Verbotszeit stets Dienst versehen" habe. ${ }^{28}$

Demnach war Albrichs Beitritt in die SA also nicht erst im Oktober 1933, sondern bereits im September 1931 erfolgt und er führte seine NS-Aktivitäten während der gesamten sogenannten Verbotszeit zwischen 1933 und 1938 weiter. Das qualifizierte ihn nach der Befreiung von der NS-Diktatur im Mai 1945 als illegalen Nationalsozialisten, wofür nach dem am 8. Mai 1945 durch die provisorische Regierung erlassenen Verbotsgesetz ein lebenslanges Berufsverbot vorgesehen war. ${ }^{29}$ Ein Beitritt im September 1931 zur SA war im Hinblick auf seinen Lebensverlauf möglich, denn Albrich hatte nach seinem Realschulabschluss vom 1. Oktober 1928 bis 31. Juli 1930 an der philosophischen Fakultät in Innsbruck die Ergänzungsprüfungen in Latein und Philosophie absolviert und sich mit 1. Oktober 1930 für sein Medizinstudium immatrikuliert. Dieses schloss er im Wintersemester 1936/37 ab.

Die enge Verstrickung von Albrich in die NS-Bewegung bereits in den 1930er Jahre zeigt auch seine Klage im Jahr 1942, dass er „wegen der nationalsozialistischen Gesinnung unserer Familie [...] in der Systemzeit" keine bezahlte Anstellung bekommen hätte. ${ }^{30}$ Tatsächlich arbeitete er nach Abschluss seines Medizinstudiums vom 1. Februar 1937 bis 1 . Juli 1937 als Volontärarzt am pathologischen Institut in Innsbruck und vom 1. Juli 1937 bis zum 1. Juni 1938 ebenfalls als Volontärarzt an der Ersten Medizinischen Klinik in Wien. Ein politisches Gutachten der Vaterländischen Front vom 7. Oktober 1937 verweist jedoch darauf, dass Albrich am 31. März 1937 in seinem Geburtsort Schruns im Montafon der Staatspartei des faschistischen Österreich beigetreten war, die Mitgliedsnummer C 260.319 erhalten hatte und über seine politische Gesinnung

26 Wenige Wochen nach dem sogenannten Anschluss bestätigte Albrich die Beitrittsdaten zur NSDAP (Juni 1933) und zur SA (Oktober 1933) im durch ihn selbst handschriftlich ausgefüllten PersonalFragebogen der NSDAP, auf dem ihm die Parteimitgliedsnummer 6.236073 zugewiesen wurde, vgl. dazu: ÖStA, Gauakt 13.539 Edwin Albrich, Personal-Fragebogen zum Antragschein auf Ausstellung einer vorläufigen Mitgliedskarte und zur Feststellung der Mitgliedschaft im Lande Österreich vom 25.05.1938. Demnach war er von Oktober 1933 bis März 1935 SA Mitglied, von September 1937 bis Januar 1938 SS Mitglied und ab Januar SA Arzt.

27 Darin bestätigte er die Beitrittsdaten zur SA mit Oktober 1933 und zur NSDAP mit Juni 1933, beide Beitritte erfolgten in Innsbruck, vgl. dazu: WStLA, Gauakt 299.462 Edwin Albrich, Personalfragebogen vom 17.12.1038.

28 WStLA, Gauakt 299.462 Edwin Albrich, Personal-Antrag vom 19.02.1943.

29 Den durchgehenden Dienst in der SA, auch während der sogenannten Verbotszeit, bestätigte Albrich in seinem Lebenslauf zum Habilitationsverfahren am 21.10.1942, vgl. dazu: ÖStA, BM Unterricht, Personalakt Edwin Albrich, Lebenslauf vom 21.10.1942, 2.

30 ÖStA, BM Unterricht, Personalakt Edwin Albrich, Lebenslauf vom 21.10.1942, 2. 
„nichts Nacbteiliges bekannt" war. ${ }^{31}$ Das Gutachten war erstellt worden, nachdem Albrich sich im Sommer 1937 um die Zulassung als Hospitant am Wiener Allgemeinen Krankenhaus beworben hatte. ${ }^{32}$ Für eine Anstellung in öffentlichen Institutionen war ein solches Gutachten notwendig und eine Mitgliedschaft in der Vaterländischen Front erwünscht. Das war Albrich bekannt und daher war er wenige Monate vor seiner Bewerbung in Schruns der austrofaschistischen Staatspartei beigetreten.

Den österreichischen Behörden war dieser späte Beitritt Albrichs zur Vaterländischen Front, die 1934 gegründet worden war, verdächtig. Sie luden ihn daher im Herbst 1937 zweimal in die für ihn zuständige Bezirksführung der Vaterländischen Front am Alsergrund in Wien vor, um ihn darüber zu befragen. Albrich folgte diesen beiden Einladungen nicht. Stattdessen legte er eine Bürgschaft des Bundeskommissärs für Personalangelegenheiten, Sektionschef Dr. Fleisch, vor, die ihn als politisch und fachlich geeignet für den Bundesdienst erklärte. Dr. Fleisch intervenierte auch persönlich für ihn ${ }^{33}$ und deswegen wurde er am 21. Februar 1938 als Hospitant zum Dienst in der Bundesfachleitung soziale Verwaltung zugelassen. ${ }^{34}$

Edwin Albrichs Klage in seinem Lebenslauf vom 21. Oktober 1942 über eine vermeintliche Nichtanstellung in der sogenannten Systemzeit ist also nur bedingt zutreffend, er hatte Ende Februar 1938 die Chance auf eine bezahlte Anstellung erhalten und er hatte mit Sektionschef Dr. Fleisch zudem einen Fürsprecher in der austrofaschistischen Verwaltung. Der rund drei Wochen nach seiner bewilligten Aufnahme in den öffentlichen Dienst erfolgte sogenannte Anschluss Österreichs an NS-Deutschland am 11./12. März 1938 machte eine solche Anstellung jedoch obsolet. Für seinen nationalsozialistischen Lebenslauf war dies von Vorteil, denn so konnte er eine „Opferbiographie“ als Nationalsozialist im Austrofaschismus vorweisen, die für ihn im NS-Staat Erleichterungen bringen konnten. Tatsächlich wurde Edwin Albrich nach dem sogenannten Anschluss durch die NSDAP auch mit der sogenannten Erinnerungsmedaille an den 13. März ausgezeichnet. ${ }^{35}$ Diese wies ihn als illegalen und lang gedienten „Kämpfer“ der NS-Bewegung aus. Das wurde durch das Personalamt der Wiener Gauleitung der NSDAP noch dadurch unterstrichen, dass sie Albrich bei der Neuerfassung aller österreichischen NSDAP-Mitglieder mit einem Beitrittsdatum „1.5.1938“ und der Mitgliedsnummer 6.236.073 vermerkte. Das Datum 1. Mai 1938 und eine Nummer aus dem Zahlenblock 6,2 Millionen war jenen österreichischen NSDAP-Mitgliedern vorbehalten, die sich in der sogenannten Verbotszeit zwischen 1933 und 1938 für die NSDAP, ihre Organisationen und ihre Ziele stark engagiert hatten. ${ }^{36}$

31 ÖStA, Gauakt 13.539 Edwin Albrich, Schreiben VF Alsergrund an Landesführung VF Wien vom 07.10.1937.

32 ÖStA, Gauakt 13.539 Edwin Albrich, Schreiben VF Amt Frontführer an Landesführung VF Wien vom 12.02.1938.

33 ÖStA, Gauakt 13.539 Edwin Albrich, Schreiben VF Amt Frontführer an Landesführung VF Wien vom 12.02.1938.

34 ÖStA, Gauakt 13.539 Edwin Albrich, Schreiben VF Landesführung Wien an VF Alsergrund vom 11.10.1937; Schreiben VF Alsergrund an Landesführung Wien vom 16.12.1937; ÖStA, Gauakt 13.539 Edwin Albrich, Schreiben VF Landesführung an Amt des Frontführers vom 21.02.1938.

35 Die Verleihung dieser Medaille dokumentiert Albrich selbst, siehe: ÖStA, BM Unterricht, Personalakt Edwin Albrich, Fragebogen für den Antrag auf Verleihung des Treudienstehrenzeichens am 01.07.1941

36 ÖStA, Gauakt 13.539 Edwin Albrich, Schreiben Gauleitung Wien an NSDAP Gauleitung vom 16.04.1943. 
Es war jedoch besonders die SA, in welcher Albrich sich betätigte und in welcher er auch Karriere machte. Während er in seinen Innsbrucker Jahren für diese nach eigener Aussage als einfacher SA Mann Nachrichtendienste versah, nahm er in der SA nach seinem Umzug nach Wien und einem mehrmonatigen Intermezzo als SS Mann der Wiener SS Motorstaffel III/1137 ab Januar 1938 als Bannarzt leitende und militärisch wichtige Positionen ein. Denn er war für die ,vormilitärische Sanitätsausbildung sowie die sanitäre Betreunng der Webrmannschaften" zuständig. ${ }^{38}$ Im April 1938 wurde er zum Sanitätsobertruppführer befördert, im November desselben Jahres zum Sanitätssturmführer ${ }^{39}$; im Januar 1940 zum Sanitätsobersturmführer; im Januar 1941 zum Sanitätshauptsturmführer; im März 1943 zum Sturmbannführer. Bis 1940 war er 2. Standartenarzt der Standarte 5, ab 1941, nach dem Einrücken seines Vorgängers in dieser Funktion, 1. Standartenarzt.

Die Vorgesetzten von Albrich in der SA waren von ihm als Arzt und Führungskraft vollkommen überzeugt und formulierten das in den jährlichen Beurteilungen entsprechend. Im Oktober 1938 taxierte ihn der Oberführer der Standarte 5 als „,harakterlich sehr gefestigt, geistig und körperlich hochwertig, rein sachlich, kameradschaftlich im und außer Dienst" sowie als „strebsamer und gewissenhafter Sanitätsfübrer, tüchtig in allen Sanitätsangelegenheiten“ bzw. als „tüchtiger, energischer und opferfreudiger Führer".40 Im Januar 1941 wurde er als Mann mit gefestigtem Charakter, hochwertiger und sehr reger geistiger und körperlicher Veranlagung sowie als sachlich und kameradschaftlich und erneut als „sehr tüchtiger und gewissenhafter Sanitätsfübrer" beschrieben. ${ }^{41}$ Im Februar 1943 schließlich war sein Charakter der Beschreibung nach offen und ehrlich sowie sein Verhalten gegen Vorgesetzte und Untergebene korrekt und seine „Führereigenschaften“ gut, weiters sei er ein ,guter Ausbildner, der sich jederzeit für die Ausbildung der Einheiten besonders einsetzt [...] als Standartenarzt sehr gut geeignet, auch für höhere Verwendung“. ${ }^{42}$

Im September 1941 rückte Albrich vom 2. zum 1. Standartenarzt der SA Standarte 5 auf, denn sein Vorgänger als erster Arzt Wilhelm Beiglböck war im Mai zum Kriegsdienst bei der Luftwaffe eingezogen worden. Beiglböck war wie Albrich schlagender Burschenschafter, Internist an der Wiener I. Universitätsklinik und Schüler Hans Eppingers. 1939 wurde er habilitiert, 1940 Oberarzt bei Eppinger. Gemeinsam mit Albrich untersuchte er die therapeutische Wirkung von Laktoflavin insbesondere bei Diabetes und sie konnten nachweisen, dass Laktoflavin bei Diabetes Zucker senkend wirkt. ${ }^{43} 1944$ wurde Beiglböck nach drei Jahren Kriegsdienst als Stabsarzt der Luftwaffe, wo er u.a. leitender Internist im Luftwaffenlazarett in Tarvis (Tarvisio, Trbiž) im Kanaltal war, zum außerplanmäßigen Universitätsprofessor für Interne Medizin an der Universität Wien berufen. Noch im selben Jahr führte er mit Wissen von Eppinger im Konzentrationslager Dachau mit Roma und Sinti Häftlingen

37 So seine Angabe zur SS Aktivität, siehe: ÖStA, Gauakt 13.539 Edwin Albrich, Personal-Fragebogen zum Antragschein auf Ausstellung einer vorläufigen Mitgliedskarte und zur Feststellung der Mitgliedschaft im Lande Österreich vom 25.05.1938, 2.

38 WStLA, Gauakt 299.462 Edwin Albrich, Karteikarte.

39 WStLA, Gauakt 299.462 Edwin Albrich, Personalfragebogen für die Anlegung der SA-Personalakte vom 17.12.1938, 2.

40 WStLA, Gauakt 299.462 Edwin Albrich, Beurteilung für SA-Sanitätsführer vom 15.10.1938 sowie Personalantrag vom 15.10.1938.

41 WStLA, Gauakt 299.462 Edwin Albrich, Beurteilung für SA-Sanitätsführer vom 08.01.1941.

42 WStLA, Gauakt 299.462 Edwin Albrich, Beurteilung für SA-Sanitätsführer vom 16.02.1943.

43 ÖStA, BM Unterricht, Personalakt Edwin Albrich, Stellungnahme Eppinger zu Ansuchen Albrich um Verleihung des Dr. med. habil. vom 10.12.1942, 2 f. 
Versuche über die Verträglichkeit von Meerwasser als Trinkwasser bei Menschen durch. Für dieses Kriegsverbrechen wurde er am 20. August 1947 in den Nürnberger Ärzteprozessen zu 15 Jahren Haft verurteilt. Am 15. Dezember 1951 wurde er vorzeitig entlassen, fand eine Anstellung an der Universitätsklinik Freiburg i. Br. bei einem vormaligen Luftwaffen- und nun leitenden Spitalarzt und wurde 1953 leitender Internist am städtischen Krankenhaus Buxtehude. ${ }^{44}$

Ein letzter Hinweis auf Albrichs zusehende Etablierung in der österreichischen NSElite in der zweiten Hälfte der 1930er Jahre ist seine Teilnahme am Kurs der sogenannten Führerschule der deutschen Ärzteschaft in Alt-Rhese. Sie wurde 1935 durch den Nationalsozialistischen Deutschen Ärztebund gegründet und hatte das ausschließliche Ziel, Ärzte und Ärztinnen, Apotheker wie Apothekerinnen und Hebammen ideologisch im Sinne des Nationalsozialismus zu schulen. Am 17. Dezember 1938 gab Albrich in seinem SA Personalfragebogen selbst an, dass er die Schule in Alt-Rehse absolviert habe. ${ }^{45}$ Das heißt, dass er sie entweder sehr früh nach dem sogenannten Anschluss oder noch während der Illegalität und unter den ersten drei Ausbildungsjahrgängen besuchte. In dieser Zeit kennzeichnete die Schule noch ganz der Elitegedanke, sie verstand sich selbst als Ausbildungsstätte der NSGesundheitselite und war nur politisch verlässlichen NSDAP-Mitgliedern insbesondere aus den Universitäten vorbehalten. Lediglich jeder sechste Arzt in NS-Deutschland war zu diesem Zeitpunkt zu einem Kurs zugelassen worden. Die Auslese blieb streng und wer einen Platz erhielt, war aus Sicht des NS-Staates ein verlässlicher Bürger mit Zukunftspotential..$^{46}$

Alt-Rehse bildete nicht fachlich aus, sondern die rund 100 Teilnehmer bzw. Teilnehmerinnen pro Kurs wurden auf die nationalsozialistische Gesundheitspolitik eingeschworen und sollten diese zurück im Beruf konsequent umsetzen. $\mathrm{Zu}$ den Unterrichtsgegenständen zählten Lehrveranstaltungen über die sogenannten Nürnberger Rassegesetze, die angebliche Rassenbiologie, militärmedizinische Fächer wie Gasschutz und Sanitätstaktik, die Anwendung der sogenannten Euthanasie an Menschen mit Handicaps, aber auch Naturheilkunde und Ernährungswissenschaften.

\section{Erfolgreiche berufliche Etablierung im NS-Staat}

Am 1. Juni 1938 erhielt Edwin Albrich als Hilfsarzt an der I. Universitätsklinik in Wien seine erste bezahlte Stelle als Mediziner seit Abschluss seiner Studien im Januar 1937, rund zwei Monate nach dem sogenannten Anschluss Österreichs an NS-Deutschland. Am 1. Oktober 1940 wurde er an derselben Klinik wissenschaftlicher Assistent bei Univ.-Prof. Dr. Hans Eppinger. Eppinger war ein anerkannter Spezialist für Lebererkrankungen und Kreislaufstörungen, Themenfelder, die auch Albrichs wissenschaftliches Arbeiten prägen sollten.

In Eppinger fand Edwin Albrich jenen Förderer, der für eine akademische und berufliche Karriere notwendig ist. Eppinger beglaubigte nicht nur Albrichs von den

44 Zur Biographie von Wilhelm Beiglböck siehe:

http://de.metapedia.org/wiki/Beiglb\%C3\%B6ck,_Wilhelm UND

http://de.wikipedia.org/wiki/Wilhelm_Beiglb\%C3\%B6ck (Zugriff 22.08.2011).

45 WStLA, Gauakt 299.462 Edwin Albrich, Personalfragebogen für die Anlegung der SA-Personalakte vom 17.12.1938, 6 .

46 Zur Geschichte dieser NS-Kaderschmiede siehe jüngst etwa die Dissertation von Thomas MAIBAUM, Die Führerschule der deutschen Ärzteschaft (Univ. Diss. Hamburg 2007). 
Behörden mehrfach eingeforderten „Ariernachweise“ ${ }^{\text {“47 }}$ persönlich, er verwandte sich auch mehrfach und erfolgreich für eine Uk-Stellung von Albrich bei dessen Einberufungen zum Militärdienst ab $1940 .{ }^{48}$ Er integrierte ihn in sein wissenschaftliches Forschungsteam an der Internen Medizin, dem u.a. Wilhelm Beiglböck angehörte. Er ließ ihn selbständig eine interne Abteilung und Ambulanzen führen. Er beauftragte ihn mit Lehrverpflichtungen etwa der Abhaltung von Perkussionskursen und praktische Übungen für Medizinstudierende; und er setzte ihn als Lehrer an der Schwesternschule des AKH und als Leiter der Diätschule ein. Mit dem Wintersemester 1942/43 las Albrich auf Eppingers Vermittlung auch an der Universität Wien über die diätetische Behandlung innerer Erkrankungen. ${ }^{49}$

Schließlich war Eppinger auch der Promoter für Albrichs Habilitation, die er am 21. Oktober 1942 mit einer Schrift über die Bedeutung der B-Vitamine für die Permeabilität der Kapillaren einreichte. ${ }^{50}$ Am 3. Juni 1943 hielt er seinen Habilitationsvortrag über die Therapie der doppelseitigen hämatogenen Nierenerkrankung. Am 30. Juli 1943 verlieh ihm der Reichsminister für Wissenschaft, Erziehung und Volksbildung „im Namen des Führers" die Ernennung zum Dozenten und die Venia legendi für das Fach Innere Medizin und wies ihn der Universität Wien zu. ${ }^{51} \mathrm{Zu}$ diesem Zeitpunkt ,wirkte Dr. Albrich an verschiedenen Webrmachtslazaretten" wie es in seinem für die Verleihung des Goldenen Ehrenzeichens des Landes Vorarlberg rekonstruierten eingangs zitierten Lebenslauf hieß.

Tatsächlich war Edwin Albrich mit 5. März 1943 zum Militärdienst bei der Waffen-SS in das SS Führungs-Hauptamt und SS-Sanitätsamt nach Berlin-Charlottenburg als einfacher SS Mann einberufen worden. ${ }^{52}$ Seine Grundausbildung in der Waffen-SS absolvierte er beim 3/SS San. Ers. Batl. in Stettin. ${ }^{53}$ Am 15. April 1943 versuchte sein Mentor Eppinger ihn noch einmal mit Verweis auf seine berufliche und wissenschaftliche Qualifikation vom Wehrdienst zurückzustellen, in dem er darauf verwies, dass Albrich ,inmitten wichtiger Forschungsarbeiten auf einem derzeit sehr wichtigen Gebiet, nämlich der Nierenerkrankung, insbesondere der Feldnephritis“" stecke und er daher in Wien nicht nur ,für die Aufrechterhaltung des klinischen Betriebes", sondern auch für die Forschung dringend gebraucht werde..$^{54}$

47 So etwa am 07.12.1938 und am 13.12.1938 siehe Fragebogen Formblatt 2, Anzeige über Verheiratung Formblatt 3 sowie Formblatt Zl. IV-1-41511-b in: ÖStA, BM Unterricht, Personalakt Edwin Albrich.

48 ÖStA, BM Unterricht, Personalakt Edwin Albrich, Schreiben Rektorat Universität Wien an Kurator Hochschulen vom 03.03.1941, Schreiben Eppinger an Reichserziehungsministerium vom 18.02.1942, Schreiben Eppinger an Reichsministerium für Wissenschaft, Erziehung und Volksbildung vom 15.04.1943.

49 ÖStA, BM Unterricht, Personalakt Edwin Albrich, Stellungnahme Eppinger zu Ansuchen Albrich um Verleihung des Dr. med. habil. Vom 10.12.1942, 1.

50 Edwin ALBRICH, Die Bedeutung der B-Vitamine für die Permeabilität der Capillaren. Ein Beitrag zum Nephrose-Nephritis-Problem (Berlin 1943).

51 ÖStA, BM Unterricht, Personalakt Edwin Albrich, Urkunde vom 30.07.1943.

52 ÖStA, BM Unterricht, Personalakt Edwin Albrich, Meldung über eine Wehrmachtseinrückung vom 04.03.1943. Die meldung ist auch dokumentiert in: WStLA, Gauakt 299.462 Edwin Albrich, Meldung über eine Wehrmachtseinrückung vom 04.03.1943.

53 ÖStA, BM Unterricht, Personalakt Edwin Albrich, Schreiben Eppinger an Reichsministerium für Wissenschaft, Erziehung und Volksbildung vom 15.04.1943.

54 ÖStA, BM Unterricht, Personalakt Edwin Albrich, Schreiben Eppinger an Reichsministerium für Wissenschaft, Erziehung und Volksbildung vom 15.04.1943. 
Im Unterschied zu 1940/41 als es Eppinger gelang, das Oberkommando der Wehrmacht davon zu überzeugen, Albrich in die militärische Forschungsabteilung zu übernehmen und ihn dann ihm selbst als wissenschaftlichen Mitarbeiter an die I. Universitätsklinik zuzuweisen, ${ }^{55}$ war er 1943 mit seiner Intervention beim Reichsministerium für Wissenschaft, Erziehung und Volksbildung nicht erfolgreich und sein Schüler versah bis Kriegsende 1945 Dienst bei der Waffen-SS. Aus den Quellen wird nicht ersichtlich, wo dieser Dienst nach der Grundausbildung geleistet wurde. Dokumentiert ist nur, dass Edwin Albrich mit dem Orden der Krone Rumäniens ausgezeichnet wurde, nicht jedoch mit welcher der fünf Klassen dieses Ordens. ${ }^{56}$ Mündlich überliefert wird, dass er Leibarzt des rumänischen faschistischen Diktators Ion Antonescu gewesen sein soll. ${ }^{57}$ Tatsächlich gab es in Rumänien bis 1944 „Kuranstalten“ für Angehörige der Waffen-SS.

Die Marktgemeinde Schruns berichtete 1966 im Zuge des Ermittlungsverfahrens zur Verleihung des Goldenen Ehrenzeichens, dass Edwin Albrich ,während des Dienstes bei der Webrmacht [sic] leitender Internist von Lazaretten, hierbei mit der Organisation und Neueinrichtung von 4 Lazaretten betraut" 58 gewesen sei.

Mehr ist über seine aktive Kriegsdienstzeit nicht bekannt. Nach der Befreiung von der NS-Diktatur 1945 kehrte Albrich nach Vorarlberg zurück und übernahm in seiner Geburts- und Heimatgemeinde Schruns im Montafon das Sanatorium Maria Rast.

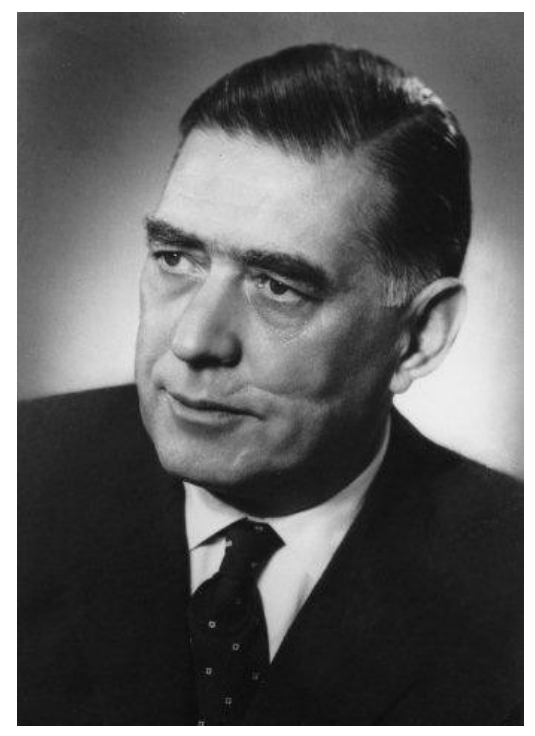

Abb. 2: Porträt Dr. Edwin Albrich.

55 ÖStA, BM Unterricht, Personalakt Edwin Albrich, Schreiben Eppinger an Rektorat Universität Wien vom 26.02.1941.

56 Siehe dazu die diversen Todesanzeigen und Nachrufe in: Amt der Vorarlberger Landesregierung, Abt. PrsR, Zahl LEZ-46/1966. Die Klassen des Ordens sind: Großkreuz, Großoffizier, Kommandeur, Offizier, Ritter.

57 Ich danke Mag. Christina Arnold (Birgitz) und Bruno Winkler (Schruns) für diesen Hinweis.

58 Amt der Vorarlberger Landesregierung, Abt. PrsR, Zahl LEZ-46/1966, Lebenslauf von Medizinalrat Dozent Dr. Albrich Edwin Marktgemeinde Schruns 30.09.1966. 


\section{Fortsetzung der erfolgreichen Berufskarriere in der Zweiten Republik}

Nach seiner politischen Amnestierung durch die Repubik Österreich initiierte Edwin Albrich ab 1948 die Errichtung einer Kuranstalt Montafon in Schruns. Sie wurde 1950 eröffnet und er leitete sie bis zu seiner Pensionierung. Zugleich stand er bis zum 3. April 1964 dem Sanatorium und Krankenhaus Maria Rast vor. 1959 gründete er das erste medizinisch-chemische Labor in Vorarlberg in Schruns und stand diesem als Geschäftsführer bis zu dessen Absiedlung an das neue Landeskrankenhaus in Feldkirch vor. ${ }^{59}$

Arnold Durig, aus Schruns gebürtig, Ordinarius für Physiologie an der Universität Wien und im Mai 1938 von der NS-Diktatur zwangspensioniert, fasste Ende der 1950er Jahre Edwin Albrichs Wirken in Schruns nach dem Zweiten Weltkrieg folgendermaßen zusammen:

„Das Werk, das Albrich in Schruns aus dem Nichts geschaffen hat - und dies muss besonders betont werden - er schuf es obne jede Subvention nur durch eigene Leistung und eigenen Erfolg, erhält er ertragreich für Schruns und das Tal und damit auch für Vorarlberg, ausschließlich auf Grund seiner eigenen hervorragenden Leistungen, unterstützt von im gleichen Geiste arbeitenden Äržten und seinen Schülern. Aus Wissen und Erfahrung als ehemaliger Akademiker in Wien und Lebrer von 16.000 Studenten schätze ich die Leistungen Albrichs als eines gründlich wissenden Internisten, Pathologen, Physiologen und als geradezu gottbegnadeten Arztes äußerst boch ein. Schruns, von dessen ärztlicher Tätigkeit früher außer dem Tal wohl niemand wusste, ist zu einem weltbekannten Kurort geworden und hat dadurch auch einen ungeabnten Aufschwung während des ganzen Jahres genommen. [...] Nicht nur prominente und führende Persönlichkeiten von Bundes- und Landesregierung, der Industrie und Technik aus ganz. Österreich kommen nach Schruns, sondern prominente Kranke aus entferntesten Ländern - aus Amerika, dem Orient, Ägypten wie auch aus Deutschland, Frankreich, England, Italien, der Schweiz u.a. mehr [...]." "60

Tatsächlich ist die Liste prominenter Patientinnen und Patienten, die in Schruns bei Edwin Albrich abstiegen, sehr lang. Aus dem Orient, dem Irak, etwa kam König Faisal II. Aus Deutschland der spätere Bundeskanzler Helmut Kohl. Aus den beiden Amerikas Ernst Rüdiger Starhemberg und Rosa Waldinger.

Starhemberg, der noch 1923 beim sogenannten Marsch auf die Feldherrenhalle von Adolf Hitler beteiligt war, sich dann aber dem italienischen Faschismus zuwandte und mit der Heimwehr in Österreich wesentlich zum Aufbau des austrofaschistischen Staates beitrug, war Ende 1955 aus dem argentinischen Exil nach Österreich zurückgekehrt und nach dem Jahreswechsel als Kurgast zu Edwin Albrich nach Schruns gekommen. Dort starb er bei einem Spaziergang in der Nähe der Kuranstalt an einem Herzinfarkt, angeblich weil er von einem kommunistischen Fotografen drangsaliert worden war. Tatsächlich hatte die KPÖ in dieser Zeit gegen die Anwesenheit von Starhemberg, vor allem aber gegen die 1955 beschlossene Restitution seiner Güter durch die Republik Österreich agitiert. ${ }^{61}$

59 Nachruf Med.-Rat Dozent Dr. Edwin Albrich. In: Vorarlberger Nachrichten (21. September 1976).

60 Amt der Vorarlberger Landesregierung, Abt. PrsR, Zahl LEZ-46/1966, Lebenslauf von Medizinalrat Dozent Dr. Albrich Edwin Marktgemeinde Schruns 30.09.1966.

61 Jürgen WEBER, Wolfgang WEBER, „Jeder Betrieb eine rote Festung!“ Die KPÖ in Vorarlberg 19201956 (=Schriftenreihe der Rheticus Gesellschaft 32, Dornbirn 1994. 


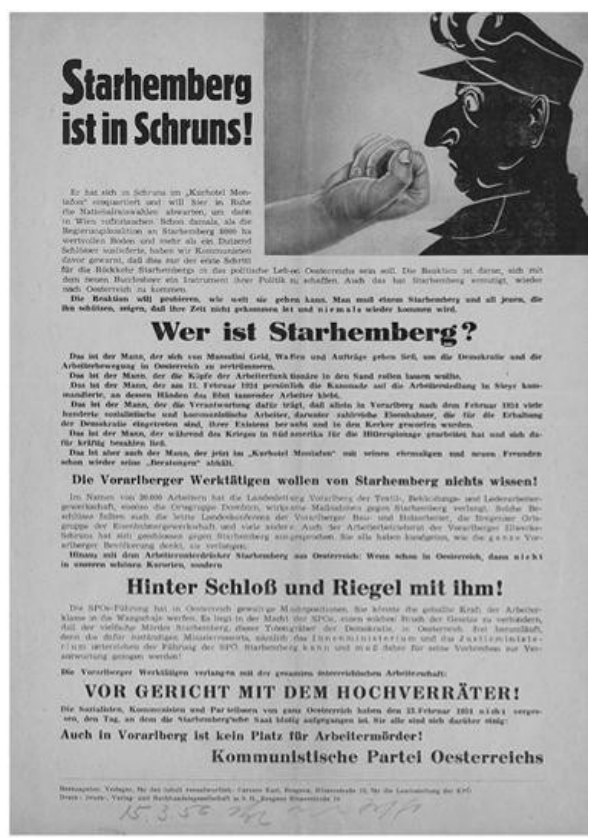

Abb. 3: Anti-Starhemberg-Flugblatt der KPÖ 1956

Beatrice Rosa Waldinger, geborene Winternitz, war aus den USA zu Edwin Albrich gekommen - mit ihrem Ehemann, dem Literaten Ernst Waldinger. Rosa war eine Tochter der jüngsten Schwester von Sigmund Freud, Pauline Regine Freud. Sie war Ende des 19. Jahrhunderts mit ihrem Ehemann Valentin Winternitz nach New York gezogen, wo ihre Tochter Rosa 1896 geboren wurde. Nach dem Tod von Valentin Winternitz 1900 zog die Familie zurück nach Wien. 1923 heiratete Rosa den Schriftsteller Ernst Waldinger, einen Mitarbeiter ihres Onkels Alexander Freud. 1938 mussten beide als Menschen jüdischen Glaubens vor der NS-Verfolgung über Paris und London in die USA flüchten, deren Staatsbürgerin Rosa war. Ihr Mann Ernst Waldinger wurde nach 1945 von der KPÖ eingeladen, doch aus dem Exil nach Österreich zurückzukehren und hier als Kulturschaffender zu wirken. Dieses Angebot lehnte Rosa jedoch ab, u.a. weil ihre Mutter und zwei Tanten im Vernichtungslager Treblinka ermordet worden waren. Ernst Waldinger besuchte daher Österreich nach 1945 nur mehr für Vortragsreisen. Bei einer solchen, 1969, zu der ihn seine Frau Rosa begleitete, und die er um einem Kuraufenthalt in Schruns erweiterte, erlitt er einen Schlaganfall. Er wurde aber soweit wiederhergestellt, dass er bettlägerig nach New York überstellt werden konnte. Dort verstarb er 1970. Seine Frau Beatrice Rosa hingegen, die nie nach Österreich zurückkehren wollte, echauffierte sich im Zuge seiner Erkrankung so sehr, dass sie einen Herzinfarkt erlitt und in Schruns verstarb. ${ }^{62}$

62 Ich danke Bruno Winkler (Schruns) für diesen Hinweis, siehe auch: http://www.dasrotewien.at/page.php?P=13907;

http://www.library.vanderbilt.edu/central/Waldinger.html;

http://www.literaturhaus.at/index.php?id=8243 (Zugriff 22.08.2011). 
Edwin Albrich verstarb wenige Jahre nach Waldingers Tod ebenfalls. Am 18. September 1976 erlag er einer schweren Krankheit und wurde, als Ehrenbürger der Marktgemeinde Schruns seit 1960, am 24. September 1976 am dortigen Friedhof unter große Anteilnahme begraben. ${ }^{63}$

Im November 1967, in seinem eingangs zitierten Schreiben an Landeshauptmann Herbert Kessler schrieb Albrich: „Ich zitiere immer aus Wilhelm Tell. Ich komme nicht mehr gerne zu langen Beratungen und Besprechungen, braucht ibr aber jemanden zu einer bestimmten Tat, dann ruft den Tell, es soll an mir nicht fehlen. Ich bin immer bereit."64 Angesichts der hier geschilderten Details zu seiner beruflichen und politischen Karriere gewinnen diese Worte eine besondere Bedeutung.

\section{Fazit}

Edwin Albrichs Berufsleben ist in dem Sinn eine typische österreichische Ärztekarriere, als dass sie nicht einmalig, sondern eine unter vielen ist. Darauf verweist etwa jene seines hier ebenfalls vorgestellten Arbeits- und Standeskollegen Wilhelm Beiglböck oder die hohe Anzahl von aufgrund ihrer NS-Tätigkeit belasteten Ärztinnen und Ärzte in Vorarlberg ebenso wie in Österreich. ${ }^{65}$ Die wissenschaftliche Literatur, in Deutschland wie in Österreich, kennt viele solcher Beispiele, jüngst etwa stellten Lisa Rettl und Peter Pirker eine weitere zu Albrich vergleichbare Biographie eines österreichischen NS-Arztes, nämlich Sigbert Ramsauer, vor. ${ }^{66}$

Edwin Albrich wurde in der NS-Zeit medizinisch und wissenschaftlich so gut ausgebildet, dass er auf Basis dieser Ausbildung nach 1945 eine erfolgreiche Karriere als international beachteter Kurarzt machte. Das verweist darauf, dass die NS-Medizin, unter dem Vorbehalt der Menschenrechtsverbrechen die sie beging, sehr modern war und nachhaltig ausbildete. Sie war etwa in der Forschung mit der internationalen Entwicklung zumindest gleich auf und setzte dort Maßstäbe, die auch Jahrzehnte später noch Gültigkeit haben. Albrichs 1939/41 erstellte und neben anderen zur Habilitation eingereichte Studie über den Zusammenhang von Lipiden und Koronarer Herzkrankheit ist noch heute state of the art für Diagnose und Behandlung einschlägiger Erkrankungen. Ähnliches gilt für den von ihm Anfang der 1940er Jahre dokumentierten Zusammenhang zwischen Diätetik und Herz-Kreislauf-Erkrankungen und der Rohkost als eine unter vielen Behandlungsmethoden für Menschen mit Gefäßerkrankungen. Die Bedeutung der von ihm und Beiglböck erkannten therapeutische Wirkung von Laktoflavin insbesondere bei Diabetes wurde hier bereits erwähnt - und seine durch den Einzug zum Kriegsdienst bei der Waffen-SS unterbrochenen Arbeiten über Leber- und Nierenerkrankungen ergänzten zumindest jenes erworbene internistische

63 Amt der Vorarlberger Landesregierung, Abt. PrsR, Zahl LEZ-46/1966, Todesanzeigen vom 19. und 24.09.1976.

64 Amt der Vorarlberger Landesregierung, Abt. PrsR, Zahl LEZ-46/1966, Schreiben Albrich an Kessler vom 29.11.1967.

$65 \mathrm{Zu}$ den Vorarlberger NS-Ärzten siehe: Wolfgang WEBER, Ärzte und Nationalsozialismus in Vorarlberg und im Bregenzerwald. In: Wolfgang WEBER, Kurt BEREUTER, Andreas HAMMERER (Hg.), Nationalsozialismus im Bregenzerwald unter besonderer Berücksichtigung der NS-,Euthanasie“ im Bregenzerwald (=Reihe Bregenzerwald 1, Rankweil 2008) 154-179. Wolfgang WEBER: Aspekte der administrativen Entnazifizierung in Vorarlberg. In: Wolfgang WEBER und Walter SCHUSTER (Hg.), Entnazifizierung im regionalen Vergleich, Linz 2004) 59-96.

66 Lisa RETTL, Peter PIRKER, "ICH WAR MIT FREUDEN DABEI". Der KZ-Arzt Sigbert Ramsauer - Eine österreichische Geschichte (Wien 2010). 
Wissen, auf dem er nach 1945 eine beeindruckende Karriere als Internist, Kurarzt und „Volksmediziner" realisieren konnte. Denn es gibt, u.a. vom durch die NS-Diktatur verfolgten und hier bereits zitierten Physiologen Arnold Durig, zahlreiche Hinweise, dass Edwin Albrich Menschen, die es sich finanziell nicht leisten konnten, aber krank waren, gratis behandelte. Das zeigt, dass er trotz (oder gerade wegen?) seiner politisch einschlägigen Überzeugung in den 1930er und 1940er Jahren die menschliche Dimension nie vergaß und sie täglich praktizierte.

Sein physisches Erbe, die Kuranstalt Montafon mit der zumindest im Tal legendären Goldschlüsselbar, blieb räumlich bis zur Gegenwart bestehen. Der Kurbetrieb wurde allerdings ein Jahrzehnt nach seinem Tod eingestellt und die Gebäude dem Verfall Preis gegeben. 2010 beschloss der Schrunser Gemeinderat den Abriss des Hotels. ${ }^{67}$ Vor dem Abriss erhielt eine Gruppe von internationalen Künstlerinnen und Künstlern unter Anleitung von Ines Agostinelli und Roland Haas noch die Möglichkeit, die Kuranstalt zur Bühne einer beeindruckenden Kunstaktion zu machen. ${ }^{68}$ Erst im Rahmen dieser künstlerischen Interventionen und in der abschließenden Projektpräsentation wurde die NS-Vergangenheit von Edwin Albrich erstmals zumindest im öffentlich-rechtlichen Fernsehen und Radio sowie im 2010 erschienen Begleitband zum Kunstprojekt problematisiert. ${ }^{69}$ Roger Martin Buergel, künstlerischer Leiter der „documenta 12" in Kassel, fand in seiner Einleitung zum Begleitband eine treffende Beschreibung für das physische Vermächtnis von Edwin Albrich und der Stellung eines Biographen in der Geschichte. Er schrieb:

„Nicbt immer ist bistorisches Erbe auffindbar. Nicht immer ist klar, wie man sich seiner bemäcbtigt. Falltüren tun sich auf beim Gang durch die Geschichte, und so kommt man ins Straucheln. Wer die nötige Wachbeit besitzt, mag Schätze entdecken. Oder schwarze Löcher, die nie und nimmer etwas preisgeben - nichts jedenfalls, was sich zur Wabrheit in Beziebung setzen lässt. So ist es bei der Kuranstalt." ${ }^{\star 70}$

\section{Autoreninformation}

Mag. Dr. Priv.-Doz. Weber Wolfgang, MA (UCL), MAS, geb. 1964, Akademischer Politischer Bildner, Privatdozent am Institut für Zeitgeschichte und Lektor am Institut für Geschichtswissenschaften und Europäische Ethnologie der Universität Innsbruck; Stabstelle Abteilung Gesellschaft, Soziales, Integration beim Amt der Vorarlberger Landesregierung in Bregenz. Postadresse: Institut für Zeitgeschichte, Innrain 52/6, 6020 Innsbruck, Österreich. Mail: wolfgangsta@aon.at

67 Kuranstalt in Schruns wird abgerissen. In: http://vorarlberg.orf.at/stories/484718/ (Zugriff 31.08.2011).

68 Die Ergebnisse dieser Kunstaktion sind in einem fantastischen Bildband dokumentiert, vgl.: Ines AGOSTINELLI, Roland HAAS (Hg.), Kuranstalt. Historisches Erbe und künstlerische Intervention (Hohenems 2010).

69 Für den Fernsehbericht vgl.: Kunst bewegt. Podiumsdiskussion anlässlich der Katalogpräsentation des Projektes „Kuranstalt“ in Schruns. In: Vorarlberg Heute (30. November 2010). Für den Radiobericht vgl.: Brisante Fragen über die NS-Vergangenheit von Kuranstaltgründer Edwin Albrich anlässlich eines Kunstprojektes in Schruns. In: Kultur nach 6. Ö2 Radio Vorarlberg (30. November 2010). Für den redaktionellen Bericht vgl.: Kuranstalt in Schruns wird abgerissen. In: http://vorarlberg.orf.at/stories/484718/ (Zugriff 31.08.2011).

70 Roger Martin BUERGEL, Einleitung. In: Ines AGOSTINELLI, Roland HAAS (Hg.), Kuranstalt. Historisches Erbe und künstlerische Intervention (Hohenems 2010). 



\section{Projektvorstellungen}





\section{Psychiatrische Landschaften. Die Psychiatrie und ihre Patientinnen und Patienten im} historischen Raum Tirol-Südtirol von 1830 bis zur Gegenwart / L'assistenza psichiatrica istituzionale e territoriale nell'area del Tirolo storico (secoli XIX-XXI). Ein Interreg IV Projekt Italien-Österreich (2008 - 2011)

\section{Forschungsstand: Psychiatriegeschichte in Tirol}

Seit über zehn Jahren erlebt die Psychiatriegeschichtsschreibung im deutschsprachigen Raum einen echten (zweiten) Boom, wobei neben dem Thema NS-Psychiatrie die im 18. und 19. Jahrhundert gegründeten psychiatrischen Anstalten, zum Teil mit Bezugnahme auf Michel Foucault und Erving Goffman, als institutionalisierte Orte der Verwahrung, Behandlung und Pflege in den Fokus getreten sind. Auch in Österreich sind nach einer ersten, teilweise von sehr (psychiatrie-)kritischen Initiativen ausgelösten und getragenen Forschungswelle in den 1980er Jahren mehrere Arbeiten zu verschiedenen psychiatrischen Einrichtungen entstanden. ${ }^{1}$ Am besten dürften im Augenblick die institutionellen Einrichtungen Wiens' ${ }^{2}$, die Anstalt Feldhof bei Graz ${ }^{3}$

1 Hans WEISS, Geschichte der Psychiatrie in Österreich. In: Österreichische Zeitschrift für Soziologie 2 (1978) 41-57; Rainer DANZINGER, Alois MARKSTEINER (Hg.), Gugging - Versuch einer Psychiatriereform. 100 Jahre Niederösterreichisches Landeskrankenhaus für Psychiatrie und Neurologie Klosterneuburg (Salzburg 1985); Paul POSCH, Landeskrankenhaus Klagenfurt. Geschichte der Kranken-, Heil- und Pflegeanstalt des Landes Kärnten in Klagenfurt und der Klagenfurter Spitäler (Klagenfurt 1987); Inghwio AUS DER SCHMITTEN, Schwachsinnig in Salzburg. Zur Geschichte einer Aussonderung (Salzburg 1985); Gernot EGGER, Ausgrenzen - Erfassen - Vernichten. Arme und „Irre“ in Vorarlberg (Bregenz 1990); Norbert SCHNETZER, Hans SPERANDIO (Hg.), 600 Jahre Valduna. Der lange Weg - vom Klarissenkloster zum Landeskrankenhaus (Rankweil 1999).

2 Karl SABLIK, Vom „Narrenturm“ zur modernen Psychiatrie. In: Erika WEINZIERL, Karl STADLER (Hg.), Justiz und Zeitgeschichte. Symposion „Schutz der Persönlichkeitsrechte am Beispiel der Behandlung von Geisteskranken 1790-1982“ (Wien 1983) 1-17; Helmut GRÖGER, Die Wiener Psychiatrie in ihrer Entwicklung. In: Amt der NÖ Landesregierung/Kulturabteilung (Hg.), Kunst des Heilens. Aus der Geschichte der Medizin und Pharmazie. Katalog des Niederösterreichischen Landesmuseums, Katalog zur Ausstellung am 4.5.-27.10.1991 (Wien 1991) 788-799; Helmut GRÖGER, Eberhard GABRIEL, Siegfried KASPAR (Hg.), Zur Geschichte der Psychiatrie in Wien (Wien, München 1997); Eberhard GABRIEL, 100 Jahre Gesundheitsstandort Baumgartner Höhe. Von den Heil- und Pflegeanstalten Am Steinhof zum Otto Wagner-Spital (Wien 2007); Alfred STOHL, Der 
und die Institutionen im ehemaligen historischen Tirol ${ }^{4}$ erforscht sein. Allerdings ist für letzteres anzumerken, dass zum früheren südlichen Landesteil des historischen Tirol, dem italienischsprachigen Trentino, wesentlich früher als für seine nördlichen Nachbarregionen einschlägige Publikationen zur Geschichte der Psychiatrie erschienen sind, was augenscheinlich mit der durch die Basaglia-Reform ausgelösten psychiatriekritischen Haltung der italienischen KollegInnen in Zusammenhang stehen dürfte. Die HistorikerInnen in Tirol kümmerten sich vorerst wenig um die Thematik, vielmehr waren es Studierende der Erziehungswissenschaften ${ }^{5}$ im Rahmen ihrer Diplomarbeiten und ein Psychiater, die sich seit Mitte der 1990er Jahre der institutionellen Entwicklung und dem Gewaltaspekt der NS-Psychiatrie in Tirol ${ }^{6}$ zuwandten. Eine erste historische Diplomarbeit zur Tiroler Anstalt in Hall wurde 1998 unter dem Aspekt von Anstaltsdisziplin von Thomas Redinger verfasst. ${ }^{7}$ Inzwischen sind, zum Teil in Vorbereitung, zum Teil begleitend zum vorgestellten Projekt ein Themenheft ${ }^{8}$, die Dissertation von Angela Grießenböck ${ }^{9}$, die Habilitationsschrift von

Narrenturm oder die dunkle Seite der Wissenschaft (Wien 2000); Andrea BRENNER, Der Wiener „Narrenturm“ und seine PatientInnen - ein erster Arbeitsbericht. In: Carlos WATZKA, Marcel CHARHOUR (Hg.), VorFreud. Therapeutik der Seele vom 18. bis zum 20. Jahrhundert. Tagungsband der „Wiener Gespräche zur Sozialgeschichte der Medizin“ (Wien 2006) 45-63; Eberhard GABRIEL, Martina GAMPER (Hg.), Psychiatrische Institutionen in Österreich um 1900 (Wien 2009).

3 Siehe dazu die Arbeiten von Carlos Watzka über die Geschichte der Behandlung psychisch kranker Menschen in der frühen Neuzeit und in der Moderne. Vgl. Carlos WATZKA, Vom Hospital zum Krankenhaus. Zum Umgang mit psychisch und somatisch Kranken im frühneuzeitlichen Europa (Köln 2005); DERS., Arme, Kranke, Verrückte. Hospitäler und Krankenhäuser in der Steiermark vom 16. bis zum 18. Jahrhundert und ihre Bedeutung für den Umgang mit psychisch Kranken (Graz 2007); DERS., Der „Irrenboom“ in Steiermark. Zum Problem der Zunahme psychischer Erkrankungen in der Moderne. In: Newsletter Moderne 5/1 (2002), 21-26; DERS., Die „Landes-Irrenanstalt Feldhof bei Graz“ und ihre Insassen 1874-1913. Eine Skizze zur Entstehung der „modernen“ Anstaltspsychiatrie in der Steiermark. In: Blätter für Heimatkunde 80/1-2 (2006) 14-40.

4 Vgl. dazu das bereits Ende der 1980er Jahre erschienene Buch von Giuseppe PANTOZZI, Die brennende Frage. Geschichte der Psychiatrie in den Gebieten von Bozen und Trient (1830-1942) (Trient 1989); Casimira GRANDI, Rodolfo TAIANI (Hg.), Alla ricerca delle menti perdute. Progetti e realizzazioni per il riuso degli ex ospedali psichiatrici nei territori italiani appartenuti all'Imperio asburgico (Trento 2002); Rodolfo TAIANI (Hg.), Alla ricerca delle menti perdute: viaggi nell'istituzione manicomiale. Ausstellungskatalog (Trento 2003); Marina PASINI, Annalisa PINAMONTI (Hg.), Ospedale psichiatrico Pergine Valsugana. Inventario dell'archivio (1882-1981) (Trento 2003).

5 Vgl. Sabina BERTONE, Die Entwicklung der Psychiatrie in Südtirol (Diplomarbeit Innsbruck 1998); Gertaud EGGER, Irren-Geschichte - irre Geschichten: zum Wandel des Wahnsinns unter besonderer Berücksichtigung seiner Geschichte in Italien und Südtirol (Diplomarbeit Innsbruck 1999); Juliane HALPER-ZENZ, Angelika PRESSLAUER, Vom Umgang mit Armen, Irren und Behinderten in Tirol. Vom Ausschluß zur Disziplinierung zur Integration (Diplomarbeit Innsbruck 1996).

6 Die Publikationen des Tiroler Psychiaters Hartmann Hinterhuber haben die Forschungen zur NSPsychiatrie in Tirol lange Zeit geprägt. Aus seinem langen Publikationsschaffen seien exemplarisch angeführt: Hartmann HINTERHUBER, Ermordet und vergessen. Nationalsozialistische Verbrechen an psychisch Kranken und Behinderten in Nord- und Südtirol (Innsbruck, Wien 1995); DERS., Das Schicksal der Überlebenden. In Verband Angehöriger und Freunde psychisch Kranker (Hg.), Wahnsinn und ethnische Säuberung, Deportation und Vernichtung psychisch Kranker aus Südtirol 1939-1945 (Bozen 1995) 49-54.

7 Thomas REDINGER, Zur Geschichte der psychiatrischen Disziplin: Die „Irrenanstalt“ von Hall in Tirol (1830-1882) (Diplomarbeit Innsbruck 1998).

8 Elisabeth DIETRICH-DAUM, Rodolfo TAIANI (Hg.), Psychiatrielandschaft/Oltre il manicomio. Themenband der Zeitschrift Geschichte und Region/Storia e regione 17/2 (2008).

9 Vgl. Angela GRIESSENBÖCK, Die „Landesirrenanstalt“ in Hall in Tirol und ihre Patientinnen und Patienten (1882-1919) (Dissertation Innsbruck 2009). 
Michaela Ralser ${ }^{10}$ und mehrere Aufsätze ${ }^{11}$ im Kontext dieses Projekts zur Geschichte der psychiatrischen Anstalten und der Klinik entstanden. Voraussetzung für die historische Forschung der jüngsten Zeit war zunächst die Sicherung, dann die systematische Erschließung des überaus reichhaltigen historischen Archivs am Landeskrankenhaus Hall seit 2004.

\section{Untersuchungsgegenstand: Psychiatrielandschaft Tirol}

Im 19. Jahrhundert verfügte das Kronland Tirol vorerst über eine und später über zwei Anstalten zur Heilung, Pflege und auch Verwahrung psychiatrischer Patienten und Patientinnen. Die 1830 eröffnete und seit 1865 als landeseigene Anstalt geführte „k. k. Irrenanstalt Hall“" nahm psychisch kranke Menschen aus Nord- und Südtirol und aus dem Trentino auf. Mit der Eröffnung der zweiten „Landesirrenanstalt“ in Pergine im Jahr 1882 war nunmehr eine getrennte Unterbringung der italienisch sprachigen Bevölkerung möglich. Gerade für die Frauen und Männer aus dem italienisch sprachigen Teil des Kronlandes war bis dahin der Weg in die Anstalt, aber vor allem die Unterbringung fern der Heimat, in einer sprachlich und wohl auch kulturell als fremd empfundenen Umgebung alles andere als einfach. Gleiches gilt für die Südtiroler PatientInnen, die nach der Abtretung des südlichen Landesteils als Folge des Ersten Weltkrieges, in das nunmehr italienische „Irrenhaus“ nach Pergine überstellt wurden. Dies sollte jedoch nicht ihre letzte zwangsweise erfolgte Übersiedelung sein. Im Zuge der so genannten Option wurden ab 1939/1940 über 700 Südtiroler PatientInnen zunächst in die damalige „Gau-Heil- und Pflegeanstalt“ Hall, von dort zum Teil nach Schussenried in Baden-Württemberg, oder direkt von Pergine nach Zwiefalten, ebenfalls in Baden-Württemberg, überstellt. Somit endete der Weg ins „Deutsche Reich" für viele SüdtirolerInnen in einer Anstalt und schlimmstenfalls mit dem Tod. Auch für die Anstalt in Hall bedeutete die Zeit des Nationalsozialismus einen gravierenden Einschnitt. Insgesamt wurden im Rahmen der NS-,,Euthanasie“ 360 Haller PatientInnen in die Tötungsanstalt nach Hartheim bzw. nach Niedernhart deportiert. Nach 1945 gingen die Wege der beiden großen Anstalten endgültig auseinander. Das Engagement von Franco Basaglia (1924-1980) und die bereits im Gesetz Nr. 431 vom 18. März 1968 („legge Mariotti“) zu Grunde gelegte Schließung der psychiatrischen Anstalten führten in Italien zu einer grundlegenden Reform der psychiatrischen Versorgung. Während das psychiatrische Krankenhaus in Pergine geschlossen wurde, nimmt das Psychiatrische Krankenhaus in Hall (seit 1.1.2011 Landeskrankenhaus Hall) neben der Universitätspsychiatrie in Innsbruck nach wie vor eine zentrale Position in der regionalen Versorgung psychisch beeinträchtigter Menschen ein. Die Reform der psychiatrischen Versorgung in Österreich ist - und da sind sich die wenigen einschlägigen Publikationen einig - aber wesentlich langsamer erfolgt als in Italien, wo die Umsetzung des Mariotti- bzw. Basagliagesetzes einen deutlichen Bruch darstellte. Als wichtige Etappe der österreichischen Psychiatriereform wird das so genannte „Unterbringungsgesetz“ für psychisch Kranke von 1991 gesehen, das bei abnehmender Bettenzahl seit den 1970er-Jahren von rund 20.000 auf 4.000,

10 Michaela RALSER, Das Subjekt der Normalität. Das Wissensarchiv der Psychiatrie: Kulturen der Krankheit um 1900 (München 2010).

11 Vgl. u. a. die Publikationen von Maria HEIDEGGER, Oliver SEIFERT, Elena TADDEI, Elisabeth DIETRICH-DAUM, Angela GRIESSENBÖCK und Michaela RALSER sowie die Beiträge auf www.psychiatrische-landschaften.net. 
den Anteil unfreiwilliger Aufnahmen von anfänglich 96 Prozent auf 20 Prozent reduzierte. ${ }^{12}$ Behandlungsbedürftigkeit ist seit dem Unterbringungsgesetz kein Grund mehr für eine Zwangseinweisung, ausgenommen sind befürchtete Selbst- bzw. Fremdgefährdungen. Auch das „Patientenverfügungsgesetz“ von 2006, das psychisch kranken Personen die Möglichkeit gibt, bestimmte Medikamente abzulehnen, gilt als Markstein der österreichischen Psychiatriereform. Die Gesundheitspolitik in Österreich folgt seit nunmehr fast zwanzig Jahren dem Leitbild einer dezentralen, gemeindenahen psychiatrischen Versorgung - eine Annäherung an das italienische Versorgungssystem scheint sich hier anzudeuten. Die aktuelle „Psychiatrielandschaft“ des historischen Raumes Tirol ist ein Ergebnis eines schwierigen, unterschiedlich schnell verlaufenden politischen und sozialen Verhandlungsprozesses, der nicht abgeschlossen ist.

Das hier vorgestellte INTERREG-Projekt verfolgte im Wesentlichen drei Ziele:

(1) Beschreibung und Vergleich der historischen und aktuellen Systeme in der Versorgung, Betreuung und Begleitung von Menschen mit psychischer Beeinträchtigung im geografischen Raum Tirol-Südtirol. Der Fokus auf die Geschichte erfolgt im begründeten Wissen um deren spezifische Gegenwärtigkeit in der aktuellen psychiatrischen Landschaft der beiden Länder ebenso wie im Alltagsbewusstsein ihrer BewohnerInnen.

(2) Sensibilisierung der Öffentlichkeit hinsichtlich des sozialen Wandels und der damit zusammen hängenden Transformation der psychiatrischen Versorgungssysteme ebenso wie der Krankheits- und Problemlagen ihrer NutzerInnen. Dies erforderte eine beide Regionen gleichwertig berücksichtigende Recherche ebenso wie eine neue, die grenzüberschreitenden Netzwerke, Forschungsressourcen und Vermittlungskompetenzen nutzende Strategie der Implementierung.

(3) Erarbeitung eines kohärenten, synergetischen und nachhaltigen Vermittlungskonzeptes unter Nutzung formeller und informeller Lernkontexte, unter Anwendung verschiedenster Medien und unter Bereitstellung unterschiedlicher Lern- und Begegnungsräume. Erstmals wurde ein solches Konzept in interdisziplinärer Zusammenarbeit von MedizinerInnen, Pflegekräften, HistorikerInnen und PädagogInnen entwickelt und grenzübergreifend realisiert.

\section{Drei Jahre - fünf „Produkte“}
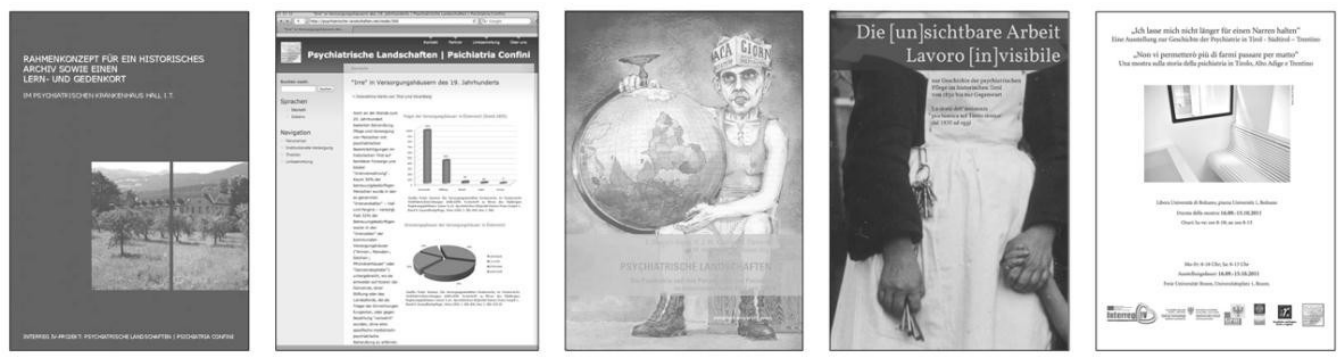

12 Vgl. die Homepage der Österreichische Gesellschaft für Neuropsychopharmakologie und Biologische Psychiatrie: $<$ http: $/ /$ www.medizin-medien.info $/$ dynasite.cfm?dssd=4172\&dsmid=60797\&dsrapid=437012> (download am 10.11.2008). 


\subsection{Konzept eines Forschungs-, Lern- und Gedenkortes}

Das erste und bereits im September 2009 abgeschlossene, in Form einer Broschüre vorliegende sowie online auf der Projekthomepage www.psychiatrischelandschaften.net bzw. www.psichiatria-confini.net verfügbare Projektergebnis wurde im Wesentlichen von Sabine Mirrione, Oliver Seifert und Carlos Watzka ausgearbeitet. Die Arbeiten konnten auf zwei Vorprojekte der Tiroler Wissenschaftsfonds unter Leitung von Elena Taddei zur Sicherung und Sichtung des Materials wie zu dessen sicherer Archivierung aufbauen. Das im Folgenden vorgestellte Konzept eines Forschungs-, Lern- und Gedenkortes bildet die Grundlage für eine Erweiterung des bereits bestehenden Historischen Archivs im Landeskrankenhaus Hall zu einer für unterschiedliche Zielgruppen offenen Vor-Ort-Einrichtung und wird dem Landeskrankenhaus Hall als Grundlage für eine mögliche Umsetzung zur Verfügung gestellt.

Hall eignet sich aus mehreren Gründen besonders für die Installierung eines solchen Lernorts. Der heutigen Psychiatrie am Landeskrankenhaus Hall kommt seit seiner Gründung als „k. k. Provinzial-Irrenanstalt“ im Jahr 1830 eine zentrale Rolle innerhalb der psychiatrischen Versorgung im historischen Tirol zu. Wie erwähnt, umfasste das historische Tirol das heutige Tirol, Südtirol und das Trentino sowie aber auch bis 1861 Vorarlberg, dessen PatientInnen bis zur Eröffnung der „Landes-Irrenanstalt“ Valduna bei Rankweil 1870 nach Hall zuständig waren. Der Name Hall ist seither ein Synonym für Wahnsinn, Verrücktheit und Andersartigkeit. Trotz dieser starken symbolischen Präsenz ist das Wissen um die Geschichte der Anstalt und um die Geschichte der psychiatrischen Versorgung ganz allgemein aber gering. Gleiches gilt für die gegenwärtige Situation der Psychiatrie und ihrer PatientInnen. Nach wie vor sind Menschen mit psychischen Problemen und ihre Angehörigen Vorurteilen, Ausgrenzung und Stigmatisierung ausgesetzt. Der Lernort soll ein Raum für Forschung, Vermittlung, Begegnung, Auseinandersetzung und Reflexion werden und damit einen nachhaltigen Umgang mit dem Thema Psychiatrie garantieren. Hierzu bedarf es einer gemischten Struktur, die verschiedenen Zielgruppen in verschiedenen Kontexten unterschiedliche Zugänge und Nutzungsmöglichkeiten anbietet.

Das Historische Archiv spielt mit seinen Quellen zur Geschichte der Anstalt eine zentrale Rolle innerhalb des konzipierten Ortes. Doch sollen die klassischen Aufgabengebiete und Angebote eines Archivs, nämlich das Sammeln, Aufbewahren und Verwalten von Quellenmaterial durch Forschung und Vermittlung ergänzt werden. Der Archivar/die Archivarin wäre dann nicht mehr nur VerwahrerIn des Wissens, sondern ÜbersetzerIn, VermittlerIn, BegleiterIn und auch selbst LernendeR. Die projektierte Verbindung mit Lern- und Gedenkort machen das Archiv zu einem dynamischen Forschungsort, der wesentlich zur Entwicklung der zukünftigen regionalen (Psychiatrie-)Geschichtsschreibung beizutragen vermag.

Auf Basis des archivierten Materials lassen sich eine Reihe von pädagogischdidaktischen Angeboten für verschiedenste Alters- und Berufsgruppen ausarbeiten. In Form von Vorträgen, Workshops und Führungen kann ein Zugang zur Geschichte der Institution im Besonderen und zur Geschichte der psychiatrischen Versorgung im historischen Raum Tirol im Allgemeinen angeboten werden. Ausgehend von der Vergangenheit können die BesucherInnen ihre persönliche Wahrnehmung sowie den eigenen und den aktuellen gesellschaftlichen Umgang mit Themen wie psychische Krankheit, Behinderung oder Ausgrenzung reflektieren. Individuelle Erfahrungen von 
betroffenen Menschen sollen Eingang finden und - falls gewünscht - wird dieses Wissen in das Archiv einfließen. Um Vermittlung und Reflexion geht es auch im Gedenk- und Erinnerungsort, der dem Schwerpunkt der NS-,,Euthanasie“ gewidmet ist. Nach 70 Jahren soll für die Opfer der NS-Zeit und deren Angehörige ein Raum geschaffen werden. Dieser frei zugängliche, öffentliche Ort soll ein Platz der Information, aber auch der Trauer, des Erinnerns, des Gedenkens und des Austauschs sein. Gemeinsam mit den BesucherInnen soll auch hier neues Wissen entstehen, das im Archiv dokumentiert und im Lernort vermittelt werden kann.

Der konzipierte Forschungs-, Lern- und Gedenkort hat unterschiedliche Zielgruppen: PatientInnen nehmen an Vermittlungsangeboten teil und besuchen spezielle Foren, in denen ihre eigenen Psychiatrieerfahrungen ausgetauscht, reflektiert und gesammelt werden sollen. Freizeitangebote für (kultur-)historisch Interessierte sollen organisiert werden und Angehörige von PatientInnen verschiedene Vermittlungsangebote wahrnehmen. Vor allem Angehörige von „Euthanasie“-Opfern sollen im Gedenkort einen Platz der Auseinandersetzung finden, indem sie selbst im Archiv recherchieren und ihre eigenen Lebensgeschichten einbringen, die wiederum Teil des Archivs werden können. Auch das Personal des Landeskrankenhauses Hall soll in speziellen Fortbildungen über die Entwicklung der ,eigenen“ Anstalt und der allgemeinen Psychiatriegeschichte informiert werden, wodurch eine auf Basis historischen Wissens stattfindende Auseinandersetzung mit dem eigenen Berufsbild sowie eine Reflexion zu aktuellen Fragestellungen ermöglichst werden soll. Eigene Erfahrungen können eingebracht und - wenn gewünscht - im Archiv dokumentiert bzw. für die Vermittlung herangezogen werden.

Auszubildenden und Berufsgruppen außerhalb des Landeskrankenhauses, die mit der Psychiatrie zu tun haben, sollen als Vorbereitung und stete Auseinandersetzung mit der eigenen Aufgabe die Möglichkeit erhalten, an Vermittlungsangeboten zur Entwicklung der institutionalisierten Psychiatrie und der psychiatrischen Versorgung teilnehmen und die eigene Rolle bewusst wahrnehmen und reflektieren zu können. Kindern und Jugendlichen sollen spezielle Vermittlungsprogramme und Projekte zu den „psychiatrischen Landschaften“ des historischen Tirol sowie zu damit eng zusammenhängenden gesellschaftlich relevanten Themen wie „normal“ sein „anders“ sein, Ausgrenzung - Integration usw. angeboten werden. Historisch Forschende, Studierende, Angehörige usw. sollen nicht nur die Archiv- und Bibliotheksräume benützen können, sondern dabei eine fachkundige Begleitung und Anleitung vorfinden, deren Forschungsergebnisse und neu geschaffenes Wissen in den dynamischen Forschungs- und Lernort einfließen.

Das vorliegende Rahmenkonzept wurde dem Landeskrankenhaus Hall und dessen Träger, der Tiroler Landeskrankenanstalten GmbH (TILAK), als Grundlage für eine mögliche Umsetzung zur Verfügung gestellt. Es versteht sich als Impuls und fundierte Ideensammlung für eine wünschenswerte Erweiterung des bereits bestehenden Historischen Archivs. Wie auch schon die Öffnung der Archivbestände vor wenigen Jahren, wäre die Realisierung des Konzepts als ein weiteres wichtiges Signal der Öffnung zu werten. Die konzipierten Nutzungsmöglichkeiten sind im Falle einer Realisierung noch in einem detaillierten, multiprofessionellen Planungsprozess weiter zu entwickeln. 


\subsection{Online-Archiv und Themenportal}

Der zweite Projektteil des Interreg IV-Projekts stellte eine Online-Dokumentation in Form einer deutschsprachigen und einer italienischen Website dar. Diese Website bietet weit mehr als eine gebräuchliche Projekthomepage. Es handelt sich um ein im Wesentlichen von Elena Taddei koordiniertes eigenes Themenportal zur Tiroler Psychiatriegeschichte, um eine Dokumentation, welche eine Sammlung von unterschiedlichen Materialien, von Fotos, Bildern, Quellen, Kartenmaterial, Tabellen zur Verfügung stellt und aufbereitet. Im Oktober 2009 wurde diese Website online gestellt. Seither wird sie laufend erweitert. Flankiert wird die online zugängliche Materialiensammlung von kurzen miteinander verlinkten Überblickstexten in deutscher und italienischer Sprache, die von ProjektmitarbeiterInnen ebenso wie von den Mitgliedern des Leitungsteams verfasst wurden. Für die Erstellung dieser Texte und für die Karten war ein hohes Ausmaß an Grundlagenarbeit zu leisten. Auf www.psychiatrische-landschaften.net bzw. www.psichiatria-confini.net finden BenutzerInnen Informationen über die Entstehung und Entwicklung der zwei Anstalten Hall und Pergine sowie der Innsbrucker „Neurologisch-Psychiatrischen Klinik“ ebenso wie über andere Formen psychiatrischer Versorgung im Kronland Tirol, etwa in den zahlreichen Versorgungshäusern. Darüber hinaus finden sich Texte über Therapieformen und Pflege sowie Kurzbiografien von Anstaltsdirektoren, Seelsorgern, sowie Karten zur Veranschaulichung der psychiatrischen Versorgung im historischen Raum Tirol, in der Donaumonarchie und in Italien. Eine Zeitleiste begleitet durch die Geschichte der Psychiatrie in einem regionalen Kontext.

\subsection{Publikation}

Das dritte Teilprojekt ist ein an ein breites Publikum gerichtetes rund 350 Seiten umfassendes Buch, das in zwei Ausgaben, in deutscher und italienischer Sprache, mit dem Titel „Psychiatrische Landschaften. Die Psychiatrie und ibre Patientinnen und Patienten im bistorischen Raum Tirol seit 1830“ bzw. „Ambienti psichiatrici. La psichiatria e i suoi pazienti nell'area del Tirolo dal 1830 a oggi" erschienen ist und vor allem von Elisabeth DietrichDaum und Hermann J.W. Kuprian koordiniert wurde. Ausgangspunkt dieses Teilprojektes war die Überlegung, zu den anstehenden Jubiläen - 180 Jahre Hall, 130 Jahre Pergine, 120 Jahre Psychiatrische Klinik - eine Schrift zur historischen Entwicklung der psychiatrischen Versorgung im ehemaligen Kronland Tirol zu verfassen. Doch haben sich die HerausgeberInnen nach einer langen Konzeptphase dafür entschieden, nicht die Institutionen, sondern die PatientInnen in den Mittelpunkt der Untersuchung und Darstellung zu stellen. Der erste Teil mit dem Titel „Psychiatrische Landschaften“ ist den Räumen, Strukturen und Transformationsprozessen in dieser Region gewidmet, geht aber auch der Frage nach, welche AkteurInnen in den verschiedenen Beziehungsfeldern der Psychiatrie in welcher Form sichtbar werden: die PatientInnen, die PflegerInnen, die Ärzte, die Angehörigen, die VertreterInnen der neuen Berufe wie TherapeutInnen und SozialarbeiterInnen, aber auch Behörden, Gerichte, Vereine und andere Organisationen. Der zweite, wesentlich umfangreichere Abschnitt mit dem Titel „Psychiatriegeschichte(n)“ stellt in Kurztexten verschiedene Aspekte der und Perspektiven auf die Psychiatriegeschichte im historischen Tirol dar: Zuschreibung und Diagnose, Zwang und Misshandlung, Beschwerden und Widerstand, Leibsprechen und Wahrsagen, Anstaltsseelsorger, Patientenschicksale im Ersten Weltkrieg und in der Optionszeit, NS-Euthanasie, 
Anstaltspflege, psychiatrisierte Kinder, die Ausgliederung geistig behinderter Menschen, die Basaglia-Reform und andere Themen. Die Bandbreite der gewählten Themen soll einerseits möglichst viele unterschiedliche Lesergruppen ansprechen, andererseits diese auf die Vielfältigkeit der Untersuchungsebenen und -felder moderner Psychiatriegeschichtsforschung aufmerksam machen.

Der dritte Teil der Publikation bietet über das Format des Zeitzeugen-Interviews aktuelle Interpretationen der jüngeren Vergangenheit der regionalen Psychiatriegeschichte an. Es wurden dazu Personen eingeladen, die entweder zentral in den Institutionen der Psychiatrie gearbeitet haben und arbeiten, wie Hartmann Hinterhuber, Christian Haring, Otto Saurer, Lorenzo Toresini oder Personen, die in Organisationen, Vereinen, Verbänden oder im extramuralen Pflegedienst tätig waren und oder noch tätig sind. Eine umfangreiche, zusammenfassende Bibliografie schließt den Band ab. Die Beiträge selbst wurden von Mitgliedern des Projektteams, der Projektpartnerorganisationen und engagierten JournalistInnen verfasst.

Die Publikation wird öffentlichen Institutionen und Bibliotheken zur Verfügung gestellt. Sie können darüber hinaus beim Verlag Innsbrucker University Press (IUP) gegen einen geringen Selbstkostenpreis für Abwicklung und Versand bezogen werden.

\subsection{Didaktikmedium}

Der Lehr- und Lernfilm „Die (un)sicbtbare Arbeit. Zur Geschicbte der psychiatrischen Pflege im historischen Tirol von 1830 bis zur Gegenwart" / "Lavoro [in]visibile. La storia dell'assistenza psichiatrica nel Tirolo storico dal 1830 ad oggi" erzählt ein weiteres Stück Tiroler Psychiatriegeschichte, die psychiatrische Pflegegeschichte. Das Filmdokument und das angeschlossene Didaktikmaterial erschließen bislang noch kaum erzählte Themen für Unterrichts- und Fortbildungszwecke im Bereich der Gesundheits- und Krankenpflege. Das Filmdokument ist ein Ergebnis der Zusammenarbeit von Erziehungswissenschafterinnen und HistorikerInnen im Rahmen des Projekts, für seine Realisierung und Produktion zeichnet Niko Hofinger verantwortlich. Die Zusammenstellung und Aufbereitung des Materials leisteten im Wesentlichen die Erziehungs- und Kulturwissenschafterin Michaela Ralser sowie als Projektmitarbeiterin Renate Fuchs, Erziehungswissenschafterin und seit 2010 selbst Lehrende in der Pflegeausbildung. Der Film enthält chronologisch aufgebaut an verschiedenen Themenschwerpunkten orientierte Einheiten, welche durch solche Sequenzierungen in einzelne Kapitel in unterschiedlichsten Formen als didaktisches Material für den Unterricht anwendbar werden. Zugleich besteht die Möglichkeit, sich das Filmdokument durchgehend anzusehen. Zusätzlich stehen didaktische Begleitmaterialien für die LehrerInnen zur Verfügung. Den Aus- und Fortbildungseinrichtungen allgemeiner und psychiatrischer Pflege wird auf diese Weise ein Medium zur Verfügung gestellt, mit dem einerseits ein Teil der regionalen Psychiatriegeschichte erarbeitet und andererseits das eigene Berufsbild kritisch hinterfragt werden kann. Es war hier unser Ziel zu zeigen, dass heute allgemein anerkannte Standards und Methoden in Betreuung, Begleitung und Therapie als zeitlich bedingte und historisch gewachsene Momentaufnahmen zu verstehen sind, die einer ständigen Veränderung unterliegen. Weiter war es dem Projektteam ein Anliegen, die häufig als „unsichtbar" erscheinende Berufsgruppe der Pflege in den Fokus zu stellen und aus ihrer Sicht Entwicklungen der Psychiatrie zu verdeutlichen. Erschwert wurde diese Aufgabe durch die Tatsache, dass bis dato eine Auseinandersetzung mit einer psychiatrischen Pflegegeschichte des Raumes Tirol und 
Südtirol nahezu gänzlich fehlte. Diese fehlende Aufarbeitung und Zugangsbeschränkungen vor allem zu jüngerem Aktenmaterial waren ausschlaggebend für den Einsatz der Oral History Methode. Dazu wurden im Herbst und Winter 2010 sowie im Frühjahr 2011 zahlreiche Gesprächsrunden zum Teil in Form von Erzählcafés mit ehemaligen psychiatrischen Pflegepersonen des Psychiatrischen Krankenhauses in Hall, der Universitätsklinik Innsbruck, Vertreterinnen des Ordens der Barmherzigen Schwestern und Personen, die in verschiedenen psychiatrischen Pflegeeinrichtungen Südtirols gearbeitet haben und zum Teil noch dort tätig sind, veranstaltet. Über mündliche Erzählungen konnte so ein wesentlicher Teil der lokalen Pflegegeschichte rekonstruiert werden, darüber hinaus erschlossen sich aber auch neue Themenbereiche, bekannte wurden vertieft, und nicht zuletzt wurden Verarbeitungsweisen von Vergangenem aus der PflegerInnenperspektive zugänglich. Für die früheren Zeiten wurden Archivquellen, Zeitungen, diverse Bildmaterialien und entsprechende Literatur herangezogen, hierzu wurde von den HistorikerInnen im Projektteam historische Grundlagenforschung geleistet. Das Filmdokument lässt neben ZeitzeugInnen auch ExpertInnen aus der Wissenschaft und Psychiatrie zu Wort kommen, die entsprechenden Shootings wurden im Mai 2011 gedreht. Der Film wurde im Herbst 2011 fertig gestellt und erstmals im Unterricht eingesetzt.

\subsection{Wanderausstellung}

Das fünfte Ergebnis des Projekts, eine am 30. Juni 2011 erstmals am Landeskrankenhaus Hall in Tirol eröffnete zweisprachige Wanderausstellung (deutsch und italienisch) zur Geschichte der Psychiatrie im historischen Raum Tirol, wandert - bildlich ausgedrückt - aus dem Projekt bzw. der Projektlaufzeit hinaus und ist wie die Publikation, das Didaktikmedium, das virtuelle Portal und der Lern- und Gedenkort Teil des angestrebten nachhaltigen und kohärenten Vermittlungskonzeptes. Die Ausstellung trägt den Titel „Ich lasse mich nicht länger für einen Narren halten“ / „Non vi permetterò più di farmi passare per matto", ein Zitat aus der Krankenakte des Jagdaufsehers Josef B., Patient in Hall um die Wende zum 20. Jahrhundert. Das Zitat verweist auf die Ausstellungskonzeption: Erzählt wird auf Grundlage der im Rahmen des Projekts ausgeführten historischen Forschungen erlebte Psychiatrie, im Zentrum stehen die Schicksale der behandelten Menschen. In Form von 31 biografischen Fallgeschichten, ausgestellt in Form von 31 aufwendig gebundenen Büchern, wird der Alltag in psychiatrischen Institutionen beider Landesteile von 1830 bis in die jüngere Vergangenheit fokussiert, werden die Spuren vergessener Schicksale von den 1830er bis in die 1970er Jahre innerhalb und außerhalb der Anstalten Hall und Pergine sowie der Klinik Innsbruck erzählt. Ausgangspunkt ist die historische Krankenakte: Diese ist Rechercheobjekt, Informationsquelle, zugleich normierende, offizielle Ausdrucksform von und über Menschen, die als „,psychisch krank“ diagnostiziert wurden, sie spiegelt jeweilige zeitgenössische Problemwahrnehmungen und Stigmatisierungsprozesse wieder - und wird in der Ausstellung selbst zum Exponat. Basierend auf diesen Krankenakten verläuft die Gliederung der Ausstellung entlang von Begriffen (Verben), die auf den psychiatrischen Alltag verweisen. An den acht Stationen - visualisiert durch eigens entworfene Ausstellungsmöbel - „begutachten“, „arbeiten“, „essen“, „,behandeln“, „,verwahren“, „töten“, „erziehen“ und „,verschicken“ werden alltägliche und dennoch oft unerwartete Einblicke in die Geschichte psychisch kranker Menschen gewährt. Essentielle Themen regionaler Psychiatriegeschichte, wie die wechselhafte 
politische und soziale Geschichte der Regionen, die Transporte der Südtiroler PatientInnen, die Öffnung und Dezentralisierung der Psychiatrie in Italien im Zuge der Basaglia Reformen, sowie zentrale Aspekte der aktuellen Psychiatriegeschichtsforschung, wie historische Diagnosestellung und therapeutische Behandlungsmethoden, die Binnenlogik des Anstaltslebens, die Geschichte der psychiatrischen Pflege, Zwang, Strafe und Erziehungsmaßnahmen im Kontext zeitgenössischer Wahrnehmungsmuster, Wegsperren, Stigmatisierung, Reintegration in die Gesellschaft und die Ermordung psychisch kranker Menschen in der Zeit des Nationalsozialismus werden aus biographischen Annäherungen heraus erzählt.

Die Ausstellungsarchitektur, konzipiert von der Architektin Celia Di Pauli, lässt die BesucherInnen in verschiedene abstrahierte Szenen des psychiatrischen Alltags eintreten und die Perspektive von PatientInnen und Personal gleichsam räumlich einnehmen. Indem die BesucherInnen sich so in verschiedene Rollen und in einzelne Situationen eines reduzierten psychiatrischen Umfeldes begeben, werden nicht nur historische Informationen vermittelt, sondern vergangene Realitäten erfahrbar gemacht. Vor einem ärztlichen Schreibtisch sitzend oder an einem Stehpult stehend können etwa biografische Fallgeschichten zum Thema Begutachten gelesen werden. Ein angedeuteter Zugabteil verweist auf die Verschickung und Entwurzelung von PatientInnen. An einer angedeuteten Werkbank werden die AustellungsbesucherInnen mit geschlechts- wie klassenspezifisch differenten Zerstreuungs-, Beschäftigungs- und Arbeitsprogrammen konfrontiert. In einer beengten Raumsituation verharrend, wird den BesucherInnen die Gewalt der Erziehungs- und Strafmaßnahmen vermittelt, die durch das Personal ausgeführt wurden, wobei hier Fallgeschichten von Kindern und Jugendlichen in der Psychiatrie im Zentrum stehen. An einem Esstisch sitzend, sieht und liest man über Hunger, Ernährung, Zwangsernährung und die alltägliche Versorgung der PatientInnen, in den „hungrigen“ 1840er Jahren ebenso wie in der Zeit der beiden Weltkriege. Die szenografische Bearbeitung der einzelnen „Kapitel“ der Ausstellung erzeugt jeweils eine konkrete körperliche Erfahrung, die den BesucherInnen im Gedächtnis verhaftet bleiben soll. Die damit verbundenen und vermittelten Informationen sollen nach Verlassen der Ausstellung leichter wieder abrufbar sein, da sie mit einem Handeln und Erleben verbunden sind. Auf diese Weise wurde und wird ein breites Ausstellungspublikum angesprochen, das von historisch Interessierten, Fachleuten im Gesundheitswesen, PatientInnen und Angehörigen bis hin zu Schulklassen reicht. ${ }^{13}$ Die Wanderausstellung wurde Ende Juni 2011 in Hall eröffnet, von Mitte September 2011 bis Mitte Oktober war sie an der Freien Universität Bozen $\mathrm{zu}$ sehen. Die weiteren Stationen waren das Toni Knapp Haus in Schwaz, die Universität Innsbruck und im Frühjahr 2012 das Schlossmuseum Landeck. Im Sommer und Herbst 2012 wird die Wanderausstellung voraussichtlich in Pergine und an verschiedenen Orten Südtirols zu sehen sein. Ihre Inhalte wurden unter der Leitung von Maria Heidegger vom wissenschaftlichen Projektteam recherchiert und aufbereitet, die Koordination des Teilprojektes sowie die Kuratierung wurden von Lisa Noggler-Gürtler geleistet, die auch weiterhin für eine breite Rezeption der Ausstellung Sorge trägt.

13 Siehe die Ausstellungsbesprechung von Michael BOSSLE, Wanderausstellung „Ich lasse mich nicht länger für einen Narren halten“. In: praxiswissen: psychosozial 2/3 (2011), 50-51. 


\section{Beteiligte Institutionen und WissenschaftlerInnen}

Leader: Institut für Geschichtswissenschaften und Europäische Ethnologie (Elisabeth Dietrich-Daum, Maria Heidegger, Hermann J.W. Kuprian, bis November 2010 Elena Taddei) sowie Institut für Erziehungswissenschaften (Michaela Ralser) an der Universität Innsbruck

Projektpartner: Südtiroler Landesarchiv / Archivio Provinciale di Bolzano in Konvention mit der Arbeitsgruppe „Geschichte und Region / Storia e regione" (Siglinde Clementi)

Assoziierte Partner: Psychiatrisches Krankenhaus des Landes Tirol in Hall, seit 1.1.2011 Landeskrankenhaus Hall (Christian Haring, Wolfgang Markl), Servizi di Salute Mentale di Merano / Dienste für psychische Gesundheit Meran (Irene Pechlaner, Lorenzo Toresini) und Universitätsklinik für Psychiatrie der Medizinischen Universität Innsbruck (Hartmann Hinterhuber)

Kooperationen: Lern- und Gedenkort Schloss Hartheim, Azienda Provinciale Servizi Sanitari della Provincia Autonoma di Trento (Archivio storico e biblioteca scientifica dell'Ex ospedale psichiatrico di Pergine), Fondazione del Museo Storico del Trentino, VertretungsNetz PatientInnenanwaltschaft, Forschungsplattform Geschlechterforschung und Forschungsplattform CEn' „Cultural Encounters and Transfers” an der Universität Innsbruck

ProjektmitarbeiterInnen: Oliver Seifert, Angela Grießenböck, Sabine Mirrione, Anselmo Vilardi (bis Oktober 2010), Renate Fuchs, Carlos Watzka (bis März 2009), Andreas Oberhofer (bis Juli 2010), Friedrich Stepanek (Februar bis September 2011).

\section{AutorenInneninformation}

Mag. Dr. Maria Heidegger, Historikerin, Mitglied des Leitungsteams des Interreg IV Projektes „Psychiatrische Landschaften. Die Psychiatrie und ihre Patientinnen und Patienten im historischen Raum Tirol-Südtirol von 1830 bis zur Gegenwart / L'assistenza psichiatrica istituzionale e territoriale nell'area del Tirolo storico (secoli XIX-XXI). Postadresse: Institut für Geschichtswissenschaften und Europäische Ethnologie, Innrain 52,6020 Innsbruck, Österreich. Mail: Maria.Heidegger@uibk.ac.at

Ao.Prof. Dr. Elisabeth Dietrich-Daum, Historikerin, Mitglied des Leitungsteams des Interreg IV Projektes „Psychiatrische Landschaften. Die Psychiatrie und ihre Patientinnen und Patienten im historischen Raum Tirol-Südtirol von 1830 bis zur Gegenwart / L'assistenza psichiatrica istituzionale e territoriale nell'area del Tirolo storico (secoli XIX-XXI). Postadresse: Institut für Geschichtswissenschaften und Europäische Ethnologie, Innrain 52, 6020 Innsbruck, Österreich. Mail: Elisabeth.Dietrich@uibk.ac.at 


\section{Die Lorenz-Böhler-Ausstellung der Vorarlberger Landesbibliothek (VLB)}

Der 125. Geburtstag von Lorenz Böhler am 15.1.2010 war für die Vorarlberger Landesbibliothek der Anlass, eine Ausstellung über den Vorarlberger Arzt ins Auge zu fassen. Lorenz Böhler wurde noch 1979 in einer Umfrage einer Regionalzeitung zum bedeutendsten Vorarlberger gewählt, seither ist er aber weitgehend in Vergessenheit geraten. Nur in Publikationen, die sich mit der Geschichte der Unfallmedizin befassen, nimmt Böhler noch immer einen gewichtigen Platz ein.

Lorenz Böhler wurde am 15. Jänner 1885 in Wolfurt als Sohn des Zimmermanns Josef Böhler und der Mutter Anna Maria Böhler, geb. Fischer, geboren. Als die Eltern 1890 nach Bregenz übersiedelten, blieb er bei seiner Großmutter, die aber bald darauf verstarb. Lorenz Böhler wohnte dann bei seiner Tante „Im Holz“, oberhalb von Wolfurt, wo er den Großteil seiner Kindheit verbrachte. ${ }^{1}$ Bereits in der Volksschule fiel den Lehrern das Talent des Jungen auf und trotz finanzieller Schwierigkeiten gelang es dem Vater das Schulgeld aufzubringen, das einen Schulbesuch im fürsterzbischöflichen Knabenseminar in Brixen ermöglichte. Nach zwei Jahren wechselte Böhler an das Bregenzer Gymnasium, später dann an die Universität Wien, wo er sich bereits im zweiten Semester erfolgreich um eines der größten Stipendien bewarb. Nach einer Praktikumszeit in Bozen, wo er auch seine spätere Frau Poldi Settari kennen lernte, promovierte Böhler 1911 zum Doktor der gesamten Heilkunde. Spontan nahm er dann eine Stelle als Schiffsarzt bei der Reederei „Austria-Americana“ an und behandelte auf seinen Reisen nach Argentinien und Brasilien hauptsächlich griechische und montenegrinische Auswanderer. 1912 kehrte er nach Europa zurück und wurde Arzt in Tetschen (heute Decin, Tschechische Republik) an der Elbe, wo er durch herausragende Heilungserfolge auffiel, was ihm eine Einladung zu einem internationalen Chirurgenkongress nach New York einbrachte. Bei der folgenden Studienreise nach Rochester (Minnesota) lernte er die damals weltweit führenden Unfallchirurgen Will und Charles Mayo kennen, die mit ihrer innovativen Organisation und Operationstechnik einen bleibenden Eindruck bei dem jungen Arzt hinterließen.

Kaum zurückgekehrt brach der Erste Weltkrieg aus, und Böhler wurde nach dem Einsatz an verschiedenen Kriegsschauplätzen nach Bozen abkommandiert, wo er ein Lazarett übernehmen sollte. Die sogenannte „Bozner Fachschule“ wurde zum Experimentierfeld für seine Technik und Schule, die er später in jahrzehntelanger Detailarbeit verfeinerte und perfektionierte. Das wohl Entscheidende war die neuartige Organisation, in der jede Schiene, jeder Handgriff und jeder Knoten standardisiert und

1 Siegfried HEIM, „Ein Mediziner wollte er werden“. Kindheit und Jugend in Wolfurt. In: Thomas FEURSTEIN (Hg.), Lorenz Böhler - Pionier der modernen Unfallmedizin (=Schriftenreihe der Vorarlberger Landesbibliothek 20, Graz, Feldkirch 2010) 27-48. 
rationalisiert wurde. Aufbauend auf den Ideen des amerikanischen Ingenieurs Frederick W. Taylor wurde jeder Arbeitsschritt analysiert, mithilfe einer akribischen Dokumentation auf seine Nützlichkeit und Effektivität überprüft und - wenn notwendig - abgeändert. ${ }^{2}$ Böhler dokumentierte seine Arbeit exakt und veröffentlichte später auch seine Ergebnisse, was zu einem Besucherstrom von Fachkollegen nach Bozen führte. Als Ergebnis seiner Erfahrungen drängte er darauf, die Unfallchirurgie als eigenes Fach aus der Chirurgie herauszulösen und die ihm unerlässlich scheinende Spezialisierung voranzutreiben - ein Vorschlag, der bei Fachkollegen zunächst noch auf wenig Gegenliebe stieß.

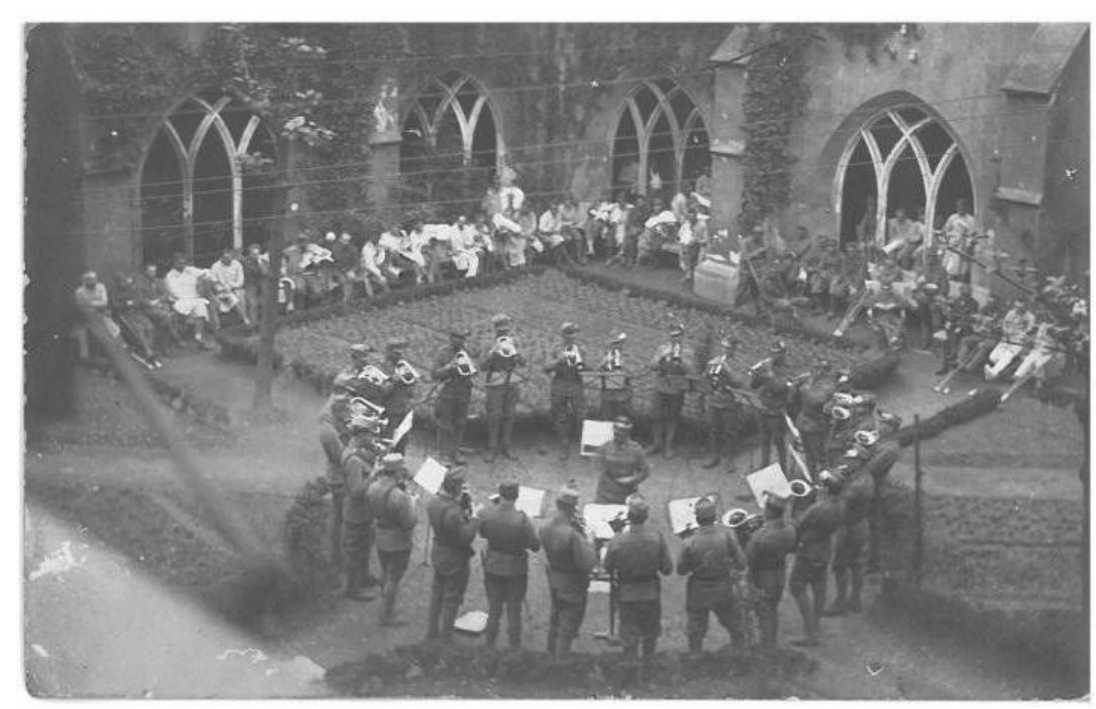

Abb. 1: Die „Fachschule in Bozen“ca. 1916

1919 präsentierte er der Leitung der Arbeiterunfallversicherung in Wien sein Konzept und versprach, durch seine Methode die dauerhafte Arbeitsunfähigkeit der Versicherten um 50-70 Prozent zu senken. Obwohl er die Genehmigung für eine anstaltseigene Unfallstation erhielt, musste das Vorhaben aufgrund der Inflation gestoppt werden.

Böhler kehrte nach Südtirol zurück, mietete sich in Gries bei Bozen in einer Villa ein und eröffnete eine chirurgische Praxis. Diese florierte zunächst nicht, worauf er sich um die Stelle des Primararztes in Brixen bewarb und 1924 dort eine Anstellung erhielt. Er kehrte dann aber bald nach Wien zurück, wo ihm nach der Währungsreform die Realisierung des ursprünglich geplanten Unfallkrankenhauses zugesagt wurde. Am 1. Dezember 1925 eröffnete in der Webergasse (20. Wiener Gemeindebezirk) das neue Spital mit 52 Betten.

2 Thomas SCHLICH, Die perfekte Maschine. Die Rationalisierung der Knochenbruchbehandlung im 1. Weltkrieg durch Lorenz Böhler. In: Thomas FEURSTEIN (Hg.), Lorenz Böhler - Pionier der modernen Unfallmedizin (=Schriftenreihe der Vorarlberger Landesbibliothek 20, Graz, Feldkirch 2010) $117-172$. 


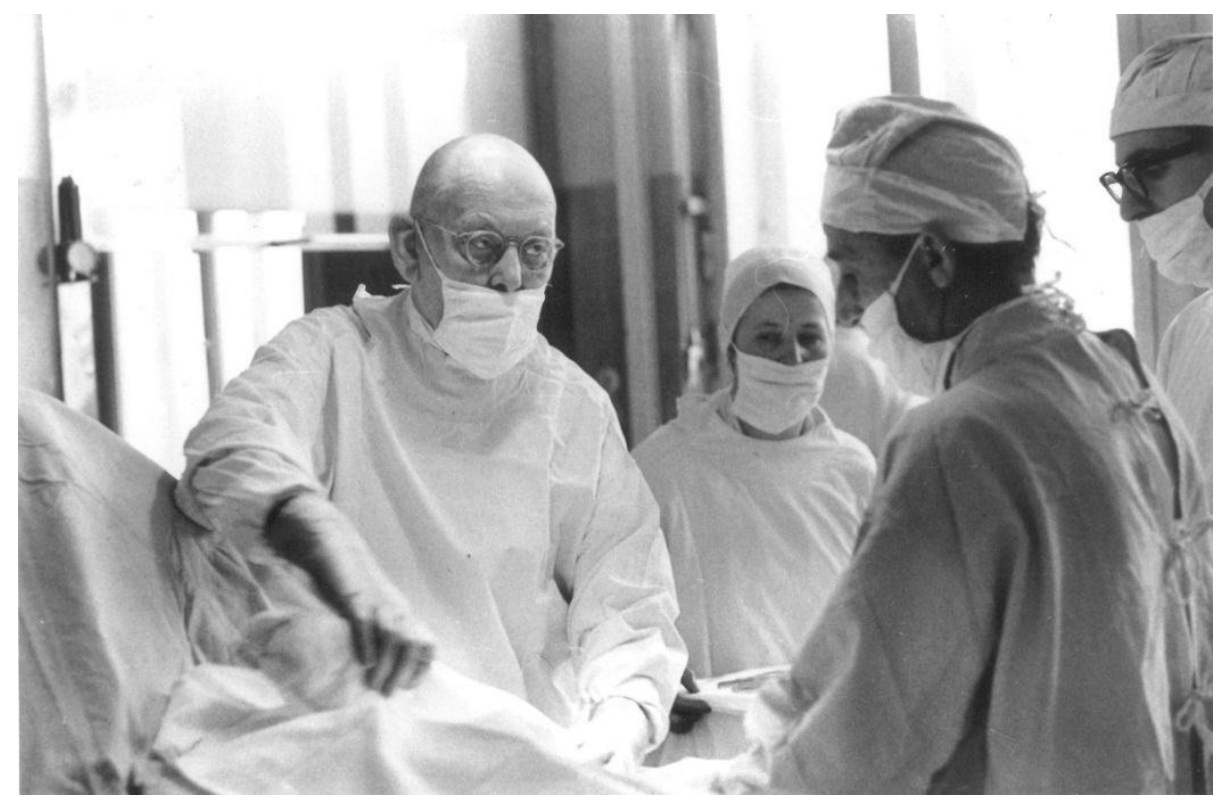

Abb. 2: Lorenz Böhler beim Operieren, ca. 1960

Von nun an schickten die Betriebe in Wien ihre Verletzten ins Unfallkrankenhaus der Versicherung, um sie dort behandeln zu lassen. ${ }^{3}$ Die bereits in Bozen formulierten Prinzipien wurden nun in klare Richtlinien gegossen, die nach Wichtigkeit geordnet folgende Ziele enthielten:

- Erhaltung des Lebens

- Erhaltung der Gliedmaßen

- Wiederherstellung der Funktion

Auf die Behandlung von Knochenbrüchen umgelegt lauteten seine Anweisungen:

- Einrichten: bei jedem Knochenbruch müssen die verschobenen Bruchstücke gut eingerichtet werden.

- Ruhigstellen: die eingerichteten Bruchstücke müssen bei sorgfältiger Beachtung des Blutumlaufes so lange ununterbrochen in guter Stellung festgehalten werden, bis sie knöchern miteinander verheilt sind.

- Üben: während der notwendigen Dauer der Ruhigstellung der gut eingerichteten Bruchstücke müssen möglichst viele oder alle Gelenke des verletzten Gliedes und der ganze Körper unter Vermeidung von Schmerzen in vollem Umfang selbsttätig bewegt werden, um Störungen des Blutumlaufes, den Schwund der Muskeln und des Kalkgehalts der Knochen sowie Einschränkungen der Beweglichkeit der Gelenke zu vermeiden. ${ }^{4}$

3 Inge LEHNE, Lorenz Böhler. Die Geschichte eines Erfolges (Wien 1991) 75.

4 Paul POVACZ, Fritz POVACZ, „Einrichten, Ruhigstellen, Üben“. Die Bedeutung Lorenz Böhlers für die Entwicklung der Unfallmedizin. In: Thomas FEURSTEIN (Hg.), Lorenz Böhler - Pionier der modernen Unfallmedizin (=Schriftenreihe der Vorarlberger Landesbibliothek 20, Graz, Feldkirch 2010) 201-230. 
Massage und passive Bewegungen gehörten nach Böhler zu den größten Schädigungen bei der Behandlung frischer Knochen- und Gelenksverletzungen, und wurden daher nicht mehr angewendet.

Die Böhlerschen Methoden wurden in der Fachwelt sehr kontroversiell auf Kongressen und in Fachzeitschriften diskutiert, wobei er als wortgewaltiger und kämpferischer Wissenschaftler bekannt war, der auch Konflikte mit anderen Kapazitäten nicht scheute.

Nachdem er schon ab 1915 begonnen hatte wissenschaftlich zu publizieren, gelang es ihm 1929, einen Verleger für sein Buch „Die Technik der Knochenbruchbehandlung“ zu finden. Das Nachschlagewerk entwickelte sich schnell zum Standardwerk, was in rascher Abfolge mehrere Neuauflagen nach sich zog. Bis zum Jahr 1963 erschienen 13 deutsche Auflagen, englische, französische, polnische, spanische, russische, ungarische und sogar eine chinesische Übersetzung folgten. ${ }^{5}$

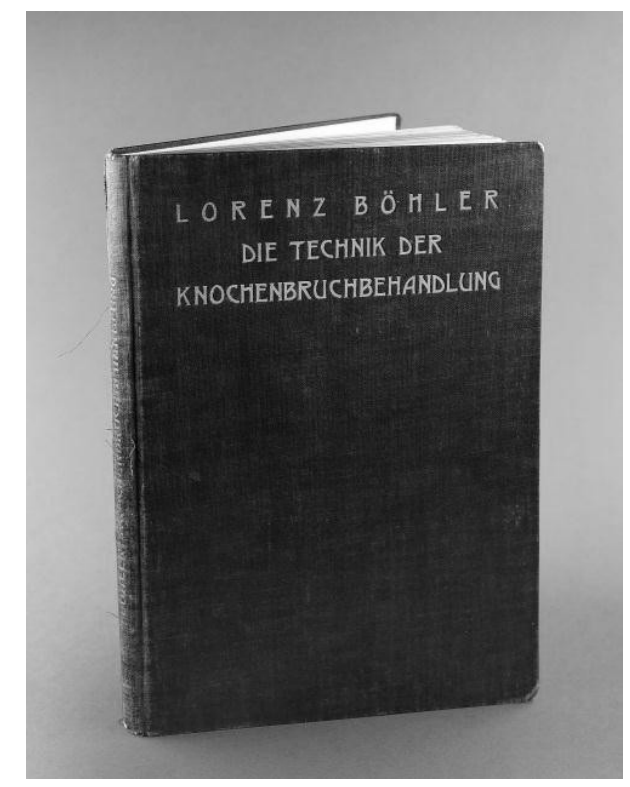

Abb. 3: Lorenz Böbler, Die Technik der Knochenbruchbehandlung. Wien 1929.

Durch den steigenden Bekanntheitsgrad der Webergasse setzte ein Besucherstrom von Fachkollegen ein (im Jahr 1937 waren es 749 Gäste aus aller Welt). ${ }^{6}$ Besonders interessant war das Konzept der Unfallversicherung auch aus volkswirtschaftlicher Sicht, da die Invalidenrenten durch die Böhlerschen Methoden signifikant gesenkt werden konnten. 1937 verlieh ihm die Medizinische Fakultät der Universität Wien den Titel des außerordentlichen Universitätsprofessors.

5 Lorenz BÖHLER, Ein Leben für die Unfallchirurgie (=Paracelsus Schriftenreihe der Stadt Villach 10, Klagenfurt 1965) 10.

6 Fritz POVACZ, Geschichte der Unfallchirurgie. 2. Aufl., (Heidelberg 2007) 163. 
1938 trat Lorenz Böhler noch vor dem Anschluss Österreichs der NSDAP bei und wurde 1940 als beratender Chirurg nach Polen und später nach Russland abkommandiert. 1942 übernahm er das Lazarett im Wiener Rudolfspital mit 400 Betten. 1945 erhielt er als Arzt das Ritterkreuz zum Kriegsverdienstorden, als Vater verlor er einen seiner Söhne, der in den Kämpfen um Wien 20jährig fiel.

Nach 1945 suchte Böhler um Löschung aus der Liste der Nationalsozialisten an und versuchte seine Position in einem Einspruchsakt zu begründen. Der wichtigste Grund für seinen Beitritt zur NSDAP sei die Sorge um seine ärztliche Position gewesen, dennoch habe er trotz Aufforderung nie eine Parteifunktion übernommen und sei dem nationalsozialistischen Gedankengut immer kritisch gegenüber gestanden. Kollegen und der Betriebsrat bestätigten das menschlich einwandfreie Verhalten Böhlers von 1938 bis 1945, was letztlich zu einer persönlichen Intervention durch Staatskanzler Dr. Karl Renner führte: „Am Ende haben doch die durch einen Unfall betroffenen Arbeiter das höhere Recht auf rettende ärztliche Behandlung als der Staat auf Ahndung einer staatsfeindlichen Haltung. “ Die endgültige Entlastung Böhlers erfolgte durch das Nationalsozialistengesetz von 1947, mit dem alle „Minderbelasteten“ nicht mehr behelligt wurden und ihre berufliche Laufbahn fortsetzen konnten. ${ }^{7}$

1947 übernahm Böhler wieder die Leitung des Unfallkrankenhauses in der Webergasse und konnte dort 1951 das 25jährige Bestehen feiern. Der vorgelegte Rechenschaftsbericht war beeindruckend: 77.532 frische Knochenbrüche waren behandelt worden, davon wurden 93.58 Prozent ohne Minderung der Erwerbsfähigkeit geheilt und bei nur 3 Prozent der Patienten konnten bleibende Störungen festgestellt werden.

Im gleichen Jahr wurde auch Böhlers jahrzehntelanger Forderung entsprochen, den „Facharzt für Unfallchirurgie“ einzuführen.

In den 50er und 60er Jahren unternahm er viele Auslandsreisen, bei denen er als Berater tätig war, zahlreiche Ehrungen und Orden entgegennehmen konnte, aber immer auch noch Patienten behandelte. So besuchte er unter anderem Spanien, Ungarn, Mexiko, Uruguay, Peru, Venezuela, Brasilien, Argentinien, Griechenland, die USA, Russland, Äthiopien, Kenia, Südafrika und auch den Iran. Nach Persien rief ihn ein Telegramm des österreichischen Botschafters, der ihn um die Behandlung der Schah-Mutter bat. Die meisten Länder, die er besuchte, hatten die Böhlerschen Methoden bereits übernommen oder beabsichtigten dies zu tun. ${ }^{8}$

Im Alter entdeckte das Ehepaar Böhler auch die Wiener Kultur und besuchte Staatsoper und Burgtheater. Die Sommer verbrachten sie vor allem in Dreikirchen, einer kleinen Bergparzelle weit oberhalb des Eisacktals, wo sich bis heute jeden Sommer die Böhler-Settari-Verwandtschaft trifft. Im hohen Alter durfte Lorenz Böhler noch einen Höhepunkt seiner Karriere erleben. Die Unfallversicherung eröffnete im Herbst 1972 anstelle der Webergasse ein neues Krankenhaus, das seither seinen Namen trägt.

Ende 1972 starb seine Frau und wenige Tage danach erkrankte auch er selbst schwer und starb am 20. Jänner 1973.

7 Bernd VOGEL, „Ich habe meine Zugehörigkeit zur NSDAP nie missbraucht“. Lorenz Böhler im Nationalsozialismus und seine „Entnazifizierung. In: Thomas FEURSTEIN (Hg.), Lorenz Böhler Pionier der modernen Unfallmedizin (=Schriftenreihe der Vorarlberger Landesbibliothek 20, Graz, Feldkirch 2010) 89-116.

8 Lorenz BÖHLER, Neue Universitätskliniken und Ordinariate in Mexiko, Frankreich, in der Schweiz, Italien und China. In: Münchener Medizinische Wochenschrift 104/19 (1962) 917-919. 


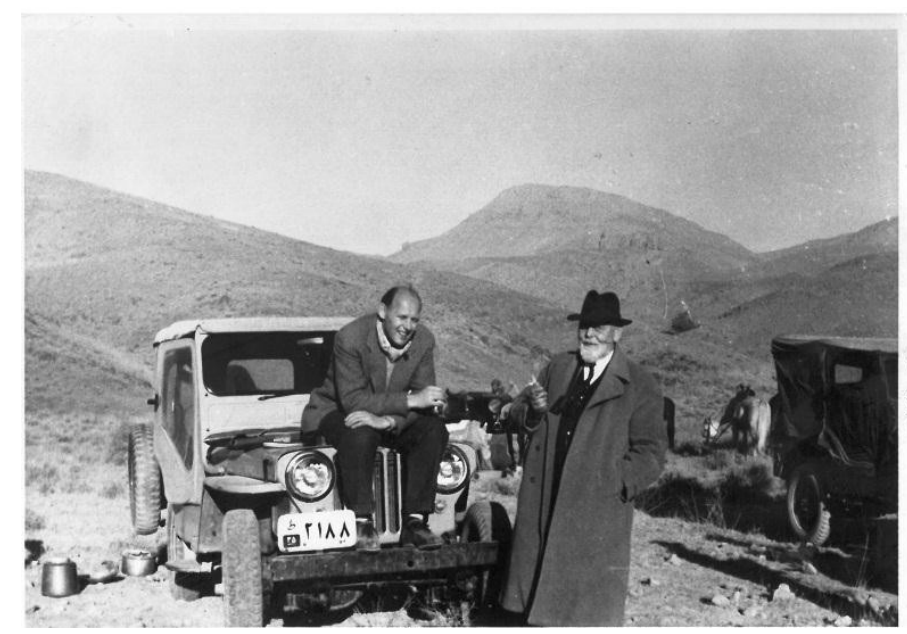

Abb. 4: Lorenz Böbler mit seinem Sohn Jörg im Iran

Im Bestand der VLB fanden sich zwar seine wichtigsten Publikationen und einige handschriftliche Dokumente, diese hätten aber bei weitem keine Ausstellung tragen können. $\mathrm{Da}$ zu den Aufgaben der VLB auch zählt landeskundliches Wissen aufzuarbeiten und durch Ausstellungen $\mathrm{zu}$ vermitteln, schien es gerechtfertigt, potentielle Leihgeber zu kontaktieren. Bald konnte das Ziel der Ausstellung näher definiert werden, nämlich Böhler als Arzt und als Mensch nicht nur Medizinhistorikern, sondern auch einem breiten Publikum näher zu bringen.

Dazu war es aber notwendig, auf Expertenwissen zurückzugreifen: Mitglieder der Familie Böhler, das Institut für Medizingeschichte in Wien, das Universitätsarchiv Wien, das Wiener Stadt- und Landesarchiv, das Lorenz-Böhler-Krankenhaus, die Gesellschaft für Unfallchirurgie und viele andere mehr stellten bereitwillig ihr Wissen und ihre Bestände zur Verfügung. Im Allgemeinen war es relativ einfach, schriftliche Dokumente aufzufinden, ungleich schwerer jedoch, medizinische Geräte aus der Zeit Böhlers zu lokalisieren. Die Frage, ob denn heute bei der Renovierung von Krankenhäusern, jeweils aussagekräftige Gegenstände an Archive und Museen abgeliefert würden, blieb meist unbeantwortet.

Die Ausstellung nahm eine Grundfläche von ca. $80 \mathrm{~m}^{2}$ ein. Vier Räume standen symbolisch für die Lebensphasen Böhlers: Ein Jugendzimmer, ein Krankenzimmer aus der Webergasse, ein Operationssaal, sowie ein multimedialer Raum, wo Originalfilme und Tonproben von Böhler abgespielt werden. Das Zusammenspiel von Flachware und Objekten prägte die Räume.

Um die Ausstellung zu einem Erfolg zu machen, musste auch eine breit gestreute Öffentlichkeitsarbeit betrieben werden. Eine wichtige Komponente ist dabei die enge Zusammenarbeit mit Partnern, allen voran die Gemeinde Wolfurt, die bereit war, zum 125.Geburtstag ihres Ehrenbürgers mit großem personellem und finanziellem Aufwand ein Rahmenprogramm zu veranstalten. Auch die AUVA, deren Konzept der Unfallbehandlung jahrzehntelang auf den Ideen Böhlers beruhte, konnte als Sponsor gewonnen werden. 


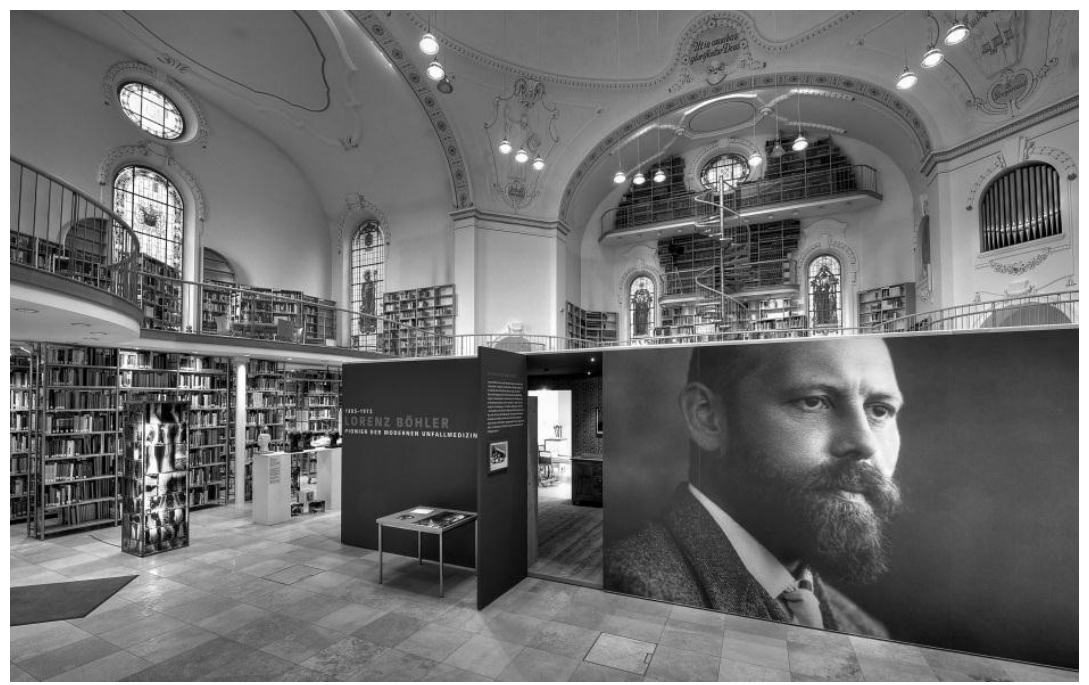

Abb. 5: Die Böhler-Ausstellung in der VLB 2010

Weiters hat sich das ORF-Landesstudio Vorarlberg dazu entschlossen, ein ÖsterreichBild über Lorenz Böhler zu produzieren, das im November 2010 ausgestrahlt wurde. Im Rückblick kann die Ausstellung als voller Erfolg bewertet werden, da 2850 Personen als Besucher gezählt werden konnten, davon 1.058 im Rahmen von 66 Führungen. Einer der Höhepunkte war der Besuch von Bundespräsident Dr. Heinz Fischer am 21.7.2010. Der Begleitband wurde insgesamt 2.200 verkauft, davon 1.200 Stück an die Österreichische Gesellschaft für Unfallchirurgie. Laut ORF konnte das Österreich-Bild über Lorenz Böhler 418.000 Zuseher verzeichnen.

\section{Autoreninformation}

Mag. Thomas Feurstein, Mitarbeiter der Vorarlberger Landesbibliothek. Postadresse: Fluher Straße 4, 6900 Bregenz, Österreich. Mail: Thomas.Feurstein@vorarlberg.at 


\section{Giovanni Alessandro Brambillas Appendice - eine Quelle zum Gesundheitswesen im Josephinismus}

\section{Einleitung}

1800 veröffentlichte Giovanni Alessandro Brambilla in Pavia den "Appendice - Alla Storia della Chirurgia austriaca militare in cui trattasi dell'erezione degli Spedali, della Fabbrica dell'Accademia Gioseffina, e de' Gabinetti in essa contenuti, con loro Piani, e con quelli degli Spedali di Campagna dell'ultima Guerra contro il Turco."1 In diesem Druckwerk beschäftigte sich der persönliche Arzt Josephs II. mit zwei großen Themen: Mit der allgemeinen Situation der verschiedenen Spitäler unter dem Monarchen und mit der Gründung des Josephinums als medizinische Ausbildungsstätte in Wien im Jahre 1785. Brambilla war für viele Verbesserungen in den Krankenhäusern der Habsburgischen Monarchie verantwortlich. So legte er größten Wert auf die Einführung verschiedener Vorschriften und besserer Hygienezustände.

Brambilla bemühte sich außerdem um eine klare Trennung von Patienten mit verschiedenen Krankheiten, sodass die Gefahr, dass sich die Patienten gegenseitig anstecken konnten, erheblich verringert wurde. Aber auch ein Rauchverbot und regelmäßiges Wechseln der Wäsche forderte er mit Nachdruck.

Im zweiten Teil des Werkes konzentrierte er sich auf die Gründung, die Errichtung und die verschiedenen Sammlungen des Josephinums. Die Akademie, die von ihm selbst eröffnet wurde, sollte in Zukunft nicht nur der Ausbildung von Ärzten, sondern auch der Förderung der medizinischen Wissenschaften dienen. In diesem sehr klar strukturierten Teil des Appendice wird die gesamte wissenschaftlich-medizinische Sammlung, die das Josephinum damals beherbergte, detailliert aufgelistet, weshalb man von einer ersten ausführlichen Inventarliste der Akademie sprechen kann. Darin genannt werden sowohl die aus Florenz stammende Wachspräparatensammlung, die es den Professoren erstmals erlaubte, ganzjährig anatomischen Unterricht abzuhalten, wie auch eine Sammlung von verschiedenen anderen Präparaten, die zum Teil Brambilla selbst der Akademie zum Geschenk gemacht hatte. In beiden Teilen beschreibt der Autor zudem aufgrund der Anwendung seiner neuen Regeln bereits erzielte medizinische Erfolge anhand zahlreicher Beispiele. Außergewöhnliche Behandlungsfälle werden hierbei in allen Details geschildert, und sollen dem Leser den Nutzen einer ,modernen' medizinischen Wissenschaft deutlich machen.

1 Deutsche Übersetzung: "Anhang - über die Geschichte der österreichischen Militärchirurgie, in der die Errichtung der Krankenhäuser, das Gebäude der josephinischen Akademie und die Errichtung der Sanitätsanlagen mit ihren Plänen und denen der Feldlazarette des letzten Krieges gegen die Türken, behandelt werden." Italienisches Original: Giovanni Alessandro Brambilla, Appendice (Pavia 1800) 
Meine Arbeit mit dem Appendice, welche die Grundlage meiner Diplomarbeit ${ }^{2}$ sowie der folgenden Ausführungen bildete, begann im Sommer 2009. Aufgrund des Titels Appendice (deutsch: Anhang) lag von Anfang an die Vermutung nahe, dass hierzu ein größeres Hauptwerk existiert, wenn auch dieses nicht zum Druck gelangte. Der Appendice dagegen liegt gedruckt in italienischer Sprache vor; der erste Arbeitsschritt in meiner Arbeit war daher, eine deutsche Übersetzung anzufertigen. Es war dabei stets meine Intention, soweit nahe wie möglich am Original zu bleiben. Eine inhaltliche Zusammenfassung des Appendice ist der Diplomarbeit beigegeben. ${ }^{3 .}$

\section{Äußere Analyse}

Der Appendice besteht aus 96 Seiten, inklusive Deckblätter und Planskizzen des Josephinums am Ende der Quelle. Hierbei handelt es sich, wie bereits erwähnt, vermutlich um den Anhang eines geplanten, größeren Werkes. Die hierbei in Frage kommende Arbeit Brambillas ist im Archiv der Universität von Pavia erhalten und umfasst mehr als 1000 handgeschriebene Seiten. Man vermutet, dass der Titel dieses Hauptwerkes „Die Geschichte der österreichischen Militärchirurgie“ lauten hätte sollen. Der Aufbau und die Struktur des Appendice lassen darauf schließen, dass es sich hier um eine Zusammenfassung der wichtigsten Aussagen des Hauptwerkes handelt,. Natürlich war es einfacher, zunächst einen 90-Seiten-Text drucken zu lassen, als mehr als 1000 Seiten Notizen, Anmerkungen und gesammelte Geschichten, Regeln und Erfahrungen in breitenwirksamer Form zu veröffentlichen. Tatsächlich ist es Brambilla - sollte dies sein Plan gewesen sein - nicht mehr gelungen, das eigentliche Hauptwerk in Reinschrift und in Druck zu bringen.

\section{Sprach- und Strukturanalyse}

Der Appendice wurde in italienischer Sprache, der Muttersprache Brambillas, verfasst. Anhand der sich immer wieder ändernden Satzstrukturen und Stiländerungen im italienischen Original ist gut ersichtlich, dass der Appendice nicht von Anfang an als ganzes Werk konzipiert war,.

Hinsichtlich der Entstehung der endgültigen Druckfassung bestehen derzeit drei verschiedene Annahmen 1. Bereits im ersten Teil des Appendice finden sich Hinweise darauf, dass es sich um eine über Jahrzehnte hinweg entstandene Sammlung handschriftlich verfasster Notizen und Aufzeichnungen handeln könnte. Daher ist denkbardass - möglicherweise aufgrund von Zeitmangel - die einzelnen Fragmente für den Druck von Brambilla selbst mehr oder weniger chronologisch aneinandergefügt wurden. Dies könnte als Erklärung dafür dienen, dass vor allem der erste Teil hinsichtlich der thematischen Abfolge nicht stimmig ist, viele Themen öfters wiederholt werden und es keinen roten Faden durch den Text gibt. 2. Die Stiländerungen, die im gesamten Appendice immer wieder auftreten, , sind vielleicht dadurch zu erklären, dass Brambilla bei der Durchsicht und Reinschrift seiner Notizen, Unterstützung von einer zweiten Person erhielt. Die Textgrundlage stammte sehr wahrscheinlich von Brambilla selbst, aber angesichts seines fortgeschrittenen Alters ist es anzunehmen, dass er nicht mehr alleine den gesamten Text für einen Druck

2 Barbara PEINTINGER, Giovanni Alessandro Brambillas Appendice - Eine Quelle zur Geschichte des Gesundheitswesens im Josephinismus (Wien 2011).

3 Ebd. 77-131 
vorbereiten konnte. 3. Es ist grundsätzlich denkbar, dass Brambilla überhaupt nur dem Verleger seine Notizen zur Verfügung stellte, und dieser das Werk in seiner endgültigen Gestalt erstellen ließ. Dies erscheint aber unwahrscheinlich.

Hinsichtlich der Beurteilung dieser Annahmen erscheint mir wahrscheinlichsten erscheint, dass sowohl die erste, als auch die zweite These zutreffen.

Die Vermutung liegt nahe, dass es Brambilla aus Zeitmangel nicht möglich war, das umfangreiche Hauptwerk zu publizieren, weshalb er in seinen letzten Lebensjahren beschloss, zumindest den Appendice, in dem hauptsächlich seine beiden „Lieblingsthemen“ behandelt werden, veröffentlichen zu lassen: Das Spitalswesen in der Habsburgermonarchie, welches sich unter Joseph II. stark verändert hatte, und sein Lebenswerk, der Bau und die Einrichtung des Josephinums. Zu den Beweggründen der Drucklegung des Appendice lassen sich jedoch nur Vermutungen anstellen, da der Autor selbst hierzu nichts mitteilte. Inwieweit vielleicht finanzielle Schwierigkeiten bei der Realisierung des Gesamtprojekts aufgetreten sind, lässt sich mit dem derzeitigen Wissensstand nicht beantworten. Man muss weiters beachten, dass zum Zeitpunkt der Veröffentlichung einige Ereignisse, die Brambilla erwähnt, bis zu 40 Jahren zurücklagen. So begleitete er Joseph II. bereits in den 1760er Jahren auf Reisen. Mit Sicherheit jedoch sind Spitalsbesuche im Rahmen von Reisen aus den 1770er Jahren im Appendice beschrieben. ${ }^{4}$ So gut wie sicher ist auch, dass sich Brambilla bei allen Reisen Aufzeichnungen machte, denn es ist kaum davon auszugehen, dass er sich knapp 70-jährig noch an alle im Text erwähnten Details der verschiedenen Krankenhäuser, die er im Lauf seines Lebens besucht hatte, erinnern hätte können. Offenbar existierten also handschriftliche Aufzeichnungen, die für den Appendice in eine druckgerechte Fassung gebracht werden konnten.

Erwähnenswert sind auch die großen strukturellen Unterschiede zwischen dem ersten und dem zweiten Teil des Appendice. Während sich der erste Teil, der sich mit dem Spitalswesen während der Regentschaft Josephs II. befasst, ohne jede Gliederung über 37 Seiten erstreckt, ist der zweite Teil, der das WienerJosephinum erörtert, gemäß den einzelnen Räume der Akademie gegliedert. Auch diese auffällige Differenz untermauert die Annahme, dass der Appendice nicht a priori für eine Publikation verfasst wurde, sondern nachträglich aus unterschiedlichen Teilen komponiert. .

\section{Grundsätzliches zu Brambillas Stil}

Bei der oft zitierten deutschen (übersetzten) Fassung der Rede, die Brambilla anlässlich der Eröffnung des Josephinums gehalten hatte ${ }^{5}$, erscheint der persönliche Arzt Josephs II. als ziemlich unhöflich und wenig diplomatisch. Nimmt man die Originalfassung des Appendice zum Vergleich heran, so formuliert Brambilla hier sehr genau und treffend, aber immer in einem höflich-diplomatischen Ton, stets darauf bedacht, niemanden direkt herauszufordern. Mehrmals kommt er auf Neider zu sprechen, deren Missgunst er nicht noch weiter erhöhen wolle. Um trotz der Anfeindungen seitens der einheimischen Professoren als Italiener persönlicher Arzt Josephs II. zu werden, hatte es im Übrigen mit Sicherheit eines hohen Maßes an diplomatischem Geschick bedurft. Obwohl Brambilla seine Meinung in keinem seiner Werke und auch nicht bei der erwähnten Eröffnungsrede verleugnete, lässt sich doch dem italienischen Originaltext

4 Vgl. PEINTINGER, Brambillas Appendice 58 und 79.

5 Giovanni Alessandro BRAMBILLA, Rede die er bey der Eröffnung der neuen k.k. medizinischchirurgischen Akademie den 7. November 1785 gehalten hat (Wien 1785). 
deutlich entnehmen, dass er darum bemüht war, niemandem zu nahe zu treten und sich nicht unnötig (zusätzliche) Feinde zu schaffen.

\section{Der 1. Teil des Appendice - Über das Spitalswesen unter Joseph II.}

Wie erwähnt, gliedert sich der Inhalt des Appendice in zwei große Themenbereiche. Zunächst beschäftigt sich der Autor mit der allgemeinen Situation der verschiedenen Spitäler der habsburgischen Monarchie zur Zeit Josephs II., zeigt die verschiedenen Missstände auf und weist insbesondere auf die Verbesserungen hin, die durch ihn selbst bereits eingeführt wurden. Größten Wert legte Brambilla auf mehr Sauberkeit und die Einführung bestimmter Hygienevorschriften, ein Wunsch der oft wiederholt wird. Interessant ist die Tatsache, dass der Appendice insgesamt keinen klaren Anfang und kein klares Ende aufweist. So beginnt Brambilla den 1. Teil ohne jegliche Einleitung gleich mit dem Problem der mangelnden Beachtung medizinischer Regeln und beendet mit der Anlage eines neuen Brunnens. Es fehlen, wie in seinen anderen Werken durchaus üblich, am Beginn Dankensreden und Huldigungen an Joseph II.. Dafür kommen sie im Appendice mitten im Text vor und wiederholen sich. Man kann ausgehen, dass dies dem Zeitmangel bei der Editierung zuzuschreiben ist.

Primär befasste sich Brambilla mit der Erforschung neuer Heilmethoden, zugleich wies er im Appendice aber auch darauf hin, dass wesentliche wissenschaftliche Erkenntnisse oft nur durch den Tod eines Patienten gewonnen werden konnten. Er berichtet von den verschiedenen Spitälern, die er gemeinsam mit Joseph II. besucht hatte, erwähnt die schlechten hygienischen Zustände sowie die teilweise sehr schlechte Versorgung der Kranken und versucht, diesen Missständen durch Verbesserungsvorschläge entgegenzuwirken. Als persönlicher Arzt des Kaisers und Direktor der JosephsAkademie hatte er ab den 1780er Jahren zweifellos beachtliche Autorität und auch mehr Erfolg mit seinen Initiativen, als noch zur Zeit der Mitregentschaft Josephs II.

Im Folgenden seien die wichtigsten Inhalte des ersten Teiles des ,Appendice summarisch wiedergegeben: Im Siebenjährigen Krieg war man, so Brambilla, dazu übergegangen, in den Palästen und Klöstern, die man außerhalb der Stadt fand, Spitäler einzurichten. Hierbei verweist der Autor besonders auf seine Kenntnisse des großen Invalidenkrankenhauses in der Nähe von Prag, und kritisiert die dortigen hygienischen Bedingungen. So wurden häufig Patienten mit unterschiedlichen Krankheiten in einem Saal zusammengelegt, wodurch sich die Ansteckungsgefahr enorm erhöhte. Im Winter war es zwecks Sparmaßnahmen sogar üblich, alle Kranken in einen Raum unterzubringen. In vielen Fällen konnten die Krankensäle nicht gelüftet werden, der Gestank in den Zimmern war daher unbeschreiblich. Oft war in den Kriegszeiten das Chaos in den Spitälern so groß, dass die Befehlshaber nicht wussten, ob ihre Soldaten noch lebten oder bereits tot waren.

Vor 1778 war es, so Brambilla weiter, üblich, dass jedes Regiment sein eigenes Spital besaß, wobei die Krankheiten in diesen oft sehr kleinen Krankenhäusern sehr schlecht kategorisiert werden konnten. Da jedes dieser Krankenhäuser eine eigene Leitung besaß, waren auch die Arbeitsbedingungen in ökonomischer Hinsicht enorm unterschiedlich. Brambilla weist auch auf den häufigen Ursprung der Spitalsbrände durch Rauchen im Krankenzimmer hin und setzte in mehreren dieser Krankenhäuser ein Rauchverbot durch. Da sich die betreffenden Soldaten darüber jedoch beschwerten, einigte man sich auf einen Kompromiss: Das Rauchen war nun zumindest am Gang erlaubt. Brambillas größte Ambition im Bereich der Militärkran- 
kenhäuser war es, die Behandlungsmethoden zu verbessern und die Chirurgen von diesen neuen Methoden zu überzeugen. So riet er ihnen, die Eiterbeulen anders zu behandeln, um sie schneller zum Abheilen zu bringen, empfahl Patienten mit inneren Erkrankungen von jenen mit anderen Erkrankungen zu trennen und die Krankensäle regelmäßig zu lüften. Oft wurden Patienten anstatt von ausgebildeten Chirurgen vom Krankenpflegepersonal behandelt, was gemäß Brambilla zu Behandlungsfehlern führte. Der Autor forderte außerdem die Verwendung unterschiedlicher Gefäße für Nahrung, Notdurft und Medikamente. Denn noch im späten 18. Jahrhundert war es beispielsweise nicht unüblich, dass die Soldaten ihre Suppe aus derselben Schüssel aßen, in denen auch ihr Blut bei der Blutabnahme aufgefangen wurde. Fenster sollten zumindest im Sommer regelmäßig geöffnet werden, wodurch sich die Luft- und Geruchssituation erheblich verbessern ließ. Die Betten der Kranken sollten alle gleichmäßig konstruiert sein, und nicht mehr wie bis dahin unterschiedliche Längen und Breiten aufweisen und darüber hinaus nur noch jeweils einer einzigen Person zugleich zur Verfügung stehen. Ruhiger brennende Öllampen sollten verhindern , dass die Patienten in der Nacht vom flackernden Licht aufgeweckt wurden. Außerdem wurden auf Anordnung Brambillas abschließbare Medikamentenkästen in den Krankensälen aufgestellt, mithilfe derer der Diebstahl von Arzneien erheblich zurückging. Das Krankenpflegepersonal sowie die Ärzte mussten sich vor und nach der Behandlung in von der Decke hängenden Wassergefäßen die Hände zu waschen. Ebenso wurden die Behandler verpflichtet, bei den Aderlässen das Blut in einem Gefäß mit Markierungen aufzufangen, um die Menge abschätzen zu können. Weiters wurden auf Anregung des Autors, wie er selbst berichtet, im Jahr 1778 in allen diesen Krankenhäusern Bestellscheine für Medikamente eingeführt. Vor allem aber begann man damals, aufgrund der verschiedenen Missstände im Krankenhauswesen, auf die Joseph II. und Brambilla auf ihren Reisen getroffen waren, über die Möglichkeit der Errichtung eines neuen großen allgemeinen Krankenhauses nachzudenken, in dem Brambilla alle geplanten neuen Vorschriften einführen konnte. An diesem Krankenhaus sollte auch eine Akademie errichtet werden, in der die Studenten nach von Brambilla entwickelten Lehrplänen unterrichtet werden sollten. Zur Behandlung sollten sowohl militärische als auch bürgerliche Patienten zugelassen werden.

Zusammen mit dem dann tatsächlich realisierten Wiener Allgemeinen Krankenhaus wurde auch ein Gebärhaus errichtet, in dem erstmalig eine für die Mutter kostenlose anonyme Geburt möglich war. ${ }^{6}$ Für die „Geisteskranken“ wurde der Narrenturm errichtet, wobei hier jeder Kranke ein eigenes Zimmer bekommen sollte. Dies war eine Neuerung, die auf ein persönliches Erlebnis Brambillas zurückging, denn bei einer seiner Reisen mit dem Herrscher besuchte er auch ein Irrenhaus, in dem sich ein junger Soldat befand, der zuvor von seinem Vorgesetzten misshandelt worden war. Da alle Geisteskranken auf engstem Raum zusammen leben mussten, regte Brambilla an, dem jungen Soldaten ein eigenes Zimmer zur Verfügung zu stellen. Da er wieder gesund wurde und schließlich sogar das Medizinstudium absolvieren und zum Doktor der Chirurgie promovieren konnte, schloss Brambilla, dass eine Einzelunterbringung heilsamer wäre.

6 Entweder wurden die geforderten Aufnahmetaxen bezahlt, oder aber die Frau musste sich als „lebendiges“ Übungsmaterial den angehenden Ärzten zur Verfügung stellen. Vgl.: Elisabeth GNEIHS Kinder die keiner wollte (Wien 2007) 124. 
Im Weiteren behandelt Brambilla auch die sieben in Wien und Umgebung gelegenen Spitäler, nämlich St. Marx, das spanische Krankenhaus, das Bäckenhäusl, das Kontumazhaus, das Krankenhaus der Invaliden, das St. Johann Nepomuk-Spital und das Krankenhaus der barmherzigen Brüder, welches er als besonders positives Beispiel hervorhebt. Immer wieder thematisiert der Autor die Frage, ob kleine oder große Krankenhäuser sinnvoller seien. Gegen die großen Einrichtungen sprach für Brambilla, dass oft Epidemien kursierten und dadurch eine höhere Anzahl von Menschen angesteckt werden konnte, gegen die kleineren aber, dass dort keine adäquate Klassifizierung der Krankheiten möglich sei. Die meisten dieser kleineren Spitäler Wiens wurden während der Regierungszeit Josephs II. umgebaut und vergrößert, manche, wie das Kontumazhaus, aber aufgelassen .Auf dem Grund des letzteren wurden sodann die Josephinische Akademie und das Allgemeine Krankenhaus errichtet

Brambilla überzeigte zudem, wie der Appendice ausführt, Joseph II. davon, dass auch die Errichtung weiterer Militärkrankenhäuser in anderen Städten und Provinzen notwendig sei, wobei dafür in den meisten Fällen aufgelassene Klöster verwendet wurden. Meistens kam der Kaiser selbst für die Errichtung auf, die laufenden Kosten mussten von den Städten übernommen werden.

\section{Der 2. Teil des Appendice - Die Gründung des Josephinums}

Im Gegensatz zum ersten Teil, der keine Überschriften oder Unterteilungen aufweist, ist der zweite Teil streng gegliedert. Brambilla beschreibt darin die Notwendigkeit der neu gegründeten Akademie, die Umstände ihrer Etablierung sowie, sehr ausführlich, die medizinisch-wissenschaftliche Sammlung, die im Josephinum aufbewahrt wurde. Auch hier lässt Brambilla die Leserinnen und Leser an zahlreichen Anekdoten teilhaben; sein Hauptaugenmerk aber liegt auf der Beschreibung der Kabinette und ihrer Ausstattung.

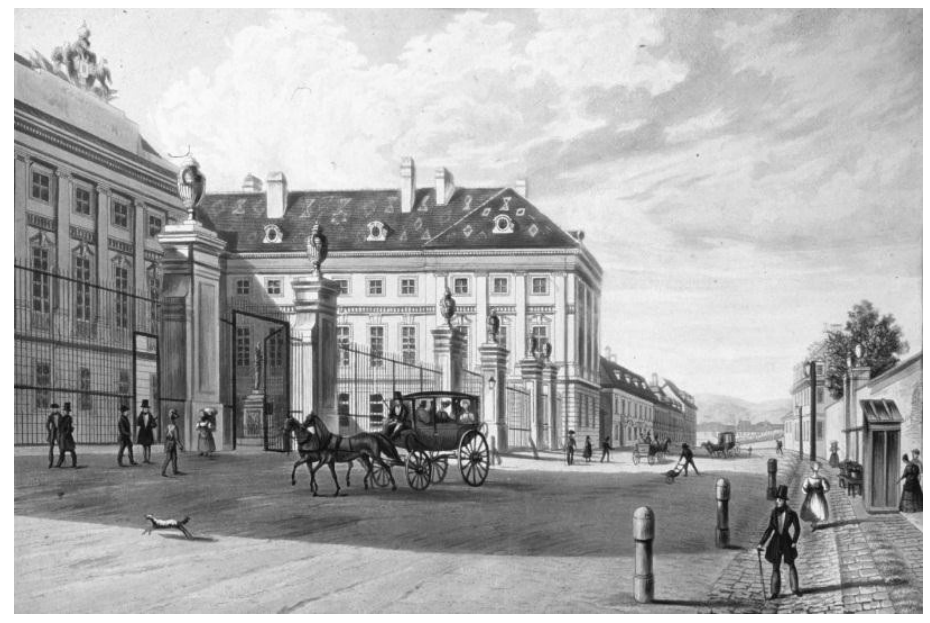

Abbildung 1: Das Josephinum im 18. Jabrhundert ${ }^{7}$

7 Die Rechte aller Abbildungen liegen beim Department und Sammlungen für Geschichte der Medizin der Medizinischen Universität Wien, Bildersammlung. 
Bereits lange vor der Gründung des Josephinums hatte der Autor die schlechte Ausbildung der Chirurgen in der Armee bemängelt .Seiner Meinung nach sollte man bereits daher in Friedenszeiten alles medizinisch Notwendige veranlassen, um im Kriegsfall vorbereitet zu sein.

Bei ihrer Fertigstellung war die Josephs-Akademie zusammen mit dem neuen Allgemeinen Krankenhaus eine der am besten ausgestatteten Spitals- und Bildungseinrichtungen Europas, worauf Brambilla stolz hinweist.. Hier konnte er als Direktor all jene Vorschriften und Regeln, die er in den vorangegangenen Jahren entwickelt hatte, durchsetzen. Einer der wichtigsten Räume der neuen Akademie war die Bibliothek, deren Buchbestand mehr als 2600 Werke umfasst haben soll. Über 360 kamen dabei aus dem persönlichen Besitz Brambillas. Er führte eine strenge Bibliotheksordnung ein, die in der Folge auch von der Bibliothek im Prager Invalidenkrankenhaus übernommen wurde und unter anderem den Umgang mit den Büchern regelte. Der Hörsaal, in dem der Unterricht stattfand, befand sich genau in der Mitte des Gebäudes im ersten Stock. Insgesamt gab es fünf Eingangstüren zu diesem Saal, zwei davon am oberen Ende, um es auch Zuspätkommenden zu ermöglichen, am Unterricht teilzunehmen, ohne diesen zu stören. Vor dem Tisch des Professors wurde eine Lampe befestigt, die es ermöglichte, nicht nur im Sommer, sondern auch im Winter, wenn es bereits früh dunkel wurde, Lektionen zu geben. An den Tagen rund um den Gründungstag wurden die Porträts der Gründer im Saal aufgehängt.

Neben der Bibliothek und dem Hörsaal gab es im Josephinum selbst den Ausführungen Brambillas zufolge noch 12 weitere Kabinette, in denen die Sammlungen der Akademie aufbewahrt wurden. In diesen Kabinetten befanden sich mineralische, pflanzliche und tierische Fundstücke, teils naturbelassen, teils chemisch verändert. Jedes Stück, das in die Sammlung eingegliedert wurde, musste in einem eigenen Protokoll verzeichnet werden. Brambillas ursprüngliche Idee war es, eine eigene Kollektion von Tierknochen sowie von menschlichen Skeletten herstellen zu lassen. Als sich jedoch die Möglichkeit eröffnete, eine Wachspräparatensammlung für die Akademie zu erwerben, wurde die Ursprungsidee verworfen. Die Professoren wurden dazu angehalten ihren Unterricht so praktisch wie möglich zu gestalten und stets Anschauungsmaterial zur Verfügung zu haben. Mit Hilfe der Wachspräparatensammlung war nun auch erstmals ein ganzjähriger anatomischer Unterricht gewährleistet, da die Verwendung von Leichen im Sommer aus olfaktorischen Gründen nicht möglich war. Zu jedem Präparat gab es eine in Latein und Deutsch verfasste Erklärung. Die Schriftstücke lagen in Schubladen unter dem entsprechenden Wachsmodell oder in einem separaten Kasten bereit. Neben den Wachspräparaten gab es auch noch eine Sammlung natürlicher Präparate, die in destilliertem Weingeist mit Zucker sowie Wasser konserviert wurden. Das Josephinum verfügte auch über eine große Sammlung von über 60 Emailaugen, anhand derer verschiedene Augenkrankheiten dokumentiert wurden. Besonders hervorzuheben ist auch die Instrumentensammlung, die alle medizinsichen Instrumente umfasste, welche damals bei Operationen notwendig werden konnten. Beschreibung, Bauart und Nutzen wurden schon 1872 in einem „Chirurgische Instrumente der militärischen Akademie von Österreich" ${ }^{\text {"8 }}$ betitelten, lateinischen Werk von Brambilla selbst beschrieben. Alle Instrumente wurden vom Wiener Instrumentenmacher Joseph Malliard hergestellt und 
bestanden ausschließlich aus Gold oder Silber. Anhand mehrerer menschengroßer Figuren konnte den Studenten der Akademie unter anderem auch eine Geburt mit all ihren möglichen Komplikationen realistisch vorgeführt werden. Zusätzlich befanden sich im Josephinum „Elektromaschinen“, die bei Nervenkrankheiten zum Einsatz kamen, sowie optische Instrumente, Dunkelkammern und mechanische Apparate, mit deren Hilfe verrenkte Körperteile wieder eingerenkt werden konnten, weiters eine Sammlung von pathologisch verformten Knochen und eine große geburtshilfliche Wachspräparatensammlung,. Zu den Schaustücken der Sammlung zählten auch Embryos, mit deren Hilfe unter anderem der zum damaligen Zeitpunkt weit verbreitete Glaube widerlegt werden sollte, dass Menschen mit schwarzer Hautfarbe mit gelber geboren und erst nach und nach ,eindunkeln“ würden. Brambilla hatte viele Stücke der genannten Sammlungen selbst der Akademie zum Geschenk gemacht. Den größten Teil der Finanzierung übernahm jedoch der Kaiser selbst.

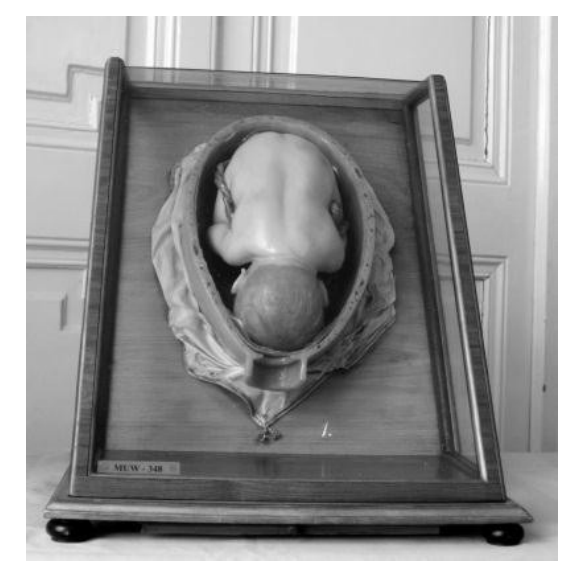

\section{Abbildung 2: Geburtshilfliches Wachspräparat}

Nach dem Vorbild der Pariser Akademie erbaut, besaß das Josephinum ein Stockwerk mehr als dieselbe. Bereits beim Betreten des vorderen Hofes wurde man an den Gründer erinnert und an zahlreichen Stellen waren Josephs-Büsten aufgestellt. Zum Zeitpunkt ihrer Eröffnung befanden sich sowohl die Akademie, als auch das Krankenhaus außerhalb der Stadtgrenze. Dennoch wurde die fertiggestellte Sammlung von zahlreichen Personen sowohl bürgerlicher als auch adeliger Herkunft besucht.

\section{Conclusio}

Giovanni Alessandro Brambilla war viel mehr als "nur" der persönliche Arzt Josephs II. ${ }^{2}$ Er spielte bei den neuen Entwicklungen, die sich im Spitalswesen und der medizinischen Wissenschaft in der Habsburgermonarchie der 1780er Jahre feststellen

9 In seinen letzten Lebensjahren war er nicht nur Reichsritter, Protochirug der Armeen, Inspektor der militärischen Hospitäler sowie Direktor des Josephinums gewesen sondern auch Mitglied der Akademien der Wissenschaften von Bologna, Mantua und Florenz und Mitglied der königlichen Universität von Montpellier. Vgl.: Giovanni Alessandro BRAMBILLA, Über die Entzündungsgeschwulst und ihre Ausgänge (Wien 1786) 1. 
lassen, eine entscheidende Rolle. So gehen viele hygienischen Maßnahmen, die Reformen der Krankenhäuser sowie auch die Gründung des Josephinums auf seine Bestrebungen zurück. Er war ein Reformator, dem es unter dem Protektorat des Herrschers gelungen ist, die Situation der Krankenhäuser nachhaltig zu verbessern, die medizinische Wissenschaft voranzutreiben und dadurch sicherlich vielen Menschen das Leben zu retten. ${ }^{10}$

Der Inhalt des von ihm verfassten Appendice bietet eine Vielzahl an Informationen über das Spitalswesen unter Joseph II. sowie über die Errichtung des Josephinums. Darüber hinaus beinhaltet diese Quelle die genaueste der bisher bekannten Beschreibungen über die einzelnen Sammlungen, die die Josephs-Akademie um 1800 besaß.

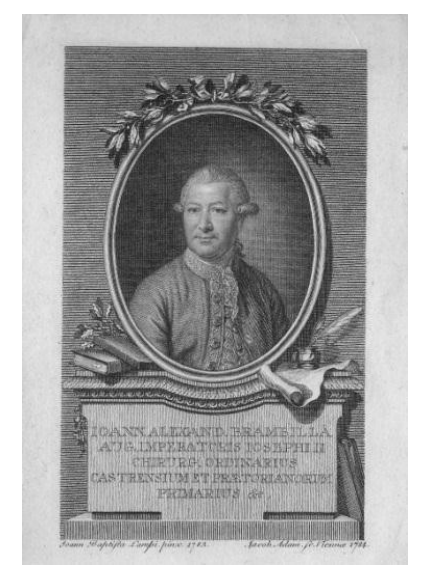

Abbildung 3: Giovanni Alessandro Brambilla

Das Ziel meiner Diplomarbeit war es, diese Informationen durch meine Übersetzung erstmals auch auf Deutsch zugänglich zu machen, den Inhalt des Werkes zu analysieren und die wichtige Rolle, die Giovanni Alessandro Brambilla bei der Entstehung der modernen Medizin spielte, deutlich herauszuarbeiten

\section{Autoreninformation}

Mag. phil. Barbara Peintinger, Historikerin, Assistentin der Ausstellungsorganisation und der Mitgliederbetreuung im Künstlerhaus. Postadresse: Department und Sammlungen der Medizinischen Universität Wien, Währinger Straße 25, 1090 Wien. Mail: babsie.peintinger@hotmail.com

10 Nach dem frühen Tod des Kaisers verlor Brambilla stetig an Macht. Er blieb noch fünf Jahre als Direktor des Josephinums, musste jedoch am 18. November 1795 zurücktreten und zog sich 1797 auf sein Gut Carpiano zurück. Vor der französischen Invasion floh Brambilla nach Padua. Von hier aus wollte er nach Wien zurückreisen, um dem neuen Monarchen, Kaiser Franz I./II. seine Dienste anzubieten. Dazu kam es jedoch nicht mehr, da er am 29. Juli 1800 an den Folgen einer Blasenentzündung starb. Giovanni Alessandro Brambilla wurde 73 Jahre alt. Vgl. Marlene JANTSCH, Johann Alexander Brambilla (Wien 1952) 90-91, auch Bruno PINCHERLE, G.A. Brambilla e la storia della medicina, in Atti dell'VIII Congresso Internazionale di Storia della Medicina (Pisa 1931) 6, Luigi BELLONI, Lo strumentario di G.A. Brambilla - Simbolo della 'preminenza ed utilità' della chirurgia, (Mailand 1971) V. 


\section{Die Grippeepidemie 1918 hinter der italienisch-österreichischen Front. Das Land Salzburg und die Provinz Modena zwischen Waffenstillstand und ärztlicher Not. ${ }^{1}$}

\section{Kontext}

Mein Beitrag zum weitgehend gut erforschten Thema „Grippe“ stammt aus meiner allgemeinen Forschungstätigkeit für meine Dissertation an der Universität Salzburg. Im Rahmen des laufenden Dissertationsvorhabens Modena und Salzburg in der Ersten Nachkriegskrise habe ich mich zuerst mit der Frage beschäftigt, ob und in welchem Ausmaß die „Spanische Grippe“ einen Einfluss auf die kriegsbedingten gesellschaftlichen Spannungen hatte. Eine weitere Frage ergab sich aus dem Bereich der Sozialgeschichte, der Medizin und des Gesundheitswesens: Welche Rolle spielte die „Mobilisierung für die Nation“ für die Sanitätsdienste des Heeres und für die Zivilbevölkerung, wo die Pandemie die Endphase dieser Mobilisierung des Sanitätswesen darstellte? Ich habe in einem Forschungsteam als Mitherausgeberin und Mitautorin gearbeitet und im Zuge dessen bereits eine Vorstudie veröffentlicht, die den Fokus auf die Sozialgeschichte der Medizin legt. ${ }^{2}$ In der Einleitung zum Buch und im Kapitel zur Grippe habe ich die These vertreten - ebenso wie die Kollegen in den übrigen Beiträgen -, dass diese Mobilisierung sowohl positive als auch negative Effekte auf die Gesundheit und Sanitätsversorgung der Zivilbevölkerung im Hinterland hatte, konkret in der „Emilia-Romagna“ und in einigen damit vergleichbaren Gebiete wie dem Land Salzburg.

Während die Dissertation eine allgemeine gesellschaftliche Strukturanalyse behandeln wird, untersuchte das Forschungsprojekt die Besonderheiten der medizinischen Forschung, der Technik und des Gesundheitswesens, repräsentiert am Beispiel der Provinzen der Emilia-Romagna. Das Projekt ist aber nicht als Regionalstudie konzipiert, sondern als Beitrag zur europäischen Sozialgeschichte: Die Implementierung und Umstellung der medizinischen und gesundheitlichen Strukturen und Pflege

1 Überarbeitete und gekürzte Fassung meines Vortrags. Die Kürzung erfolgte aufgrund des Vertrags mit dem Verlag CLUEB.

2 Fabio MONTELLA, Francesco PAOLELLA, Felicita RATTI (Hg.), Una regione ospedale - Medicina e sanità in Emilia-Romagna durante la Grande Guerra [Eine Spital-Region. Medizin und Gesundheitswesen in der Emilia-Romagna während des Ersten Weltkrieges] (Bologna 2010). Meine Beiträge beinhalten die Verfassung der methodologischen Einleitung (Premessa) und des Kapitels «Qui sono diventati „spagnoli“ in molti». Storia sociale comparata della pandemia influenzale 1918-1919 nella Provincia di Modena e nel Land Salisburgo. 
wird als Zeichen der Modernisierung, Industrialisierung und Mobilisierung für die Nation in Waffen im Sinne der unter anderen von Eric Leeds, John Horne und Giovanna Procacci entwickelten Theorien verstanden. ${ }^{3}$

\section{Provinz und Stadt Modena, Land und Stadt Salzburg}

Sowohl die Provinz Modena als auch das Land Salzburg waren noch zu Beginn des Ersten Weltkrieges zwei ausgeprägte Agrarregionen. Modena war (und ist noch immer) nicht von mediterraner Ernährung geprägt. Modena und Salzburg erwiesen sich als Gesellschaften mit einer im Frieden normalerweise fleischlastigen Küche (Schwein und Rind). Butter, Schweinefett oder Schmalz waren die gängigen Fette.

Ihre geopolitische Lage hinsichtlich der Frontnähe und als wichtige Knotenpunkte der Verkehrswege machten sie zu idealen logistischen Zentren für den Abtransport, die Verteilung und die Unterbringung von Kriegsgefangenen und Flüchtlingen, sowie für Sanitätseinrichtungen und Durchgangslager. Die relative Nähe zur Front führte aber nicht dazu, dass sie zu Kampfgebieten wurden, obwohl die Gefahr einer Besetzung in bestimmten Momenten bzw. nach der Schlacht von Karfreit und nach dem Waffenstillstand bestand.

Die Hungersnot war ein gemeinsames und gravierendes Problem für verschiedene europäische Gebiete. Im Wesentlichen war diese Not in Salzburg strukturell ${ }^{4}$ und kriegsbedingt sehr groß, während diese in Modena groß und kriegsbedingt war. Dort aber war die hygienische Lage aufgrund der mangelhaften sanitären Anlagen (nicht abgedeckten Kanäle), der Armut und des in Teilen der Bevölkerung vorherrschenden Analphabetismus sehr problematisch. In beiden Regionen traten ab 1917 verschiedene Krankheiten wie zum Beispiel Ruhr und andere Darmerkrankungen auf. Auch die Pocken (Blattern) waren eine immanente Gefahr; Masern, „Schafblattern“, manchmal auch Scharlach und Röteln und ähnliche Krankheiten traten sehr häufig auf.

\begin{tabular}{|c|c|c|}
\hline Stadt bzw. Region & 1910er Jahre & 1920er Jahre \\
\hline Salzburg Stadt & 36.188 & 37.856 \\
\hline Modena Stadt & 116.429 & 131.362 \\
\hline Salzburg Land & 214.737 & 214.200 \\
\hline Modena Provincia & 380.678 & 421.670 \\
\hline
\end{tabular}

Tabelle 1: EinwohnerInnen-Zablen5

3 Vgl. z.B. John HORNE (Hg.), State, society and mobilization in Europe during the First World War, (Cambridge 1997). Giovanna PROCACCI, Warfare-welfare. Assistenza, controllo sociale e militarizzazione in Italia und Hermann J. W. KUPRIAN, Warfare, Welfare: società, politica e militarizzazione in Austria. In: Emilio FRANZINA (Hg.), Una trincea chiamata Dolomiti/Ein Krieg zwei Schützengräben (Udine 2003).

4 Vgl. die sehr detaillierte und der Hungersnot gewidmete Dissertation: Gottfried KÖFNER, Hunger, Not und Korruption. Der Übergang Österreichs von der Monarchie zur Republik am Beispiel Salzburgs (Salzburg 1980).

5 Offizielle Volkszählungen, Statistik Austria, Digitalisierte Statistiken - Bevölkerungsstand. http://www.statistik.at/web_de/statistiken/bevoelkerung/volkszaehlungen_registerzaehlungen/ 


\section{Quellenlage und Quellenkritik. Was bieten Archive und Bibliotheken für die sozialhistorische Forschung in der Medizin?}

Länder und Provinzen beherbergen allgemein eine große Reihe von Archiven, was eine relativ breite und befriedigende Forschung ermöglicht hat. Im Wesentlichen habe ich im Salzburger Landesarchiv, im Archiv der Stadt Salzburg, im Archivio di Stato di Modena (Staatsarchiv), im Archivio della Provincia di Modena (Archiv der Provinz), im Archivio Storico del Comune di Modena, im Archivio Storico del Comune di Carpi und anderen historischen Archiven der Gemeinden geforscht. Außerdem wurden die Alt- und die Zeitungsbestände der Universitätsbibliotheken Salzburg und Modena eingesehen.

Man muss an dieser Stelle leider betonen, dass im Archiv der Stadt Salzburg eine gravierende Lücke festgestellt wurde: Es fehlen die Akten des Stadtphysikats. Die Akten des Gesundheitsamts der Gemeinde Modena sind hingegen sehr detailliert und bieten nicht nur einen Blick auf die Provinzhauptstadt, sondern auch auf einige Gemeinden. Angesichts der Informationsdichte dieser Quelle und die fehlenden Vergleichsmöglichkeiten bedenkend, ist dieser Verlust bedauerlich.

Eine Quellenart, die ich besonders kommentieren möchte, sind die Sterberegister. Das italienische Muster enthält in der Regel sehr wenige nützliche Informationen für ForscherInnen: Sie sind meistens unkonkret, langatmig und voller bürokratischer, aber inhaltsleerer Anmerkungen. Eine Ausnahme bildet das Sterberegister der mantuanischen Gemeinde Quingentole. ${ }^{6}$ Dieses Beispiel enthält zumindest die wichtige Information, dass einige der Verstorbenen österreichisch-ungarische Kriegsgefangene waren. Durch eine lokale Chronik konnte dann festgestellt werden, dass diese der Grippe zum Opfer gefallen sind. In vielen Fällen können die Lücken von den so genannten Atti di polizia mortuaria (Bestattungsbehördenakten ${ }^{7}$ ) geschlossen werden. Dort findet man entsprechende Informationen, die aber nicht statistisch verwendbar sind, da hier nur für die Bestattung problematische Fälle dokumentiert sind. Im Gegensatz dazu sind die österreichischen Register sehr dicht: kurz, klar, voll detaillierter Informationen (Adresse, Beruf, soziale Stellung bis zum Bestattungsort). ${ }^{8}$

Ergänzend $\mathrm{zu}$ diesen Quellen wurden viele Zeitungen eingesehen: Il Domani (Sozialistische Wochenzeitung für Modena und Provinz), Il Dopoguerra (Blatt des „Antideutschen Bundes“), Gazzetta dell'Emilia (Hauptzeitung mit lokalen Berichten für die Provinz und die Stadt), Salzburger Chronik, Salzburger Volksblatt, Salzburger Wacht und Tauern Post. Dadurch konnten viele Fakten und Daten, die epidemiologisch interessant waren, gefunden werden, ebenso Quellen zur Frage der Mentalitäten,

bevoelkerungsstand/index.html] (Zugriffsdatum: 18. Oktober 2007), Heinz DOPSCH, Hans SPATZENEGGER (Hg.) Geschichte Salzburgs. Stadt und Land, Band II, 2. Teil (Salzburg 1988) 1342-1345 bzw. Istat, aus der digitalisierten Zusammenfassung der Statistikamt der Provinz Modena, Modena Statistiche, Osservatorio Demografico online, Popolazione Censita, Serie storica. [http: / $/$ www.modenastatistiche.it $/$ page.asp?IDCategoria $=175 \&$ IDSezione $=4410 \&$ Speciale $=$ OssDem Form\&excel=no\&TipoForm=3\&cod_tipo_dato=6] (Zugriffsdatum: 18. Oktober 2007).

6 Diese Daten stammen vom Bürgermeister Quingentoles, Mag. Alberto Manicardi, der eine kurze Beschreibung der lokalen Kriegsgefangenenlager für eine lokale Ausstellung herausgegeben hatte. Vgl. Alberto MANICARDI, Marco und Paola FURIO, Il campo di concentramento di Quingentole. Un dramma dimenticato 1918-1919 (Quingentole 2009). Die Gemeinde Quingentole grenzt an die Provinz Modena.

7 Archivio Storico del Comune di Modena, Atti Amministrativo, cat. Sanitá (Akten des Gesundheitsamtes).

8 Archiv der Stadt Salzburg, Todesregister 1917-1918. 
Kritik und Zensur. Außerdem habe ich aktuelle und auch aus den betreffenden Jahren stammende Fachzeitschriften gesichtet, die einen Einblick in die zeitgenössischen Debatten und Diskurse, Theorien und den Wissensaustausch ermöglichen. Für eine vertiefende Analyse der erhobenen epidemischen Daten wurden außerdem die Wiener Medizinische Wochenschrift, Giornale di medicina militare (hier werden zwei Ausbrüche in der Militärschule epidemisch vollständig beschrieben), Il Policlinico beigezogen.

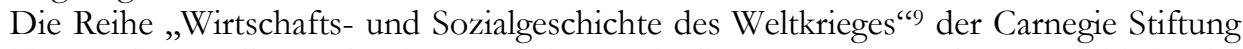
bietet als Quelle und Literatur eine unbedingt zu nützende Möglichkeit für SozialforscherInnen und Sozialforscher der Kriegs- und unmittelbaren Nachkriegszeit. Auch der 1921 veröffentlichte Bericht der österreichischen Abteilung für Gesundheitsstatistik ist ein wichtiges Werk mit der doppelten Rolle Quelle/Literatur ${ }^{10}$. Der 1926 veröffentlichte Band der Carnegie Stiftung enthält die letzte wissenschaftliche Untersuchung der Grippe im österreichischen Raum. Spätere Schilderungen sind nur in Chroniken niedergelegt. Diese sind besonders für die österreichischen Gebiete ertragreich. Die wenigen Beispiele italienischer „Chroniken“ oder ähnlicher Quellen sind aber meist nur mittels methodisch überlegter und von „Lokalwissen“ unterstützter Quellenkritik gut nutzbar.

Glücklicherweise war es mir möglich, den letzten Augenzeugen des Krieges und der Pandemie zu interviewen. Der ehemalige Pfarrer der Gebirgsgemeinde Pievepelago, Don Antonio Galli, Jahrgang 1908, hat mir detailliert von den Jahren 1918-1925 berichtet. Seine Erinnerungen enthalten auch den Ausbruch der Grippe. ${ }^{11}$

\section{Medizin und Gesundheitswesen - Quantitative und/oder qualitative Evaluierung?}

In meiner Publikation wie auch in meiner spezifischen Forschung wird Medizin als „globalisierte“ Wissenschaft verstanden. Auch wird betont, welch führende Rolle die mitteleuropäischen und besonders die deutschsprachigen Medizinschulen spielten auch für das Land und für die Region, wo laut umstrittener Rekonstruktionen die ältesten Universitäten der Welt entstanden sein sollen. Ebenfalls klar wurde vom Forschungsteam und in letzter Analyse von mir bestätigt und vertieft, dass die USA wissenschaftlich, technologisch und wirtschaftlich zunehmend wichtiger wurden.

Meine Forschung zum Thema „Grippe“ hat die Themen der Zensur und der Repression seitens der jeweiligen zuständigen Behörden, der Ängste und des Humors der jeweiligen Bevölkerungen untersucht. Auch wichtig erscheinen die möglichen Zusammenhänge im Kontext von Sieg oder Niederlage. Aus diesen Themen ergibt sich eine sozialhistorische Analyse, welche meine eigenen heuristischen Erkenntnisgewinne mit den bisher vorhandenen Studien zusammenbringt. Dies ist besonders der Fall bei den Sozialstudien über den Ersten Weltkrieg sowie der Denkanstöße von Andrew Price-Smith über die Wechselwirkungen zwischen Staat, Sicherheit und

9 Herbert ELIAS, Grippe. In: Clemens PIRQUET, Volksgesundheit im Krieg. II Teil (= Wirtschaftsund Sozialgeschichte des Weltkrieges - Österreich-und-Ungarn-Serie, Wien 1926). Giorgio MORTARA, Mortalità e morbosità. In: La salute pubblica in Italia durante e dopo la guerra (= Storia economica e sociale della guerra mondiale - Serie Italiana, Bari 1925).

10 Siegfried ROSENFELD, Die Grippeepidemie des Jahres 1918 in Österreich (Wien 1921).

11 Interview mit Don Antonio Galli, Pievepelago, 26.02.2010. Über die Plattform Youtube besteht auch die Möglichkeit, ein von Fabio Montella durchgeführtes Interview über den Ersten Weltkrieg anzusehen [http://www.youtube.com/watch?v=wZWud4x_1ik]. 
öffentlicher Gesundheit. Price-Smiths These über die Zusammenhänge zwischen dem Zusammenbruch und der Grippe in dem Deutschen Reich und in Österreich-Ungarn wurde von mir in dem Kapitel widerlegt. Die These wurde aufgrund des Vergleichs mit den Umständen im schwer belasteten aber siegreichen Königreich Italien kritisiert. ${ }^{12}$ Analysiert wurden auch verschiedene epidemische Daten (hauptsächlich Grippefälle, Todesfälle, Zeiträume von epidemischen Wellen), die aber keine vollständige und zuverlässige epidemische Beschreibung zulassen. Es war also nur möglich, einige Tendenzen zu skizzieren und allgemeine Schlüsse über die Ausbreitungsmuster zu ziehen. Offizielle Medizin und „Volksmedizin“, präventive bzw. reaktive Maßnahmen und soziale Auswirkungen wurden auch von mir betrachtet, verglichen und analysiert. Der vergleichende Ansatz verspricht vielfältige neue Erkenntnisse über eine relativ „globalisierte“ offizielle Medizin sowie über Organisation und Gestaltung der Gesundheitsanstalten und der Hygienemaßnahmen. Es zeigte sich aber auch, dass sowohl die „volksmedizinischen“ Praktiken als auch die sozialen Auswirkungen stark von den lokalen Umständen und Verhältnissen beeinflusst wurden.

Meines Erachtens wäre es darüber hinaus auch sehr interessant zu rekonstruieren, wie die schweizerische Epidemie des Sommers mit der österreichischen und der italienischen in Zusammenhang steht. Das impliziert, wie schon Eugenia Tognotti erwähnt hat, dass der Ausgangspunkt der Epidemie in Brest im September 1918 als unwahrscheinlich anzunehmen ist. Viel wahrscheinlicher erscheint mir nach meiner Rekonstruktion, dass schon früher und nicht nur in Frankreich tödliche Grippefälle aufgetreten sind. ${ }^{13}$

\section{Autoreninformation}

Felicita Ratti (Modena, 1982), BA, MA, Doktorandin für Geschichte an der Universität Salzburg und Mitarbeiterin am Historischen Institut Modena. Postadresse: Unterfeldstraße 32, 5071 Walserfeld, Österreich. Mail: felicita.ratti@stud.sbg.ac.at

12 Andrew T. PRICE-SMITH, Contagion and Chaos. Disease, Ecology and National Security in the era of globalisation (Cambridge, Massachusetts 2009).

13 Vgl. die Salzburger Zeitungen, die Modenesischen Zeitungen und andere Blätter aus Emilia sowie die Rekonstruktion der Grippe in Italien von Eugenia TOGNOTTI, La "Spagnola" in Italia. Storia dell'influenza che fece temere la fine del mondo (1918-19) (Milano, 2002). Vgl. auch die Analyse der Grippeepidemie in der Provinz Reggio Emilia von Michele BELLELLI, Aspetti e problemi dell'epidemia di spagnola a Reggio Emilia. In: MONTELLA, PAOLELLA, RATTI, Una Regione Ospedale 233-254. 


\section{Tagungsberichte}





\section{Medizinhistoriographische Themen am 13. Internationalen Kongress zur Erforschung des 18. Jahrhunderts (Karl-Franzens- Universität Graz, 25. - 29. Juli 2011)}

Vom 25. bis 29. Juli 2011 fand an der Karl-Franzens-Universität Graz, organisiert unter der Leitung von Univ.-Prof. Dr. Dr.h.c. (mult.) Harald Heppner, der 13. Internationale Kongress zur Erforschung des 18. Jahrhunderts statt. Tausend Wissenschafterinnen und Wissenschafter aus etwa 40 Staaten diskutierten in englischer, französischer und deutscher Sprache auf der Basis von gut 900 Referaten in 135 Sektionen und Workshops ihre neusten Forschungsergebnisse. ${ }^{1}$ Erfreulicherweise war auch die Medizingeschichtsschreibung in diesem interdisziplinären Umfeld lebendig zugegen, und der Verein für Sozialgeschichte der Medizin hatte einen gewichtigen Anteil an dieser Präsenz. Eine kleine Rundschau soll dies zur allgemeinen Kenntnis bringen und idealiter Impulse und Anknüpfungspunkte für weitere Forschungen ermöglichen.

Neben einem regionalen Schwerpunkt auf Mittel- und Osteuropa galt auch der Wahrnehmung von "Zeit" besondere Beachtung. Das dem Kongress vorgeschaltete Nachwuchsseminar wandte sich vorwiegend auch Fragen der „Vorsorge“ zu. In diesem für die Sozialgeschichte der Medizin prädestinierten Umfeld gelang es Barbara Peintinger (Universität Wien) nach einem rigiden Selektionsprozess mit einer Ausfallsrate von fünfzig Prozent, ihre Auseinandersetzung mit Giovanni Alessandro Brambillas Appendice, durchgeführt im Rahmen einer von Sonia Horn betreuten Diplomarbeit, zu positionieren. Außerdem kann aus dieser „Auftaktveranstaltung“ Adeline Gargam (Université Européenne de Bretagne) mit ihren Forschungen zur Frage vorgeblich fragiler Gesundheitszustände gebildeter, aufgeklärter Frauen und deren angeblich negativen Konsequenzen für die Gesellschaft erwähnt werden. ${ }^{2}$ Ebenso verdient Andrea Haslanger (University of Chicago) Beachtung, die sich literaturwissenschaftlich mit Repräsentationen von Menschen imitierenden Automaten in der Spätaufklärung beschäftigt. Riccardo Capoferro (Sapienza Università di Roma)

1 Siehe für die Titel der in weiterer Folge größtenteils referierten Beiträge im Detail das Programmheft: Organisationskomitee des Kongresses (Hg.), 13th International Congress for Eighteenth Century Studies / XIIIe Congrès International d'étude de XVIIIe Siècle / 13. Internationaler Kongress zur Erforschung des 18. Jahrhunderts. 25. - 29. Juli 2011 Graz/Austria, redigiert von Harald Heppner, Andreas Golob, Sabine Krammer (Graz 2011), hiernach zitiert als „Programm“. Das Programm kann auch online eingesehen werden: http://18thcc.uni-graz.at/ . Etwaige Kontaktaufnahmen sind über den Kongresssekretär, der auch für allgemeine Auskünfte zur Verfügung steht, möglich: an.golob@unigraz.at .

2 Auch in einer Sektion über Mythen im Zeitalter der Aufklärung vertreten, vgl. Programm 77. 
befasste sich schließlich mit Models of Futurity in "A Journal of the Plague Year" aus der Feder Daniel Defoes.

Hinsichtlich des eigentlichen Kongresses mag mit dem allgemeinen Medizingeschichtepanel begonnen werden. Unter dem breit gefassten Titel Gesundheit und Krankheit/Körper und Seele und unter der Leitung Sonia Horns und Andreas Golobs bot es ein Potpourri, das durch seine Vielfalt bestach. ${ }^{3}$ Nachdem Lukas Lang (Universität Graz) mit seinen konzeptuell-theoretischen Ausführungen zur medizinischen Polizei das Feld quasi aufbereitet hatte, und auch mit bisher unbekannten Quellen aus den Beständen der Polizeioberdirektion aufwarten konnte, galt ein Schwerpunkt dem Josephinum, das durch zwei eng mit dem Haus Verbundene vertreten war. Markus Swittalek berichtete über seine Forschungen zur Baugeschichte des Josephinums und dessen Einbettung in den Städtebau unter Joseph II. im Allgemeinen, während Monika Grass das Studium an dieser Institution im Zeitraum von 1785 bis 1820 skizzierte. Nebenbei sei angemerkt, dass das Josephinum mit einer eindrucksvollen Posterausstellung präsent war, die sich als zentraler Blickfang in der Nähe des Kongressbüros erwies. In einer zweiten, kultur-, mentalitäts- und sozialgeschichtlichen Sitzung sprach Irmgard Egger (Universität Wien) über Friedrich Schillers medizinisches und anthropologisches Cuvre. Mladen Kozul (University of Montana) steuerte anhand erotischer Romane Überlegungen zum Spannungsfeld von Wissenschaft, Fiktion, Erotik, Medizin und Religion bei. Anthony Mahler (University of Chicago) siedelte sein Referat ebenfalls im Grenzraum zwischen Lektüre und Medizin an und berichtete über seine Forschungen zum diätetisch vertretbaren Leseverhalten am Beispiel Georg Christoph Lichtenberg. Den Abschluss dieses gut besuchten Panels bildete Elisabeth Lobenwein (Universität Salzburg) mit ihrem Paper zur Wahrnehmung tot geborener, kranker und verletzter Kinder anhand der Mirakelberichte von Maria Luggau in Kärnten.

Carlos Watzka (Universitäten Graz und Eichstätt) versammelte zum Thema Christliche Caritas im Mittel- und Osteuropa des 18. Jahrhunderts eine diesen beträchtlichen Raum repräsentierende Referentenschaft. ${ }^{4}$ Er selbst widmete sich den Bemühungen der Barmherzigen Brüder in diesem Gesamtraum, und Petr Jelínek (Wien) ging in diesem Zusammenhang mit einer Analyse der Klientel der Spitäler ins Detail. Monika Lipp (Eötvös Loránd Universität Budapest) näherte sich dem Konvent Eger/Erlau aus kunsthistorischer Perspektive. Auch Maria Böhmer (European University Institute, Firenze/Florenz) widmete sich einem Konvent dieses Ordens, nämlich jenem in Venezia/Venedig und dessen Umgestaltung vom Militärkrankenhaus zu einer Einrichtung für psychisch Kranke. Über die Barmherzigen Brüder hinausgehend referierte Bettina Blessing (Institut für Geschichte der Medizin der Robert Bosch Stiftung, Stuttgart) über die Situation in den Hospitalorden im Allgemeinen im ausgehenden 18. Jahrhundert angesichts der Säkularisierung. Elisabeth Pauli (Universität Graz) erweiterte schließlich den Ordenshorizont, indem sie die Gefangenenfürsorge der Unbeschuhten Trinitarier thematisierte, und Dragica Cec (University of Primorska, Koper) brachte abseits der Orden die Armenfürsorge in den Pfarren Krains und des Gebiets um Triest(e) in die durchwegs rege Diskussion ein.

Praktiken in Krankenhäusern und Gefängnissen standen im Mittelpunkt der Sektion "Beyond time" - Inmates in Places of Custody, die Alfred Stefan Weiß (Universität Salzburg)

3 Programm 81.

4 Ebd. 50f. 
und Martin Scheutz (Universität Wien) organisiert hatten. ${ }^{5}$ Erfreulicherweise korrespondierte dieses Panel auch mit dem Schwerpunkt „Zeit“. Elke Hammer-Luza (Steiermärkisches Landesarchiv Graz) eröffnete den Reigen mit einem Paper zum Leben Gefangener in Graz. Christina Vanja (Universität Kassel) sponn mit Ihren Überlegungen zu Abläufen in Protokliniken den Faden weiter, und Maria Heidegger (Universität Innsbruck) setzte mit ihrer Beleuchtung temporaler Phänomene in der frühen Psychiatrie den Schlusspunkt.

Abgesehen von diesen Panels, die deutlich das Engagement des Vereines für Sozialgeschichte der Medizin in Fragestellungen des 18. Jahrhunderts und seinen Vernetzungsgrad insbesondere in Mittel-, Ost- und Südosteuropa aufzeigen, müssen noch zwei Sektionen genannt werden. Yasuyoshi Ao (Universität Kyūshū) und Makoto Masuda (Universität Kyōto) verhandelten den Onaniediskurs in ihrem Workshop La relecture des textes pluridimensionnels de Samuel Auguste Tissot. ${ }^{6} \mathrm{Im}$ Rahmen dieser Veranstaltung lieferte Kazuhiko Sekitani (Kwansei-Gakuin- Universität) einen Vergleich mit der Lage in Japan, bevor Yasuyoshi Ao sich Tissot im Allgemeinen zuwandte und Daisuke Tsujibe (Universität Fukuoka) die Argumentationstechniken des Schweizer Arztes untersuchte. Aurora Chery (Université Lyon 3 - Jean Moulin) lenkte das Augenmerk schließlich auf ihre Fallstudie über Ludwig XVI. und dessen vermeintliche „Gefährdung“ durch eine Phimose. Die zweite einschlägige Sektion hatte einen weiteren prominenten Akteur der Medizingeschichte des 18. Jahrhunderts, nämlich Franz Anton Mesmer, im Visier. ${ }^{7}$ Die Organisatoren David Armando (Istituto per la storia del pensiero filosofico e scientifico moderno, C.N.R., Napoli/Neapel) und Bruno Belhoste (Université Paris 1 - Panthéon Sorbonne) führten in die Propagandaarbeit der Société de l'harmonie universelle ein, und auch Philippe de Laborde Pédelahore (Musée Basque de Bayonne) befasste sich mit einer vergleichbaren regionalen Einrichtung für Bordeaux und Bayonne. Paul Monod (Middlebury College, Vermont) beleuchtete die Verbreitung magnetischer Heilmethoden in Großbritannien, und auch eine weitere Etappe im kolonialen Indien kam durch Kapil Raj (École des Hautes Études en Sciences Sociales, Paris) zur Sprache. Eine Fallstudie zu Wolfgang Amadeus Mozarts Beziehungen zu Mesmer von Alessandro Stile (Istituto per la storia del pensiero filosofico e scientifico moderno, C.N.R., Napoli/Neapel) sowie ein Überblick zur Historiographie über den Mesmerismus durch Patrizia Delpiano (Universität Torino/Turin) komplettierten das Panel. Die Hinwendung zu Emotionen, also zu anthropologischen Erscheinungen, die im Grunde genommen gegen die Rationalität der Aufklärung in Stellung gebracht werden können, stand im Mittelpunkt zweier Panels, die hier nur kurz erwähnt werden sollen. Dabei standen einerseits Adam Smith und seine Theory of Moral Sentiments im Zentrum, ${ }^{8}$ andererseits wandte sich eine Sektion explizit Theorien über Gefühle in der deutschen Frühaufklärung ${ }^{9}$ zu. Immanuel Kant wurde schließlich in seinen Stellungnahmen zum Materialismus beleuchtet. ${ }^{10}$

Abgesehen von diesen einschlägigen Panels seien auch noch einige Einzelbeiträge erwähnt, die nicht in dezidiert medizinhistoriographischen Kontexten präsentiert wurden, den medizinhistorisch Interessierten jedoch ins Auge fielen. Michael Yonan

\footnotetext{
Programm 49.

Ebd. 75.

Ebd. 82.

Ebd. 62.

Ebd. 66.

10 Ebd. 82.
} 
(University of Missouri) etwa befasste sich in einer Sektion zur Porträtkunst mit Kindertotenbildern an Maria Theresias Hof. ${ }^{11}$ Lilla Krász (Eötvös Loránd Universität Budapest) konnte Ihren Beitrag über in deutschen Zentren ausgebildete Ärzte und deren Einfluss auf den fachspezifischen und allgemeinen Wissenstransfer in einem regional ausgerichteten Panel über das Königreich Ungarn präsentieren. ${ }^{12}$ In ähnlicher Weise verhielt es sich mit Ovidiu Mureşanu (Babeş-Bolyai Universität ClujNapoca/Klausenburg), der sich monographisch mit dem aus Siebenbürgen stammenden und im Fürstentum Moldau tätigen Arzt Michael Czakul auseinandersetzte. ${ }^{13}$ Außerdem bereicherte Lia Chisacof (Institute for South-East European Studies of the Romanian Academy) mit ihren Ausführungen über das Aufeinandertreffen „westlicher" und lokaler Heilmittel in Rumänien eine Sektion zum Gegensatzpaar Orientalismus/Okzidentalismus. ${ }^{14}$ Janine Christina Maegraith (University of Cambridge) kam mit Ihren Forschungen zu Klosterapotheken und über die ländliche Armenfürsorge im südwestdeutschen Raum in einer Sektion über Frauenklöster zu Wort, ${ }^{15}$ während sich Heiko Pollmeier ${ }^{16}$ (zuletzt Paul Klemperer Fellow of the New York Academy of Medicine) einer Erötertung von Kontroversen der Aufklärung anschloss und in diesem Zusammenhang die französische Debatte über die Inokulation repräsentierte. Christian Bachhiesl (Universität Graz) erschloss dem internationalen Publikum einen lokalen Fall von Herzfresserei und trug so zu einer wissenschaftsgeschichtlichen Sektion bei. ${ }^{17}$ Barry Murnane (Martin-Luther-Universität Halle-Wittenberg) verknüpfte ebenfalls blutrünstige Versatzstücke des Vampirdiskurses mit Fragen zu Kosmopolitismus beziehungsweise Nationalismus, um die eine weitere Sektion kreiste. ${ }^{18}$ Heiko Weber (Akademie der Wissenschaften Göttingen) stellte im Kontext der sich entwickelnden Naturgeschichte sein Projekt über Johann Friedrich Blumenbachs Anthropologie und insbesondere deren antirassistische Komponenten vor. ${ }^{19}$ Sorana Corneanu (Universität București/Bukarest) thematisierte in einer vielfältigen allgemeinen Sektion unter dem Titel "Rock around the Clock" schließlich die Tugend der Geduld und deren Stellenwert im 18. Jahrhundert, ${ }^{20}$ einen Aspekt, der auch für die Sozial- und Kulturgeschichte der Medizin noch Früchte tragen könnte.

11 Programm 54.

12 Ebd. 56.

13 Ebd. 87.

14 Ebd.

15 Ebd. 58.

16 Ebd. 84.

17 Ebd. 72.

18 Ebd. 80.

19 Ebd. 90.

20 Ebd. 47. 


\section{Rezensionen}





\title{
Christian Baudelot, Roger Establet, Suicide. The Hidden Side of Modernity. Cambridge- Malden (Polity Press) 2008, 210 Seiten
}

\author{
Rezension von Carlos Watzka
}

Mit der englischen Übersetzung des zuerst 2006 in französischer Sprache erschienen Werkes der beiden Soziologen Christian Baudelot und Roger Establet ist eines der bedeutendsten Werke der jüngeren sozialwissenschaftlichen Suizidforschung einem weiteren internationalen Publikation zugänglich gemacht worden.

Neben dem unbestreitbaren Nutzen für die gegenwartsbezogene Suizidologie bietet diese Monographie wichtige und vielfältige Aufschlüsse auch für historisch orientierte Arbeiten zum Thema der Selbsttötung: Der englische Untertitel liefert bereits das auch in dieser Hinsicht zentrale Stichwort: Modernität bzw. Modernisierung. In insgesamt 11 Kapiteln gehen die Autoren der Frage nach, inwieweit Suizid, soziale Strukturen und gesellschaftlicher Wandel in Zusammenhang miteinander stehen, und verweisen auf erhebliche Veränderungen im historischen Verlauf: „There is ony a very partial overlap between the social picture of suicide in the nineteenth century and in the twentieth." (S. 12)

Im (unnummerierten) Einleitungskapitel „Suicide and Society” (S. 1-12) werden einige grundlegende Informationen zum Thema gegeben: Suizid ist in allen Gesellschaften ein seltenes Phänomen, betrifft aber dennoch, wenn man die LebenszeitWahrscheinlichkeiten betrachtet, 1 bis $2 \%$ der Bevölkerung europäischer Gegenwartsgesellschaften. Die sozialpsychologische Bedeutung von Selbsttötungen ist zudem, verglichen mit der relativen Seltenheit ihres Vorfallens, eine große; und alle, sowohl europäischen, als außer-europäischen Gesellschaften kennen das Phänomen. Erörtert werden weiters methodische Fragen, insbesondere im Hinblick auf die Gültigkeit von (amtlichen) Suizidstatistiken.

Kapitel 1 (S. 13-22) widmet sich sodann der Frage „Does Povery Protect?”. Die Autoren zeigen darin eine komplexe, aber nur auf den ersten Blick paradoxe Konstellation auf: Zum einen zeigen internationale Vergleiche einen deutlichen positiven Zusammenhang zwischen dem Bruttoinlandsprodukt eines Staates und der Höhe der Suizidrate, zum anderen zeigen innerstaatliche Vergleiche zumindest für den Bereich der industrialisierten Staaten, dass es jeweils die ärmeren Regionen, Gemeinden und sogar Stadtteile sind, die im Vergleich zu begünstigteren Gebieten tendenziell deutlich höhere Suizidraten aufweisen.

In Kapitel 2 - „Take off ...”, S. 23-35 - wird dann die Problematik des Zusammenhangs von Suizidalität und Modernisierung näher ausgebreitet, und zwar zunächst am Beispiel der beiden 'aufsteigenden Mächte' par excellence der zweiten Hälfte des 20. Jahrhunderts, Indien und China. Die hierbei zentralen Erkenntnisse finden sich bereits in den Abschnittsüberschriften: „India 1950-2000: an economic giant is born and 
suicide takes off” und „1980-2000: China awakens and suicide rates rise”. In China sind derzeit etwa $20 \%$ aller Todesfälle im Alter zwischen 15 und 34 auf Selbsttötungen zurückzuführen. Für die 'aufholende Modernisierung' Asiens im späten 20. Jahrhundert scheinen sich also die Grundthesen Durkheims, gewonnen an seiner Analyse der europäischen Entwicklung im späten 19., zu bestätigen: „modernity results in individualism and individualism results in suicide." (S. 33) Andererseits kam es, wie die Autoren zu Recht hervorheben, in Europa nach dem Erscheinen von Durkheims fundamentaler Studie (1897) keineswegs zu einem monotonen, bis heute anhaltenden weiteren Anstieg der Suizidhäufigkeiten, trotz sicherlich nicht abnehmenden Individualisierungstendenzen.

Der Erhellung dieses Umstandes widmet sich Kapitel 3 („The Great Turning Point”, S. 37-60): Baudelot und Establet liefern hier eine höchst wichtige Beobachtung: „In the nineteenth century suicide was an urban phenomenon; rates are now lowest in metropolitan cities such as London, Paris and New York. It is as th[r]ough the twentieth century had developed new ways of protecting individuals." (S. 37) Die rapide Modernisierung des 19. Jahrhunderts, mit all ihren negativen Effekten bis hin zu den hohen Suizidraten, beginne damit nun als eine Übergangsphase zu erscheinen. Und wie auch immer die Zusammenhänge eigentlich zu erklären seien, der Rückgang der Selbsttötungsraten in den ökonomisch am meisten 'entwickelten' europäischen Staaten ist jedenfalls ein realer: Die Suizidraten etwa in Frankreich hatten ihr (bisheriges) 'Allzeithoch' im Zeitraum zwischen 1890 und 1910, mit Werten von bis zu 25 oder 26 (Suizide pro 100.000 Einwohner und Jahr). Diese Entwicklung zurückgehender Suizidraten, deren Anfänge mancherorts schon bald nach 1900 einsetzt, wird von den Autoren, auf Grundlage zahlreicher früherer empirischer Erhebungen sowie eigenen Auswertungen statistischen Materials, nicht zuletzt als Folge sich verändernder allgemeiner Lebensbedingungen betrachtet: „The big cities were gradually becoming more human and more civilized." (S. 42) Allerdings, auch darauf weisen Baudelot und Establet hin: Der Rückgang der Selbsttötungshäufigkeiten verlief im westlichen und mittleren Europa im 20. Jahrhundert keineswegs linear. Im Gegenteil musste für etliche Staaten nach einer Periode deutlichen Rückgangs in den 50er und 60er Jahren ein teils massiver, erneuter Anstieg in den 1970er bzw. 1980er Jahren konstatiert werden. Diese Schwankungen stehen, wie die Autoren nachweisen können, in einem gewissen Zusammenhang mit der Entwicklung der Kaufkraft, sind aber offensichtlich auch von anderen Faktoren abhängig.

Kapitel 4 - „The Trente Glorieuses”, S. 61-79 - setzt die Untersuchungen zum Zusammenhang von ökonomischem Wandel und Suizidalität fort: Offenbar bringe derselbe gewisse Veränderungen mit sich - Bedeutungsverlust der Religion, Auflösung traditioneller Familienbande u.a. -, die 'suizidfördernd' seien, aber auch andere, welche in die Gegenrichtung wirkten; die letzteren würden vielleicht, so eine bemerkenswerte Hypothese der Autoren, erst langfristiger wirksam werden, als die ersteren. Diese potentiell suizidprotektiven Auswirkungen des Modernisierungsprozesses fassen Baudelot und Establet mit dem Begriff „creative individualism” zusammen, wobei sie sich u.a. auf die Postmodernismus-Forschungen von Ronald Inglehart stützen: Wohl würden sich traditionelle Ordnungen auflösen, die postmodern-individualistische Gesellschaft kreiere aber ihre eigenen, neuen, im Bereich des Familienlebens ebenso, wie in der Arbeitswelt. Solche neuen Einstellungs- und Handlungsmuster lassen sich in den sozio-kulturellen Zentren der 'Postmodernisierung', den Städten und den oberen Dienstleistungsschichten, besonders deutlich feststellen. 
In Kapitel 5 - „The Soviet Exception”, S. 80-99 - folgt sodann die Erörterung eines Sonderweges, jenes des ehemaligen 'Ostblocks', und dies wiederum unter historischlangfristiger Betrachtung: Zunächst wird auf die bedrückende, derzeitige Situation hinsichtlich Suizid, insbesondere Suizid von Männern, in diesen Staaten verwiesen: Die Selbsttötungsraten der männlichen Bevölkerung erreichen Werte von 60 bis 80 je 100.000 Einwohner und Jahr. Als potentiell verursachender Faktor wird, neben dem Aspekt der negativen ökonomischen Entwicklung besonders seit dem Zusammenbruch der Sowjetunion, auch hoher Alkoholkonsum thematisiert. Jedoch verweisen die Autoren auch auf den bislang wenig bekannten Umstand einer langen Tradition hoher Suizidraten in der ehemaligen Sowjetunion. Es scheint, als seien die Zahlen schon unmittelbar nach der Machtübernahme durch die KP rasch angestiegen, besonders in den großen Städten und bei den administrativen und intellektuellen Eliten. Innerhalb der KP nahm das Problem des Suizids schon in den 1920er Jahren derartige Ausmaße an, dass sich die Parteiführung zu spezifischen Kampagnen gegen diese 'Epidemie' veranlasst sah, freilich mit wenig Erfolg. Verlässliche Daten fehlen aber für die Zeit zwischen ca. 1930 und 1960; für die Phase danach konnten neuere Forschungskooperationen französischer und russischer Demographen aber mittlerweile nachweisen, dass sich die Suizidrate in der Sowjetunion bereits seit 1965 in deutlichem, stetigen Anstieg befand, unterbrochen lediglich durch einen -scharfen, aber kurzfristigen Rückgang in den Jahren der 'Perestrojika'.

Anschließend an diesen Exkurs, der die Bedeutung sowohl politischen wie ökonomischen Strukturwandels besonders klar darstellen konnte, führen die beiden französischen Soziologen ihre Argumentation mit Bezug auf Westeuropa weiter. Kapitel 6 - „The Oil Crisis and Suicide amongst the Young”, S. 101-122 - arbeitet die unterschiedlichen Effekte ökonomischen und generell gesellschaftlichen Wandels auf unterschiedliche Alterskohorten heraus, und stellen für die französische Situation einen massiven Bruch in der Mitte der 1970er Jahre fest: „Individuals who were born after 1955, whose suicide rate at the ages between 20 and 40 is much higher than for their elders, discover, when they begin work, a world that is very different to the one experienced by their elders: no upward mobility, a relative fall in income, mass unemployment, rising rates of poverty. The social content of a whole life stage, namely youth, has [...] changed drastically." (S. 107) Im weiteren Verlauf werden ähnliche Veränderungen, mit gewissen Differenzen in der genauen zeitlichen Verortung, anhand von statistischem Material für die meisten Staaten des westlichen Europa, konstatiert. Zugleich werden in diesem Kapitel auch Schichtunterschiede näher thematisiert: ,the ability to predict the healthcare we might need is determined by the capital, in particular the cultural capital at an individual's disposal. The differences between managers and workers has [sic] less to do with the symptoms they complain of than in the strategies they use when they consult doctors. [...] Consulting a psychiatrist and foreseeing the risks associated with [...] depression are not behaviors that are equally socially acceptable or expected in the town and in the countryside, in city centres or on suburban estates." (S. 107f.)

Diese Aspekte der Untersuchung werden sodann in Kapitel 7 - „Suicide and Social Class: An Overview”, S. 123-139 - noch vertieft, indem Analysen auf regionaler und individueller Ebene ins Zentrum der Aufmerksamkeit rücken. Die hier in Zusammenschau präsentierten empirischen Erhebungen aus unterschiedlichen Staaten zum Zusammenhang von Suizidrisiko und Schichtzugehörigkeit liefern ein in der Tendenz eindeutiges Bild: Die Suizidhäufigkeiten sowohl der hinsichtlich Einkommen, 
Bildung und beruflichem Status 'schwächsten' Schichten sind heute weit höher, als jene der mittleren und oberen Gesellschaftsschichten: „The rich are spared and the poor are at risk." (S. 127) Allerdings stellt sich diese Konstellation erst im Verlauf des 20. Jahrhunderts ein; in den Gesellschaften des 19. Jahrhunderts waren die rückständigsten Schichten und Regionen noch jene, die von der Suizidalität am wenigsten betroffen waren. Auch für die Verhältnisse in den letzten Jahrzehnten gilt es aber zu differenzieren, wie sich etwa bei der Untersuchung der Assoziation von Arbeitslosigkeit und Suizidrisiko zeigt: „There is nothing universal about the link between unemployment and suicide", stellen Baudelot und Establet zurecht fest (S. 133). Die Effekte der ersteren auf das zweitere unterscheiden sich vielmehr deutlich nach Geschlecht, nach Alter und - last not least - nach dem jeweils gegebenen staatlichen oder privaten (bes. familiären) System sozialer Sicherung. Als besonders aufschlussreich erweisen sich weiters die Ausführungen der Autoren zu den Suizidrisiken unterschiedlicher Berufsgruppen, wobei vor allem die großangelegten empirischen Untersuchungen von Nicolas Bourgoin sowie dem INED zur Situation in Frankreich zwischen ca. 1970 und 1995 referiert werden: Hierin zeigt sich, dass Landarbeiter und Hilfsarbeiter in Industrie und Handwerk die höchsten Suizidraten unter den zahlenmäßig starken Berufskategorien aufweisen, gemeinsam mit unqualifizierten Berufstätigen in der Beamtenschaft (vgl. S. 136f.). Jedoch wird deren Suizidrate, zumindest in den frühen 1990er Jahren, noch übertroffen von der von geschäftsführenden Managern. Insgesamt ergibt eine soziologische Analyse der gravierenden Differenzen in diesen Bereichen: „the econonomic and social factors that influence suicide [risk] are to be found in the social value attributed to individuals both by society and by themselves." (S. 139)

An diesen Beobachtungen schließt das folgende, 8. Kapitel an („The Twentieth Century: Greater Protection for the Ruling Classes”, S. 141-160): hierin wird nochmals auf die gesellschaftliche Ungleichverteilung der Suizidraten im 19. Jahrhundert Bezug genommen; insbesondere die Bildungseliten (Intellektuelle, Mediziner, Juristen usw.) waren damals weit stärker als heute von Selbsttötungen betroffen. Es muss aber festgehalten werden, dass auch das städtische Proletariat sehr hohe Suizidraten aufwies. Die Frage nach schichtspezifischen Suizidraten wird hierbei u.a. anhand der besonders reichhaltig vorhandenen - US-amerikanischen Daten untersucht; dies führt Baudelot und Establet schließlich zu einer näheren Differenzierung auch des Begriffes der „Armut”, welche das Verhältnis des Armen und seines gesellschaftlichen Umfeldes mitberücksichtigt: „Becoming poor in a rich society [...] leads to much greater suffering than being poor in a poor society." (S. 155) Hier wird das schon aus der strukturfunktionalistischen Soziologie bekannte Phänomen der 'relativen Deprivation' angesprochen (ohne freilich als solches bezeichnet zu werden). Die Autoren folgern: „Suicide is revealing: it exposes deep divides between the top and bottom of the social scale in terms of health, life expectancy and well-being." (S. 156), und sie verweisen, mit Bourdieu, auf die grundlegende Bedeutung der sozialen Teilhabe, der Teilnahme am 'sozialen Spiel' für die individuelle psychische Gesundheit: ,[...] joining in a social game $[\ldots]$ we ultimately expect $[. .$.$] not just some recompense for our contribution, but$ the validation of our status as subjects." (S. 156). Genau diese emotional wertvolle, zwischenmenschliche Anerkennung ist aber in der modernen, weitgehend 'anonym' funktionierenden Gesellschaftsordnung für einen erheblichen Teil der Menschen nicht in ausreichendem Maße zu erlangen. Dies wurde bekanntlich schon von vielen Theoretikern als Ursache für negative soziale Erscheinungen gerade im Bereich 
individueller Devianz und Pathologie postuliert, und führt die Autoren zur Debatte um die Etablierung einer „kulturellen und sozialen Mindestbeteiligung” (S. 159), welche nicht nur im materiell-ökonomischen Sinn zu verstehen sei, als mögliche, strukturell wirksame Maßnahme auch zur Reduzierung der Suizidzahlen in unseren 'entwickelten', europäischen Gesellschaften der Gegenwart.

Kapitel 9 - „And yet Women Survive ...”, S. 161-178 - thematisiert schließlich die bis dahin nicht systematisch erörterte, basale Differenzierungsvariable „Geschlecht”. Baudelot und Establet unterstreichen hier die weitgehende Homogenität des Befundes einer enormen 'Übersterblichkeit' der Männer durch Suizid im Vergleich zu Frauen, auch bei international vergleichender Betrachtung, heben aber auch wichtige Ausnahmen, wie China, Indien und Sri Lanka, hervor, wo die Differenzen weniger stark ausgeprägt sind bzw. sich sogar, im Falle mancher chinesischer Regionen, umkehren. Sodann werden die Einflüsse von - traditionellen wie modernen Familienstrukturen auf das suizidale Verhalten eingehend diskutiert, wobei auch ethnologische Befunde aus 'archaischen' Gesellschaften beigebracht werden (NeuGuinea, S. 173f.).

Das (wiederum unnummerierte) Abschlusskapitel (S. 179-195) widmet sich der Frage, welche 'Lektionen' die sozialwissenschaftliche Beschäftigung mit Suizid für die Soziologie insgesamt bereithält: Hierzu resümieren die Autoren mit Blick auf die komplexe Verursachung von Suizid als individueller Erscheinung: „Sociology doesn't explain everything" (S. 181), verweisen aber auch auf das spezifische Erkenntnispotential derselben gegenüber Individuum-zentrierten Herangehensweisen, wie sie besonders in der Medizin dominieren. Abschließend werden noch einmal die drei Faktoren ökonomischer Wohlstand, soziale (Des-) Integration und Selbstachtung in ihren Interferenzen im Verlauf des Modernisierungs-Prozesses und den resultierenden Folgen für das Phänomen der Suizidalität betrachtet, mit dem bedrückenden Befund, dass die gesamtgesellschaftlichen Entwicklungen der letzten Jahrzehnte das Suizidrisiko gerade der jungen Alterskohorten ansteigen ließen. Baudelot und Establet schließen mit der Empfehlung an die Suizidforschung, die Auswirkungen ökonomischer Veränderungen - insbesondere der neoliberalen Globalisierungsagenda - auf kulturelle Strukturen, sei es auf der Ebene einzelner Länder oder im Rahmen der 'Weltgesellschaft', stärker in den Blick zu nehmen.

Die Relevanz dieser Ausführungen gerade auch für historische Perspektivierungen des Phänomens Suizid ist, denke ich, offensichtlich, so etwa, wenn man sich für die auffälligen Diskrepanzen zwischen vormodernen und modernen Gesellschaften interessiert, was die politische und gelehrt-intellektuelle Wahrnehmung von Suizidalität als Problem betrifft. Auch für Untersuchungen, die primär sozialstrukturelle und kulturelle Differenzen innerhalb einer bestimmten historischen Phase im Hinblick auf suizidales Verhalten in den Blick nehmen wollen, kann das vorliegende Werk zweifellos von erheblichem Wert sein, und dies sicher nicht nur im Bereich der 'neueren und neuesten Geschichte', obwohl diese im Fokus der beiden Autoren steht. Insgesamt handelt es sich nach meinem Dafürhalten um eines der wichtigsten neueren Werke sozial- und kulturwissenschaftlicher Orientierung zum Thema 'Suizid' aus kontinentaleuropäischer Provenienz, sodass einem früheren Rezensenten durchaus zugestimmt werden kann, welcher die Studie so charakterisierte: „This book is essential reading for anyone who is interested in understanding how society can increase suicide risk and [how it can] protect from suicide." (Brian Mishara). 
Gerade was die sprachliche und formale Ebene betrifft, sind jedoch, auch einige Monita unvermeidlich: Nicht selten scheint eine gewisse Inexaktheit im Ausdruck in der französischen Originalausgabe, etwa was die Wiedergabe von Berufsklassifikationen betrifft, durch die Übersetzung ins Englische noch gemehrt worden zu sein. (vgl. bes. S. 132-139) Auch Formulierungsfehler im Original wurden bei der Übersetzung ins Englische nicht korrigiert bzw. um neue vermehrt, sodass das Sinnverständnis beim Lesen an manchen Stellen erheblich beeinträchtigt wird (z.B. S. 20, 135), und der mutmaßlich intendierte Aussagegehalt mühsam rekonstruiert werden muss. Auch sind an einigen Stellen faktische Inkorrektheiten zu finden, etwa in Bezug auf die Höhen von nationalen Suizidraten (S. 37) oder die Werte von Korrelationskoeffizienten (S. 131); teils sind diese wohl auf schlichte Tippfehler zurückzuführen - was sie umso ärgerlicher erscheinen lässt, da bei weitem nicht jedem Leser aufgrund von methodologischen und/oder inhaltlichen Vorkenntnissen eine richtigstellende Lektüre zugetraut werden kann.

Dennoch ist das rezensierte Werk zweifellos eine Empfehlung für alle an „Suizid” als Forschungsgegenstand Interessierten; bei der Rezeption von faktischen Details gilt es aber, Vorsicht walten zu lassen. Für mögliche neue Auflagen der Studie oder auch eine etwaige Übersetzung ins Deutsche bleibt aber zu wünschen, dass man sich von Seiten der Autoren oder sonst kompetenter Personen dieser ja vergleichsweise leicht behebbaren Defizite annehmen möge. 


\section{Vereinsnachrichten}





\section{Rückschau 2011}

Wie bereits bewährte Tradition, veranstaltete der Verein für Sozialgeschichte der Medizin auch im nun zu Ende gehenden Jahr eine Jahrestagung unter dem ,Reihentitel "Geschichte(n) von Gesundheit und Krankheit".

Diese wurde in Kooperation mit dem Lern- und Gedenkort Schloss Hartheim sowie der Fachhochschule Oberösterreich von 30. Juni bis 2. Juli in Alkoven, respektive am Eröffnungsabend - in Linz abgehalten. Hauptverantwortlich für Planung und Organisation zeichneten diesmal Carlos Watzka für den Verein) und Florian Schwanninger für den Lern- und Gedenkort Schloss Hartheim. Die Tagung widmete sich diesmal dem Thema „Behinderung(en). Exklusion, Inklusion und Partizipation aus sozial- und kulturgeschichtlicher Perspektive“. Insgesamt 13 ReferentInnen erörterten hierzu einschlägige Forschungs-, diesmal zum Teil aber auch Vermittlungs- und PraxisProjekte.

Das Interesse an der Veranstaltung war erfreulicherweise ein großes. Dies betrifft zum einen die Teilnehmerzahl vor Ort, welche zeigte, dass es den Veranstaltern gelungen war, über die zahlenmäßig doch begrenzte ,Gemeinde“ der medizinhistorisch Forschenden in Österreich hinaus ein interessiertes ,Publikum' anzusprechen, insbesondere professionell und/oder im Rahmen der Selbstvertretung mit der Thematik „Behinderung(en)“ befasste Personen. Gerade diese TeilnehmerInnenZusammensetzung sorgte für intensive, teils durchaus kontroverse, dennoch aber in freundschaftlicher Atmosphäre geführte, und so insgesamt sehr fruchtbare Debatten im Anschluss an Vorträge.

Die Tagung stieß zugleich auch auf bemerkenswertes mediales und fachöffentliches Interesse. Zu erwähnen ist insbesondere der Bericht über ausgewählte Inhalte im Rahmen einer Folge der Sendereihe „Dimensionen - Welt der Wissenschaften“ des Radiosenders Ö1; auch wurde von Seiten des geschichtswissenschaftlichen OnlineInformationsportals HSK die Veröffentlichung eines Tagungsberichts ebendort angeregt. Ein ausführlicherer Bericht ist daher in Bälde auf den Internet-Seiten von HSK abrufbar.

Im Rahmen der Jahrestagung fand, wie gleichfalls bereits traditionell, auch die Jahreshauptversammlung des Vereins für Sozialgeschichte der Medizin statt. Hierbei wurden u.a. die Neuwahl des Vorstandes vorgenommen und Veränderungen in der Zusammensetzung des wissenschaftlichen Beirats vorgenommen.

Das bisherige Vorstandsteam blieb angesichts seiner guten Zusammenarbeit und des bekundeten Willens der Amtsträger, auch weiterhin zur Verfügung zu stehen, weitgehend erhalten, jedoch rückte Alfred Stefan Weiß (Institut für Geschichte der Universität Salzburg) auf Wunsch der übrigen Vorstandsmitglieder als Vereinssekretär neu in diesen Kreis ein. Auf diese Weise wurde seinem starken Engagement für die Vereinsagenden in den letzten Jahren auch formal Ausdruck verliehen. Im Zusammenhang mit dieser Neubesetzung kam es auch zu Veränderungen bei den Stellvertreter-Funktionen, wobei Marcel Chahrour dem Vereinsvorstand nunmehr als Finanzreferent-Stellvertreter angehört, und Christian Promitzer, der diese Funktion bislang innehatte, aus dem Vorstand ausschied. 
Beiden sei an dieser Stelle für ihr - bisheriges wie sicher auch künftiges - Engagement für die Aktivitäten des Vereins herzlich gedankt!

Was den wissenschaftlichen Beirat belangt, so war es im vergangenen Jahr ein Bestreben des Vorstandes, das bestehende Gremium durch die Aufnahme neuer Mitglieder zu erweitern, insbesondere im Hinblick auf das in den letzten Jahren konsequent umgesetzte peer-review-Verfahren bei der Begutachtung von Beitragsvorschlägen für den „Virus“, betreffend welcher aktive Mitglieder des wissenschaftlichen Beirats als wertvolle Ansprechpartner der Herausgeber fungieren können.

In diesem Sinne konnte der bisherige Beirat, der in den letzten Jahren auch Abgänge zu verzeichnen hatte, bereits um zwei prominente neue Mitglieder erweitert werden, nämlich Prof. Dr. Gerhard Baader (Berlin) sowie Prof. Dr. Christina Vanja (Kassel). Ihnen beiden sei an dieser Stelle für ihre Bereitschaft zur Mitwirkung an der Vereinstätigkeit herzlich gedankt, ebenso wie den schon länger amtierenden Angehörigen des Beirats für ihre diesbezüglichen Aktivitäten.

Ein weiterer wichtiger Punkt, zu welchem bei der Jahreshauptversammlung 2011 eine Beschlussfassung erfolgte, war schließlich die Finanzierung der Vereinsagenden. Wie schon im Editorial des „Virus 9“ näher ausgeführt, war die diesbezügliche Lage des Vereins in den letzten Jahren nicht eben günstig. Auf Initiative des Vereinspräsidenten konnte jedoch durch eine konsequente Mahnaktion betreffend ausständiger Mitgliedsbeiträge einerseits, eine massive Umgestaltung der Produktionsstrukturen des ,Virus' andererseits im Laufe von 2011 eine ausgeglichene Bilanz der Vereinsgebarung ohne verbleibende Außenstände wieder hergestellt werden.

Jedoch trat in der ersten Jahreshälfte 2011 auch eine neue, unerwartete Schwierigkeit im Hinblick auf die Finanzierung der Vereinstätigkeiten auf, nämlich die - den im wissenschaftlichen Bereich Tätigen unter den LeserInnen sicher schon bekannte ersatzlose Streichung sämtlicher Druckkostenförderungen durch das Bundesministerium für Wissenschaft und Forschung. Aus diesen Mitteln hatte der Verein bislang einen erheblichen Teil der Produktionskosten des Virus abdecken können; der Entfall dieser Förderung schuf eine erneute Finanzierungslücke bei der Erstellung der Zeitschrift von jährlich zwischen 1.000.- und 2.000.- $€$.

Um den ,Virus' auch weiterhin - und zwar als Print-Produkt, nicht nur als OnlineZeitschrift - als Jahresband herausgeben zu können, musste daher im Vorstand erneut über Veränderungen in der Finanzierungsstruktur des Vereins nachgedacht werden. Es bestand hierbei Einhelligkeit, dass zumindest die Basisaktivitäten des Vereins (jährliche Tagung, jährlicher Zeitschriftenband, Betrieb der homepage) von nun an auf Grundlage möglichst feststehender, von Förderungen und Sponsorengeldern unabhängigen Einnahmen gesichert werden sollten. Zur Erreichung dieses Zieles schien insbesondere eine moderate Anhebung des derzeit ja - im Vergleich zu ähnlichen Institutionen - immer noch eher geringen Mitgliedsbeitrags geeignet. Auf Antrag des Vorstandes hat die Jahreshauptversammlung am 2. Juli 2011 daher beschlossen, die Mitgliedsbeiträge mit Wirksamkeit ab dem Kalenderjahr 2012 wie folgt anzuheben bzw. neu zu regeln:

$\begin{array}{lll}\text { Mitgliedsbeitrag (Standard) } & € \text { 25.- jährlich } & \text { (statt bisher } € \text { 15.-) } \\ \text { Mitgliedsbeitrag ermäßigt } & € \text { 15.- jährlich } & \text { (bisher nicht möglich) }\end{array}$

(auf Antrag an den Vorstand für alle Personen mit weniger als $€$ 1.000.-

persönlichem Monats-Nettoeinkommen)

Mitgliedsbeitrag als Förderer $\quad €$ 50.- $\quad$ (statt bisher $€$ 30.-, freiwillig) 
Wir ersuchen alle Vereinsmitglieder um Verständnis für diese Erhöhung der Mitgliedsbeiträge und möchten in diesem Zusammenhang betonen, dass mit der nun erfolgten Anpassung auch langfristig die Finanzierung der Vereinsaktivitäten „aus eigener Kraft" sichergestellt erscheint. Selbstverständlich ist mit der Entrichtung der Mitgliedsbeiträge wie bisher der kostenlose Bezug des ,Virus‘ verbunden.

Im Hinblick auf die Tagungsveranstaltungen sieht sich der Vereinsvorstand dagegen veranlasst, in Hinkunft auch zumindest moderate Tagungsbeiträge von den TeilnehmerInnen einzuheben, um so die anfallenden Kosten, einschließlich der Reisekostenunterstützung für JungwissenschafterInnen, abdecken zu können. Diese werden etwa im Falle der kommenden Jahrestagung in Radkersburg $€$ 50.- betragen. Nähere Informationen zur Tagung werden in Bälde über den Email-Verteiler des Vereins ausgesendet.

Für den Vereinsvorstand

Carlos Watzka, p.t. Präsident 
Vorstand:

Ehrenpräsidentin: Univ. Prof. Mag. DDr. Sonia Horn

Präsident: Univ. Prof. Dr. Carlos Watzka

Stv. Präsidentin: Univ. Prof. Dr. Elisabeth Dietrich-Daum

Sekretär: $\quad$ Ass. Prof. Dr. Alfred Stefan Weiß

Stv. Sekretärin: Mag. Dr. Gabriele Dorffner

Stv. Sekretärin: Mag. Dr. Maria Heidegger

Finanzreferent: Mag. Dr. Andreas Golob

Finanzref.-Stv.: Mag. Marcel Chahrour

Wissenschaftlicher Beirat:

Univ. Prof. Dr. Gerhard Baader, Berlin

Univ. Prof. Dr. Gunda Barth-Scalmani, Innsbruck

Univ. Prof. Dr. Robert Jütte, Stuttgart

Univ. Prof. Dr. Christine Marosi, Wien

Univ. Prof. DDr. Werner Mohl, Wien

Univ. Prof. Dr. Christina Vanja, Kassel

Univ. Prof. Dr. Claudia Wiesemann, Göttingen

\section{Vereinsziele:}

Förderung der Forschung und Vermittlung von Wissen auf dem Gebiet der Sozial- und Kulturgeschichte der Medizin, der Geschichte von Gesundheit und Krankheit und angrenzenden Thematiken, insbesondere durch:

- Veranstaltung von Tagungen, Ausstellungen, Seminaren und Vorträgen

- Herausgabe von wissenschaftlichen Veröffentlichungen und Unterstützung von Publikationsprojekten

- Durchführung von sowie Förderung und Beratung bei einschlägigen Forschungsprojekten

- Zusammenarbeit mit Einrichtungen mit ähnlichen Zielen im In- und Ausland

- Etablierung intensiver und produktiver Kooperationen medizinhistorisch Forschender

- Unterstützung von jungen, einschlägig tätigen Wissenschafterinnen und Wissenschaftern

- Mediale Vermittlung von Informationen zur Sozial- und Kulturgeschichte der Medizin

Kontakt:

Verein für Sozialgeschichte der Medizin, Georgistraße 37, A-1210 Wien

www.sozialgeschichte-medizin-org

Email: carlos.watzka@uni-graz.at 